\title{
ESTIMATIVAS E UTILIZACÃO DA CAPACIDADE DE CAMPO
}

\author{
LAERCIO DUARTE SOUZA
}

Orientador: Prof. Dr. KLAUS REICHARDT

Dissertação apresentada à Escola Superior de Agricultura "Luiz de Queiroz", da Universidade de São Paulo, para obtenção do título de Mestre em Agronomia - Area de Concentração: Solos e Nutrição de Plantas. 
i i.

ESTIMATIVAS E UTILIZAÇAO DA

CAPACIDADE DE CAMPO

Laércio Duarte Souza

Aprovado em: 05/02/1990

Comissão Julgadora:

Prof. Dr. Klaus Reichardt

Prof. Dr. Zilmar Ziller Marcos

Prof. Dr. Paulo Leonel Libardi
ESALQ/USP

ESALQ/USP

ESALQ/USP

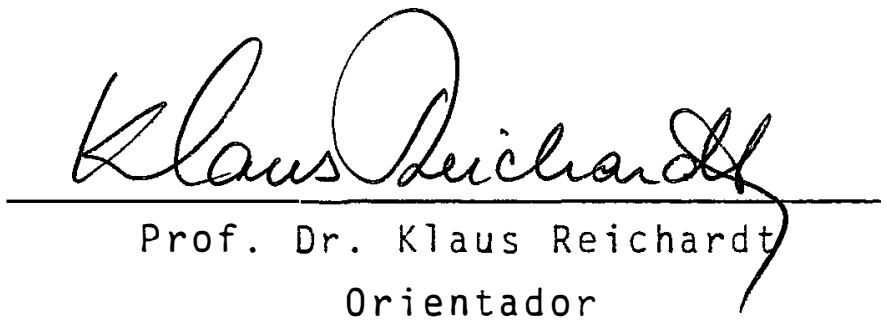


i i i.

\section{A FERNANDA}

pelo companheirismo e carinho

ao longo desta jornada, como em toda

a vida;

A JERONIMO, DANIEL, TATYANA e PALLO AUGUSTO

pelas ausências nas nossas

brincadeiras que não pude suprir, neste periodo.

a manOEL DO VALE SOUZA C

ABELNICE DUARTE SOUZA, meus pais, c aos meus irmãos.

DEDICO. 
iv.

"O sistema de conceitos é criação do homem, bem como as regras do sintaxc, que constituem a cotrutura dos sistemas conceptuais.

Os conceitos e proposiçōes adquirem 'sentido' ou 'conteūdo' apenas atravēs das suas conexōes com as experiēncias sensoriais. A conexão destas ültimas com os primeiros $\bar{e}$ puramente intuitiva, e nāo de naturezá lōgica em si mesma. 0 grau de certeza com o qual essa conexāo ou ligaçāo intuitiva pode ser admitida c a unica difcrença entrc a fantasia desprovida de conteüdo c a 'verdadc' cientifica".

Albert Einstein

$(1879-1955)$ 


\section{AGRADECIMENTOS}

Ao Prof. Dr. KLAUS REICHARDT pelos muitos ensinamentos, e ao clima de franqueza e liberdade científica propiciados na execução deste trabalho;

Aos Profs Drs Zilmar Ziller Marcos e Paulo Leonel Libardi, pela disponibilidade com que sempre nos atenderam e as inūmeras sugestōes;

Ao Prof. Dr. Joelito 0. Rezende, meu primeiro professor de Física do Solo;

Ao Prof. Dr. Geraldo V. França, pela acolhida amiga e huma na quando aqui chegamos;

Aos Profṣ Sérgio 0. Moraes, Osny Bacchi, Durval D. Neto e Alvaro Silva, pelo companheirismo informal permitido;

Aos laboratoristas Josē Ademir Rodrigues e Ivan Josē Moretti pelas muitas horas de paciēncia e acuidade;

Ao colega Ariovaldo Luiz Turatti pela inestimável colaboração na instalação dos experimentos;

Ao colega otávio Minoru pelos primeiros ensinamentos na área de informātica;

Ao "sunsei" Miguel de Carvalho pela grande paz interior trans mitida por sua pessoa e suas aulas;

A EMBRAPA - Empresa Brasileira de Fesquisa Agropecuāria, pe la oportunidade oferecida: 
A Escola Superior de Agricultura "Luiz de Queiroz", em especial ao Depto. de Solos, Geologia e Fertilizantes, e ao Depto. de Fỉsica e Meteorologia pela viabilização des se trabalho;

A todos que direta ou indiretamente colaboraram, agradeço. 


\section{INDICE}

Pāg ina

RESUMO

vi i

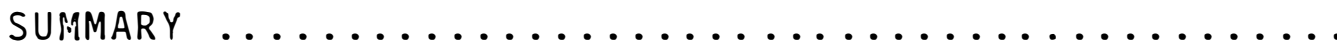

$x$

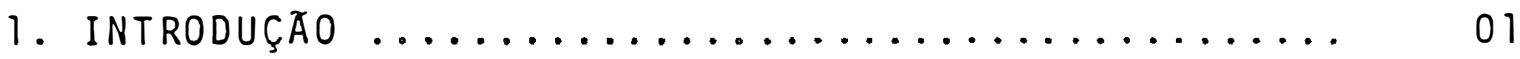

2. REVISÁO DE LITERATURA $\ldots \ldots \ldots \ldots \ldots \ldots \ldots \ldots \ldots \ldots . \ldots \ldots$

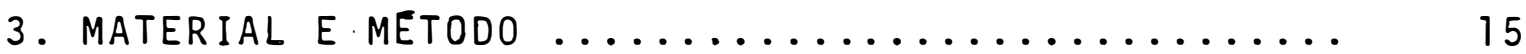

3.1. Area experimental e clima ................ 15

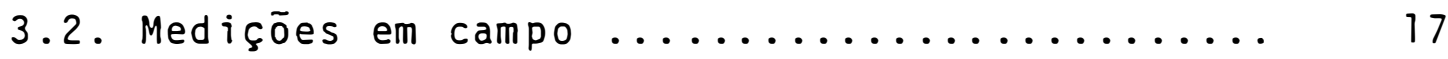

3.2.1. Instrumentos de medição ......... 17

3.2.1.1. Potenciais da água no solo. 17

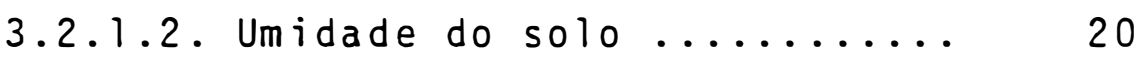

3.3. Medições em laboratōrio .............. 21

3.3.1. Potencial matricial da água do solo. 21

3.3.2. Granulometria e densidade da particu 1 a ........................ 22

3.4. Aspectos teōricos nas medições ........... 22

4. RESULTADOS E DISCUSSAO $\ldots \ldots \ldots \ldots \ldots \ldots \ldots \ldots \ldots$

5. CONCLUSOES ........................... 42

REFERENCIAS BIBLIOGRÁFICAS $\ldots \ldots \ldots \ldots \ldots \ldots \ldots \ldots \ldots \ldots \ldots \ldots \ldots$

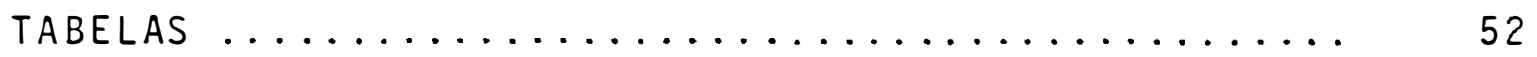

FIGURAS $\ldots \ldots \ldots \ldots \ldots \ldots \ldots \ldots \ldots \ldots \ldots \ldots \ldots \ldots \ldots \ldots \ldots \ldots \ldots$

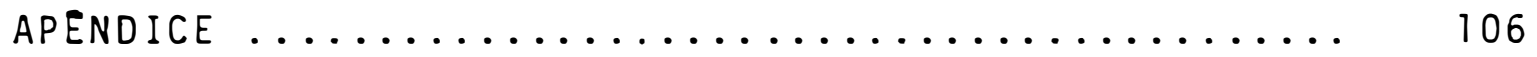


$v i j i$

\section{ESTIMATIVAS E UTILIZAÇAOO DA \\ CAPACIDADE DE CAMPO}

Autor: LAERCIO DUARTE SOUZA

Orientador: Prof. Dr. KLAUS REICHARDT

RESUMO

Estudou-se o conceito da capacidade de campo de Veihmeyer e Hendrickson e sua versão utilizando a curva de retenção de àgua. O trabalho experimental de campo foi condu zido em dois solos de propriedades fisico-quimicas distintas: um Latossolo Vermelho-Amarelo fase arenosa e um Terra Roxa Es truturada em uma parcela de $6 \times 4 \mathrm{~m}$ em cada solo. Em cada parce la foram instalados 20 tensiōmetros com manōmetro de mercūrio em I inha, distantes $0,5 \mathrm{~m}$ um do outro e alternando as profund $\underline{i}$ dades em 15 e $25 \mathrm{~cm}$. As mediçōes em laboratōrio para elabora ção das curvas de retenção, foram realizadas usando amostras de solo com estrutura indeformada (anel volumétrico de $50 \mathrm{~cm}^{3}$ ). As tensōes utilizadas foram $5,10,60$ e $100 \mathrm{~cm}$ de àgua em funil de placa porosa, e 344, 1033, 3099, 5165 e 15495 cm de āgua em cāmaras de pressão de Richards. 0 ajưste das curvas foi feito segundo a equação de Van GENUCHTEN (1980).

As determinações da umidade a base de massa do so10 nas parcelas de campo ao longo do tempo, foram realizadas com "trado holandés" e as densidades do solo para cada local da amostragem com anēis cilindricos. 
Os resultados mostraram grande variabilidade para os parāmetros potencial da àgua, porosidade total e granulometria, em ambos os solos e em todas as profundidades, e a necessidade de apresentar o conceito de uma forma dinâmica, enfocando medidas como fluxo de āgua ao longo do perfil e menos as caracteristicas de sua matriz. 


\section{ESTIMATIVES AND UTILIZATION \\ OF FIELD CAPACITY}

Author: LAERCIO DUARTE SOUZA

Adviser: Prof. Dr. KLAUS REICHARDT

\section{SUMMARY}

Veihmeyer \& Hendrickson's concept of field capacity and it's version envolving the soil water retention curve, were studied using two soils with distinct physicochemical properties: one Yellow Red Latosol, sandy fase and "Terra Roxa Estruturada". In $6 \times 4 \mathrm{~m}$ experimental plots 20 mercury manometer tensiometers were installed, along a transect, $0.5 \mathrm{~m}$ appart from each other, alternating the depth from 15 to $25 \mathrm{~cm}$. Laboratory soil water retention curves were established using core samples of $50 \mathrm{~cm}^{3}$, submitted to sucction in porous plate finnels for pressure heads of -5 , $-10,-60$ and $-100 \mathrm{~cm}$ of water, and submitted to pressure in pressure plate apparatus, for pressure heads of $-344,-1033$, $-3099,-5165$ and $-15495 \mathrm{~cm}$ of water. The curves were adjusted according to Van GENUCHTEN'S (1980) model.

Soil water content determinations in the field plots, as a function of time, were made using a traditional auger. Data was transformed in a volumetric basis 
using bulk density data obtained through the use of volumetric cylinders of $50 \mathrm{~cm}^{3}$.

Results show a great variability in space and time, for soil water potential, total porosity and particle size distribution, indicating the need of a dynamic presentation of the concept, giving more emphasis to soil water fluxes within the profile, and less emphasis to soil matrix characteristics. 


\section{INTRODUCÃO}

Os mecanismos de entrada e de saída da āgua no solo são diversos, e as observações demonstram manifestações de propriedades diferentes entre seu molhamento e secamento. Nestes processos dināmicos, ocorre no entanto que uma certa quantidade de àgua, interagindo com a matriz do solo e o clima, tem maior permanēncia no solo. Este volume de āgua em equilibrio com o solo, retida por fenómenos de capilarida de e de adsorção, em um estado de energia que requer forças maiores que a gravidade para locomover-se, define a condição da ăgua no solo denominada "capacidade de campo".

Este estado de quase imobilidade da água no solo, caracterizado como condicāo de "fluxo de drenagem desprezivel" na definição do conceito, tem sido caracterizado através de medidas relacionadas ao estado de energia da ãgua,

umidade do solo e também com algumas características da matriz do solo.

Estas tentativas de definiçào do conceito através de parāmetros estāticos (potenciais da àgua, granulome- 
tria, porosidade, etc.), não atingiram uma relação plenamente aceitável devido ao desencontro dos resultados obtidos por di versos autores. Apesar de aceito que as relaçōes entre poten cial matricial da àgua $\left(\psi_{m}\right)$ e umidade do solo ( $\left.\theta\right)$ são unĩvocas para um mesmo solo, não está de todo comprovado que algum ponto, ou estado, desta relação seja para qualquer situação o ponto de imobilidade da àgua, ou de "fluxo desprezível".

E inquestionāvel a importāncia básica do conceito para estudos da relação àgua-solo, como é inquestionável tambēm sua restrita utilização apenas na ārea de engenharia de irrigação. Este fato pode ser atribuído a preocupação cons tante de determinação do ponto de umidade do solo, ou do esta do de energia da āgua no solo, para que seja iniciado ou interrompido o molhamento, sendo esta informação utilizável somente com disponibilidade de irrigação. Falta para uma utili zação mais ampla do conceito, uma abordagem quanto a evolução interativa do perfil do solo, das condiçōes de molhamento-secamento e do clima, que são fatores capazes de retardar ou adiantar o momento para que seja atingido o estado de "fluxo descendente desprezível" na relação àgua-solo.

Em relação à uma conceituação dināmica de "cá pacidade de campo", as mediçōes são prioritariamente realizadas em campo, sendo o tempo um elemento fundamental, mantendo-se uma preocupação com o perfil do solo no que se refere a distribuiçäo da àgua, e menos às caracteristicas intrinsecas da sua matriz. 
Acredita-se que para cada sistema de molhamen to aplicado ao solo, em função da distribuição da umidade no perfil antes do molhamento, haverā diferentes relações entre o potencial da agua, a umidade do solo e o fluxo de āgua descendente. Assim, com o objetivo de melhor compreender o estabelecimento destas relaçōes, de maneira a permitir uma maior utilização do conceito de capacidade de campo, foi realizado este trabalho. 


\section{REVISÃO DE LITERATURA}

o solo é o reservatório de água para as plantas, um reservatōrio aberto para a atmosfera e para os horizontes mais profundos do perfil, e periodicamente reabastec $\underline{i}$ do pela chuva, lençol freático ou irrigação.

A capacidade de retenção de água pelo solo estā diretamente relacionada a sua matriz e a distribuição espa cial dos poros. Esta interação sofre também influēncia de fá tores como: taxas de evaporação e transpiração local, tipo de cultura estabelecida, densidade de plantio, profundidade de raizes, natureza do perfil do solo em profundidade e impedimentos à drenagem (CASSEL \& NIELSEN, 1986).

A dificuldade de se estimar ou medir a quantidade de āgua no solo, que através de um equilíbrio dināmico nele permanece por mais tempo, tem criado metodologias empiri cas para a medição deste pàràmetro, apresentando controvérsias quanto a sua generalização para diferentes tipos de solo.

Segundo o Glossary of Soil Science Terms, a ca pacidade de campo é definida como: "quantidade de āgua rema- 
nescente no solo, 2 ou 3 dias após irrigação, quando a drenagem livre é desprezivel".

Esta definição, ê oriunda basicamente da emitida por VEIHMEYER \& HENDRICKSON (1931), que a completaram pos teriormente relacionando o estado da energia da água neste ponto de umidade, com a tensão de $-1 / 3$ atm (VEIHMEYER \& HENDRICKSON, $1949)$.

Estes dois trabalhos juntamente com o de COLMAN (1946) serviram de base a divulgação e utilização do termo "capacidade de campo".

A associação do conceito com o potencial da āgua no solo, é que gerou maior número de trabalhos sobre o as sunto.

A definição do potencial da āgua no solo segun do o Comite de Terminologia de Fisica de Solos da Sociedade Internacional de Física do solo é a seguinte: "o potencial to tal da àgua no solo é a quantidade de trabalho que deve ser realizada por unidade de massa, volume ou peso de àgua pura, para transportar, reversivel e isotermicamente, uma quantidade infinitesimal de āgua desde um reservatōrio de āgua pura num nível determinado e à pressão atmosférica (estado de referéncia) para um ponto considerado dentro do sistema soloplanta-atmosfera".

A unidade mais utilizada para o potencial è energia por peso de āgua, por traduzir-se em carga hidrāulica (cm de àgua), facilitando muito os cālculos envolvidos na mediçāo (R OSE, 1966 ; REICHARDT, 1985; LIBARDI, 1984 ). 
0 potencial total é um somatōrio de vārios com ponentes, onde os principais são:

Potencial osmōtico: assume importāncia em solos salinos e na presença de membrana semi-permeāveis.

Potencial de pressão: atua nos solos acima do ponto de saturação.

Potencial gravitacional: atuação constante, é medido em relação a um referencial padrão, arbitrārio, tomado igual a zero.

Potencial mātrico: é resultado das forças de tensão e capilaridade associadas. A capilaridade resulta da tensão superficial da àgua e do àngulo de contato com as partículas sōlidas, e a adsorção resulta da interação da polaridade físicoquímica entre a àgua e as particulas do solo.

Os potenciais osmōtico, de pressão e gravitacio na tēm descrição analítica, mas o potencial mātrico atē o momento so tem sido descrito experimentalmente (REICHARDT, $1985)$.

Entre os trabalhos que associaram a capacidade de campo com o estado de energia da àgua no solo, a maioria foi realizada em laboratório e com diversas metodologias quanto ao tratamento das amostras. 
LEAMER \& SHAW (1941), utilizando a "mesa de tensão", propuseram a tensão de $40 \mathrm{~cm}$ de āgua como o indicatị vo do fim da drenagem livre, e também a divisão do espaço poroso da amostra em porosidade capilar e não capilar a partir deste ponto.

Valores de 30 a $150 \mathrm{~cm}$ de àgua foram encontrados por RICHAROS (1949), mas foi COLMAN (1947) quem primeiro assumiu o potencial de $1 / 3$ de atmosfera como medida mais está vel para a capacidade de campo. Enquanto JAMISON \& KROTH(1958) trabalhando com 121 perfis de solo constataram que a sucção que mais se aproximava da capacidade de campo variou de menos de $10 \mathrm{~cm} \mathrm{H}{ }_{2} \mathrm{O}$ a mais de $100 \mathrm{~cm}$ de $\mathrm{H}_{2} \mathrm{O}$ em função da textura e teor de matéria orgānica das amostras.

Entre os trabalhos que procuraram associar as determinações da capacidade de campo em laboratōrio e em campo, podemos citar o de MARSHALL \& STIRK (1949), que usando có mo critério de campo o fim da drenagem livre, encontraram tem pos diferentes entre solos para atingirem este estado de equi librio.determinando para solos arenosos 28 horas, areno-argilosos 45 horas e argilosos 120 horas, e comparando as umidades atingidas neste periodo com as encontradas em laboratório sub metidas a tensão de 55,90 e $35 \mathrm{~cm} \mathrm{H}{ }_{2} \mathrm{O}$ para arenosos, francoarenosos e argilosos respectivamente, e afirmam ainda, que me $\underline{s}$ mo trabalhando com colunas uniformes de solo, na capacidade de campo o potencial matricial não foi igual em todas as profundidades. 
SALTER \& HAWORTH (1961) adotando como critério de campo o fim da drenagem livre, 68 horas apōs saturação, em solos submetidos a diversos manejos agrícolas, encontrou para cada solo uma melhor tensão que a este associou, não ocorrendo uma generalização que satisfizesse a todos os solos em estudo; ainda atribuiram as discrepàncias encontradas na litera tura quanto ao cālculo da àgua disponível, as determinaçōes da capacidade de campo usando solos em condiçōes artificiais e o uso de métodos arbitrārios em laboratōrio.

0 tempo para considerar o fim da drenagem 1 ivre é um critério empírico e varia entre diversos autores, co mo citado anteriormente SALTER \& HAWORTH (1961) adotaram 68 horas, RIVERS \& SHIP (1971) adotaram 48 horas como critério de campo e $1 / 10$ bar em laboratōrio trabalhando com solos de diversas texturas, e concluem que ambas as medidas subestimam a capacidade de campo em solos arenosos e siltosos. FREIRE (1979) adotando 5 dias como fim da drenagem livre encontrou diferentes umidades e potenciais para cada horizonte de um Latossolo Roxo, e diferenças entre a relação potencial versus umidade determinada em campo e em laboratōrio. BORGES \& MEDI NA (1981) realizando determinaçōes em campo e em laboratörio, salientam que os resultados obtidos foram de 0,1 a 0,4 bar, devido as variaçōes do prōprio critērio de drenagem desprezīvel, em campo e nas amostras sob pressão.

Procurando equacionar os diversos tipos de erros nas medidas da relação potencial versos umidade, CAMP- 
BELL (1988) após ampla revisão quanto aos instrumentos e critérios utilizados nas medidas propōe uma equação do tipo $\psi m=-a \theta^{-b}$, onde $\underline{a}$ e $\underline{b}$ são empiricos e variam com as caracteristicas e propriedades do solo.

A grande variabilidade de valores encontrados por diversos autores, tentando medir um mesmo fenōmeno, afastam o potencial de $1 / 3$ de atmosfera como uma generalização adequada para definir o conceito, assim como outras definições estáticas também não tem conseguido plena aceitação.

Associaçōes da capacidade de campo tambēm têm sido realizadas com a matriz do solo, relacionando a umidade obtida a $1 / 3$ atmosfera com textura, porosidade e densidade do solo. PETERSEN et alii (1968) trabalhando com diversos ti pos de solo, encontraram correlação positiva entre a umidade volumétrica a $1 / 3$ de atmosfera e a porcentagem de argila. MacLEAN \& YAGER (1972) trabalhando com 143 amostras de 31 perfis, encontraram correlação positiva entre a umidade volumétrica a $1 / 3$ de atm, e os teores de limo e carbono orgānico nas camadas superficiais, e correlação negativa com os teores de areia fina nas camadas mais profundas. Trabalhando com um total de 1323 solos, num total de 5350 horizontes, levanta 'dos em diversas publicaçōes, RAWLS et alii (1981) observaram que dados como porosidade total, umidade volumétrica residual e logaritmo da distribuição do tamanho de poros, tēm distribuição normal de frequēncia, e na maioria dos casos estudados, a umidade na diferença entre o potencial a $1 / 3$ atm e 
15 atm foi maior que a porosidade total calculada, criticando a diversidade das metodologias e a confiabilidade das rela ções testadas. MANFREDINI et alii (1984) trabalhando com um Latossolo Vermelho Amarelo e Areias Quartzosas, com semelhante porosidade total e diāmetro médio ponderado de particulas (DMP), mas diferentes quanto aos teores de areia grossa, nota ram que apresentaram idēntica condutividade hidrāulica satura da mas diferentes condutividades sob condição não saturada, atribuindo esta diferença ao teor de areia grossa e sua influēncia na determinação do tamanho dos poros.

Alguns autores, têm analisado o aspecto dināmico da capacidade de campo que essencialmente trata do fluxo da àgua no solo, mas encontram dificuldades para definir um parāmetro para o conceito devido a imprecisão de termos como desprezivel e negligível utilizados na definição do mesmo.

Neste aspecto, medidas dinâmicas como fluxo ou condutividade hidráulica, relacionadas ou não com características do solo, tambēm não atingem um consenso. 0 trabalho de MCKEAGUE \& TOPP (1985) com nove solos de diferentes classes tex turais, não encontrou relação significativa entre textura e condutividade hidráulica saturada (Ko), e destaca a alta variabilidade de ko na superficie, devido ao manejo agricola, o que ocasiona uma redistribuição tambēm desuniforme da àgua em Frofundidade. GUMBS (1974) analisando determinaçōes na condu tividade hidrāulica saturada (Ko) em campo e em laboratório, observa que sistematicamente as medidas feitas em laboratōrio 
são maiores que as de campo, e encontra relaçōes apenas entre Ko e teor de areia grossa. MURALI et alii (1979) encontraram relaçōes entre condutividade hidrāulica saturada (ko) e teor de matēria orgānica, areia e argila em 20 solos da India, mas não encontraram uma sistematização para a condutividade hị drāulica não saturada, afirmando que nesta situaçāo quando ocorre o esvaziamento dos macroporos, o espaço poroso dos microporos embora possam. ser semelhantes entre solos, interagem diferentemente com a àgua em função da natureza dos seus agregados. MARCOS (1971) trabalhando com dois solos semelhan tes quanto ao grau de agregação, mas diferentes quanto a natu reza e teor do colóide, conclue que nestes solos diversas um $\underline{i}$ dades podem estar em equilíbrio com um mesmo potencial, em função da variação do diāmetro māximo das partículas que compõe os agregados. WHITMYER \& BLAKE (1989) trabalhando com amostras preparadas artificialmente com diversas porcentagens de areia, silte e argila e relacionando com a condutividade hidrāulica saturada (Ko), afirmam que o aumento de argila diminuiu Ko, e aumentando a relação silte/argila aumenta Ko. GROENE VELT \& BOLT (1971) ressaltaram as dificultades de medidas hidrāulicas em solos expansivos, onde a mineralogia determina forte influēncia na matriz do solo.

Outros trabalhos têm abordado aspectos referen tes a processos de medição, ou seja, como medir e o que medir. CHOUDHURY \& MILLAR (1982), utilizando medidas de fluxo em balanços hídricos para irrigação, afirmam que a 
partir da capacidade de campo ( no caso 0,1 atm), as perdas por dre nagem profunda, a depender do solo e do tipo de cultura estabe lecida, pode chegar a $50 \%$ da água aplicada por irrigação, e ressalta a necessidade de definição de "fluxo desprezivel" pa ra cada solo e cultura.

KLUTE (1972) fazendo uma ampla revisão de métodos de campo e laboratōrio para determinação da condutividade hidrāulica e do fluxo, aponta o método do perfil instantāneo como de medidas mais acuradas. HILLEL et alii abordam o método do perfil instantāneo, explicitando toda a sua metodologia.

As dificuldades quanto a caracterização de medidas que representem a capacidade de campo, tem feito surgir modelos teóricos que buscam uma previsibilidade da relação po tencial versus umidade de forma dināmica, através de dados obtidos em outros momentos desta relação.

0 modelo de curva caracteristica desenvolvido por VAN GENUCHTEN (1980) baseado na teoria de MUALEM (1976), é um dos mais utilizados para estas determinaçōes atualmente, apesar das restrições ao modelo feitas por VAN GENUCHTEN \& NIELSEN (1985) quanto aos parāmetros empīricos da equação a, $\underline{m}$ e $\underline{n}$ e suas interdependēncias, alegando como ideal a indepen dència de cada um destes fatores no ajuste da equação proposta.

MARCOS (1971) afirma que o ponto de inflexão da curva caracteristica de um determinado solo, è a sua capacida 
de de campo, devido a mudança da rélação entre as variáveis (potencial versus umidade), e indica o potencial matricial de 0,06 atm como a melhor estimativa para o conceito. Estudo semelhante foi realizado por FERREIRA (1983) com o ponto de in flexão da curva, encontrando potencial matricial semelhante. PREVEDELLO et alii (1981) adotando um modelo matemático tambēm baseado na curva característica, procuram simplificar o método do perfil instantāneo.

A instrumentaçāo tambēm tem evoluído com aparelhos como a sonda de neutrons para medir a umidade. A util $\underline{j}$ zaçāo de tensiōmetros também tem progredido desde o trabalho de RICHARDS (1938) e tornou-se mais criteriosa, quanto a medição de condutāncia e pressão de borbulhamento em cāpsulas porosas e a colocaçào de tensiōmetros no solo; como sugerem SoUzA et alii (1979), que antes da instalação em campo, seja feito um estudo morfolōgico do solo, e para eliminar o acūmulo de bolhas de ar dentro do aparelho recomenda uma fluxão em todos os aparelhos a cada 5 dias. VILLAGRA (1988) trabalhan do em Terra Roxa Estruturada, procura estabelecer os desvios das medições em função do erro dos instrumentos e da variabilidade espacial dos solos.

Deve ser ressaltado mais uma vez nesta revisão, a falta de um consenso geral quanto ao conceito de capacidade de campo, e consequentemente, das medidas que possam representā-10. MARSHALL (1959) afirma: "Não existe método de medida em laboratório que possa ser um real substituto da"ca- 
pacidade de campo: em campo, devido a vários fatores, entre eles pode-se destacar as propriedades fisicas do perfil como um todo e as condições iniciais de umidade do solo". CASSEL \& NIELSEN (1986) comentam que além do método escolhido para medir a capacidade de campo, é fundamental o critério de escolha dos pontos devido a variabilidade espacial dos solos, e o nūmero de pontos em função do tamanho da ärea. REICHARDT (1988) afirma que a capacidade de campo é o resultado de um comportamento dināmico da água no perfil do solo e não uma ca racteristica intrínseca da sua matriz; diz ainda que a princi pal causa da redução do fluxo de drenagem é a drāstica redução da condutividade hidrāulica em poucos dias, e não do gradiente de potencial que pouco varia no periodo inicial após saturação.

Finalizando, NIELSEN et alii (1972), citam afir mativa de RICHARDS (1928) ainda atual: "Estudos do movimento da água no solo e sua disponibilidade às plantas têm sido largamente experimentais, e agora e necessāria uma compreensí vel teoria que lhes sirva de guia". 


\section{MATERIAL E MÉTODO}

\subsection{Area experimental e clima}

Com o intuito de estudar aspectos dināmicos relacionados ao conceito de capacidade de campo, foram escoIhidos dois solos com caracteristicas fisico-quimicas acentuadamente diferentes, a fim de dar maior abrangēncia aos pa ràmetros estudados. O primeiro solo localiza-se próximo a Associação dos Funcionārios da ESALQ, no campus da USP em Piracicaba, SP, é classificado como Latossolo Vermelho Amarelo (LVA), fase arenosa. O segundo solo, localizado nas proximidades do Posto Meteorológico da ESALQ, também em PiracicabaSP, é classificado como Terra Roxa Estruturada (TRE). Algumas caracteristicas físicas e quimicas de ambos podem ser vistos na Tabela 1 .

O clima da região, segundo Wilhelm KUeppen, é sub-tropical com inverno seco (Cwa), apresentando como média anual da precipitação pluviométrica $1247 \mathrm{~mm}$, temperatura de $28,50 \mathrm{C}$ e umidade relativa de $69 \%$. 
A época em que foram instalados os experimen tos no campo beneficiou o monitoramento do processo de secamento apenas por drenagem dos solos, pela reduzida precipita ção ocorrida no periodo como mostram as Figuras 1 e 2.

\subsection{Medições em campo}

Em cada solo foi delimitada uma parcela de $6 \times 4 m$, através de um dique feito com solo circunvizinho, com altura de $30 \mathrm{~cm}$, mantendo-se a declividade natural da ārea 2,5 i para o LVA e 4,2\% para a TRE.

As parcelas foram inundadas de forma lenta e gradual com 4 sifões colocados na parte mais alta da parcela. Os sifões foram abastecidos por um reservatōriode 1000 litros colocados ao lado da parcela, reabastecido continuamente e mantido sempre cheio. Foi adicionada àgua atē a formação de uma lámina de $5 \mathrm{~cm}$ de altura na parte mais alta da parcela, atingindo $20 \mathrm{~cm}$ de altura na parte mais baixa no LVA e 30

$\mathrm{cm}$ na TRE. A lämina foi mantida por 2 horas e gastou-se apro ximadamente 5000 litros, em cada parcela. Este procedimento causou um molhamento propositalmente desuniforme ao longo da parcela.

Após inundação as parcelas foram cobertas com plāstico, para prevenir a evaporação (Figura $A$ ). 


\subsubsection{Instrumentos de medição}

\subsubsection{Potenciais da àgua no solo}

Foram utilizados tensiōmetros para medir os potenciais mátricos da àgua no solo. Esses foram construídos com tubos de PVC com 0,5 polegada de diāmetro e o comprimento variando segundo a profundidade de instalação. Uma das extremidades foi vedada com rolha de borracha e a outra com uma cápsula porosa, testada quanto à condutāncia e à pressão de borbulhamento à l a tm.

os tubos plásticos para medir a altura da coluna de mercūrio do manōmetro, com $2 \mathrm{~mm}$ de diāmetro interno, foram acoplados ao próprio tubo de PVC juntamente com o reservatōrio de mercúrio (Figura B).

Instalaram-se 20 tensiōmetros em cada parcela, em linha, na direção do declive, a $0,25 \mathrm{~m}$ de distāncia um do outro e alternando a profundidade em 15 e $25 \mathrm{~cm}$; cada par de tensiōmetro com profundidade diferente, ocupando $0,5 \mathrm{~m}$ em $1 \mathrm{i}$ nha, foi considerado como área individualizada dentro da parcela, resultando assim 10 áreas de amostragem de $2 \mathrm{~m}^{2}$ (Figura A).

Os valores obtidos da altura da coluna de mer cūrio ( $\mathrm{h} \mathrm{Hg}$ ), da distāncia da superficie do solo ao nivel superior do mercúrio na cuba (hc), e a distāncia da superficie do solo à profundidade da cāpsula ( $H z$ ) (vide Figura $B$ ), foram utilizadas nas förmulas: 


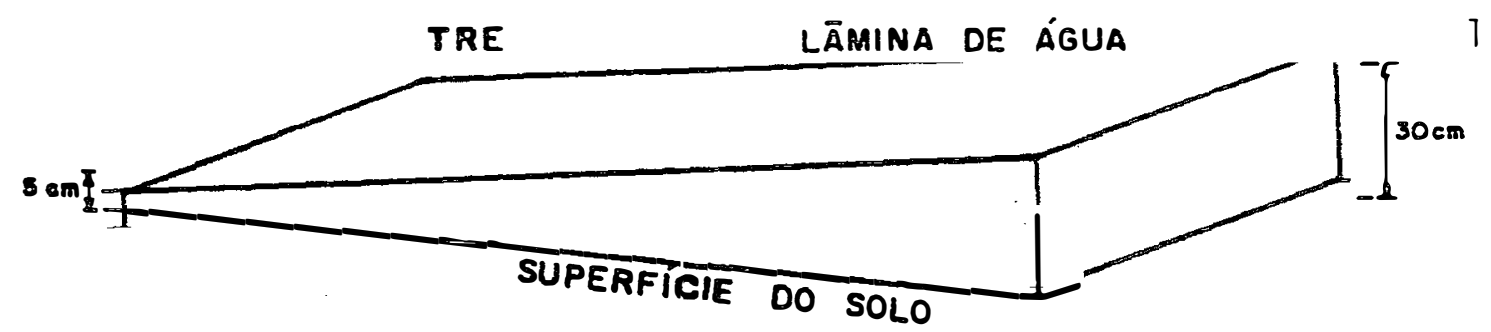

18.
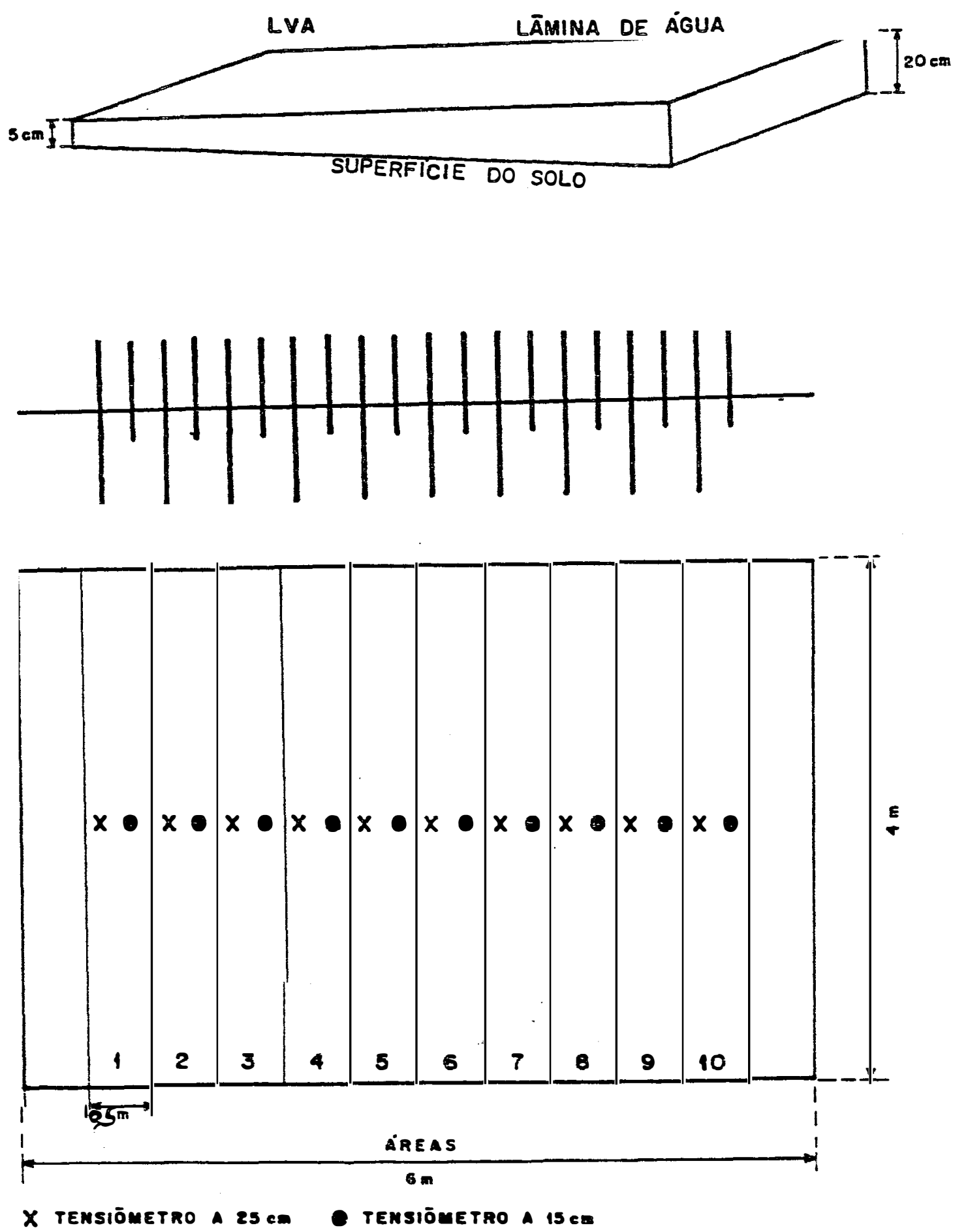

Figura A. Esquema de inundação das parcelas e localização dos tensiōmetros. 


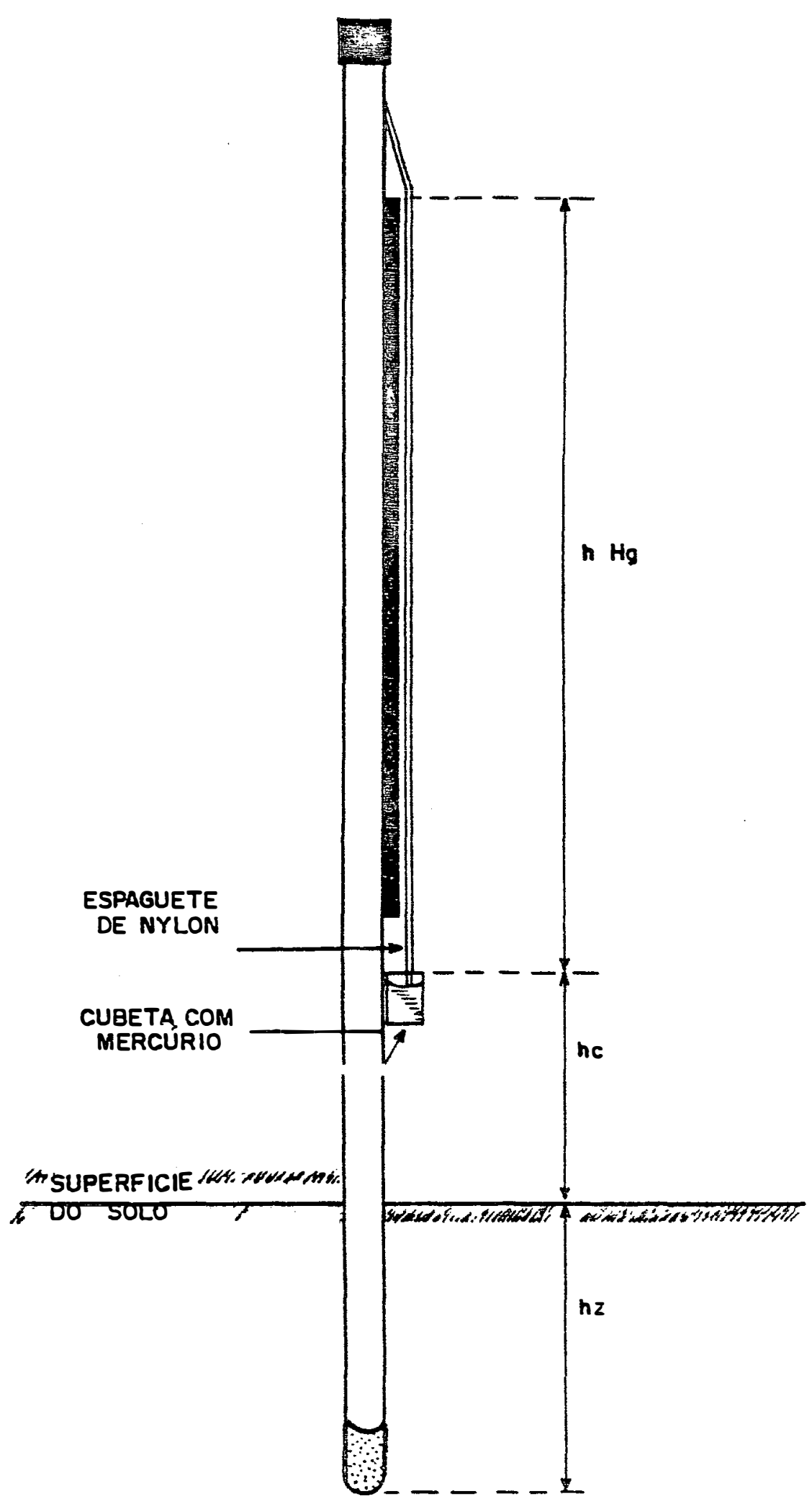

Figura B. Tensiōmetros utilizados. 


$$
\begin{aligned}
& \psi_{m}=-12,6 \mathrm{hHg}+\mathrm{hc}+\mathrm{hz} \\
& \psi_{t}=-12,6 \mathrm{hHg}+\mathrm{hc}
\end{aligned}
$$

Sendo a equaçāo (1) utilizada para o cālculo do potencial mátrico da água no solo $\left(\psi_{\mathrm{m}}\right)$, e a equação para o potencial total ( $(t)$, ambos em cm de água.

A instalação dos tensiōmetros foi feita em orificios abertos com trado helicoidal com diāmetro igual ao dos tubos de PVC, tendo-se o cuidado de propiciar um bom contato entre a cápsula e o solo.

\subsubsection{Umidade do solo}

As amostras de solo foram retiradas com trado tipo "holandēs" das camadas de $0-10 \mathrm{~cm}, 10-20 \mathrm{~cm}$ e $20-30$ cm nas 10 áreas dentro da parcela, sendo cada amostragem realizada entre 6 e 8 horas da manhã, desenrolando-se o plästico prōximo ao dique, evitando perdas por evaporação na proximidade dos tensiómetros. Inicialmente o periodo de amostra gem foi de 24 horas, passando a 48 horas e ao final do experi mento a cada 72 horas.

As amostras foram acondicionadas em latas de aluminio, vedadas com fita durex e levada ao laboratório onde eram pesadas com a umidade de campo, levadas a estufa a 1050 C por 48 horas para obtençào da massa de terra.

Para cada amostra determinou-se inicialmente a 
umidade gravimétrica (g de āgua/g de solo), e a umidade volumétrica $\left(\mathrm{cm}^{3}\right.$ de àgua/cm ${ }^{3}$ de solo) foi obtida utilizando valores de densidade do solo ( $g$ massa de solo/volume total em $\mathrm{cm}^{3}$ ) determinadas em trincheiras próximas $(5 \mathrm{~m})$ às parcelas.

\subsection{Medições em laboratório}

\subsubsection{Potencial mātrico da água do solo}

Ao final do experimento de campo, quando se julgou que as variações das medidas de potencial e umidade não mais apresentaram variaçōes perceptīveis, 0 plástico foi removido e abriu-se uma trincheira paralela à linha dos tensiōmetros com $0,5 \mathrm{~m}$ de profundidade, de onde se retiraram amostras de solo com estrutura indeformadas, o mais próxi mo possivel de cada cápsula do tensiometro; foram retiradas 10 amostras da profundidade de $15 \mathrm{~cm}$ e $10 \mathrm{na}$ profundidade de $25 \mathrm{~cm}$, isto é, uma para cada tensiōmetro.

os cilindros utilizados nesta amostragem, com $50 \mathrm{~cm}^{3}$ aproximadamente, foram trabalhados no sentido de elimi nar os excéssos de solo, e em suas bases foram colados papéis porosos para facilitar seu contato com a placa porosa do equ 1 pamento de extraçào de āgua, utilizada para a determinação do potencial mátrico da água no solo.

As amostras foram saturadas lentamente, de 
baixo para cima com lāmina d'àgua crescente por 24 horas, até o nivel do cilindro. Neste nivel foram mantidas por mais 24 horas para assegurar sua saturação. As amostras foram submetidas inicialmente a sucções de $-5 ;-10 ;-60$ e $-100 \mathrm{~cm}$ de coluna de āgua por meio de "placas de tensão" (Figura C) e posteriormente submetidas à nressñes em "panelas de pressão" de placa porosa (Figura $D$ ), para medir a umidade nos potenciais de $-344,33 ;-1033 ;-3099 ;-5165$ e -15495 cm de àgua (RICHARDS, 1949). Entre cada determinação as amostras eram novamente sa turadas de forma lenta, tomando-se o cuidado de não perder so 10. No final, as mesmas amostras foram utilizadas para deter minar a densidade do solo.

\subsubsection{Granulometria e densidade da particula}

As anālises granulométricas foram realizadas pelo mētodo da pipeta, com agitação Wagner 16 horas e dispersantes $\mathrm{NaOH} 1$ Normal. A densidade das particulas foi realiza da com balão volumétrico de $50 \mathrm{ml}$ e álcool etîlico absoluto (EMBRABA, 1979).

\subsection{Aspectos teōricos nas mediçōes}

A condutāncia hidrāulica das cápsulas porosas dos tensiōmetros é definida como a vazào de água que passa a- 


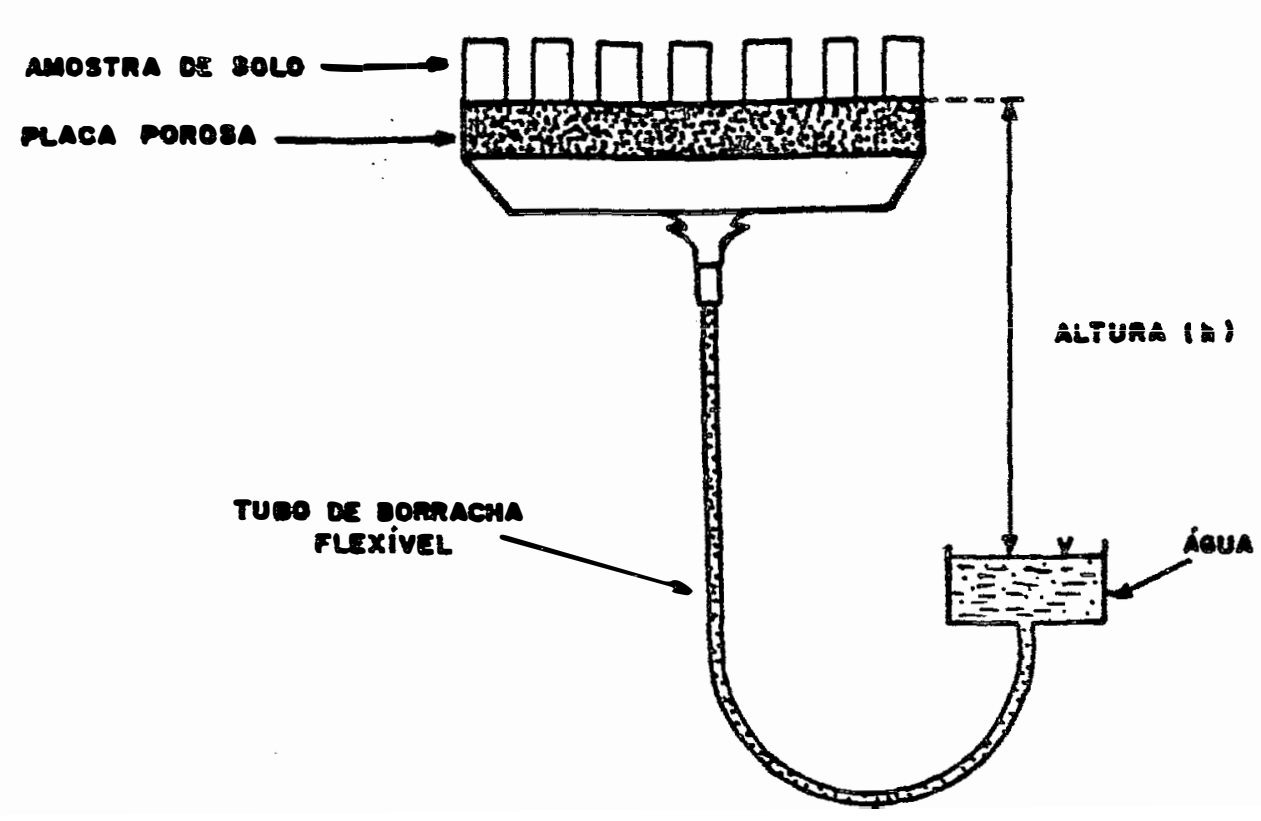

Figura C. Placa porosa sob tensão.

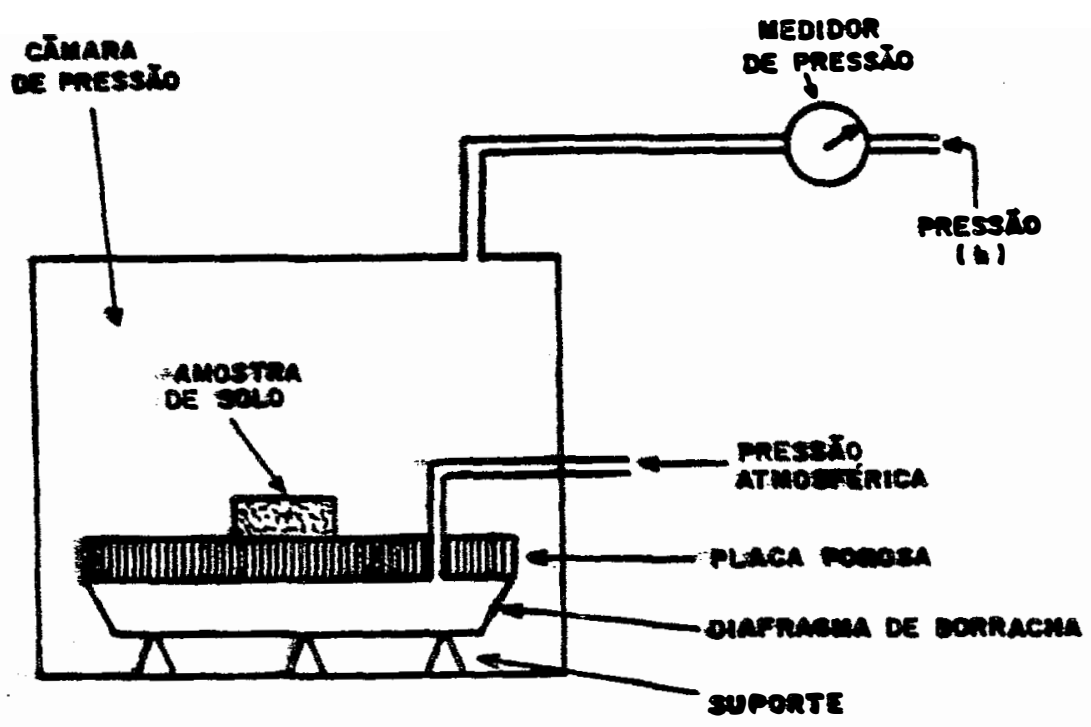

Figura D. Placa porosa sob pressäo. 
través da parede da cápsula por unidade de diferença de preso sāo. Cápsulas com maior condutāncia refletem com maior rapidez o estado de energia da àgua no solo, pois o equilíbrio ē mais imediato.

A determinação foi feita pelo método da carga decrescente, cuja equaçāo ē:

$$
\begin{aligned}
& c=a-\frac{\ln \left(h_{1} / h_{2}\right)}{t_{2}-t_{1}} \\
& c=\text { condutāncia da cāpsula }\left(\mathrm{cm}^{2} / \mathrm{s}\right) \text {; } \\
& a=\text { àrea da secção transversal do tubo (cm); } \\
& h_{1}=\text { potencial hidrāulico no tempo } t_{l} \text { (cm de } \\
& h_{2}=\text { potencial hidrāulico no tempo } t_{2} \text { (cm de }
\end{aligned}
$$

A pressão de borbulhamento é definida como a pressão minnima de ar aplicada na cápsula saturada de água, na qual o ar começaria a borbulhar através de seus poros. No caso dos tensiōmetros esta pressão deve ter o valor mínimo de 0,8 a 1,0 atm (LIBARDI, 1987 ).

As determinaçōes do fluxo e da condutividade hidrāulica não saturada do solo, foram realizadas pelo método do perfil instantàneo, utilizado por HILLEL et alii (1972), com a modificaçäo introduzida por CHO et alii (1977).

A equação de Buckinghan-Darcy nos fornece a densidade de fluxo de āgua em solo não saturado, sendo: 


$$
q=-K(0) \partial \psi / \partial z
$$

$q=$ densidade de fluxo de āgua (cm/s);

$K(\theta)=$ condutividade hidráulica do solo não saturado (cm/s), que é função do seu conteúdo de āgua $\left(\theta=\mathrm{cm}^{3} / \mathrm{cm}^{3}\right)$;

$\psi=$ potencial total da āgua no solo (cm);

$z$ = coordenada vertical de posição $(\mathrm{cm})$.

Neste trabalho não se considerou o sinal negativo do lado direito da equação, para facilitar os cálculos envolvendo logaritmos do fluxo (q).

A equação da continuidade fornece a variação da umidade no tempo em dado elemento de volume, sendo:

$$
\frac{\partial \theta}{\partial t}=-\frac{\partial q}{d z}
$$

A combinação das equações (3) e (4) é a equação de RICHARDS, que é a equação diferencial geral que descre ve o movimento da āgua em solos não saturados:

$$
\frac{\partial \theta}{\partial t}=\frac{[\partial K(\theta) \partial \psi / \partial z}{\partial z}
$$

Em condições de drenagem interna, com a superfície do solo coberta com plástico, a integral da equação (5), de $z=0$ na superficie do solo até uma profundidade qualquer $z=L$, nos informa 0 fluxo de água nesta profundidade em qualquer tempo: 


$$
\int_{0}^{L} \frac{\partial \theta}{\delta} \frac{\theta}{t} d z\left[K(\theta) \frac{\delta}{\delta} \frac{\psi}{z}\right]_{0}^{L}
$$

ou

$$
\int_{0}^{L} \frac{\partial \theta}{\partial t} d z\left[K(\theta) \frac{\partial \psi}{\partial z}\right] L-\left[K(\theta) \frac{\partial \psi}{\partial z}\right] 0
$$

Como na superficie do solo $(z=0)$ não hă fluxo devido a cobertura plástica, o segundo termo à direta é igual a zero, e a equação (7) fica:

L

$$
\int_{0}-\frac{\partial}{\partial}-\frac{\theta}{t}-d z=\left[K(\theta) \frac{\partial}{\partial} \frac{\psi}{z}\right] L
$$

Explicitando $K(\theta)$ teremos:

$$
\begin{aligned}
& {[K(\theta)]_{L}=\frac{\int^{L}(\partial \theta / \partial t) d z}{\delta \psi / \partial z}} \\
& {[K(\theta)]_{L}=\text { condutividade hidráulica em } z=L \text {, para } 0 \text { va- }} \\
& \text { lor de umidade que prevalece em } z=L \text {, em da- } \\
& \text { do tempo } t \text {; } \\
& \text { L } \\
& \int-\frac{\psi^{\prime}}{d t}-d z=q_{L} \text { que é } 0 \text { fluxo em } z=L \text { em dado tempo } t ; \\
& 0 \\
& {\left[\frac{\partial \psi}{\partial z}\right]_{L}=\underset{\text { dado tempo } t .}{\text { gradiente de potencial total em } z=L \text { em }}}
\end{aligned}
$$


Segundo o procedimento de HILLEL et alii(1972) para o cālculo de $K(\theta)$, a integral da equação (9) pode ser aproximada por um somatōrio:

$$
a_{L}=\int_{0}^{L} \frac{\partial \theta}{\partial} d z=\sum_{i=1}^{n}\left(\theta \bar{\theta}_{L} / \partial t\right) \Delta z
$$

Obtida a umidade do solo $(\theta)$ em função de $\underline{z} e$ t, o fluxo é facilmente determinado calculando $\partial \theta / \partial t$ a partir de grāficos de $\theta$ versus $t$ para cada camada $(0-10 \mathrm{~cm}, 10-20 \mathrm{~cm}$ e $20-30 \mathrm{~cm})$.

A obtenção de $\partial \psi / \partial z$ é feita de maneira semelhante, em gráficos de $\psi$ versus t, obtidos a partir das leituras dos tensiōmetros em cada profundidade (15 e $25 \mathrm{~cm}$ ).

A modificação introduzida na equação (10) por CHO et alii (1977) foi:

$$
q_{L} \equiv \sum_{i=1}^{n} \partial\left(\bar{\theta}_{j} \cdot \Delta_{z}\right) / \partial t=\sum_{i=1}^{n} \partial A / \partial t=\partial \bar{A}_{L} / \partial t
$$

sendo A o armazenamento de āgua no solo, aproximado por:

$$
A=\int_{0}^{\Delta z} \theta \cdot d z=\bar{\theta} \cdot d z
$$

onde considerando a profundidade de $20 \mathrm{~cm}$

$$
\bar{\theta}=\frac{{ }^{\theta} 0-10+{ }^{\theta} 10-20}{2}
$$


Este procedimento permite substituir os cálcú los de $\partial \theta / a t$ para cada camada nos diversos tempos, pelo cálculo direto $\partial A_{L} / \partial t$ a partir de grā́ficos de $A$ versus t.

Se a relação entre $A$ e $t$ for do tipo:

$$
A_{L}=a+b \ln t
$$

então

$$
\frac{d A_{L}}{d t}=-b / t
$$

ou

$$
q L=-b / t
$$

Obedecendo a recomendaçäo de AHUJA et alii (1987). não se considerou o gradiente como unitário nos tempos iniciais para melhor precisão das determinações.

Para a determinação dos pontos de inflexão das curvas caracteristicas ( $\psi$ versus $\theta$ ) obtidas com as amostras in deformadas, utilizou-se a equação de VAN GENUCHTEN (7980):

$$
\theta=a_{r}+\frac{\left(\theta_{s}-\theta_{r}\right)}{\left[1+(x h)^{n}\right]^{m}}
$$

ou

$$
h=\frac{1}{\alpha}\left[\left(\frac{\theta_{s}-i_{r}}{e-\theta_{r}}\right)^{1 / m}-1\right]^{1 / n}
$$


onde:

$$
\begin{aligned}
{ }_{\mathrm{s}}= & \text { umidade volumétrica saturada }\left(\mathrm{cm}^{3} / \mathrm{cm}^{3}\right) ; \\
\theta_{r}= & \text { umidade volumétrica residual }\left(\mathrm{cm}^{3} / \mathrm{cm}^{3}\right) \text { a } \\
& -15495 \mathrm{~cm} \text { de āgua; } \\
\mathrm{h}= & \text { potencial mátrico em } \mathrm{cm} \text { de ägua } \\
& (+) ; \\
a, m, n= & \text { parämetros referentes a caracteristicas } \\
& \text { do solo, determinados de forma empirica. }
\end{aligned}
$$

A obtenção do ponto de inflexão da curva característica foi obtido atravēs da segunda derivada da equação (15) (Dourado Neto \& Libardi, 1989)', obtendo-se a equação:

$$
a=\left(\frac{m}{1-m}\right)^{m}\left(\theta_{s}-\theta_{r}\right)+e_{r}
$$

Nota: Foi considerada como perdida a ārea 10 do LVA devido a problemas com o tensiōmetro na profundiade de $25 \mathrm{~cm}$.

DOURADO NETO, D. e LIBARDI, P.L. Determinação do ponto de inflexão das curvas caracteristicas de solos (em elabo ração). 


\section{RESULTADOS E DISCUSSÃO}

Os dados da umidade volumétrica $(\theta)$, potencial mátrico da āgua no solo $\left(\psi_{\mathrm{m}}\right)$ e armazenamento da àgua no per fil $(A z)$, obtidos no campo em função do tempo estāo nas Tabelas 2 (LVA) e 3 (TRE). De uma maneira geral, podemos afirmar a validade do modelo de regressāo $(y=a \pm b$ lnt) para os trēs paràmetros acima no LVA, onde os coeficientes de correlação $(r)$ foram altos (menor valor $r=0,806$ ). Quanto à Tabela 3 (TRE), o modelo não foi adequado aos dados obtidos, o que equi vale dizer que a muito lenta diminuição de $\theta, \psi m$ e $A z$ em função do tempo, não foi exponencial. Obteve-se grande nümero de coeficientes de correlação ( $r$ ) menores que 0,1 ou próximos deste valor.

As Figuras 3,4 e 5 mostram o comportamentoda umidade volumétrica ( 9 ) das dez àreas em funçào do tempo (ent) nas profundidades de 0-10, 10-20 e 20-30 cm no LVA, res pectivamente. Para facilitar a visualização foram colocados em grā́fico somente os modelos de curva das āreas extremas, a ārea 1 (submetida a maior lāmina de āgua em $t=0$ ), a ārea 9 
(submetida a menor lāmina em $t=0$ ) e ārea 5 centralizada na parcela. Podemos observar uma diminuiçāo de $\theta$ diferenciada e sistematizada entre as āreas; na profundidade de $0-10 \mathrm{~cm}$ a ārea $1\left(a_{1}\right)$ com maior lāmina de ăgua inicialmente, manteve-se mais úmida que a ārea $9\left(a_{9}\right)$, a ārea 5 manteve-se mais ūmida supostamente devido a centralização da ārea; na profundidade de $10-20 \mathrm{~cm}$ a ārea 9 continua com menor retenção de āgua e inverte-se as posiçōes entre al e a 5 ; na profundidade de 20-30 cm novamente alteram-se as posições das curvas em relação as āreas, sendo nesta profundidade a ag a de menor umida de.

Estas inversões tornam-se explicāveis devido ao fato que a maior drenagem numa camada superior deve causar maior acúmulo de àgua nas camadas inferiores por um certo tem po, ou seja ag que teve menor umidade que a, de 0-10 cm e 10$20 \mathrm{~cm}$, apresentou maior umidade na camada de $20-30 \mathrm{~cm}$. As posições da àrea 5 sāo resultados de diversos efeitos dināmicos da drenagem, submetida aos efeitos interativos do secamento entre $a_{1}$ e $a_{g}$, sendo inclusive a ärea cuja curva mais apro xima-se da curva média (Grāficos 3a, 4a e $5 a$ ).

A explicação para curvas de secamento desuni formes entre āreas continuas de um mesmo solo, e que a partir de um instante $(t=0)$ a uma profundidade de 0 a $35 \mathrm{~cm}$ ocorria uma saturaçào homogènea, estā no fato do molhamento ter sido desuniforme e ter criado diferentes gradientes entre o limite 
da ārea saturada $(0-30 \mathrm{~cm})$ e o continuo do perfil, em profundidade. Isto é confirmado nas Figuras 9 e 10 , onde se observa a distribuição do potencial mātrico no LV́A 15 e 25 cm; nota-se que a àgua em interação com o solo na ag esteve sempre com menores potenciais (após $t=0$ ) devido ao fato de haver menor umidade no perfil em profundidade nesta área.

Uma observação conjunta das Figuras $3,4,5,9$ e 10 mostra que tanto os dados de $\theta$ como do $\psi m$ sāo dispersos em profundidade, e mais dispersos conforme o solo seca em qualquer profundidade.

Em relação a TRE os dados de umidade (Figuras 6, 7 e 8) apresentam grande dispersão nas trés, profundidades e em qualquer tempo, não permitindo uma sistematização diferenciada entre āreas, pois as variaçōes da umidade volumétrica foram minimas, havendo inclusive aumento de $\theta$ com o tempo $\left(a_{1}=0-10 \mathrm{~cm}\right)$ devido a baixa taxa de drenagem do horizonte $B$ textural, localizado de 35 a $55 \mathrm{~cm}$ de profundidade (vide Tabe la 3 ), que através deste impedimento praticamente uniformizou o decréscimo da umidade no tempo em todas as āreas, obtendo se curvas quase paralelas entre al, $a_{5}$ e ag. Isto pode ser confirmado pelos dados médios (Figuras 6a, 7a e $3 a$ ) onde a curva de $0-10 \mathrm{~cm}$ é desuniforme quanto a expectativa do secamento, e de 10 a $20 \mathrm{~cm}$ e 20 a $30 \mathrm{~cm}$ também contrariam a expectativa e podem ser consideradas paralelas ao eixo de $x$, i $\underline{s}$ to $\bar{e}$, int. 
A distribuição do potencial mátrico em função do tempo (Figuras 11 e 12 ) nas profundidades de $15 \mathrm{~cm}$ e $25 \mathrm{~cm}$ respectivamente, foi sistemática entre āreas para $15 \mathrm{~cm}$ de profundidade, ou seja, a ārea l com maior lāmina de água nicial manteve a água retida com maior potencial mátrico que a ārea 10; o que não ocorreu na profundidade de $25 \mathrm{~cm}$, onde as curvas a e a 10 são sobrepostas e a área 5 é paralela e prōxima a estas.

Os dados mēdios (Figuras 11 a e 12a) mostram a tendēncia descontínua da diminuição do potencial em ambas as profundidades, e com diferenças minimas entre as mesmas, confirmando que não houve efeito de uma redistribuição diferencia da para as umidades nem para os potenciais mátricos neste solo.

Foi tambēm calculado o armazenamento de āgua no solo, na camada de 0 a $20 \mathrm{~cm}$ no LVA (Figura 13) e na TRE (Figura 14). No LVA a área 9 apresentou menor armazenamento que a área 1 , confirmando o ocorrido com a umidade que também apresentou o maior decréscimo no tempo, mas os potenciais mätricos mostraram que a ăgua estava retida com maior energia nesta profundidade, e ainda assim foi menos armazenada. Na Figura $13 a$ estão os dados do armazenamento médio, que mostram uma real diminuição do armazenamento nesta profundidade $(0-20 \mathrm{~cm})$.

Quanto a TRE (Figura 14), os dados novamente mostraram-se não tendenciosos a uma sistematização por ārea e 
com alta dispersão, como indicam os coeficientes de correlação na Tabela 3. Os dados médios (Figura 14a) mostram inclusive que a taxa de armazenamento flutuou com o tempo e a diferença entre o primeiro e o último dia de medição é de aproximadamente $2 \mathrm{~mm}$.

As medidas do fluxo de água no solo no LVA ( $F \underline{i}$ gura 15) mostram a ārea 9 com maior fluxo descendente que a ārea 1; ou seja, a ārea 9 submetida a menor lāmina de āgua $(t=0)$, que apresentou maior diminuição da umidade e do armazenamento no tempo e com água retida com maior energia pelo solo (menor $\psi_{m}$ ), manteve-se perdendo água em profundidade mais rapidamente por todo o tempo que a área 1 , mais úmida e com maior $\psi \mathrm{m}$. Este resultado assume importāncia de critica para quando é assumido o critério do "fluxo desprezível" para determinar a capacidade de campo, estando inerente a este "fluxo desprezível" uma relação de umidade elou potencial mátrico que será estabilizada. O que os dados mostram é uma ārea mais seca (ag) e com a água retida com maior energia mantendo um fluxo 1,5 a 2,5 vezes maior que a área mais úmida (a $)$ ), - que descaracteriza a tentativa de relação implicita do fluxo com a umidade e o potencial mátrico, comprovando que as medidas de fluxo são condicionadas pela dinàmica da água no perfil. ou seja, as condiçōes iniciais de umidade do solo e sistema de molhamento.

Na Figura 16, estão os dados de fluxo da TRE, novamente com alta dispersão e sem possibilidade de sistemati 
zação entre āreas; ocorrendo inclusive fluxo ascendente nas áreas 1 e 3 (fator $\underline{b}$ positivo na equação de regressáo do armá zenamento). 0 surgimento do fluxo ascendente, pode ser atribuído ao aquecimento da cobertura plástica na superficie do solo, causando o surgimento de um gradiente térmico entre a superfície do solo mais próximo ao plástico e o solo em profundidade, causando movimento ascendente nesse volume de água quase estagnado devido ao impedimento da drenagem.

Estes resultados valem como alerta ao estudo do perfil como um todo, pois os dados relativos ao fluxo não são de atribuição da camada de 0 a $20 \mathrm{~cm}$ onde se realizou as medidas, mas sim devido as limitações de drenagem do horizonte B textural localizado a partir de $35 \mathrm{~cm}$ de profundidade na TRE.

Em relação aos gradientes do potencial total a Figura 17 mostra a distribuição no tempo no LVA; nota-se que o gradiente não foi unitário mesmo nos tempos iniciais, por tratar-se de uma camada sub-superficial (AJUHA et alii, 1987); e que 0 gradiente aumenta de 1,5 a 2,0 vezes entre 0 tempo inicial e o tempo final das medidas, enquanto que o fluxo se reduz de 200 a 300 vezes neste mesmo periodo, não podendo por tanto o aumento de um justificar a redução tão drástica do outro.

Os gradientes determinados na TRE, apresentaram se com sinal negativo na maioria das áreas (vide tabelas de dados no Apēndice final), significando fluxo ascendente, 
inviabilizando para objeto deste estudo a sua utilização, mas servindo mais uma vez para realçar os problemas causados por camadas de baixa permeabilidade em estudos da dinâmica da àgua. Consequentemente a condutividade hidráulica na TRE não foi estimada.

A determinação da condutividade hidráulica não saturada no LVA, foi obtida através da divisão do fluxo da àgua no solo pelos gradientes do potencial total. Como a condutividade é uma função da umidade, esta foi descrita em relação a diferença da umidade volumétrica nos-diversos tempos $(\theta)$ e a umidade volumétrica saturada $\left(\epsilon_{s}\right)$. Os resultados mostraram-se coesos, pois a expectativa $\bar{e}$ de dispersão minima para um mesmo solo (Figuras 18).

Procurando testar os dados obtidos em campo com algumas definições da capacidade de campo encontradas na literatura, elaborou-se a Tabela 4 (LVA) e Tabela 5 (TRE) relativas a estes critérios. Foram caracterizados "fluxos despreziveis" de drenagem como: 1) $5 \%$ e $10 \%$ de uma taxa de evapotranspiração (ET) hipotética; 2) umidades volumētricas $\left(\mathrm{cm}^{3} / \mathrm{cm}^{3}\right)$ e potenciais mátricos ( $\mathrm{cm}$ de àgua) após 2, 3, 10 dias de saturação e 3) umidades volumétricas $\left(\mathrm{cm}^{3} / \mathrm{cm}^{3}\right)$ quando os potenciais mátricos atingem 60 e $100 \mathrm{~cm}$ de àgua.

No LVA (Tabela 4) em relacào ao critērio de 5 e 10: de evapotranspiracão (ET), nota-se que os tem- 
pos necessārios para atingir este fluxo foram diversos para cada ārea. Para 5\% da ET a ārea l demorou 341 horas e a ārea 9;533 horas, o que significa dizer que por todo este tempo o fluxo foi maior que 5\% da ET. Para $10 \%$ da ET o tempo variou desde 117 horas na ārea 4 (ārea de fluxo mais baixo) até 266 horas na ārea 9 (ārea de fluxomaior que 10\% da ET por mais tempo). Note-se ainda que nestes momentos de fluxo homogèneo atingidos em tempos diferentes por cada àrea, os potenciais mātricos a 15 e 25 cm e tam bēm a umidade volumétrica (0 a $20 \mathrm{~cm})$ tambēm não são homogêneas para as diversas àreas, descaracterizando, mais uma vez, o critērio de "fluxo desprezível" na tentativa implicita de caracterizar um potencial ou uma umidade para a ca pacidade de campo.

Os critérios relativos ao tempo apōs drenagem mostraram que para cada àrea em um mesmo tempo, ocorreram diferentes potenciais mātricos a 15 e $25 \mathrm{~cm}$ e umidades volumétri cas $(0-20 \mathrm{~cm})$ e os dados podem ser considerados extremos entre $a_{1} e_{9} a_{9}$ Mas com uma interferéncia sistemática dos valores de $a_{4}$ e $a_{5}$ que supera um dos extremos para qualquer medida $\left(\psi_{15}, \because 25\right.$ e 6$)$.

Em relação aos potenciais mátricos determina dos no campo, relacionados a umidade volumétrica ao iongo do tempo de redistribuiçāo da āgua e que foram comparados com as umidades obtidas em laboratōrio nas tensōes de 60 e $100 \mathrm{~cm}$ de āgua; os da- 
dos de campo mostram que em poucas horas atingiu-se estes potenciais. As regressōes entre as umidades das determinaçōes em campo e em laboratório estão nas figuras 19a, 19b, 19ce e 19d, ressaltando que as melhores regressões foram com o poten cial de $60 \mathrm{~cm}$ de āgua $(r=0,704)$, significando que esta determinação em laboratório é muito prōxima da que ocorre em campo, sendo a de menor variaçāo em funçāo da dināmica da āgua, mas de uma forma geral, os resultados não são estimativas que possam substituir uma determinação pela outra.

Os mesmos critérios aplicados à TRE (Tabela 5) mostram-se mais uma vez desordenados entre āreas, em todas as medidas (fluxo, tempo e potencial mātrico). As medidas dos potenciais para a tensão de $60 \mathrm{~cm}$ de āgua em relação a tempo na profundidade de $15 \mathrm{~cm}$ a inda pōde ser relacionado em ho ras, mas para $25 \mathrm{~cm}$ de profundidade utilizou-se o tempo em anos devido a grandeza do número em horas. Para a tensão de $100 \mathrm{~cm}$ de àgua na profundidade de 15 e $25 \mathrm{~cm}$ o tempo tende a infinito. Devido a isto a única comparação possĩvel entre as umidades foi a tensão de $60 \mathrm{~cm}$ de àgua e a $15 \mathrm{~cm}$ de profundidade, que obteve um coeficiente de correlaçāo de 0,266 (Figura 20a).

As medidas da umidade volumētrica versus poten cial mátrico realizadas em laboratório com amostras indeformadas estão relacionadas na Tabela 6 (LVA) e Tabela 7 (TRE); para esta condição com saturação homogénea e controlada, amos tras de um mesmo solo e profundidade, e distantes $0,5 \mathrm{~m}$ uma da 
outra (distāncia entre tensiōmetros de mesma profundidade na parcela), as amostras podem ser consideradas como repetições, e os desvios das medidas devem ser atribuídos a variabilidade espacial e/ou erros no processo de medição. A varia bilidade espacial pode ser comprovada, mas não dimensionada neste trabalho, nas Tabelas 9 (LVA) e IO (TRE), onde estão as anālises granulométricas, densidades do solo e das particulas e a porosidade total; quanto aos erros de medição vale ressaltar duas fases da metodologia que acreditamos como causadoras de desvios, a primeira diz respeito aco preparo das amostras, com o tratamento artezanal da eliminação dos excessos de terra do cilindro que a contém, para facilitar o contato solo-placa porosa. 0 segundo é ligado ao momento de retirada da amostra da placa, que também é orientado por uma noção de "fluxo desprezível" possibilitando mais uma vez interpretações empíricas, que nāo podem ser generalizadas para diversos tipos de solo.

Com os dados das Tabelas 6 e 7 , foram traçadas as curvas características (modelo de VAN GENUCHTEN, 1980) referentes ao LVA de 12 a $15 \mathrm{~cm}$ (Figura 21), LVA de 22 a $25 \mathrm{~cm}$ (Figura 22), TRE de 12 a $15 \mathrm{~cm}$ (Figura 23) e TRE de 22 a 25 cm (Figura 24), onde se percebe que devido a dispersão hā uma curva para cada ārea amostrada, o que foi comprovado determinando-se o ponto de inflexão de cada curva pelo método de DOURADO \& LIBARDI (1989), obtendo-se pontos de inflexāo diferentes para cada ārea. Curvas características com ponto de 
inflexão diferentes significam relaçōes diferentes entre a umi dade volumētrica e o potencial matricial, e significam solos diferentes.

Em busca das semelhanças e/ou diferenças que puderam influir na geometria da curva caracteristica, utilizou-se os dados das Tabelas 9 (LVA) e 10 (TRE), que são as análises granulométricas, densidades do solo e da partícula, a porosidade total e o ponto de inflexão da curva, representado por uma umidade volumétrica (TPi) e a respectiva medidado potencial matricial (hpi), e realizaram-se algumas correlações (Tabela 11).

E primeiramente possivel afirmar que as curvas caracteristicas obtidas para um mesmo solo e profundidade não foram iguais, porque o material (solo) contido nos cilinaros, onde se realizaram as medidas, não era exatamente o mesmo, e é plausivel supor que alguns dos componentes determinados tenham maior ou menor influência na geometria da curva, e que es tas curvas possam ser representadas pelo ponto de inflexão, para um efeito de diferenciamento entre as mesmas. Podemos observar que os valores dos coeficientes de correlação foram maiores para o LVA, o que pode ser atribuido as dificuldades de medição na TRE com amostras indeformadas, devido a sua pequena mas já problemática capacidade de expansào.

Os melhores resultados apresentados na Tabela 11 , tomando-se como critério o indice de correlaçào ( $r$ ) foram para hpi $\times$ T60, hpi $\times$ T100, phi $\times$ T344, Tpi $\times T_{5}$ e Tpi $\times$ T10 
em ambos os solos, com exceção a profundidade de 12 a $15 \mathrm{~cm}$ na TRE. O que numa anālise genērica é uma contradição, pois em termos do potencial da água no solo no ponto de inflexão da curva (hpi), as melhores regressões foram com as umidades determinadas entre 60 e $344 \mathrm{~cm}$ de āgua; e em termos de umidade no ponto de inflexão da curva (Tpi) as melhores regressões obtidas foram com umidades determinadas entre 5 e $10 \mathrm{~cm}$ de àgua.

Devido aos coeficientes de variação obtidos na determinação do ponto de inflexão ( $v$ ide Tabelas 9 e 10 ) torna-se difícil a aceitação deste critērio como medida prā tica e representativa da capacidade de campo, apesar do respaldo teórico que esta definição para o conceito tem embutida, devido a sua extrema dificuldade de determinação.

Vale um questionamento quanto aos modelos es timativos da curva caracteristica, e da determinação do ponto de inflexão, além da própria variabilidade impressa no preparo artezanal das amostras indeformadas para estas determinações. 
5. CONCLUSOES

As anālises dos resultados obtidos nos permitem afirmar que:

1) A capacidade de campo é um conceito ideal de um estado de energia transitōrio e dināmico, fundamentalmen te um ponto de equilibrio da relação àgua-solo. Deve por isso ser estudado e expresso também de forma dināmica, levando em consideração as condições inicial e de contorno para o moIhamento-secamento do solo.

2) Para cada condição inicial de umidade de um solo, em interação com as diversas condições de molhamento possiveis, ocorrerāo mūltiplas formas de secamento; e em cada uma destas formas ocorrerá uma nova relação de caracterização temporal entre o fluxo e a umidade e, como consequéncia, do potencial da água no solo.

3) Em seu estado atual, o conceito de capacida 
de de campo não tem uma definição adequada ou uma equação, ūnica e aceitāvel de forma abrangente, mas diversas medidas apìcāveis a diversos fins. A utilização de um critério para definir medidas para o conceito, tem sido dependente do objetivo de utilização das medidas.

4) Caracterizações da capacidade de campo, através de parāmetros estáticos como determinados valores do potencial da água no solo, ou relacionadas a matriz do solo (granulometria, porosidade total e densidade do solo entre ou tras) não apresentam correlações que possam ser sistematizadas entre solos, e não devem ser adotadas.

5) Capacidade de campo quando estimada através de medidas em laboratōrio, segundo uma metodologia e um critério qualquer para o conceito, é uma estimativa da capacidade da amostra em reter àgua e não da capacidade de campo do so10, pois em relação ao perfil como um todo, depende da locali zação da amostra. Os resultados para um mesmo critério apresentarão variaçōes em profundidade, mesmo que o solo seja homogèneo.

6) As medições realizadas em campo mais utilizadas para definir o conceito são as medidas de fluxo, condutividade hidrāulica e potencial da àgua no solo, que se referem a pontos ou planos paralelos a superficie do solo, em pro 
fundidade, onde são realizadas estas medições. $E$ coerente portanto, que se refiram a um plano ou superficie em profundi dade e não ao solo como um todo.

7) As relaçōes entre o potencial mätrico $\left(\psi_{m}\right)$ e a umidade do solo $(\theta)$ determinados em campo e em laboratōrio, não apresentaram-se como alternativas substituíveis de uma determinação pela outra, devido aos baixos coeficieites de correlação apresentados. 


\section{REFERẼNCIAS BIBLIOGRAFICAS}

AHUJA, L.R.; BARNES, B.B.; CASSEL, D.K.; BRUCE, R.R.; NOFZI GER, D.L. Effect of assumed unit gradient during drainage on the determination of unsatured hidraulic conductivity and infiltration parameters. Soil Science Society America Journal, Madison, 51: 235-43, 1987.

BORGES, E.A. \& MEDINA, B.F. Correlação entre capacidade de campo determinada in situ e em laboratōrio. Aaropecuāria Técnica, Viçosa, $\underline{2}(1): 50-61$, 1981 .

CAMPBELL, G.S. Soil water potential measurements: an overview. Irrigation Science, New York, $\underline{9}$ : 265-73, 1988.

CASSEL, D.K. \& NIELSEN, D.R. Field capacity and available wa ter capacity. In: KLUTE, A., ed. Methods of soil analysis. Part I. Physical and mineralogical methods. Madison, American Society of Agronomy, Soil Sciene Society of America, 1986. p.901-26.

CHO, T.; NOMURA, Y.; YANO, T.; SKIKASHO, S.: INOUE, M. The use of neutron moisture meter in studies of soil water regimes; water management in a sand dune area. Tottory, Totiory University/Faculty of Agriculture, 1977. 48p. 
CHOUdHURY, E.N. \& MILLAR, A.A. Retenção e movimento de àgua em latossolo vermelho amarelo irrigado em Petrolina (PE). Revista Brasileira de Ciēncia do Solo, Campinas, 7: 21-6, 1983.

COLMAN, E.A. A laboratory procedure for determining the field capacity of soils. Soil Science, Madison, 67: 277 - 83, 1947.

EMPRESA BRASILEIRA DE PESQUISA AgROPECUARIA. Manual de métodos de anālise de solo. Rio de Janeiro, SNLCS, 1979. Iv.

FERREIRA, M.M. \& MARCOS, Z.Z. Estimativa da capacidade de campo de latossolo roxo distrófico e regossolo através do ponto de inflexão da curva caracteristica de umidade. Ciēncias Prāticas, Lavras, ㄱ(1): 96-101, 1983.

FREIRE, J.C. Condutividade hidráulica e capacidade de campo de latossolo roxo distrófico não saturado. Revista Brasileira de Ciência do Solo, Campinas, 3 : 73-7, 1979.

GROENEVELT, P.H. \& BOLT, G.H. Water retention in soil. Soil Science, Madison, 113 $(4): 232-45,1971$.

GUMBS, F.A. Comparison of laboratory and field determined sa tured hydraulic conductivity and frediction from soil particle size. Soil science, Madison, 5l(3): 375-82, 1974.

HILLEL, D.; KRENTOS, V.D.; STYLIANOU, Y. Procedure and test of an internal drainage method for measuring soil hydraulic characteristics in situ. Soil Science, Madison, 114 (4): 395-400, 1972. 
JAMISON, V.V. \& KROTH, E.M. Available moisture storage capacity in relation to textural composition and organic matter content of several Missouri soils. Soil science Society of America Proceedings, Madison, 22: 189-92, 1985.

KLUTE, A. The determination of hydraulic conductivity and diffusivity of unsatured soils. Soil Science, Madison, 113(4): $264-76,1972$.

LEAMER, R.W. \& SHAW, B. A simple apparatus for measuring non capillary porosity on an extensive scale. Journal of American Society of Agronomy, 33: 1003-8, 1941.

LIBARDI, P.L. Dināmica da água no sistema solo-pianta-atmos-: fera. Piracicaba, CENA, 1984. 232p.

LIBARDI, P.L. Determinação da condutāncia hidrāulica e da pressāo de borbulhamento das cápsulas porosas para tensiōmetros. Piracicaba, ESALQ/Depto. Fisica e Meteorologia, 1987. 5p. (Mimeografado).

Maclean, A.H. \& YAgER, T.U. Available water capacities of Zambian soils in relation to pressure plate measurements and particle size analysis. Soil Science, Madison, 113 (1): $23-9, \quad 1970$.

MANFRedini, S.; PAdOVESE, P.P.E.; OLIVEIRA, J.B. de. Efeito da composição granulométrica da fração areia no comportamento hidrico de latossolos de textura média e areias quar tzosas. Revista Brasileira de Ciēncia do Solo, Campinas, S: $13-6,1984$. 
MARCOS, Z.Z. Estrutura, agregaçào e água no solo. Piracicaba, 1968. 55p. (Mestrado - Escola Superior de Agricultura "Luiz de Queiroz"/USP).

MARCOS, Z.Z. Morphologic and physical properties of fine tex ture oxisols, State of São Paulo. Columnus, 1971. 272p. (Ph.D. - Ohio State University).

MARSHALL, T.J. \& STIRK, G.B. Pressure potential of water moving downward into soil. Soil Science, Madison, 68 (5): $359-70,1949$.

MARSHALL, T.J. Distribution. of water in soil. In:

Relation between water and soil. Farnhan Royal, CAB, 1959. p.39-45 (Commonwealth Bureau of Soils. Technical Communica tion, 50).

MCKEAGUE, J.A. \& TOPP, G.C. Pitfalls in interpretation of soil drainage from soil survey information. Canadian Journal of Soil Science, Ottawa, 66: 37-44, 1986.

MUALEM, $Y$. A new model for predicting the hydraulic conductivity of unsatured porous media. Water Resources Research, Washington, 12(3): 513-22, 1976.

MURALI, V.; KRISHNA MURTI, G.S.R.; SINHA, A.K. Statistical re lationships of water flow parameters with soil matrix and porosity properties. Journal of Hidrology, Amsterdam, 4l: $371-6, \quad 1979$.

NIELSEN, D.R.; BIGGAR, J.W.; COREY, J.C. Application of flow theory to field situations. Soil science, Madison, 113 (4): 254-63, 1972 . 
PETERSEN, G.W.; CUNNINGHAM, R.L.; MATELSKI, R.P. Moisture characteristics of Pensilvania soils. I. Moisture retention related to texture. Soil Science.Society of America Proceedings, Madison, $\underline{\Xi}(2): 271-5$, 1968 .

PREVEDELLO, B.M.S.; PREVEDELLO, C.L.; LIBARDI, P.L. Simplif cação analitica do método do perfil instantāneo para obten ção da condutividade hidráulica não saturada em condições de campo. Revista Brasileira de Ciēncia do Solo, Campinas, $\underline{5}: 93-7,1981$.

RAWLS, W.J.; BRAKENSIEK, D.L.; SAXTON, K.E. Estimation of soil water properties. Transaction of ASAE, St. Joseph, 25(5): $1316-20$, 1982 .

REICHARDT, $K$. Processos de transferéncia no sistema soloplanta - atmosfera. Campinas, Fundação Cargill, 1975. $286 p$.

REICHARDT, K. Capacidade de campo. Revista Brasileira de Ciēncia do Solo, Campinas, 12: 211-6, 1988.

RICHARDS, L.A.; RUSSEL, M.B.; NEAL, D.R. Further developments on apparatus for field moisture studies. Soil science Society of America Proceedings, Madison, $\underline{2}$ : 55-64, 1938.

RICHARDS, L.A. Methods of measuring soil moisture tension. Soil Science, Madison, 68: 95-112, 1949 .

RIVERS, E.D. \& SHIPP, R.F. Available water capacity of sandy and gravelly North Dakota soils. Soil Science, Madison, 113(2): 74-80, 1971 . 
ROSE, C.W. Agricultural physics. Oxford, Pergamon Press, 1966. $230 p$.

SALTER, P.J. \& HAWORTH, F. The available-water capacity of sand. loam soil. I. A critical comparison of methods of determining the moisture content of soil at field capacity and at the permanent wilting percentage. Journal of Soil. Science, $0 x$ ford, $12(2): 326-34,1961$.

SOUZA, M.L.P.; LIBARDI, P.L.; REICHARDT, K. Propagação de erros na medida de fluxos de àgua no solo em condições de campo. Revista Brasileira de Ciência do Solo, Campinas, 3: $137-40,1979$.

SOIL SCIENCE SOCIETY OF AMERICA. Glossary of soil science terms. Madison, 1984 .

VAN GENUCHTEN, M.Th. A closed-form equation for predicting the hydraulic conductivity of unsatured soils. Soil science Society of America Journal, Madison, 44: 892-8, 1980.

VAN GENUCHTEN, M.Th. \& NIELSEN, D.R. On describing and predicting the hydraulic properties of unsatured soils. Annales Geophysicae, Paris, $\underline{3}(5): 615-28,1985$.

VEIHMEYER, F.J. \& HENDRICKSON, A.H. The moisture equivalent as a measure of the field capacity of soils. Soil science, Madison, 32(3): 181-93, 1931 .

VEIHMEYER, F.J. \& HENDRICKSON, A.H. Methods of measuring field capacity and permanent wilting percentage of soils. Soil Science, Madison, 68: 75-95, 1949 . 
VILLAGRA, M.M.; MATSUMOTO, O.M.; BACCHI, 0.0.S.; MORAES, S.0.; LIBARDI, P.L.; REICHARDT, K. Tensiometria e variabilidade espacial em terra roxa estruturada. Revista Brasileira de Ciēncia do Solo, Campinas, 12: 205-10, 1988.

WHITMYER, R.W. \& BLAKE, G.R. Influence of silt and clay on the physical performance of sand-soil mixtures. Agronomy Journal, Madison, 81: 5-12, 1989 . 
52.

$T A B E L S$ 


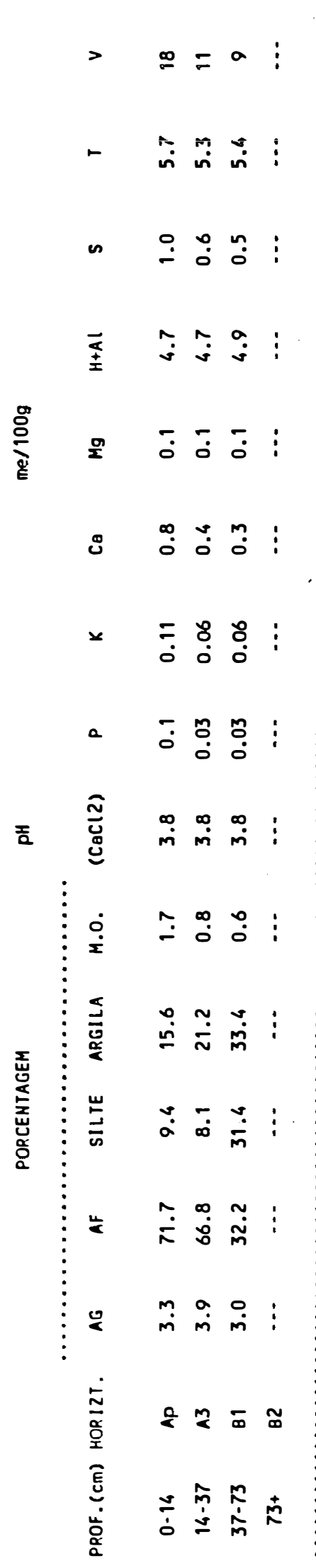

$$
\begin{aligned}
& >\quad \begin{array}{lllll}
\bar{\kappa} & 8 & \overline{0} & \frac{0}{0} & \alpha \\
\dot{\alpha} & \dot{\alpha} & \alpha & \bar{\alpha} & \hat{a}
\end{array}
\end{aligned}
$$

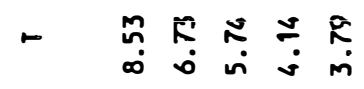

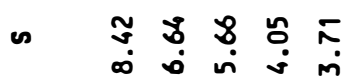

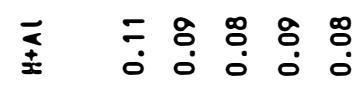

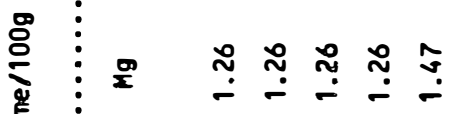$$
\text { \& } \hat{i} \text { m }
$$

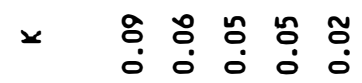

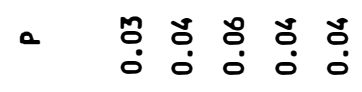

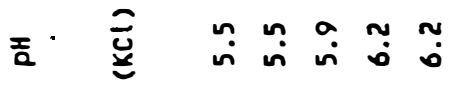$$
\text { 밀 }
$$
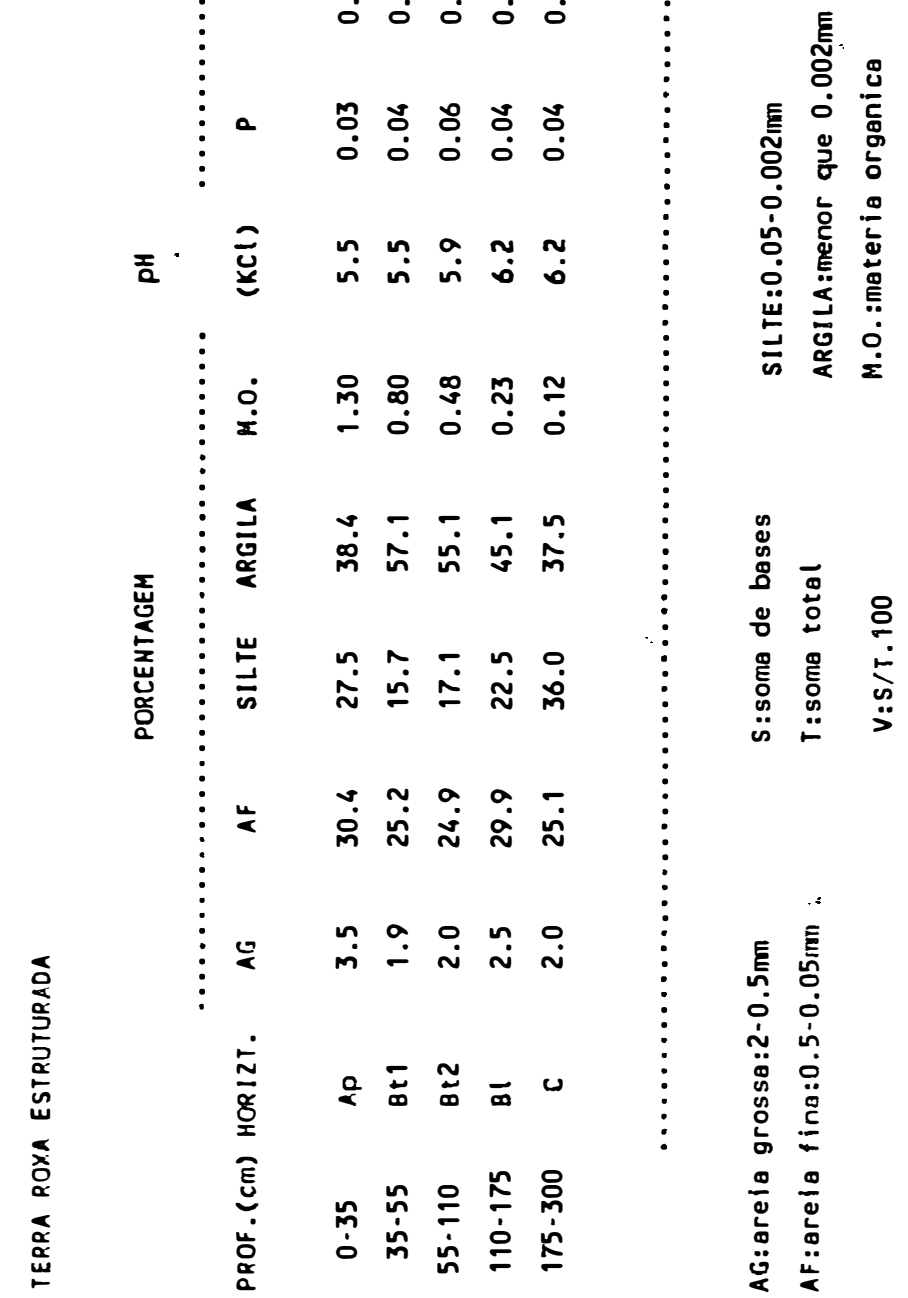
- ว

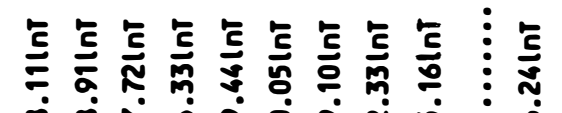

54.

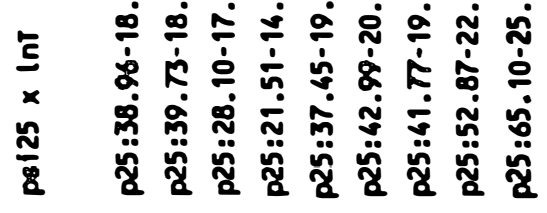

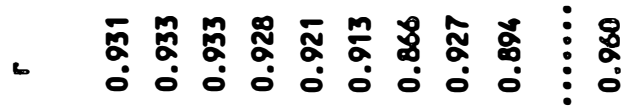

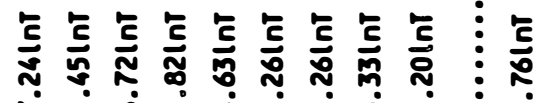

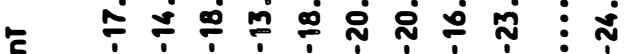

× रें

品

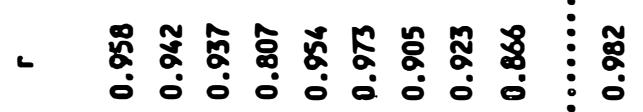

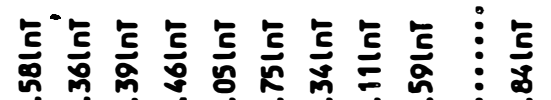

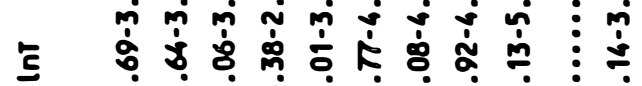

× $\quad$ ก

₹

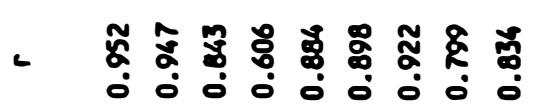

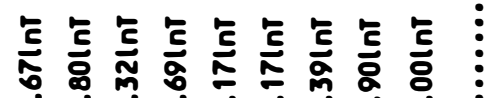

$\$$

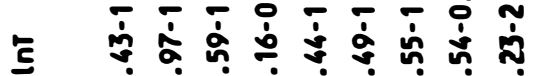

5 में

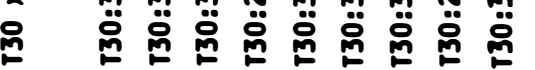

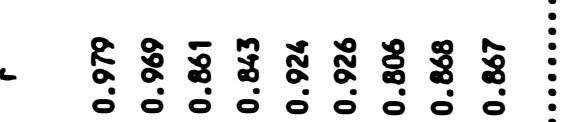

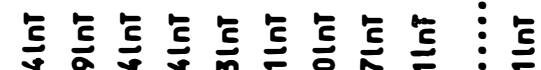

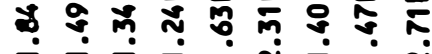

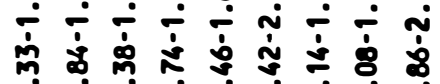

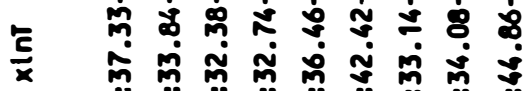

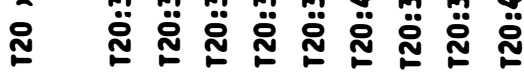

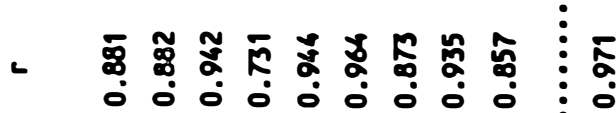

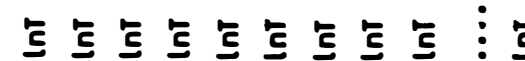

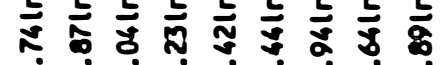

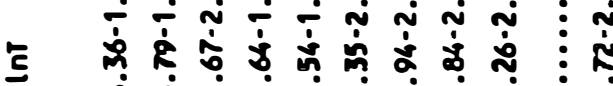

× की

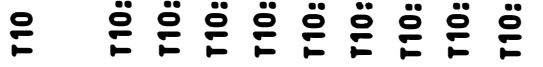




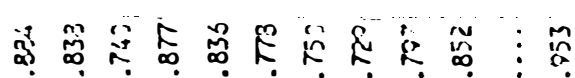

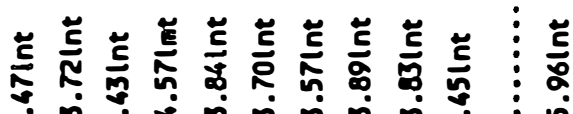

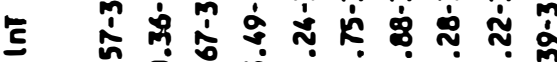

$\times \quad$ o 음

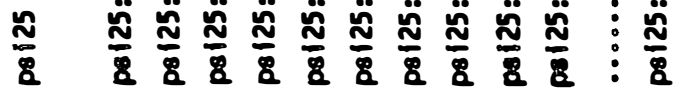

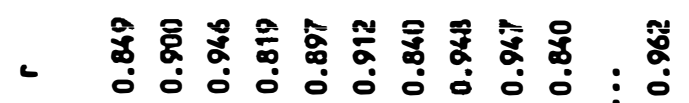

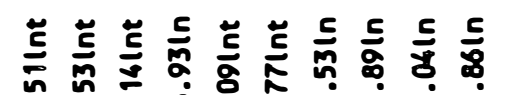

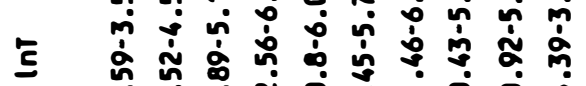

×

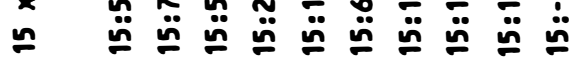

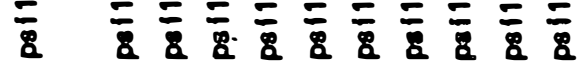

- 产

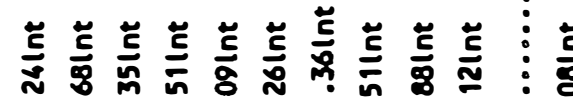

E m

× Kू்

₹

Е

జّำ

\%

- 중

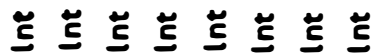

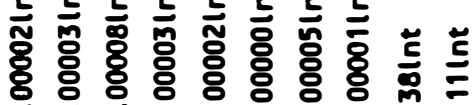

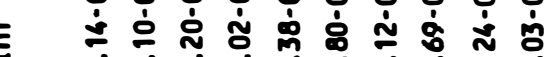

ذ̇

\&

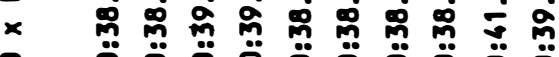

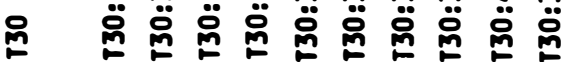

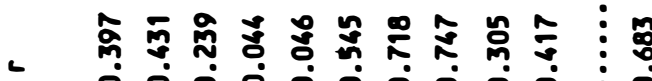

000000

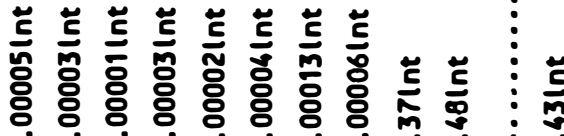

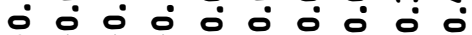

$\stackrel{8}{8}$

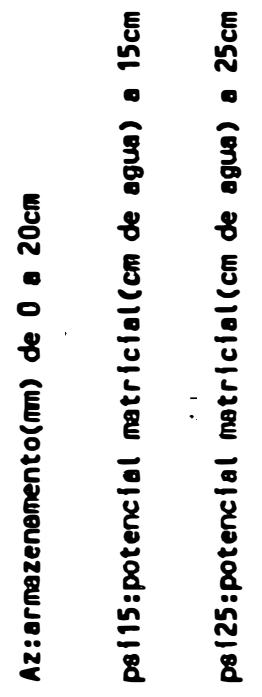

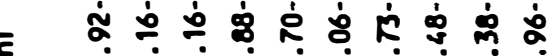

:

¿े

号

官

हो

n 0 is is o i a :

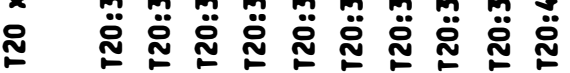

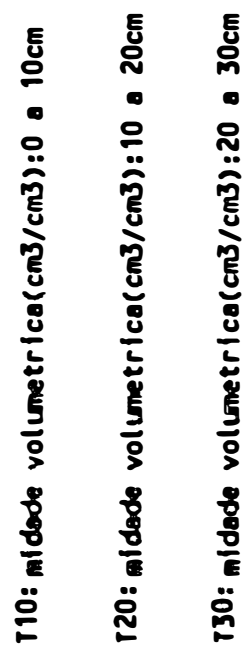




\begin{tabular}{|c|c|c|c|c|c|c|c|c|}
\hline FLUXO: & & 5XET & & & & 10XET & & \\
\hline \multicolumn{2}{|c|}{ t(hrs) } & psit15 & psizs & teta:0020 & thenrs) & pois5 & peizs & teta: $0-20$ \\
\hline A1 & 341.43 & -135.40 & -140.82 & 20.05 & 170.71 & -123.39 & 128.19 & 21.29 \\
\hline 12 & 319.80 & -109.21 & -146.70 & 19.76 & 159.90 & 99.19 & 133.64 & 20.92 \\
\hline 13 & 322.57 & -146.24 & -146.81 & 19.81 & 161.29 & 133.27 & 136.53 & 20.98 \\
\hline A6 & 236.38 & -107.39 & -115.35 & 22.46 & 117.19 & 97.82 & 105.42 & 23.29 \\
\hline 15 & 290.19 & -136.03 & -152.36 & 21.09 & 145.09 & 123.12 & 138.89 & 23.18 \\
\hline 16 & 452.00 & -156.17 & -161.71 & 19.66 & 226.00 & 142.13 & 147.81 & 21.30 \\
\hline$A 7$ & 413.00 & -154.33 & -151.48 & 19.10 & 206.52 & 140.29 & 138.24 & 20.61 \\
\hline 18 & 391.14 & -141.72 & -171.85 & 18.79 & 195.57 & 130.29 & 156.37 & 20.21 \\
\hline A9 & 532.95 & -181.04 & -195.88 & 16.54 & 266.48 & 164.96 & 178.46 & 18.48 \\
\hline
\end{tabular}

\begin{tabular}{lrrr} 
TEMPO: & \multicolumn{3}{c}{24 HORAS } \\
& PSi15 & PSi25 & teta:0-20 \\
A1 & 89.64 & 92.74 & 24.81 \\
A2 & 71.77 & 97.78 & 24.11 \\
A3 & 97.62 & 100.78 & 24.21 \\
A4 & 75.90 & 82.72 & 25.24 \\
A5 & 89.59 & 103.91 & 25.92 \\
A6 & 96.71 & 102.85 & 26.63 \\
A7 & 96.88 & 97.13 & 25.27 \\
AB & 96.14 & 109.52 & 24.52 \\
A9 & 109.12 & 117.87 & 25.22
\end{tabular}

\begin{tabular}{rrr}
\multicolumn{3}{c}{$\pi$ HORAs } \\
psi15 & psi25 & teta:0-20 \\
108.58 & 112.64 & 22.84 \\
87.65 & 118.55 & 22.26 \\
118.19 & 120.25 & 22.35 \\
91.09 & 98.74 & 23.89 \\
110.06 & 125.26 & 24.25 \\
118.96 & 124.88 & 24.02 \\
118.96 & 118.12 & 22.89 \\
114.08 & 134.05 & 22.26 \\
134.61 & 145.51 & 22.14
\end{tabular}

\begin{tabular}{lcc}
\multicolumn{3}{c}{240 HORAS } \\
psi15 & psi25 & teta:0-20 \\
129.33 & 134.44 & 20.68 \\
105.05 & 141.31 & 20.24 \\
140.74 & 141.57 & 20.34 \\
107.73 & 115.73 & 22.41 \\
132.49 & 148.66 & 22.41 \\
143.35 & 149.02 & 21.16 \\
143.33 & 141.11 & 20.29 \\
133.74 & 160.94 & 19.79 \\
162.54 & 173.81 & 18.77
\end{tabular}

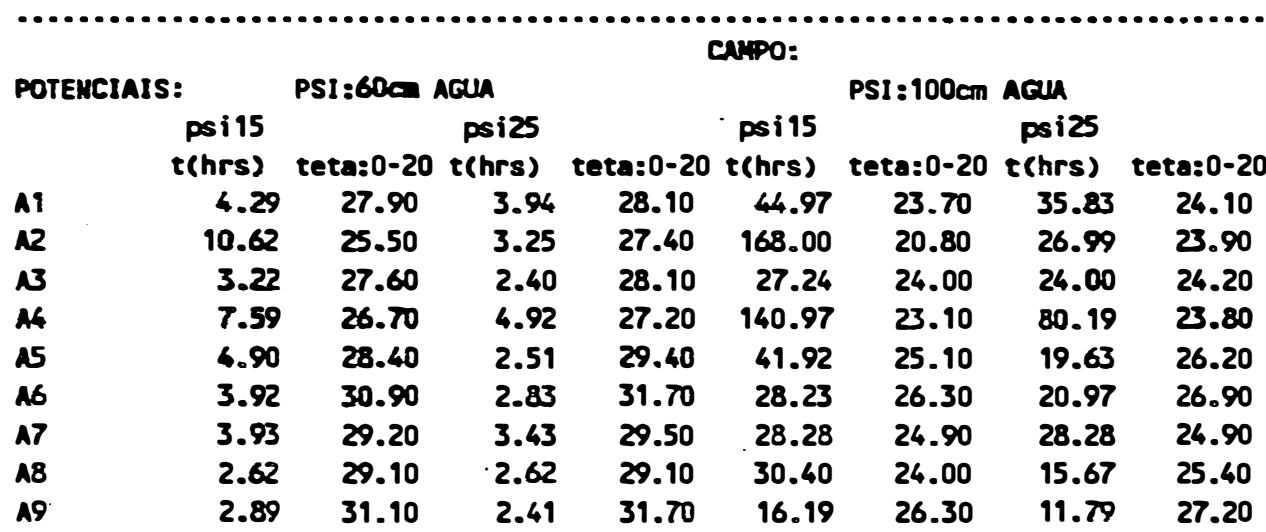

\section{EVAPOTRANSP IRACAO: ET}

ET :5nom/dias>>0.21m/h

10XET $: 0.021 \mathrm{ma} / \mathrm{h}>>>5 \times E T=0.0105 \mathrm{~km} / \mathrm{h}$ 
tabela5: criterios utilizados en cempo

para daterminar a "capacidado de cempo"

apl icados - TRE

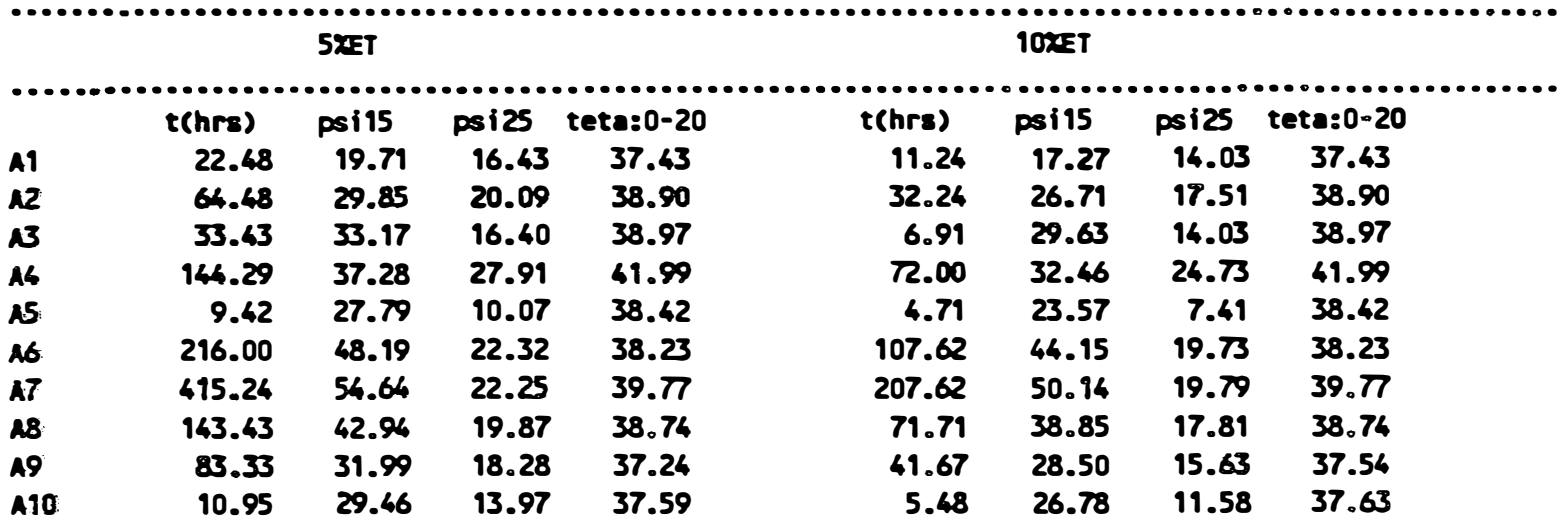

\begin{tabular}{|c|c|c|c|c|c|c|c|c|c|}
\hline & \multicolumn{3}{|c|}{26 HORAS } & \multicolumn{3}{|c|}{$\boldsymbol{T}$ HORAS } & \multicolumn{3}{|c|}{240 HORAS } \\
\hline & psils & psizs & teta:0-20 & psils & psizs & têta: 0.20 & psils & psizs & teta:0-20 \\
\hline A? & 19.96 & 16.66 & 37.43 & 23.79 & 20.74 & 37.43 & 28.02 & 24.65 & 37.43 \\
\hline 12 & 25.38 & 16.42 & 38.90 & 30.35 & 20.50 & 38.90 & 35.79 & 24.98 & 38.90 \\
\hline 13 & 31.49 & 15.27 & 38.97 & 37.14 & 19.04 & 38.97 & 43.35 & 23.19 & 38.97 \\
\hline A & 24.85 & 19.72 & 41.99 & 32.46 & 24.73 & 41.99 & 40.81 & 30.25 & 41.99 \\
\hline 15 & 33.48 & 13.66 & 38.42 & 40.17 & 17.87 & 38.42 & 47.50 & 22.49 & 38.42 \\
\hline 196 & 35.51 & 14.18 & 38.23 & 41.85 & 18.25 & 38.23 & 48.80 & 22.71 & 38.23 \\
\hline$A 7$ & 36.05 & 12.08 & 39.79 & 33.22 & 16.01 & $39 . \pi$ & 51.08 & 20.30 & 39.77 \\
\hline 18 & 32.41 & 12.96 & 38.74 & 38.88 & 17.20 & 38.74 & 45.97 & 21.87 & 38.74 \\
\hline 19 & 25.72 & 13.52 & 37.78 & 31.26 & 17.72 & 37.30 & 37.32 & 22.33 & 36.78 \\
\hline 190 & 32.49 & 16.67 & 37.55 & 36.73 & 20.46 & 37.48 & 49.39 & 24.61 & 37.41 \\
\hline
\end{tabular}

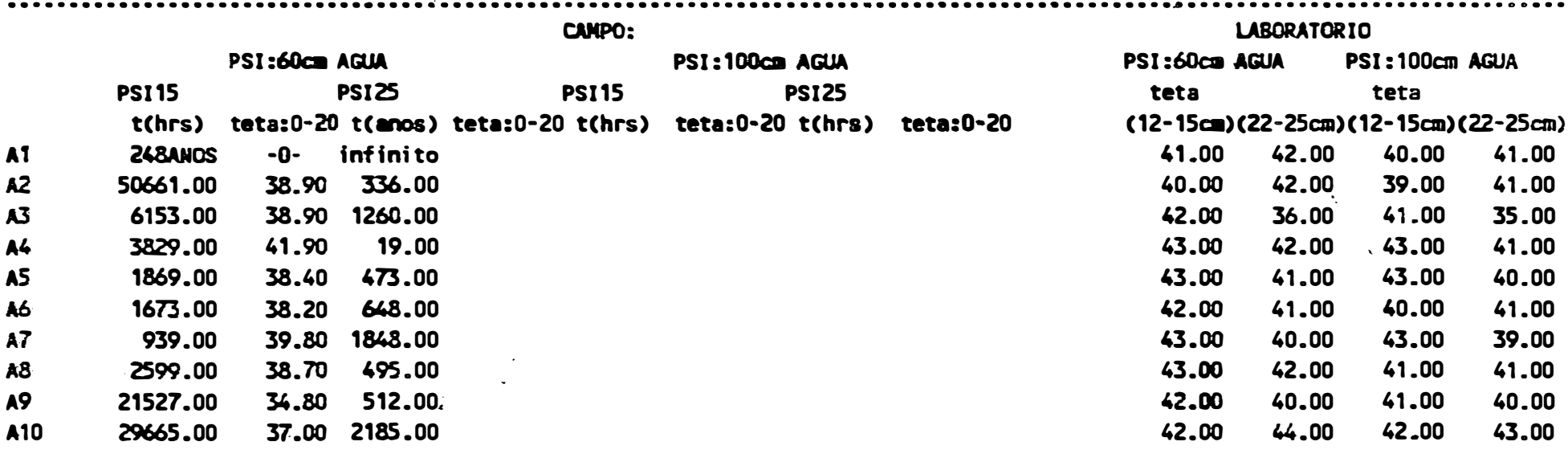

psil5:potencial motricial(ca de agus) a 15an de profundidade

psizs:potencial metricial(ca de agua) a $25 \mathrm{~cm}$ de profundiade

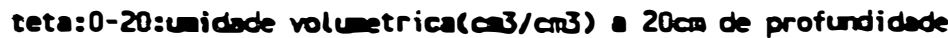

EVAPOTRANSPIRACAO:ET

ET:Sordiass>0.21 a/h

10XET : $0.021 \mathrm{wa} / \mathrm{h}>>>5 x E T: 0.0105 \mathrm{~mm} / \mathrm{h}$ 
tabela 6:Determinacao en laboratorio das umidades volumetricas $(\mathrm{cm} 3 / \mathrm{cm} 3)$ em funcao dos potenciais matricos(cm de agua) com amostras indeformadas no LVA

LVA: $12-15 \mathrm{~cm}$

(el iminada AT)

POTENCIAL MATRICO

\begin{tabular}{|c|c|c|c|c|c|c|c|c|c|}
\hline & $5 \mathrm{~cm}$ & $10 \mathrm{~cm}$ & $60 \mathrm{~cm}$ & $100 \mathrm{~cm}$ & $364.44 \mathrm{~cm}$ & $1033 \mathrm{~cm}$ & $3099 \mathrm{~cm}$ & $5165 \mathrm{~cm}$ & $15495 \mathrm{~cm}$ \\
\hline A1 & 0.43 & 0.43 & 0.27 & 0.23 & 0.17 & 0.15 & 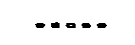 & 0.13 & 0.11 \\
\hline$A 2$ & 0.45 & 0.42 & 0.25 & 0.21 & 0.15 & 0.13 & 0.11 & 0.11 & 0.10 \\
\hline$A 3$ & 0.42 & 0.41 & 0.26 & 0.22 & 0.16 & 0.14 & 0.12 & 0.12 & 0.11 \\
\hline A6 & 0.40 & 0.41 & 0.28 & 0.23 & 0.17 & 0.15 & 0.13 & 0.13 & 0.12 \\
\hline A5 & 0.39 & 0.39 & 0.30 & 0.25 & 0.26 & 0.26 & 0.19 & 0.15 & 0.16 \\
\hline A6 & 0.37 & 0.38 & 0.28 & 0.26 & 0.22 & 0.21 & -0000 & 0.16 & 0.13 \\
\hline A8 & 0.42 & 0.42 & 0.32 & 0.27 & 0.19 & 0.17 & 0.15 & 0.14 & 0.13 \\
\hline 19 & 0.65 & 0.45 & 0.35 & 0.30 & 0.27 & 0.26 & 0.21 & 0.18 & 0.16 \\
\hline A10 & 0.46 & 0.46 & 0.31 & 0.26 & 0.18 & 0.16 & 0.14 & 0.13 & 0.12 \\
\hline medias & 0.42 & 0.42 & 0.29 & 0.25 & 0.19 & 0.18 & 0.12 & 0.14 & 0.12 \\
\hline dsv.pdr. & 0.03 & 0.02 & 0.03 & 0.03 & 0.04 & 0.04 & 0.09 & 0.02 & 0.02 \\
\hline ev & 6.76 & 5.79 & 10.30 & 10.71 & 19.56 & 24.50 & 74.83 & 14.58 & 13.72 \\
\hline
\end{tabular}

LVA:22-25cm

(eliminada A8)
POTENCIAL MATRICO

$5 \mathrm{~cm} \quad 10 \mathrm{~cm} \quad 60 \mathrm{~cm} \quad 100 \mathrm{~cm} \quad 344.44 \mathrm{~cm} \quad 1033 \mathrm{~cm} \quad 3099 \mathrm{~cm} \quad 5165 \mathrm{~cm} \quad 15495 \mathrm{~cm}$

\begin{tabular}{|c|c|c|c|c|c|c|c|c|c|}
\hline$A 1$ & 0.42 & 0.63 & 0.28 & 0.23 & 0.17 & 0.15 & 0.13 & 0.12 & 0.11 \\
\hline$A 2$ & 0.45 & 0.45 & 0.27 & 0.23 & 0.17 & 0.14 & 0.13 & 0.12 & 0.11 \\
\hline$A 3$ & 0.46 & 0.46 & 0.30 & 0.25 & 0.18 & 0.16 & 0.16 & 0.13 & 0.12 \\
\hline A6 & 0.46 & 0.46 & 0.31 & 0.26 & 0.20 & 0.17 & 0.16 & 0.16 & 0.12 \\
\hline A5 & 0.45 & 0.46 & 0.28 & 0.26 & 0.18 & 0.16 & 0.13 & 0.13 & 0.13 \\
\hline 16 & 0.43 & 0.43 & 0.33 & 0.28 & 0.20 & 0.17 & 0.15 & 0.15 & 0.12 \\
\hline$A 7$ & 0.45 & 0.46 & 0.29 & 0.26 & 0.17 & 0.15 & 0.13 & 0.13 & 0.13 \\
\hline$A 9$ & 0.47 & 0.67 & 0.31 & 0.26 & 0.19 & 0.16 & 0.15 & 0.16 & 0.13 \\
\hline A 10 & 0.45 & 0.46 & 0.33 & 0.25 & 0.20 & 0.18 & 0.15 & 0.14 & 0.13 \\
\hline medias & 0.45 & 0.45 & 0.30 & 0.25 & 0.18 & 0.16 & 0.14 & 0.13 & 0.12 \\
\hline dsv.pdr. & 0.01 & 0.09 & 0.02 & 0.02 & 0.01 & 0.01 & 0.01 & 0.01 & 0.01 \\
\hline$c r$ & 3.17 & 3.05 & 6.85 & 6.12 & 6.82 & 7.22 & 6.30 & 7.07 & 6.43 \\
\hline
\end{tabular}


tabala 7:Determinacao en laboratorio das unidades volumbericas(cm3/cm3) en funceo dos potenciais metricos(cm de agu) can anostras indeformedas no TRE

tre: $12-15 \mathrm{~cm}$

Sca

POTENCIAL MATRICO

\begin{tabular}{|c|c|c|c|c|c|c|c|c|c|}
\hline & Scan & $10 \mathrm{~cm}$ & $60 \mathrm{~cm}$ & $100 \mathrm{co}$ & $344.44 \mathrm{~cm}$ & $9053 \mathrm{a}$ & 30990 & $5965 \mathrm{~cm}$ & $95495 \mathrm{ca}$ \\
\hline A1 & 0.67 & 0.67 & 0.49 & 0.40 & 0.36 & 0.36 & 0.32 & 0.30 & 0.27 \\
\hline$A 2$ & 0.45 & 0.45 & 0.40 & 0.39 & 0.36 & 0.35 & 0.36 & 0.32 & 0.29 \\
\hline$A 3$ & 0.44 & 0.43 & 0.42 & 0.61 & 0.38 & 0.36 & 0.36 & 0.32 & 0.28 \\
\hline A6 & 0.46 & 0.46 & 0.43 & 0.43 & 0.40 & 0.37 & 0.36 & 0.34 & 0.31 \\
\hline AS & 0.45 & 0.45 & 0.43 & 0.43 & 0.39 & 0.37 & 0.33 & 0.33 & 0.28 \\
\hline 16 & 0.45 & 0.46 & 0.62 & 0.40 & 0.37 & 0.35 & 0.33 & 0.31 & 0.28 \\
\hline$A 7$ & 0.45 & 0.45 & 0.43 & 0.43 & 0.60 & 0.38 & 0.36 & 0.36 & 0.31 \\
\hline 18 & 0.46 & 0.45 & 0.63 & 0.41 & 0.38 & 0.36 & 0.34 & 0.32 & 0.29 \\
\hline A9 & 0.67 & 0.47 & 0.42 & 0.41 & 0.36 & 0.34 & 0.33 & 0.31 & 0.27 \\
\hline$A 10$ & 0.48 & 0.47 & 0.42 & 0.42 & 0.36 & 0.34 & 0.32 & 0.31 & 0.26 \\
\hline Hicotias & 0.46 & 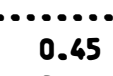 & 0.06 & 0.41 & ט. & 0.36 & 0.36 & 0.32 & 0.28 \\
\hline dsv.pdr. & 0.01 & 0.01 & 0.01 & 0.01 & 0.02 & 0.01 & 0.01 & 0.01 & 0.02 \\
\hline ev & 2.55 & 2.82 & 2.24 & 3.26 & 6.95 & 3.81 & 3.99 & 3.95 & 5.50 \\
\hline
\end{tabular}

tre: $22-25 \mathrm{~cm}$

$5 \mathrm{~cm} \cdot 10 \mathrm{~cm}$

A)

A2

13

A6

N5

A6

A7

A8

A9

A10

POTENCIAL MATRICO

$\begin{array}{cccccccccc}\text { dias } & 0.46 & 0.45 & 0.41 & 0.40 & 0.37 & 0.35 & 0.36 & 0.32 & 0.29 \\ \text { crvpdr. } & 0.03 & 0.03 & 0.02 & 0.02 & 0.02 & 0.02 & 0.02 & 0.02 & 0.02 \\ \text { cr } & 6.31 & 5.85 & 6.88 & 4.95 & 4.76 & 5.36 & 5.64 & 5.83 & 6.29\end{array}$


60.

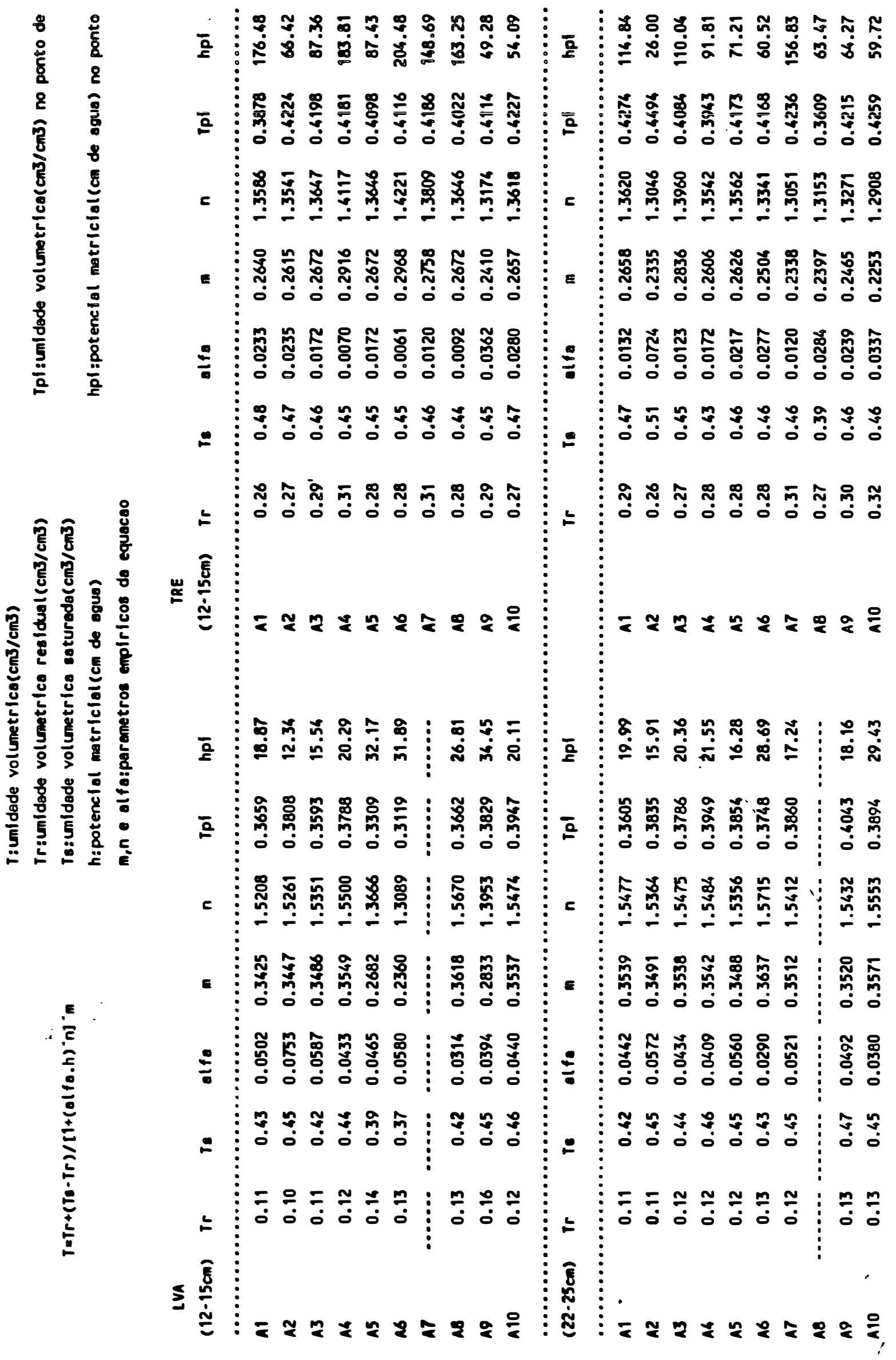


TABELA:9 Anolise de al gunas caracteristicas das cnostras indeformedos,

- os parametros obtidos no deteraínacao do ponto de inflexao

de curve carseteristica(Tetapi - hpi) referente a cada anostra, no LUA

profundidade: $12-15 \mathrm{~cm}$

\begin{tabular}{|c|c|c|c|c|c|c|c|c|c|}
\hline NREA & AG & $A F$ & SILTE & ARGILA & $\left.D p(g / a)^{3}\right)$ & $g(\cos 3)$ & PT & TETACPI) & $h(P I)$ \\
\hline A1 & 23 & 51 & 9 & 17 & 2.96 & 1.52 & 0.48 & 0.3659 & 18.87 \\
\hline 12 & 23 & 53 & 8 & 16 & 3.03 & 1.67 & 0.51 & 0.3808 & 12.34 \\
\hline$A 3$ & 26 & 52 & 8 & 16 & 3.32 & 1.53 & 0.56 & 0.3593 & 15.54 \\
\hline A6 & 21 & 53 & 6 & 20 & 3.07 & 1.56 & 0.50 & 0.3788 & 20.29 \\
\hline 15 & 22 & 49 & 9 & 20 & 2.98 & 1.63 & 0.65 & 0.3309 & 32.17 \\
\hline A6 & 21 & 52 & 9 & 18 & 2.96 & 1.65 & 0.46 & 0.3119 & 31.89 \\
\hline$A 7$ & 22 & 51 & 8 & 19 & 3.03 & 1.58 & 0.48 & $\ldots$ & $\ldots$ \\
\hline$A B$ & 20 & 51 & 10 & 19 & 3.07 & 1.53 & 0.50 & 0.3662 & 26.81 \\
\hline A9 & 21 & 51 & 9 & 19 & 2.85 & 1.50 & 0.67 & 0.3829 & 34.65 \\
\hline A10 & 20 & 50 & 8 & 22 & 3.07 & 1.65 & 0.53 & 0.3947 & 20.11 \\
\hline dias & 21.70 & 51.30 & 8.60 & 18.60 & 3.03 & 1.56 & 0.69 & 0.36 & 23.61 \\
\hline $\begin{array}{l}\text { cv.pdr. } \\
\text { cv }\end{array}$ & $\begin{array}{l}1.27 \\
5.85\end{array}$ & $\begin{array}{l}1.19 \\
2.31\end{array}$ & $\begin{array}{r}1.02 \\
12.16\end{array}$ & $\begin{array}{l}1.80 \\
9.68\end{array}$ & $\begin{array}{l}0.12 \\
3.91\end{array}$ & $\begin{array}{l}0.06 \\
3.95\end{array}$ & $\begin{array}{l}0.03 \\
6.16\end{array}$ & $\begin{array}{l}0.03 \\
6.89\end{array}$ & $\begin{array}{r}7.51 \\
31.81\end{array}$ \\
\hline
\end{tabular}

profundidade:22-25ca

\begin{tabular}{|c|c|c|c|c|c|c|c|c|c|}
\hline AREA & $\mathbf{A G}$ & AF & SILTE & ARGILA & $D p(g / c m 3) d$ & $g / \cos 3)$ & PT & TETA(PI) & $h(P I)$ \\
\hline A1 & 22 & 53 & 6 & 19 & 3.07 & 1.51 & 0.51 & 0.3605 & 19.99 \\
\hline 12 & 22 & 52 & 7 & 19 & 3.03 & 1.43 & 0.53 & 0.3835 & 15.91 \\
\hline$A 3$ & 22 & 51 & 6 & 21 & 3.07 & 1.52 & 0.50 & 0.3786 & 20.36 \\
\hline AG & 23 & 69 & 10 & 18 & 2.85 & 1.51 & 0.67 & 0.3949 & 21.55 \\
\hline 15 & 26 & 50 & 5 & 21 & 2.96 & 1.49 & 0.49 & 0.3856 & 16.28 \\
\hline A6 & 21 & 51 & 6 & 22 & 3.02 & 1.58 & 0.48 & 0.3748 & 28.69 \\
\hline A7 & 22 & 50 & 7 & 21 & 3.12 & 1.48 & 0.53 & 0.3860 & 17.26 \\
\hline AB & 22 & 46 & 11 & 21 & 3.02 & 1.49 & 0.51 & $\ldots$ & $\ldots$ \\
\hline A9 & 22 & 67 & 10 & 21 & 2.92 & 1.68 & 0.49 & 0.6063 & 18.16 \\
\hline A10 & 21 & 50 & 10 & 19 & 3.07 & 1.55 & 0.50 & 0.3894 & 26.63 \\
\hline dias & 22.10 & 69.90 & 7.80 & 20.20 & 3.01 & 1.50 & 0.50 & 0.38 & 20.29 \\
\hline v.pdr. & 0.83 & 2.02 & 2.09 & 1.25 & 0.08 & 0.06 & 0.02 & 0.01 & 3.92 \\
\hline cv & 3.76 & 6.05 & $26 . \pi$ & 6.18 & 2.62 & 2.60 & 3.53 & 3.05 & 19.33 \\
\hline
\end{tabular}

AG:areia grossa:2-0.5m AF:areia fina:0.5-0.05em SILTE: $0.05-0.002 \mathrm{~mm}$ ARGILA:anenor que $0.002 \mathrm{~mm}$
Dp:densidade das particulas $\left(g / \mathrm{cm}^{3}\right)$ Ds: densidade do solo $(9 / 003)$

PT:porosidade total( (X)

Tpi :umidade vol. no pto. de inflexsolom3/cos3)

hpi:pot.matricial no pto. de inflexso(cn de agua) 
TABELA 10 Analise de algumas caracteristicas fisicas das costras indaformedas, - os paranetros dbtidos na determinaceo do ponto de inflexeo da curva caracteristica(Tetapi e hpi) referentes a cado ansestra, na TRE

profundidade: 12-15ca

\begin{tabular}{|c|c|c|c|c|c|c|c|c|c|}
\hline AREA & AG & AF & SILTE & ARGILA & Dp & Ds & POROSID. & teta(PI) & $h(P I)$ \\
\hline A1 & 91 & 23 & 30 & 36 & 2.46 & 1.68 & 0.32 & 0.6227 & 56.09 \\
\hline$N 2$ & 9 & 26 & 30 & 37 & 2.55 & 1.67 & 0.35 & 0.6916 & 49.28 \\
\hline 13 & 11 & 26 & 30 & 35 & 2.55 & 1.75 & 0.31 & 0.6022 & 163.25 \\
\hline A & 19 & 23 & 28 & 38 & 2.55 & 1.71 & 0.33 & 0.6186 & 148.69 \\
\hline AS & 12 & 26 & 29 & 35 & 2.56 & 1.72 & 0.33 & 0.6116 & 204.48 \\
\hline 16 & 26 & 36 & 29 & 35 & 2.52 & 1.69 & 0.33 & 0.6098 & 87.63 \\
\hline A7 & 12 & 23 & 31 & 34 & 2.53 & 1.76 & 0.31 & 0.6181 & 183.81 \\
\hline AB & 11 & 25 & 30 & 34 & 2.51 & 9.72 & 0.31 & 0.6198 & 87.36 \\
\hline$A 9$ & 12 & 23 & 30 & 35 & 2.56 & 1.62 & 0.37 & 0.6226 & 66.62 \\
\hline$A 10$ & 13 & 22 & 29 & 36 & 2.59 & 1.63 & 0.37 & 0.3878 & 176.48 \\
\hline medias & 12.60 & 26.70 & 29.60 & 35.50 & 2.56 & 1.69 & 0.33 & 0.61 & 122.13 \\
\hline dsv.pdr. & 3.93 & 3.85 & 0.80 & 1.20 & 0.03 & 0.04 & 0.02 & 0.01 & 56.03 \\
\hline$C D$ & 31.19 & 15.58 & 2.70 & 3.39 & 9.33 & 2.65 & 6.16 & 2.48 & 65.87 \\
\hline
\end{tabular}

profundidade:22-250

\begin{tabular}{|c|c|c|c|c|c|c|c|c|c|}
\hline AREA & AG & AF & SILTE & ARGILA & DP & Ds & POrosio. & teta(PI) & $h(P I)$ \\
\hline A1 & 10 & 18 & 23 & 69 & 2.52 & 1.59 & 0.37 & 0.4259 & 59.72 \\
\hline 12 & 10 & 20 & 28 . & 62 & 2.64 & 1.79 & 0.35 & 0.6215 & 66.27 \\
\hline 13 & 8 & 20 & 23 & 69 & 2.6 & 1.67 & 0.43 & 0.3609 & 63.67 \\
\hline A4 & 10 & 18 & 23 & 69 & 2.59 & 1.73 & 0.33 & 0.6263 & 156.83 \\
\hline AS & 10 & 23 & 25 & 62 & 2.63 & 1.65 & 0.37 & 0.6168 & -60.52 \\
\hline A6 & 12 & 20 & 26 & 62 & 2.52 & 1.68 & 0.33 & 0.6173 & 71.21 \\
\hline A7 & 9 & 26 & 26 & 49 & 2.67 & 1.66 & 0.38 & 0.3943 & 91.81 \\
\hline AB & 11 & 22 & 27 & 60 & 2.56 & 1.66 & 0.36 & 0.4084 & 110.04 \\
\hline A9 & 10 & 23 & 31 & 36 & 2.53 & 1.56 & 0.39 & 0.4494 & 26 \\
\hline A10 & 10 & 22 & 27 & 61 & 2.56 & $1 . \pi$ & 0.33 & 0.6276 & 116.86 \\
\hline edias & 10.00 & 21.00 & 25.90 & 63.10 & 2.58 & 1.64 & 0.37 & 0.61 & 81.87 \\
\hline$\underset{\text { ev }}{\text { dsv.pdr. }}$ & $\begin{array}{r}1.00 \\
10.00\end{array}$ & $\begin{array}{l}2.00 \\
9.52\end{array}$ & $\begin{array}{l}2.63 \\
9.37\end{array}$ & $\begin{array}{l}6.21 \\
9.76\end{array}$ & $\begin{array}{l}0.05 \\
1.94\end{array}$ & $\begin{array}{l}0.08 \\
4.84\end{array}$ & $\begin{array}{l}0.03 \\
8.69\end{array}$ & $\begin{array}{l}0.02 \\
5.69\end{array}$ & $\begin{array}{l}35.25 \\
63.06\end{array}$ \\
\hline
\end{tabular}

AG:areia grossa:2-0.5m AF : areia fina:0.5-0.05m SILTE:0.05-0.002. ARGILA:-ror ave $0.002 \mathrm{~mm}$
Dp:densidade das particulas(g/on3)

Ds:densidade do solo(g/0 3 )

PT:porosidade total( $(x)$

Tpi:umidade vol. no pto. de inflexao( $03 / \mathrm{cm} 3)$

hpi:pot.eatricial no pto. de inflexaoran de agus) 


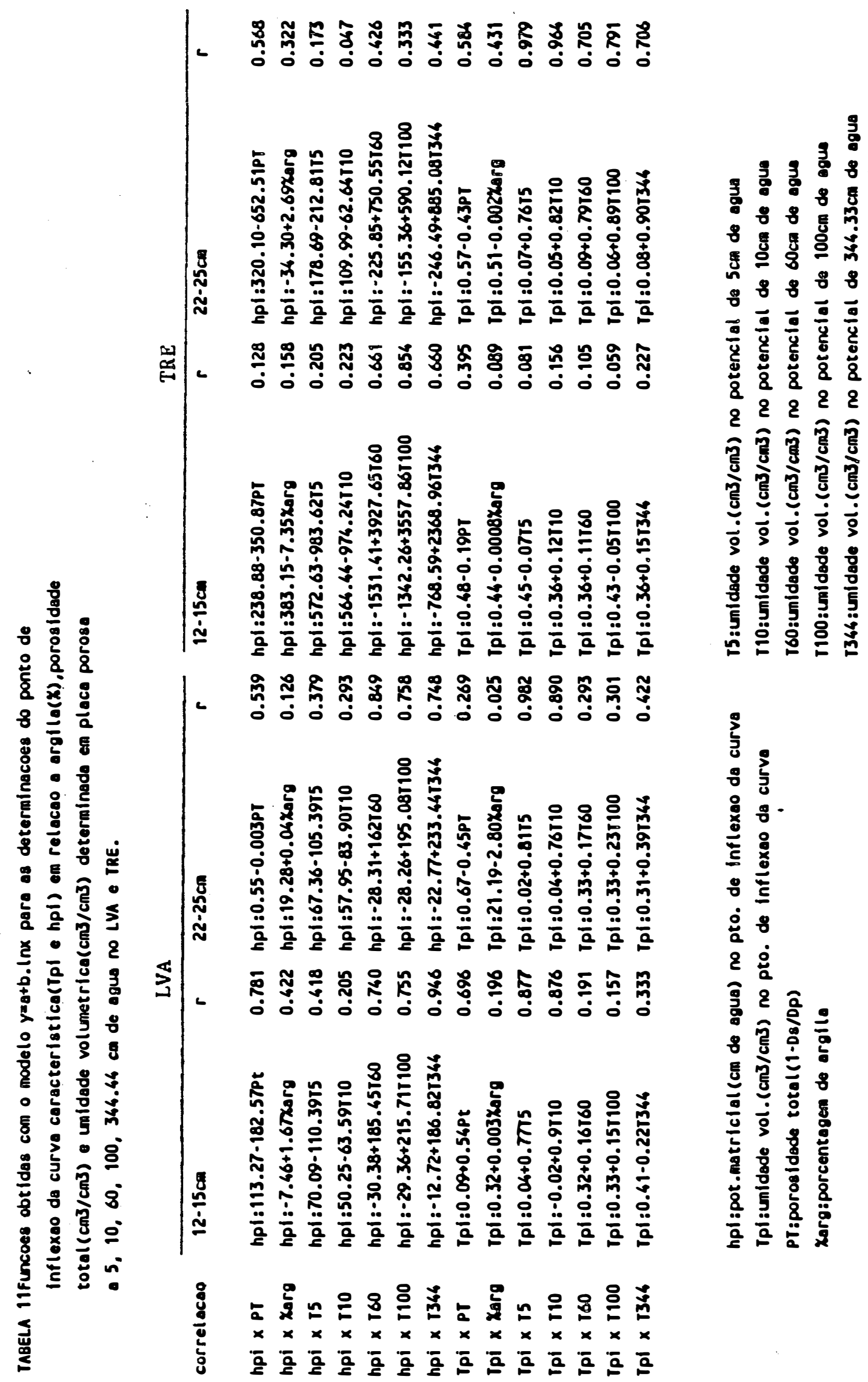


64.

$F$ I $G \cup R A S$ 
65.

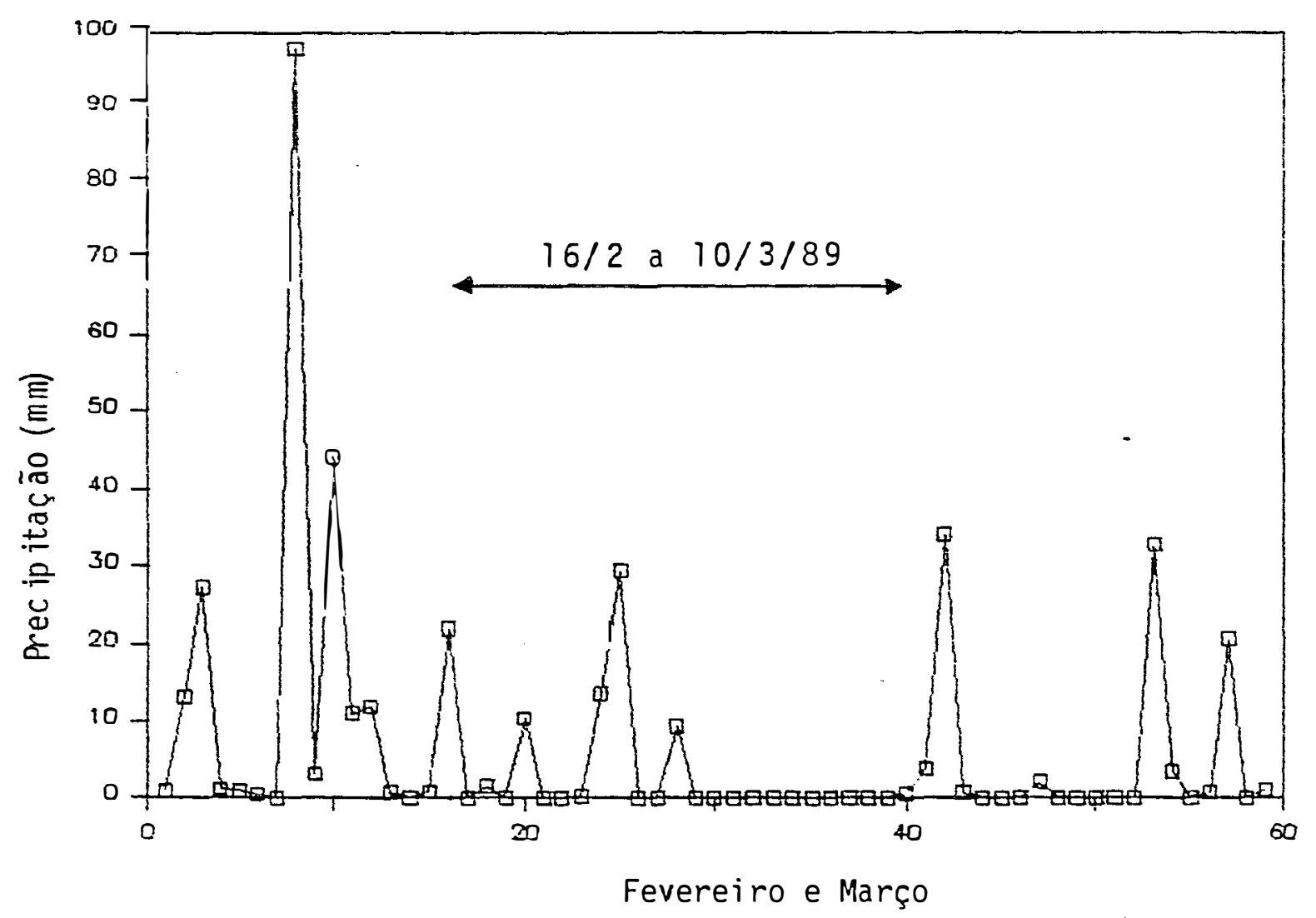

Figura 1. Periodo de permanēncia da cobertura plástica na superficie do solo LVA $(16 / 2$ a $10 / 3 / 89)$ e o indice plu viométrico local. 


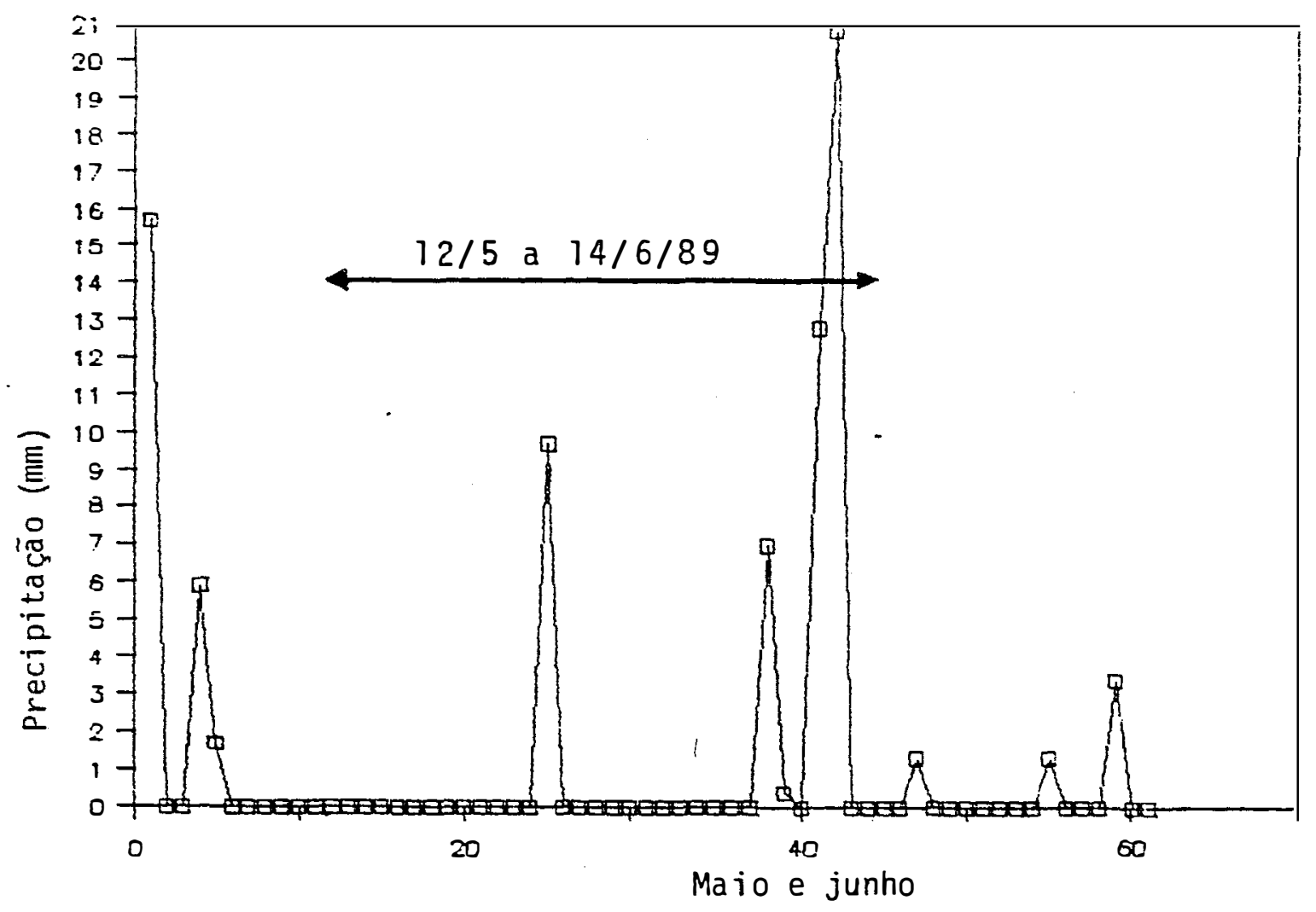

Figura 2. Perīodo de permanēncia da cobertura plàstica da superficie do solo TRE $(12 / 5$ a $14 / 6 / 89)$ e o indice plu viométrico local. 
67.

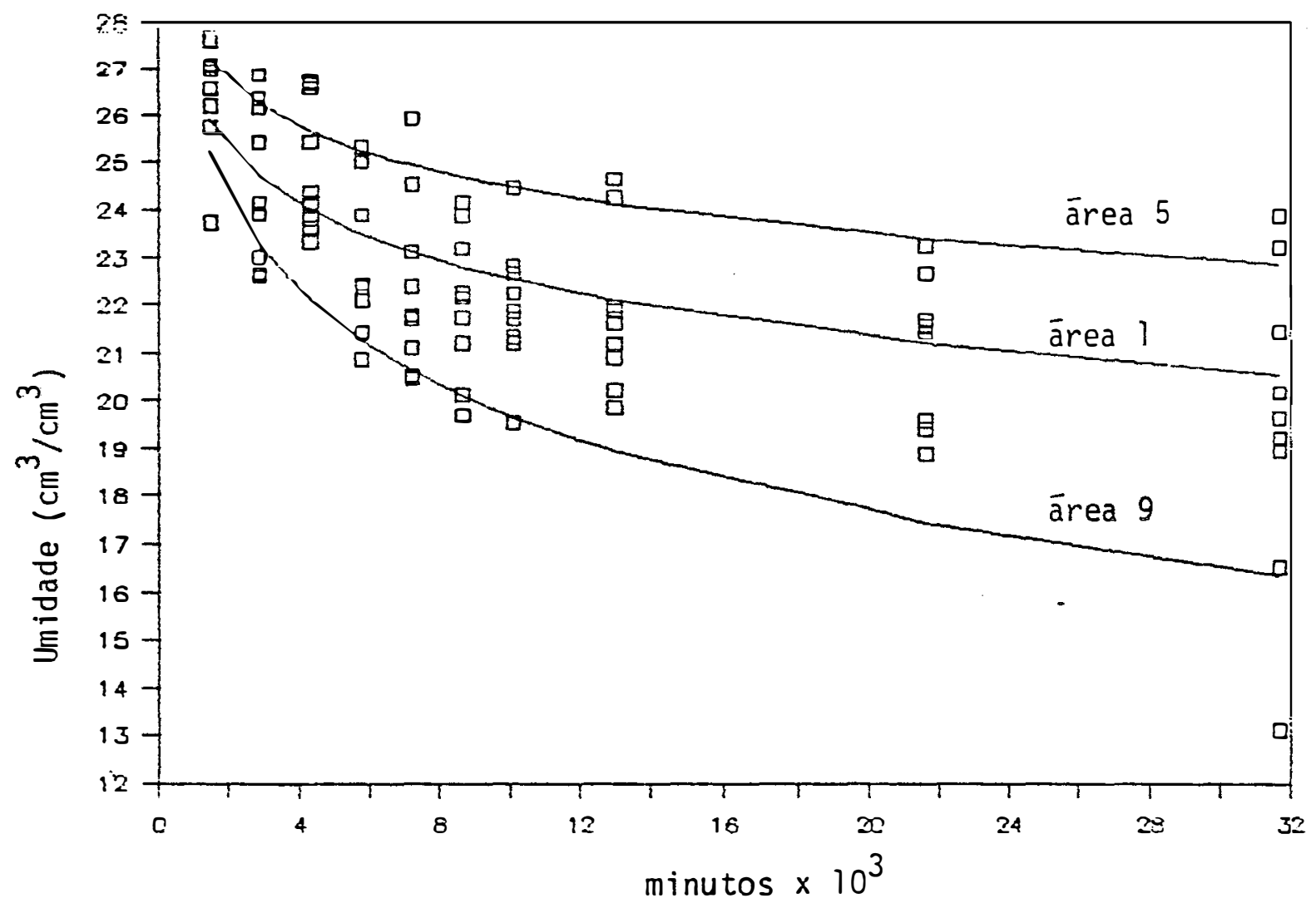

$$
\begin{array}{lll}
\text { ärea 1: } & \theta=38,36-1,74 \text { lnt } & r=0,881 \\
\text { ärea 5: } & \theta=37,54-1,45 \text { lnt } & r=0,944 \\
\text { ärea 9: } & \theta=46,26-2,89 \text { lnt } & r=0,857
\end{array}
$$

Figura 3. Distribuição da umidade volumétrica $\left(\mathrm{cm}^{3} / \mathrm{cm}^{3}\right)$ na ca mada de 0 a $10 \mathrm{~cm}$ no LVA em função do tempo (minú tos $\times 10^{3}$ ). 
68.

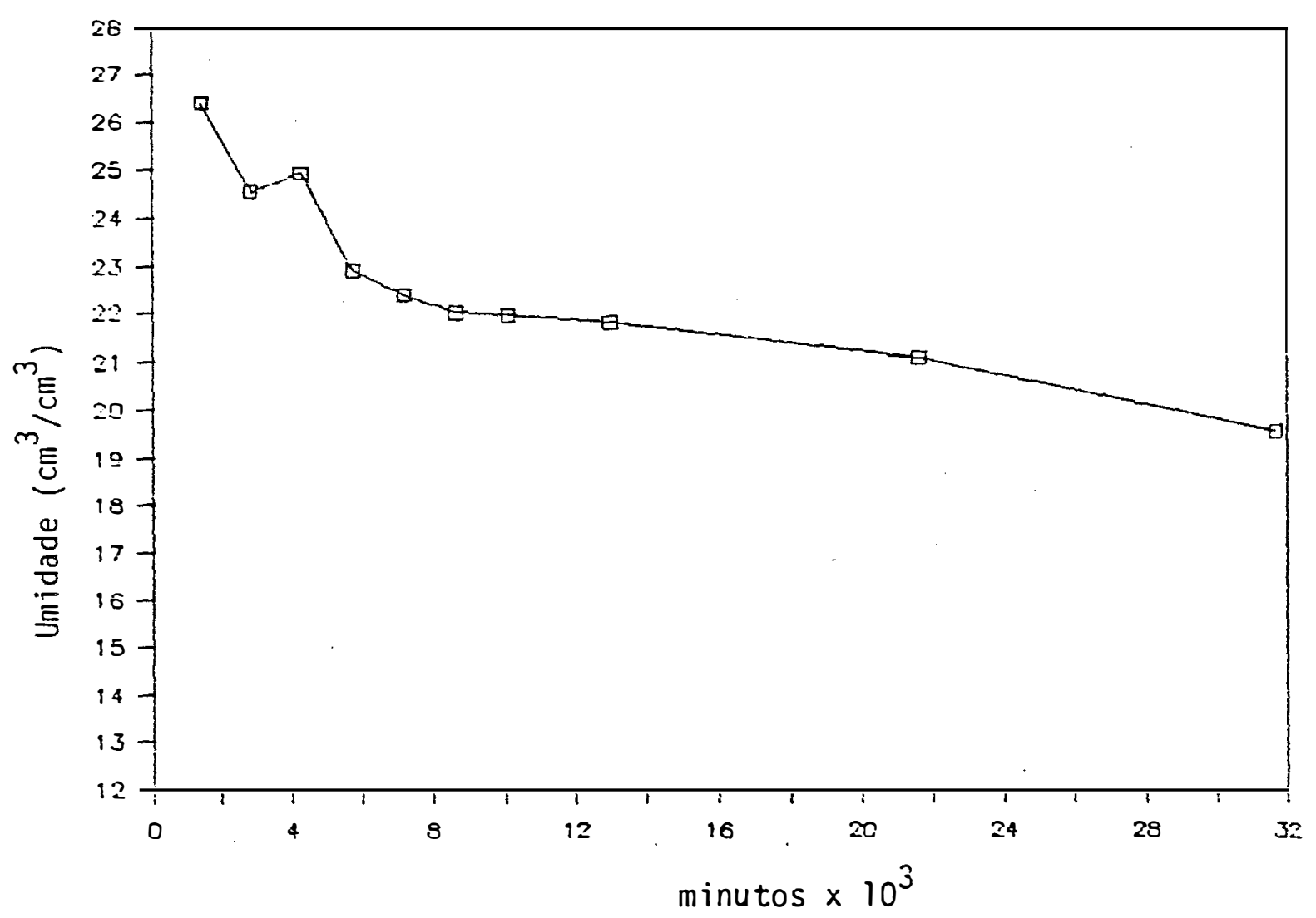

ärea 1 a 9: $\bar{\theta}=41,74-2,13$ lnt $\quad r=0,971$

Figura 3a. Distribuição mēdia da umidade volumētrica $\left(\mathrm{cm}^{3} / \mathrm{cm}^{3}\right)$ na camada de 0 a $10 \mathrm{~cm}$ no LVA em função do tempo (minu $\left.\operatorname{tos} \times 10^{3}\right)$. 


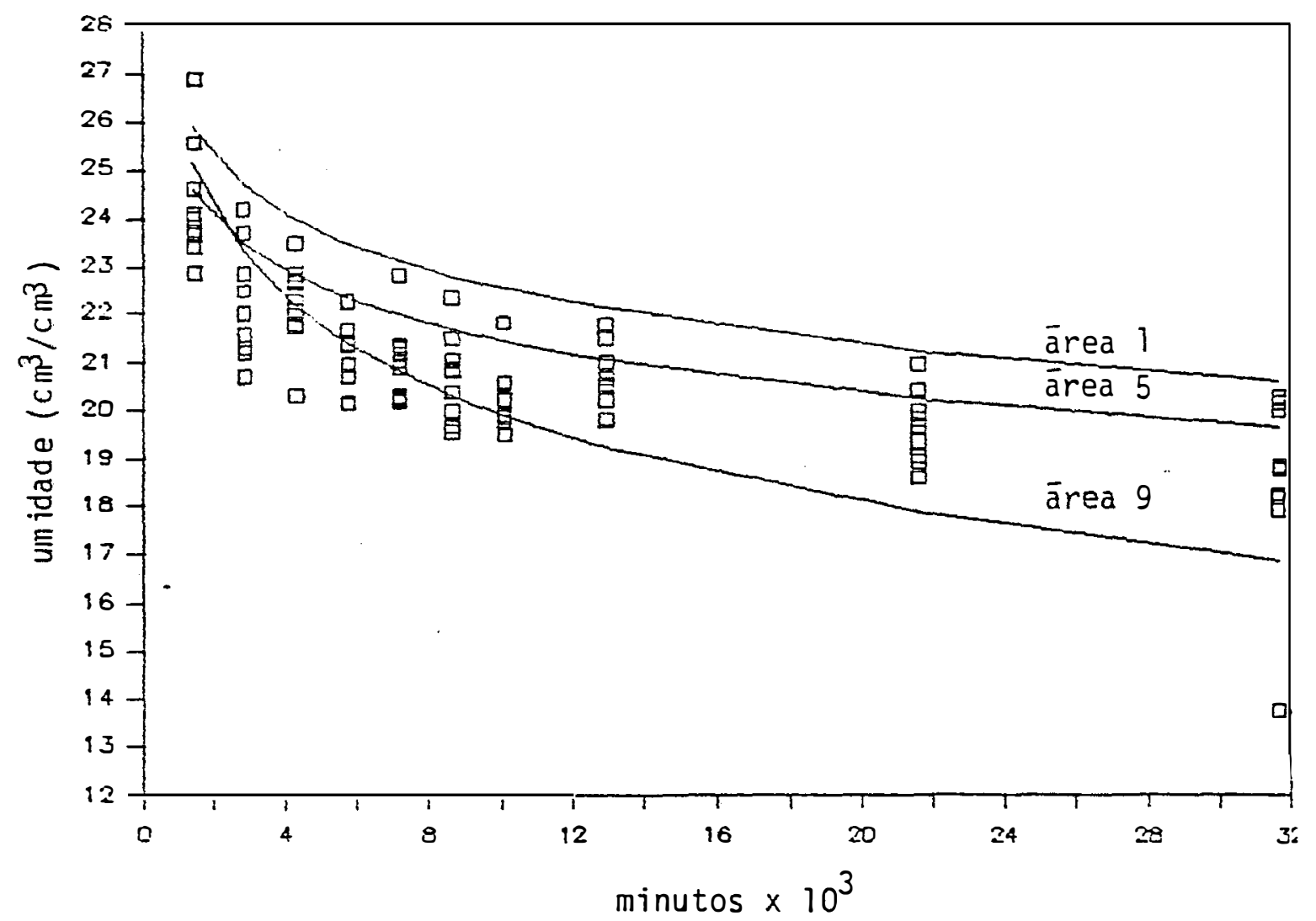

$$
\begin{array}{llll}
\text { ärea 1: } e=37,33-1,84 \mathrm{nt} & r=0,979 \\
\text { ärea 5: } e=36,46-1,63 \mathrm{nt} & r=0,924 \\
\text { ärea 9: } e=44,86-2,71 \mathrm{nt} & r=0,867
\end{array}
$$

Figura 4. Distribuição da umidade volumētrica $\left(\mathrm{cm}^{3} / \mathrm{cm}^{3}\right)$ na camada de 10 a $20 \mathrm{~cm}$ no LVA em função do tempo (minutos $\times 10^{3}$ ). 


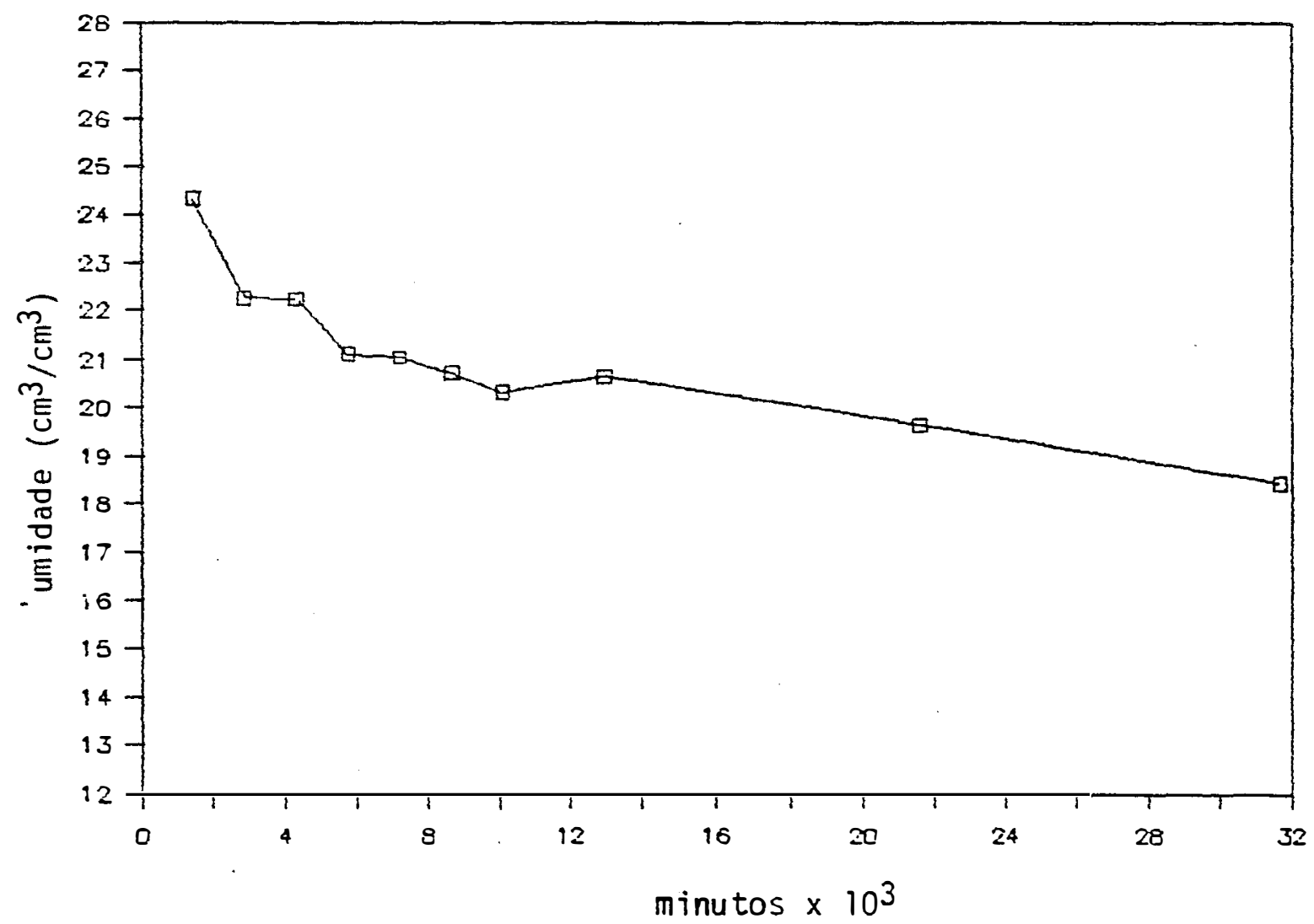

ärea 1 a $9: \bar{\theta}=36,32-1,71$ lnt $\quad r=0,976$

Figura 4a. Distribuição mēdia da umidade volumétrica $\left(\mathrm{cm}^{3} / \mathrm{cm}^{3}\right)$ na camada de $10-20 \mathrm{~cm}$ no LVA em função do tempo (minutos $\times 10^{3}$ ). 


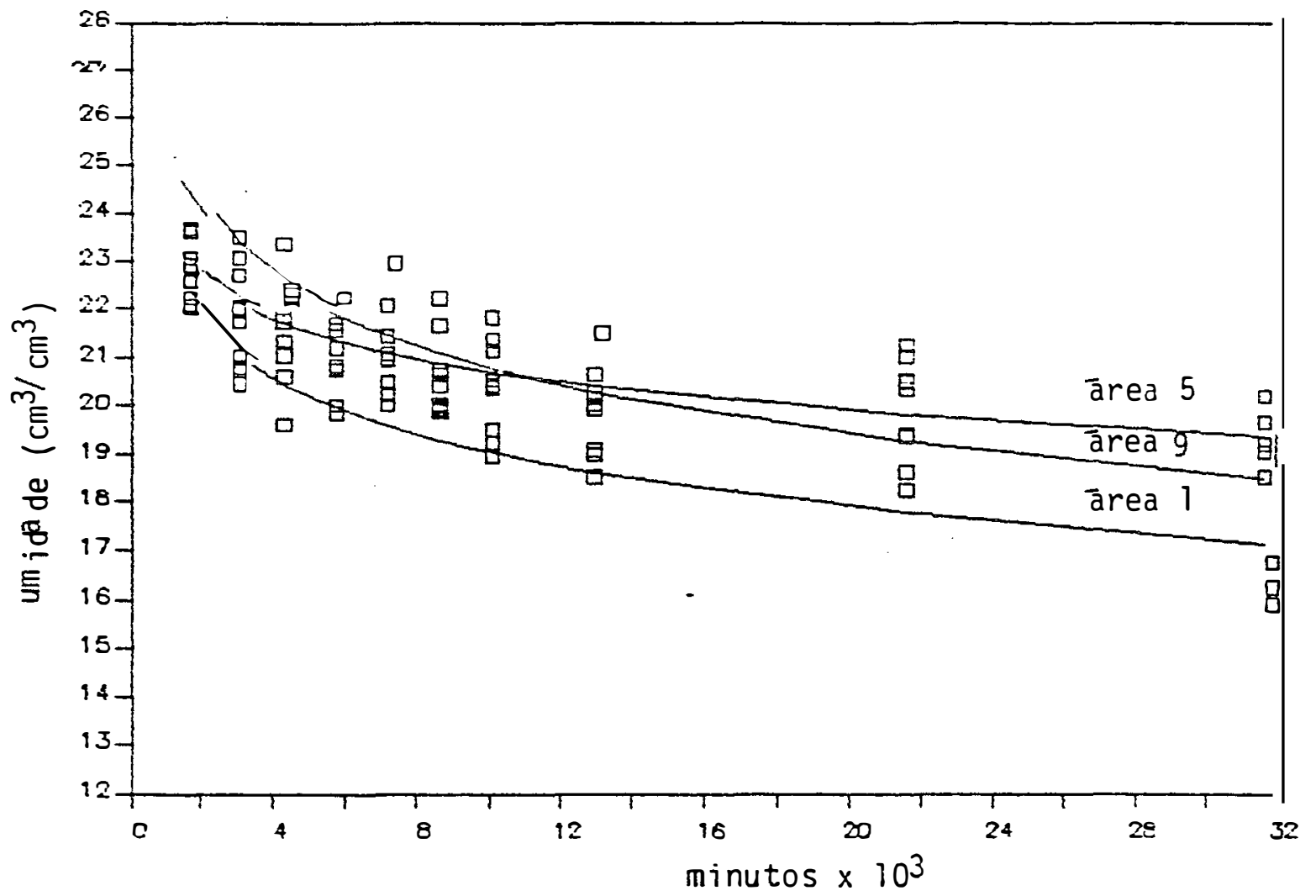
ārea 1: $\theta=34,43-1,67$ lnt
$r=0,952$
àrea 5: $\theta=31,44-1,17$ lnt
$r=0,884$
area 9: $\theta=39,23-2,00$ lnt
$r=0,834$

Figura 5. Distribuição da umidade volumētrica $\left(\mathrm{cm}^{3} / \mathrm{cm}^{3}\right)$ na $\mathrm{ca}$ mada de 20 a $30 \mathrm{~cm}$ no LVA em função do tempo (minutos $\left.\times 10^{3}\right)$. 
72.

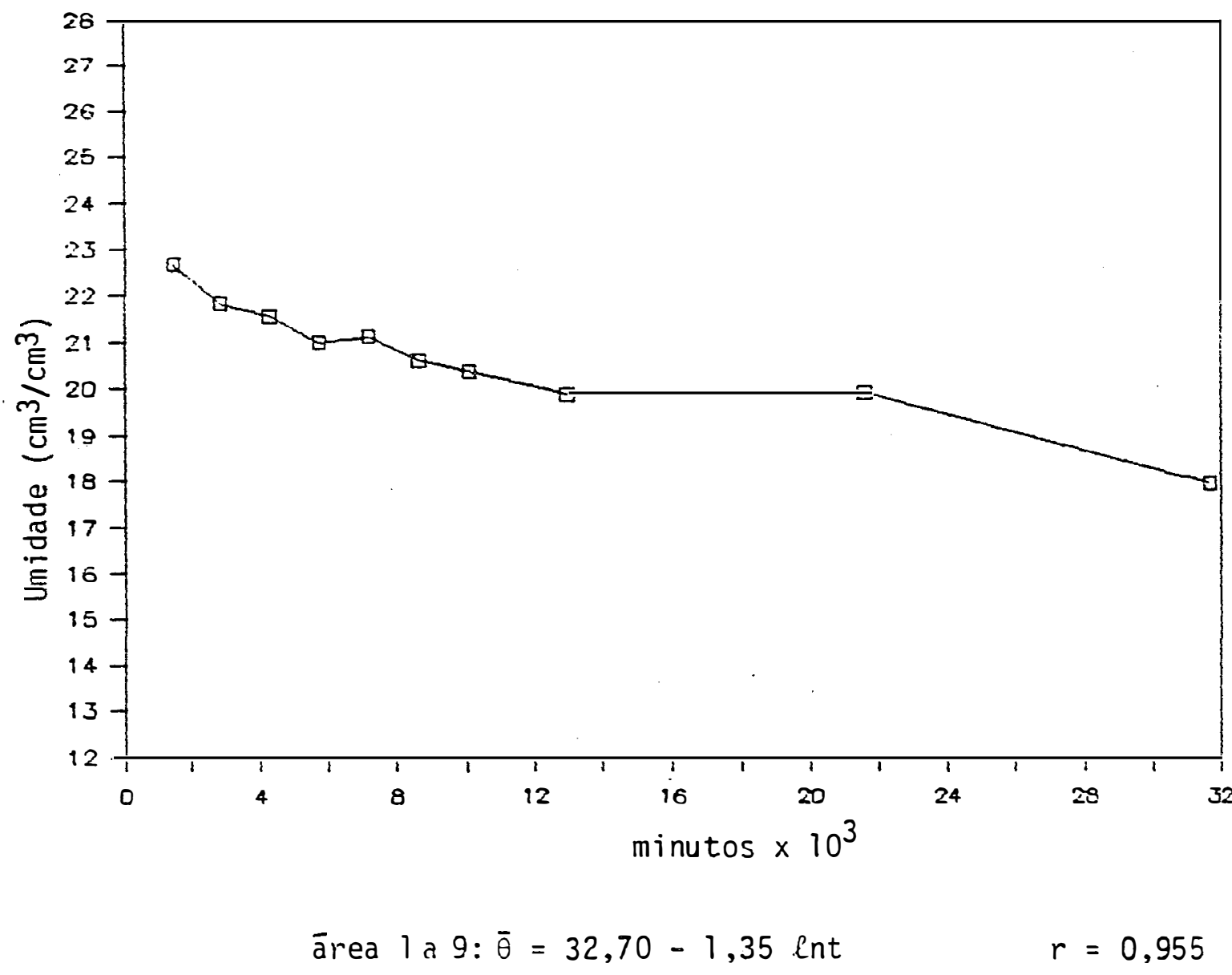

Figura 5a. Distribuição da média da umidade volumétrica ( $\mathrm{cm}^{3} /$ $\mathrm{cm}^{3}$ ) na camada de 20 a $30 \mathrm{~cm}$ no, LVA em função do tempo (minutos $\times 10^{3}$ ). 
73.

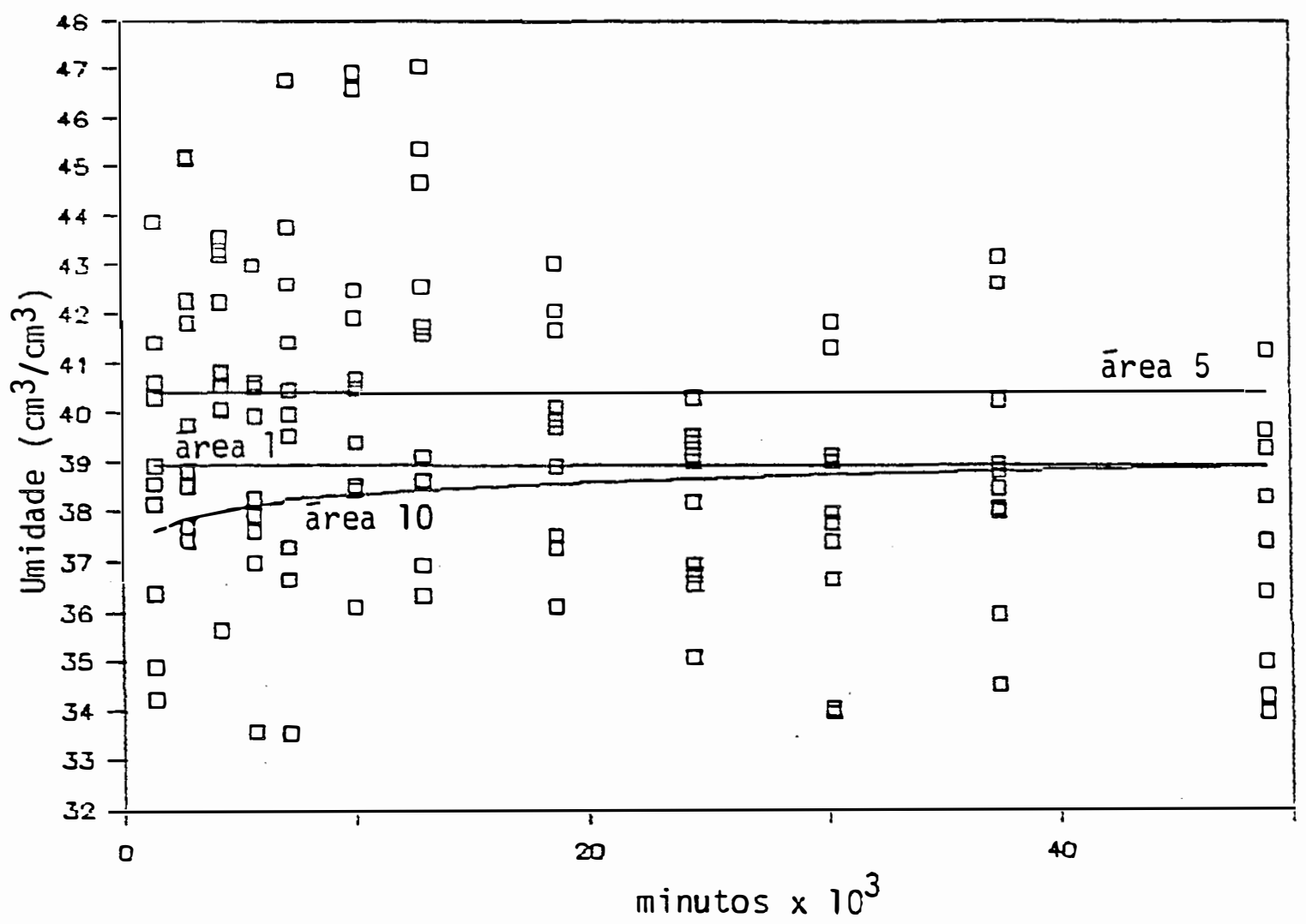

$$
\begin{array}{lll}
\text { ärea 1: } \theta=38,94-0,00 \text { lnt } & r=0,028 \\
\text { ärea 5: } \theta=40,41-0,0001 \text { lnt } & r=0,6842 \\
\text { ärea 10: } \theta=34,97+0,37 \text { lnt } & r=0,157
\end{array}
$$

Figura 6. Distribuição da umidade volumétrica $\left(\mathrm{cm}^{3} / \mathrm{cm}^{3}\right)$ na ca mada de 0 a $10 \mathrm{~cm}$ na TRE, em função do tempo (minutos $\left.\times 10^{3}\right)$. 


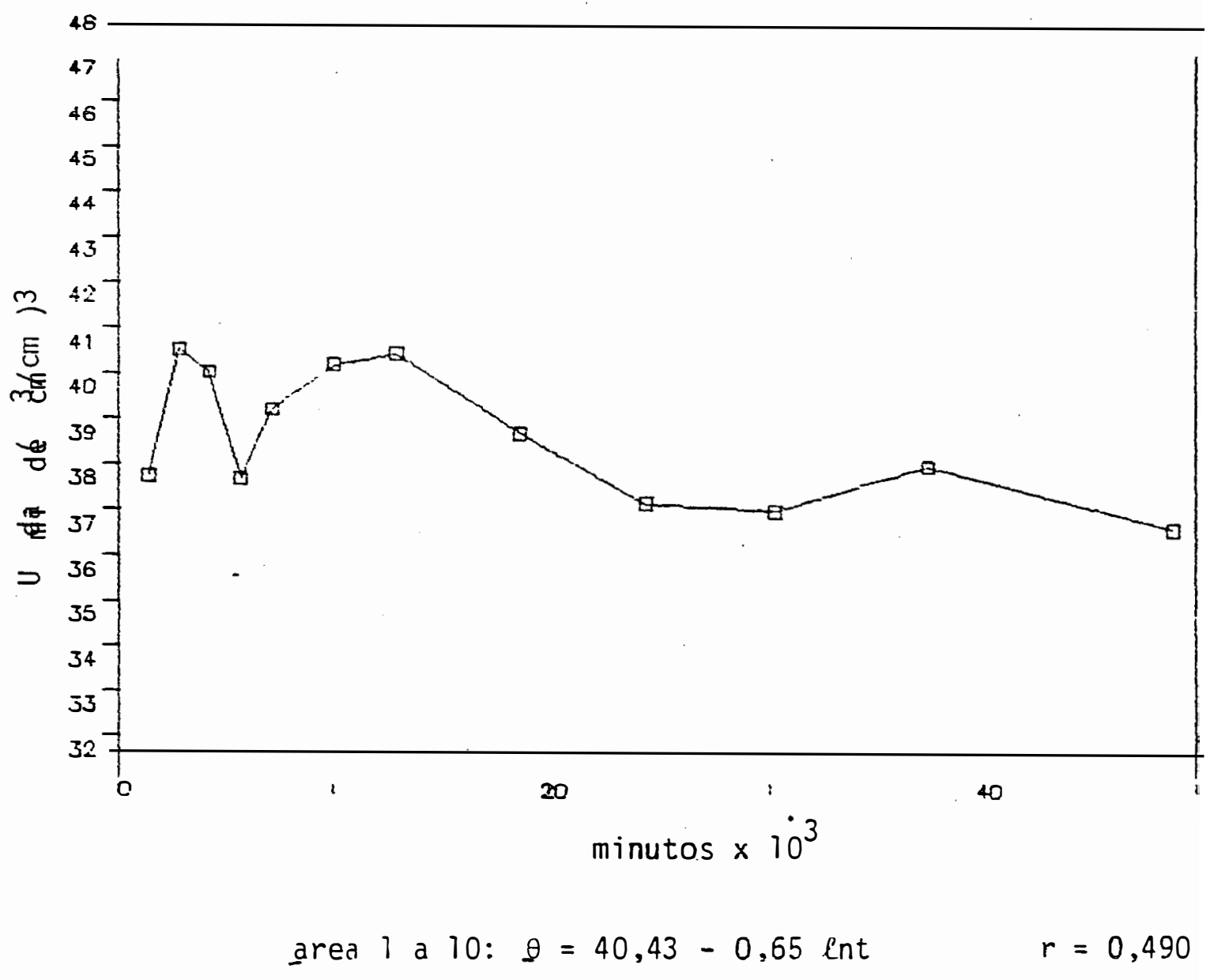

Figura 6a. Distribuição mēdia das umidades volumētricas $\left(\mathrm{cm}^{3} /\right.$ $\mathrm{cm}^{3}$ ) na camada de 0 a $10 \mathrm{~cm}$ na TRE em função do tempo (minutos $\times 10^{3}$ ). 


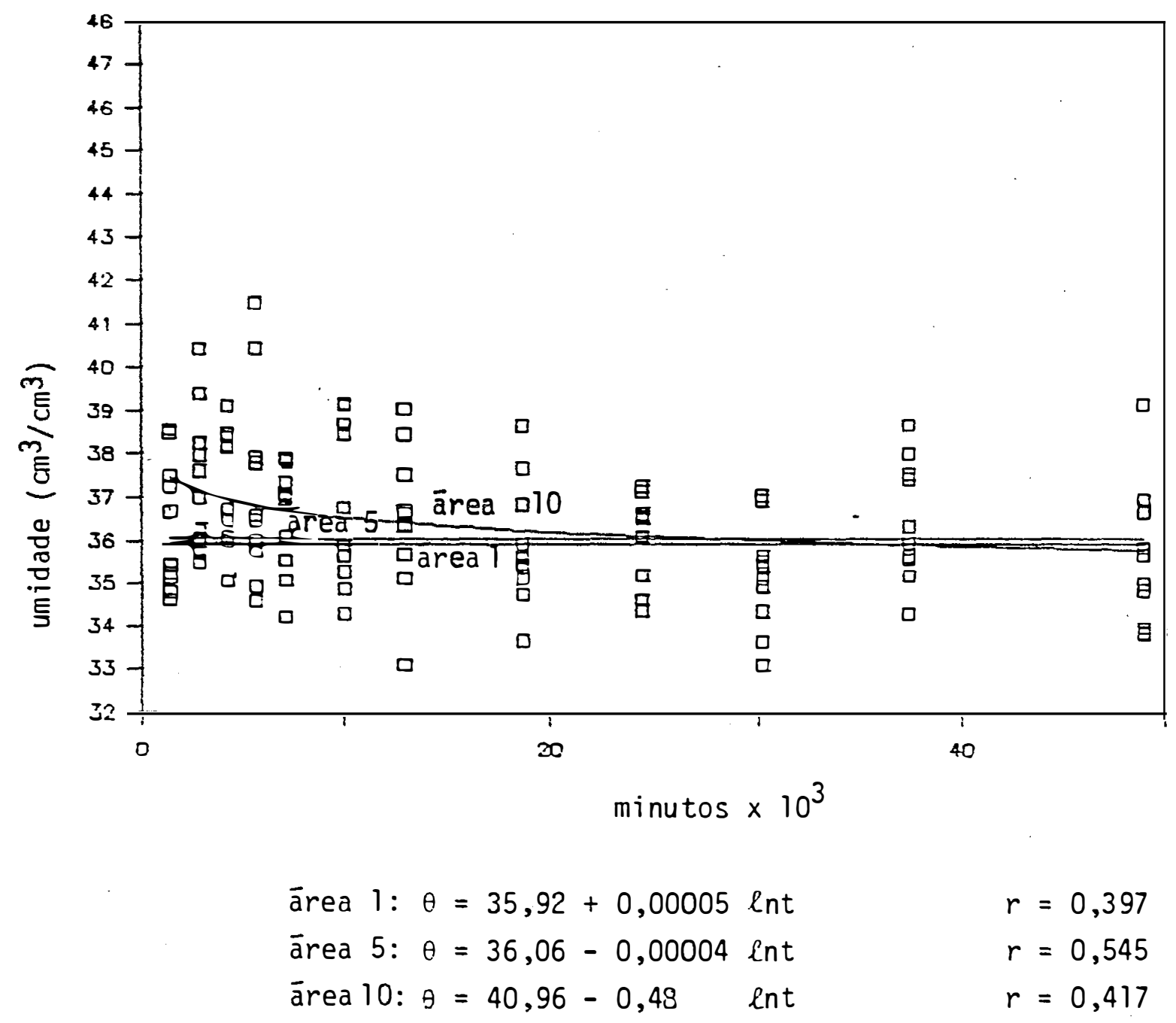

Figura 7. Distribuição da umidade volumétrica $\left(\mathrm{cm}^{3} / \mathrm{cm}^{3}\right)$ na camada de 10 a 200 na TRE em função do tempo (minu tos $\times 10^{3}$ ). 


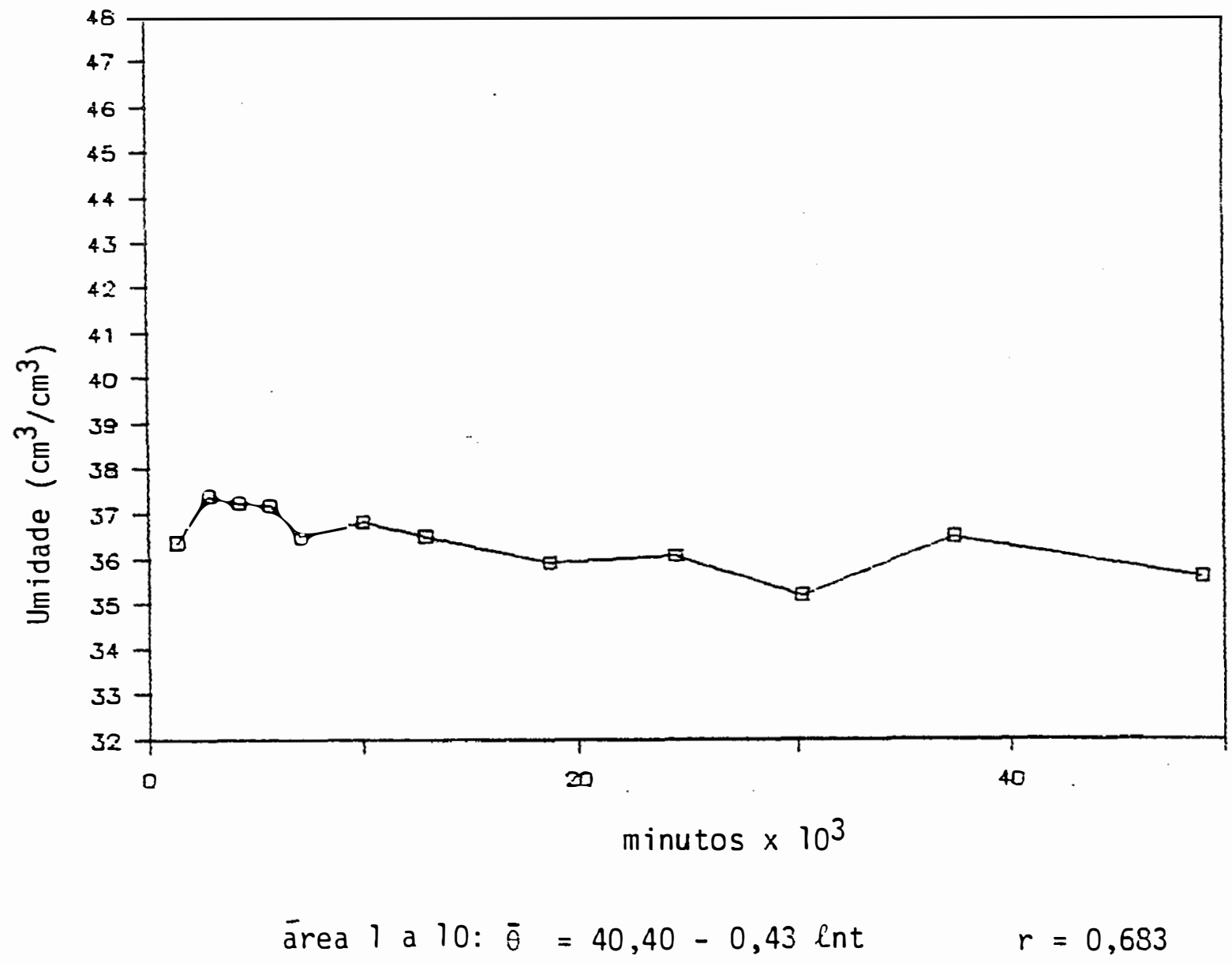

Figura 7a. Distribuição mēdia das umidades volumétricas $\left(\mathrm{cm}^{3} /\right.$ $\mathrm{cm}^{3}$ ) na camada de 10 a $20 \mathrm{~cm}$ na TRE, em função do tempo (minutos $\times 10^{3}$ ). 


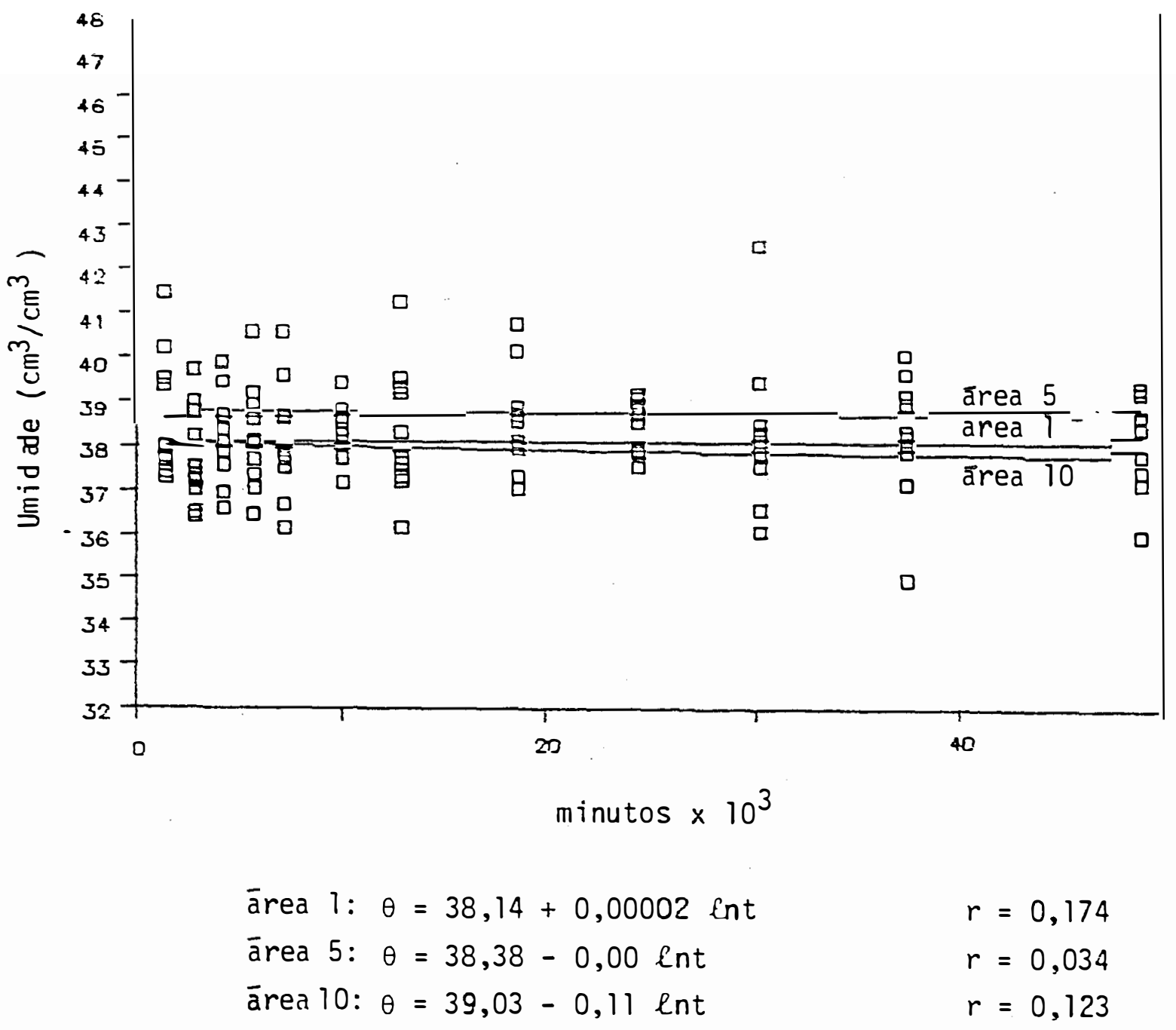

Figura 8. Distribuiçāo da umidade volumétrica na camada de 20 a $30 \mathrm{~cm}$ na TRE em funçào do tempo (minutos $\times 10^{3}$ ). 
78.

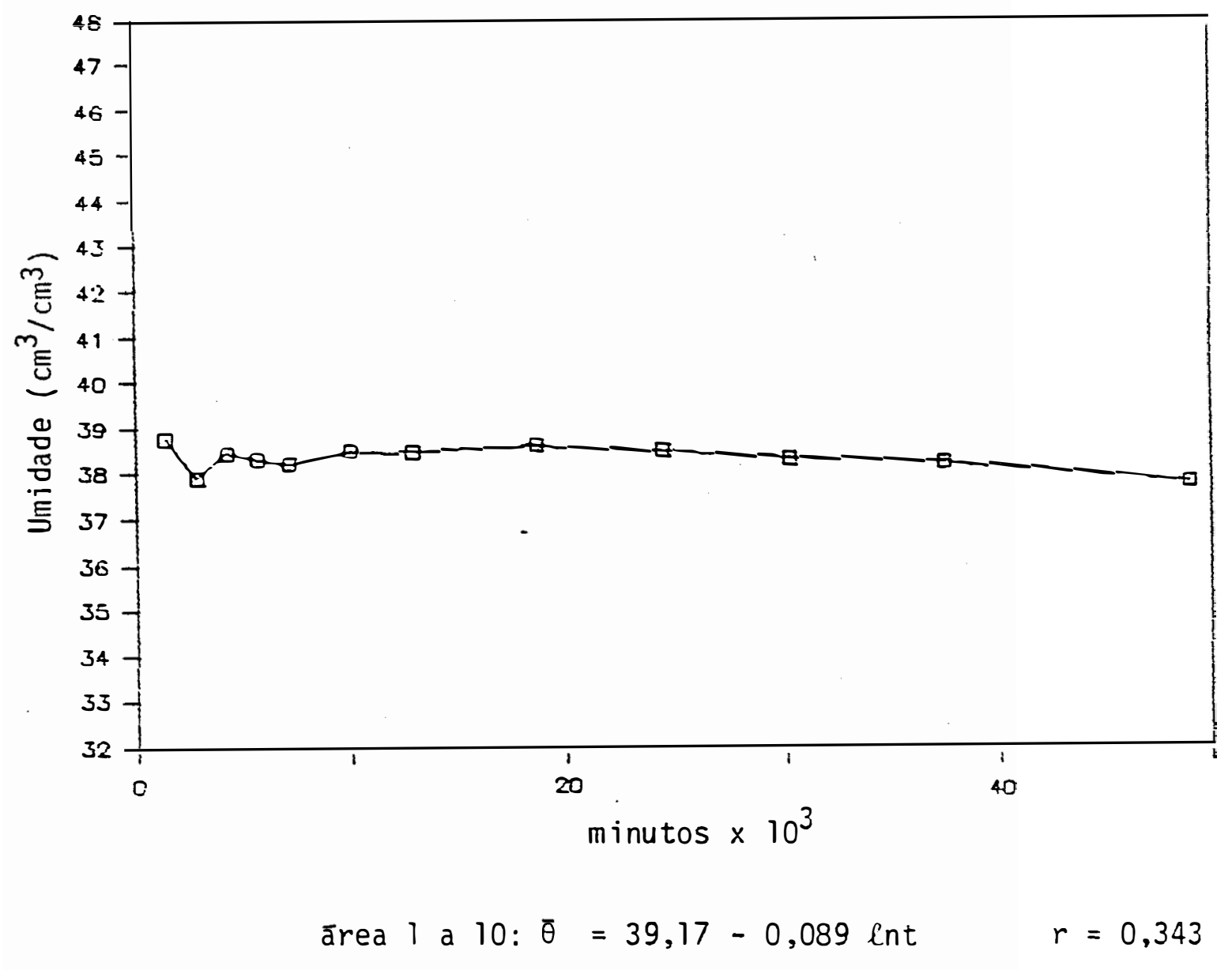

Figura 8a. Distribuição média das umidades volumétricas na ca mada de 20 a $30 \mathrm{~cm}$ na TRE em funçāo do tempo (minu $\left.\operatorname{tos} \times 10^{3}\right)$. 


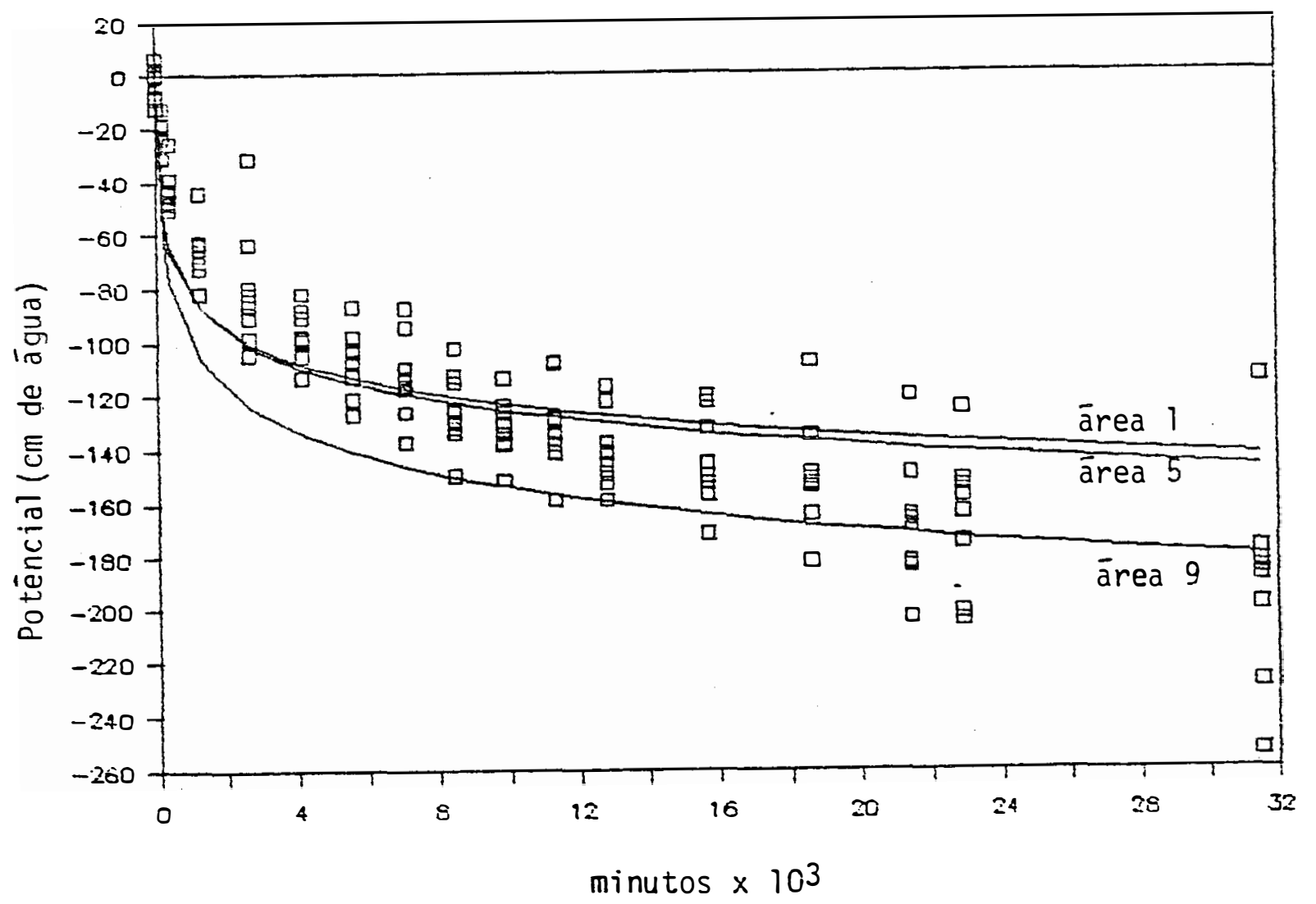
ärea 1: $\psi_{15}=35,74-17,24$ lnt
$r=0,931$
ärea 5: $475=45,89-18,63$ lnt
$r=0,921$
ärea 9: $\psi_{15}=59,60-23,20$ lnt
$r=0,894$

Figura 9. Distribuição dos potenciais mátricos (cm de āgua) na profundidade de $15 \mathrm{~cm}$ no LVA em funçào do tempo (minutos $\times 10^{3}$ ). 
80.

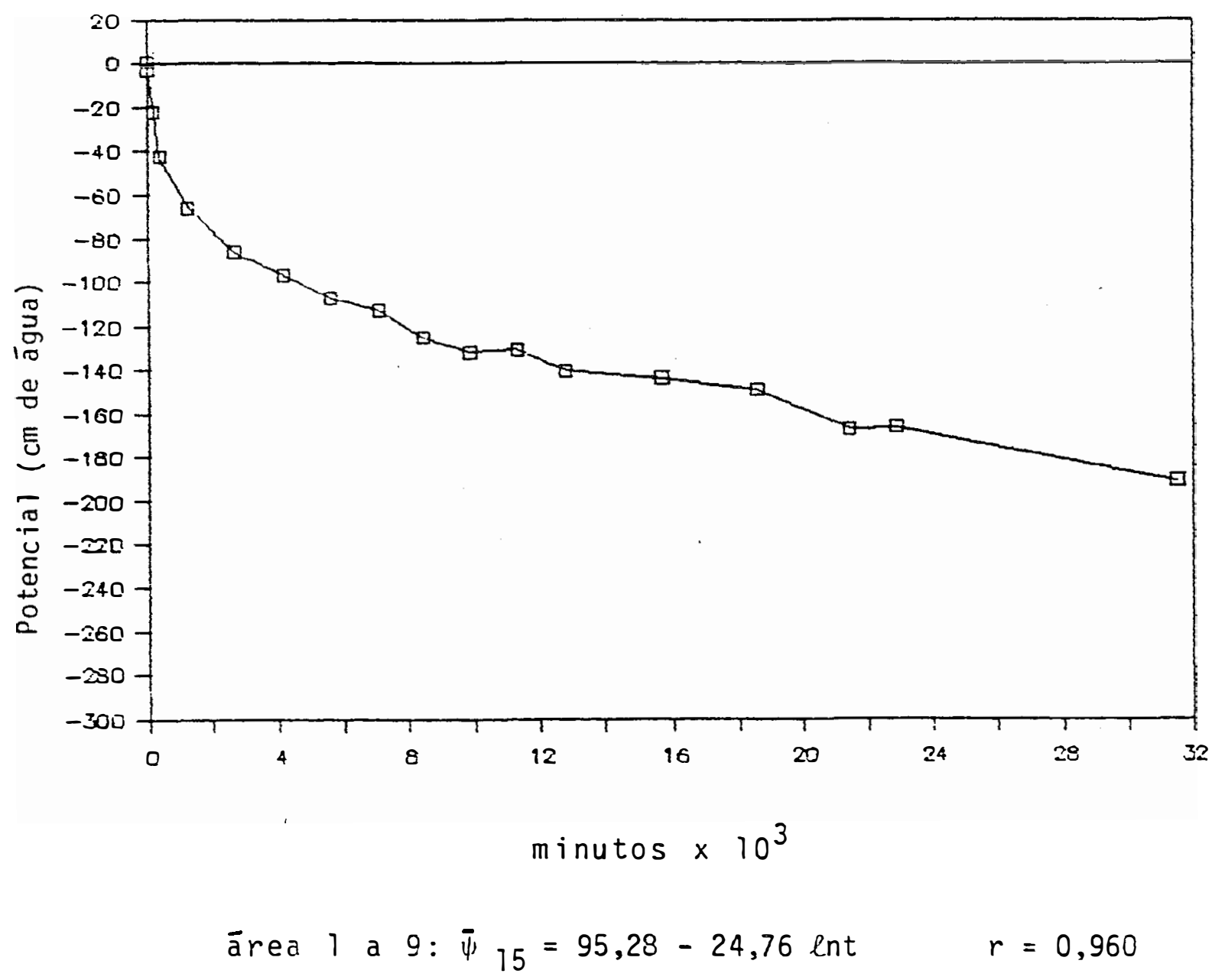

Figura 9a. Distribuição mēdia dos potenciais mátricos (cm de āgua) na profundidade de $15 \mathrm{~cm}$ no LVA em função do tempo (minutos $\times 10^{3}$ ). 
81.

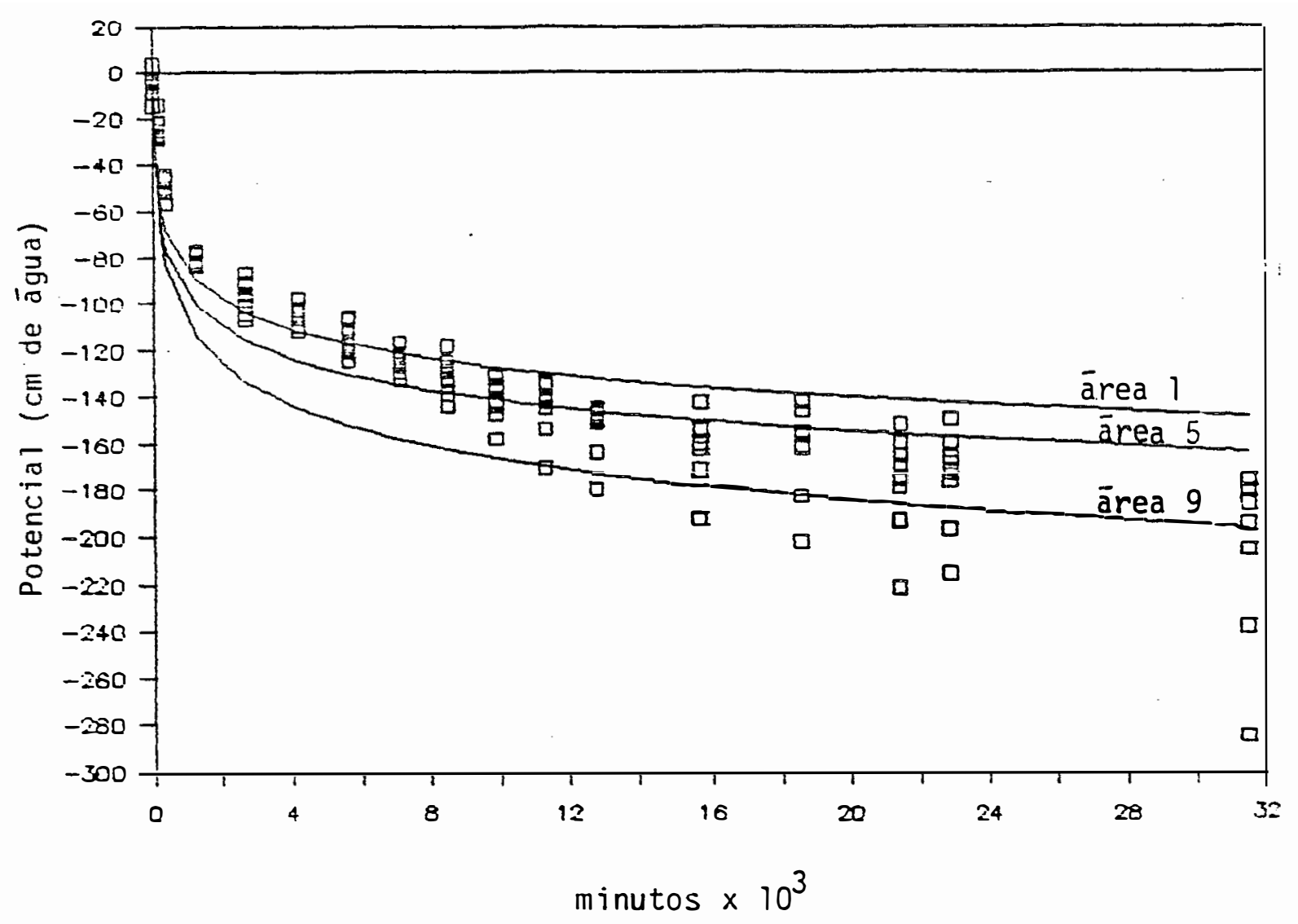
ärea 1: $\psi_{25}=38,96-18,11$ lnt
$r=0,949$
ärea 5: $\psi_{25}=37,45-19,44$ lnt
$r=0,950$
ärea 9: $\psi_{25}=65,10-25,16 \ell \mathrm{nt}$
$r=0,883$

Figura 10. Distribuição dos potenciais mātricos (cm de āgua) na profundidade de $25 \mathrm{~cm}$ no LVA, em função do tempo (minutos $\times 10^{3}$ ). 
82.

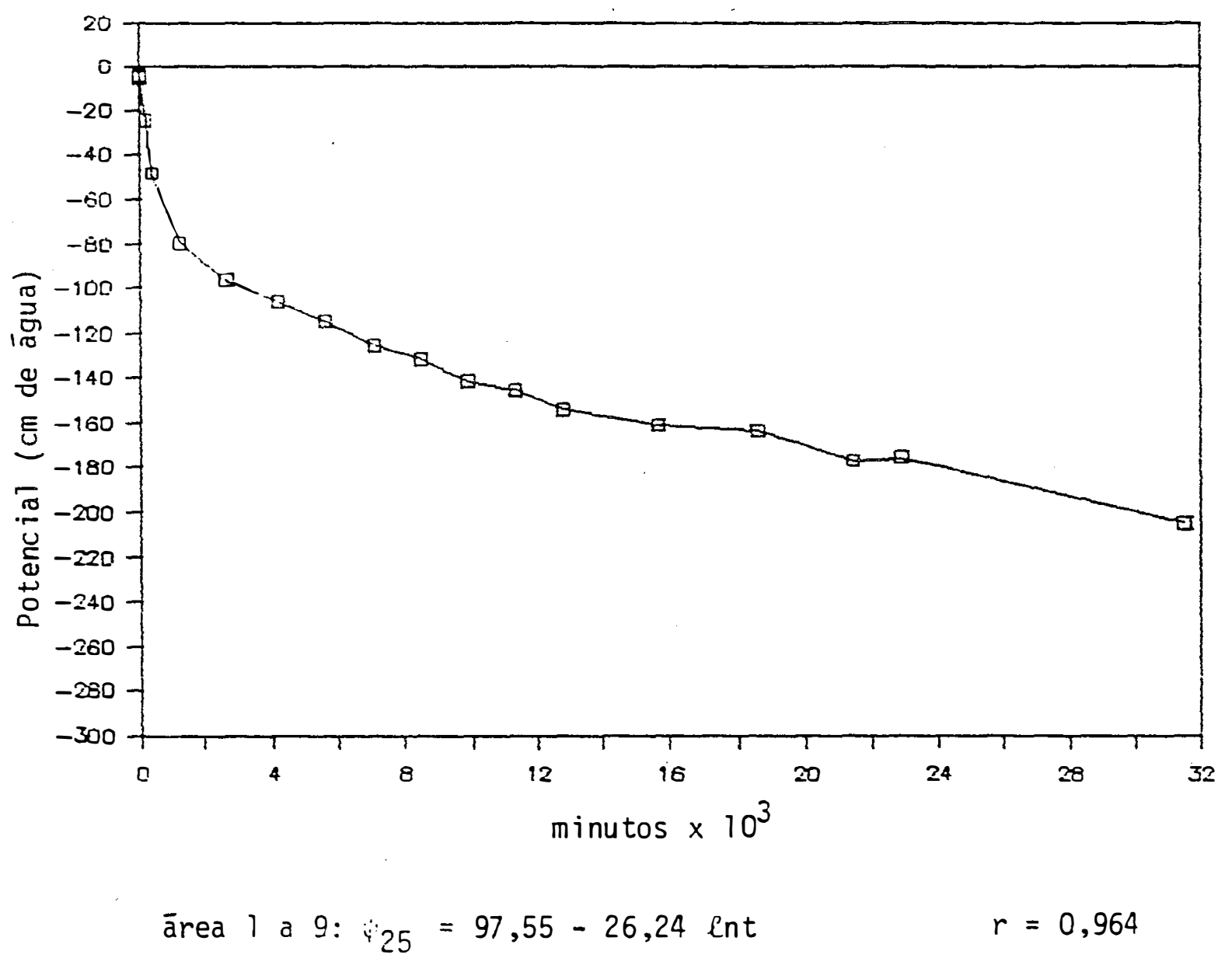

Figura 10a. Distribuição mēdia dos potenciais mātricos (cm de ägua) na profundidade de $25 \mathrm{~cm}$ no LVA, em funçào do tempo (minutos x 103). 


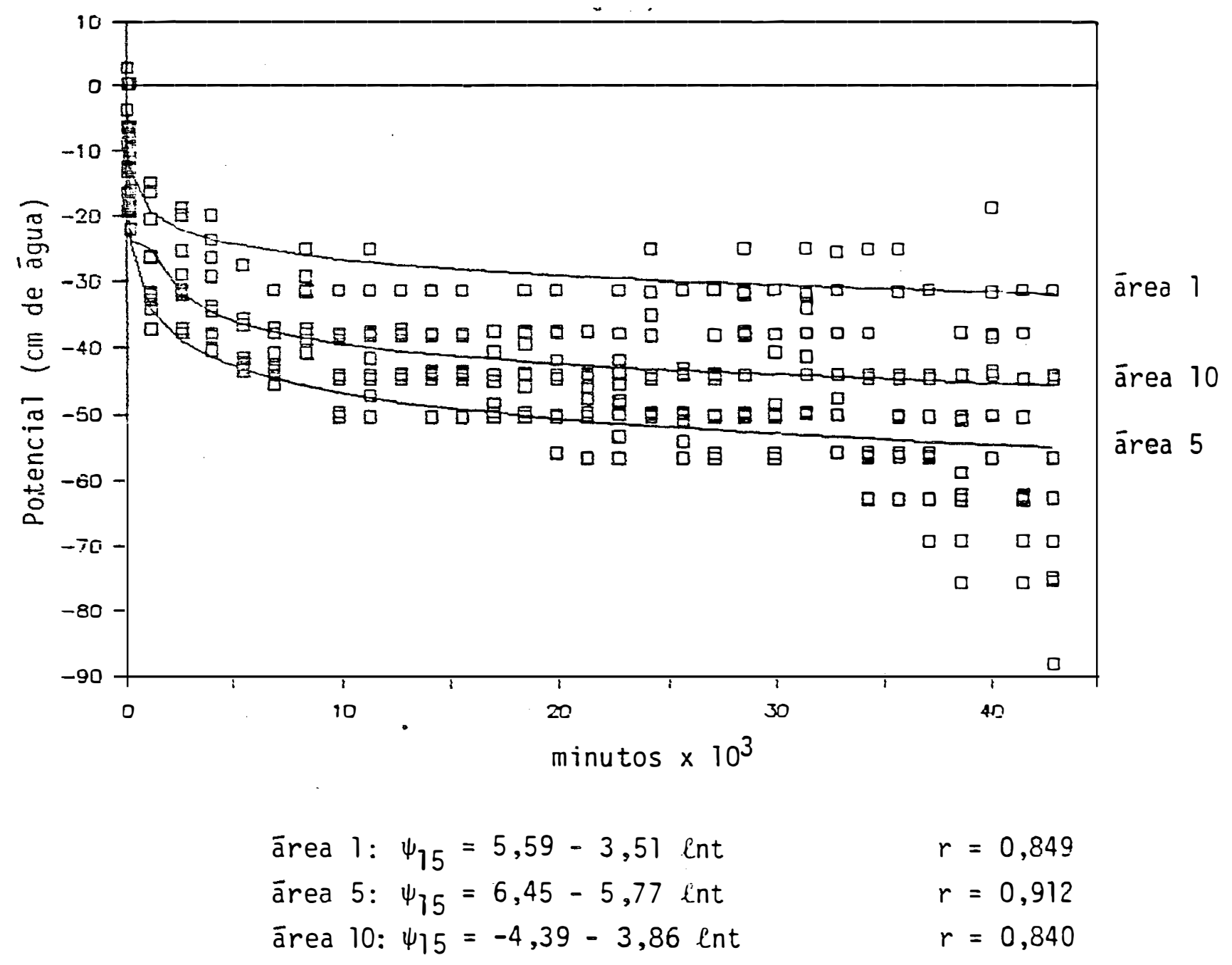

Figura 11. Distribuição dos potenciais mátricos (cm de água) na profundidade de $15 \mathrm{~cm}$ na TRE, em funçào do tempo (minutos $\times 10^{3}$ ). 
84.

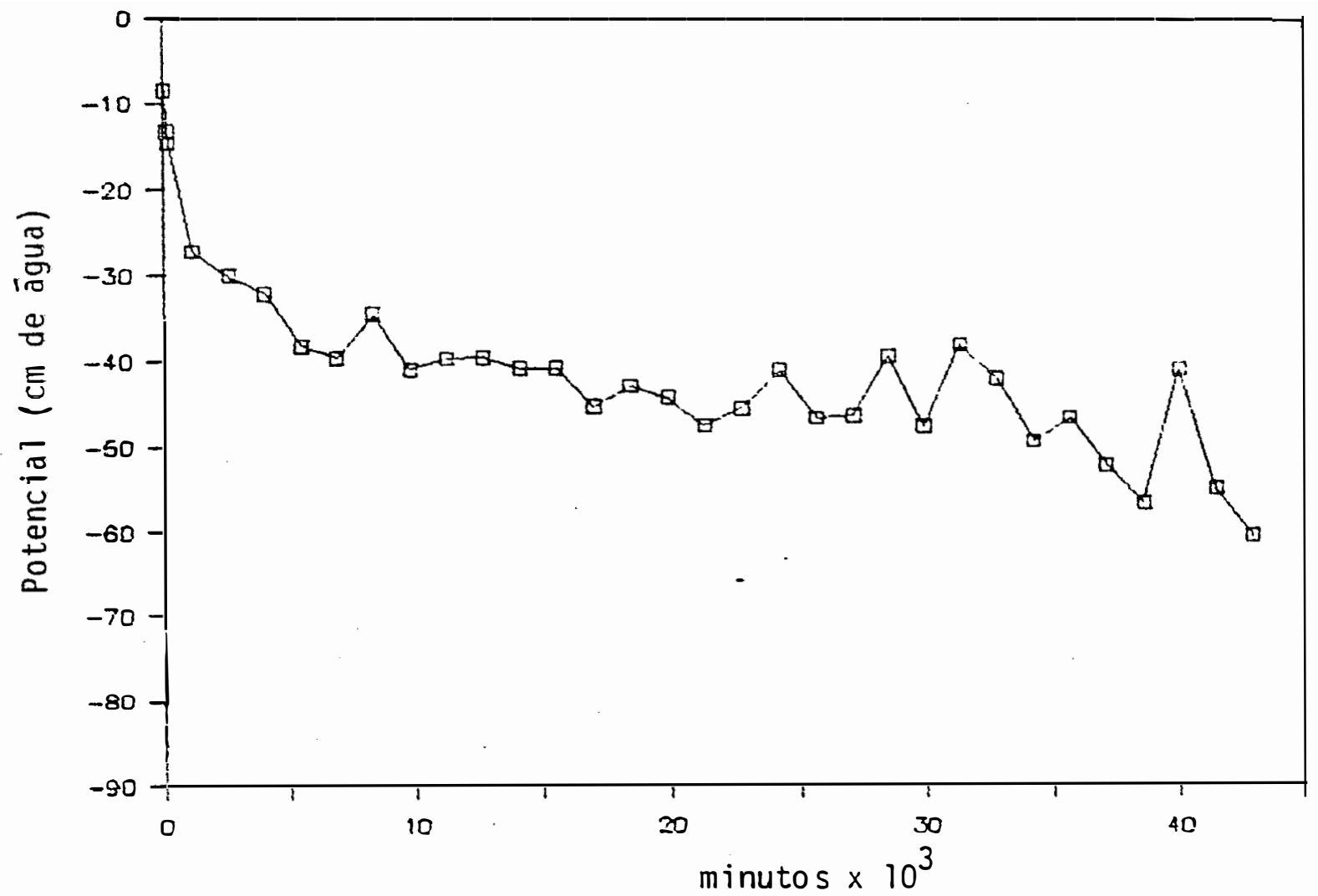

$$
\text { ārea 1 a 9: }{ }_{25}=19,90-6,49 \text { ent } \quad r=0,933
$$

Figura 1la. Distribuição média dos potenciais mátricos (cm de água) na profundidade de $15 \mathrm{~cm}$ na TRE em fun ção do tempo (minutos $\times 10^{3}$ ). 
85.

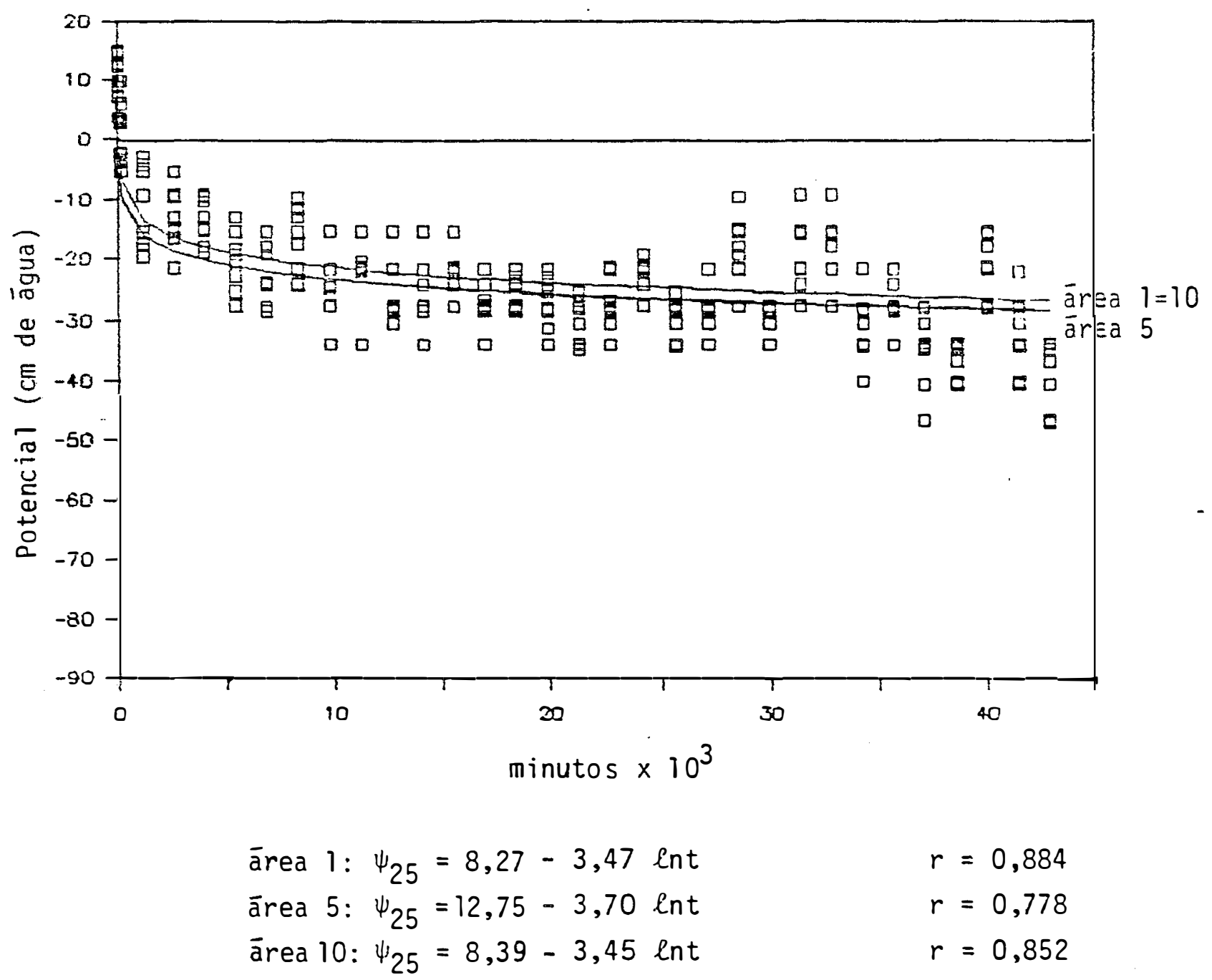

Figura 12. Distribuiçāo dos potenciais mátricos (cm de água) na profundidade de $25 \mathrm{~cm}$ na TRE em funçào do tempo (minutos $\times 10^{3}$ ). 
86.

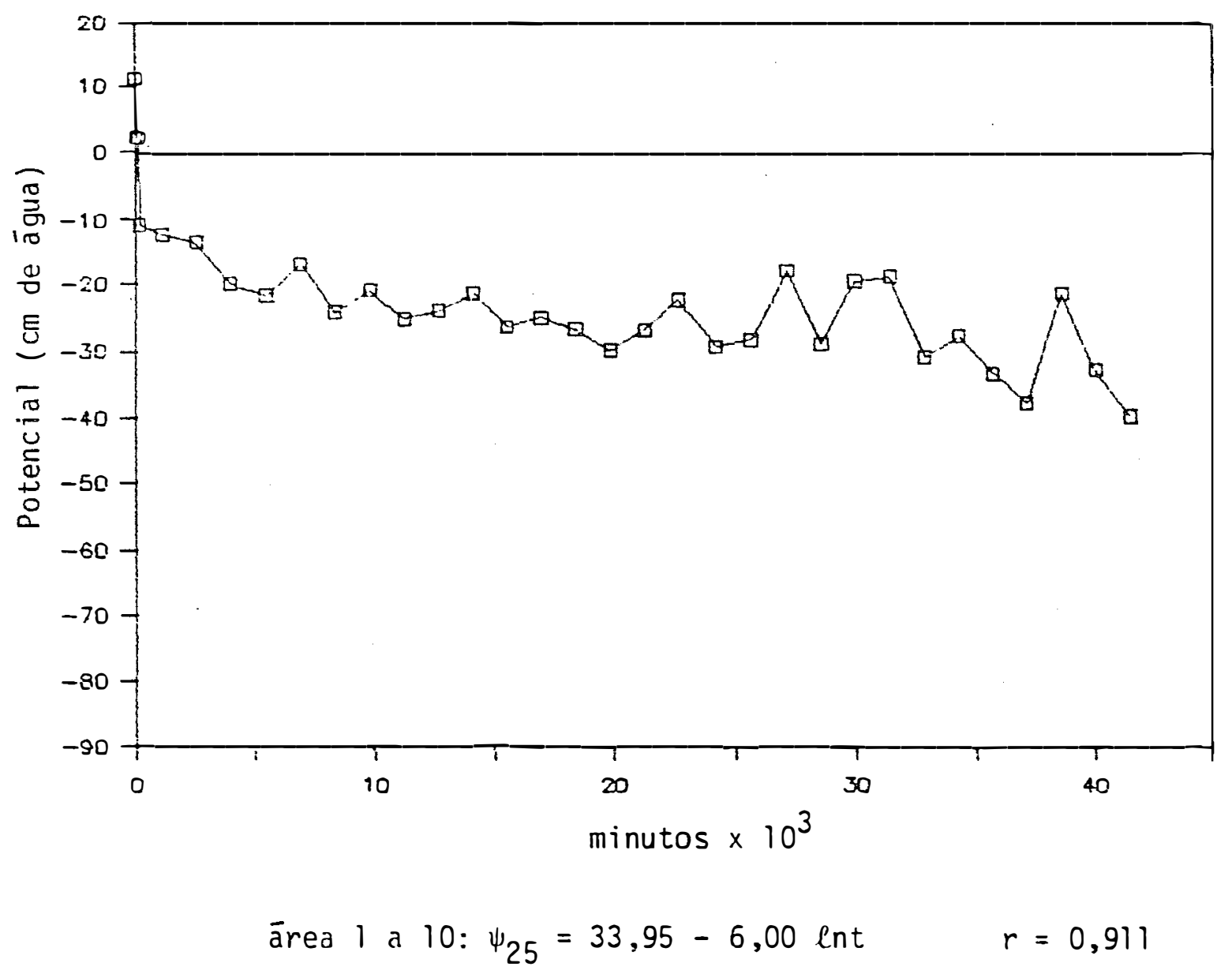

Figura 12a. Distribuição média dos potenciais mātricos (cm de água) na profundidade de $25 \mathrm{~cm}$ na TRE em funçào do tempo (minutos $\times 10^{3}$ ). 
87.

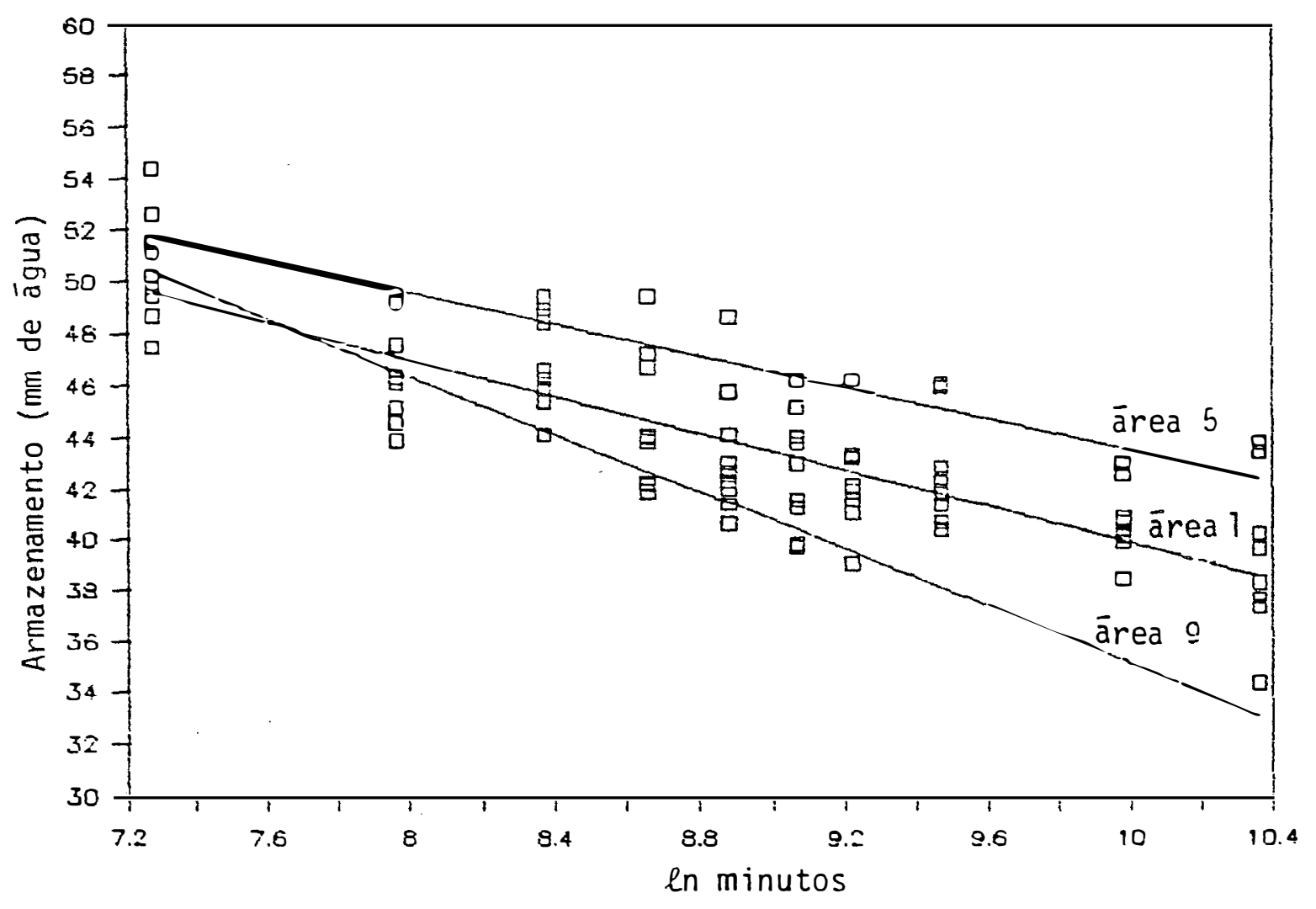

$$
\begin{array}{lll}
\text { ärea } 1=A z=75,69-3,58 \mathrm{lnt} & r=0,958 \\
\text { ärea } 5=A z=74,00-3,05 \mathrm{lnt} & r=0,954 \\
\text { ärea } 9=A z=91,13-5,57 \text { lnt } & r=0,866
\end{array}
$$

Figura 13. Distribuição do armazenamento de àgua (mm) na profundidade de 0 a $20 \mathrm{~cm}$ no LVA em funçào do tempo (ln minutos). 
88.

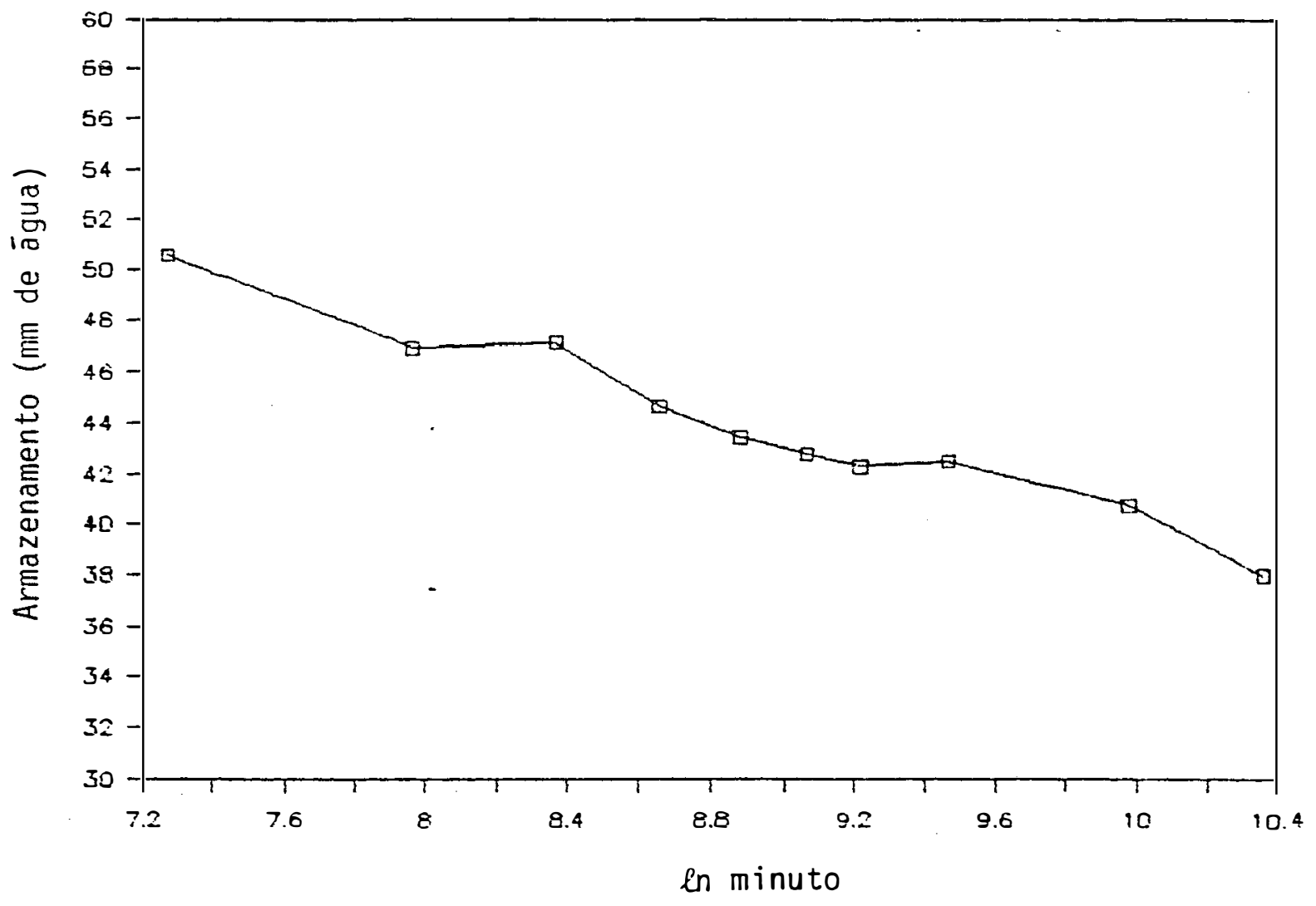

ärea 1 a 9: $A z=78,14-3,84$ lnt $\quad r=0,982$

Figura 13a. Distribuição média dos armazenamentos de água (mm) na profundidade de 0 a $20 \mathrm{~cm}$ no LVA em função do tempo (ln minutos). 


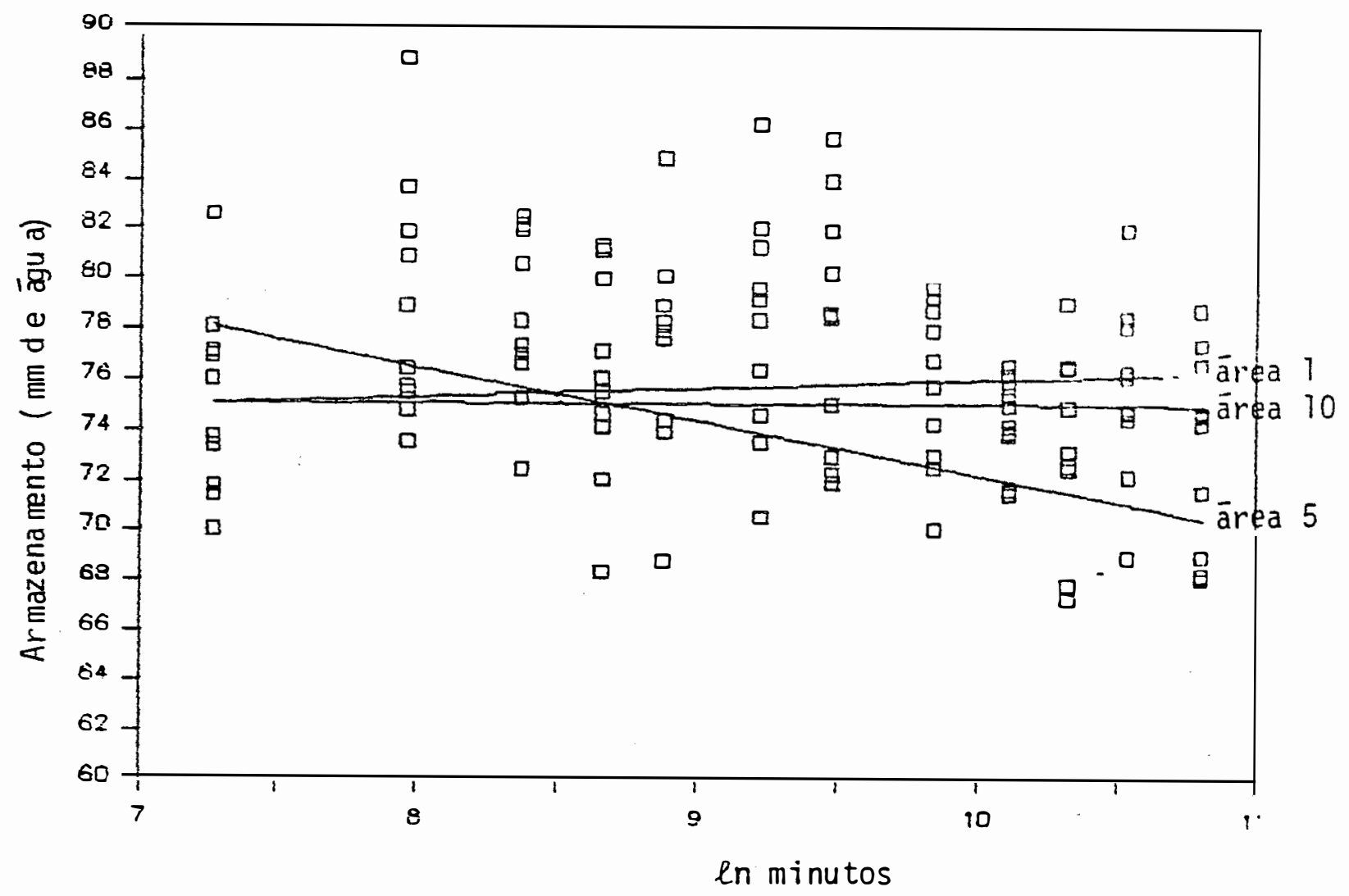

$$
\begin{array}{lll}
\text { ärea } 1=A z=73,37+0,24 \text { lnt } & r=0,052 \\
\text { ärea } 5=A z=94,54-2,26 \text { lnt } & r=0,643 \\
\text { ärea } 10=A z=75,93-0,12 \text { lnt } & r=0,134
\end{array}
$$

Figura 14. Distribuição dos armazenamentos de āgua (mm) na profundidade de 0 a $20 \mathrm{~cm}$ na TRE em funçào do tempo (in minutos). 
90.

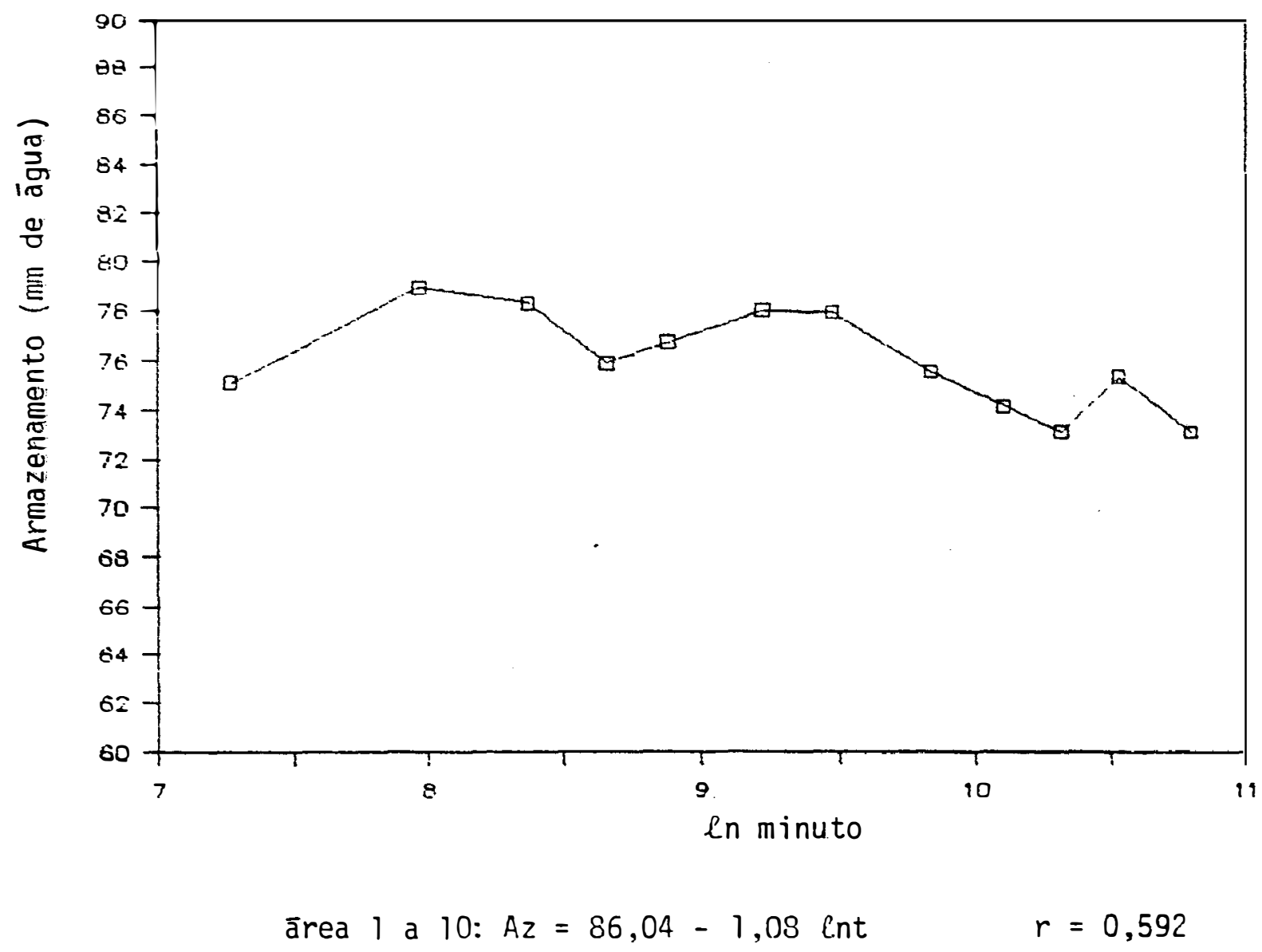

Figura 14a. Distribuição mēdia dos armazenamentos de àgua (mm) na profundidade de 0 a $20 \mathrm{~cm}$ na $R$ E em função do tempo (in minutos). 
91.

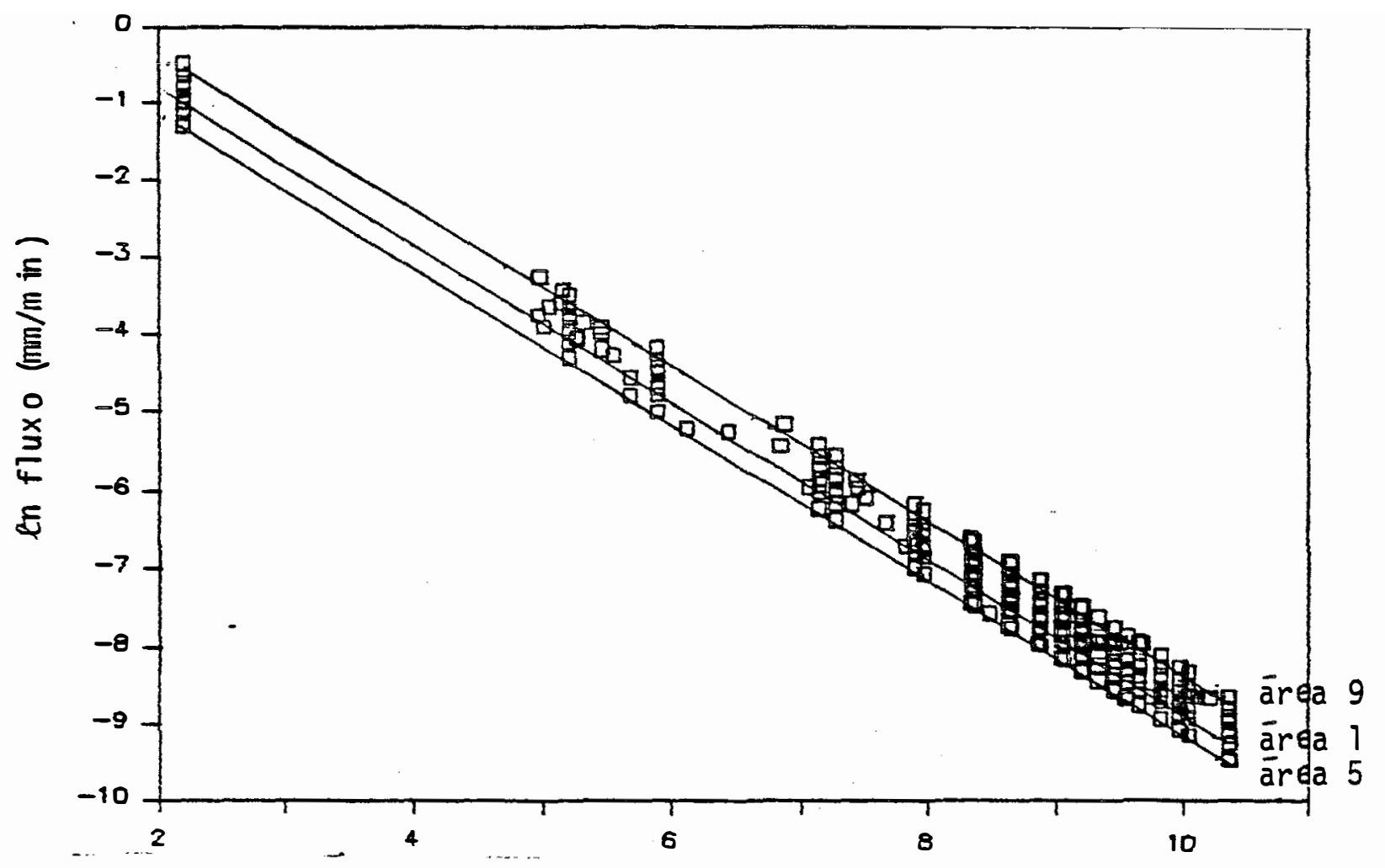

en minutos

$\begin{array}{lll}\text { ärea 1: } \ln q=1,28-1,00 \text { lnt } & r=1,00 \\ \text { ärea 5: } \ln q=1,1-1,00 \text { lnt } & r=1,00 \\ \text { ärea 9: } \ln q=1,72-1,00 \text { lnt } & r=1,00\end{array}$

Figura 15. Distribuição do fluxo ( $\ell \mathrm{n} \mathrm{mm} / \mathrm{min}$ ) na profundidade de $20 \mathrm{~cm}$ no LVA em função do tempo (ln minutos). 


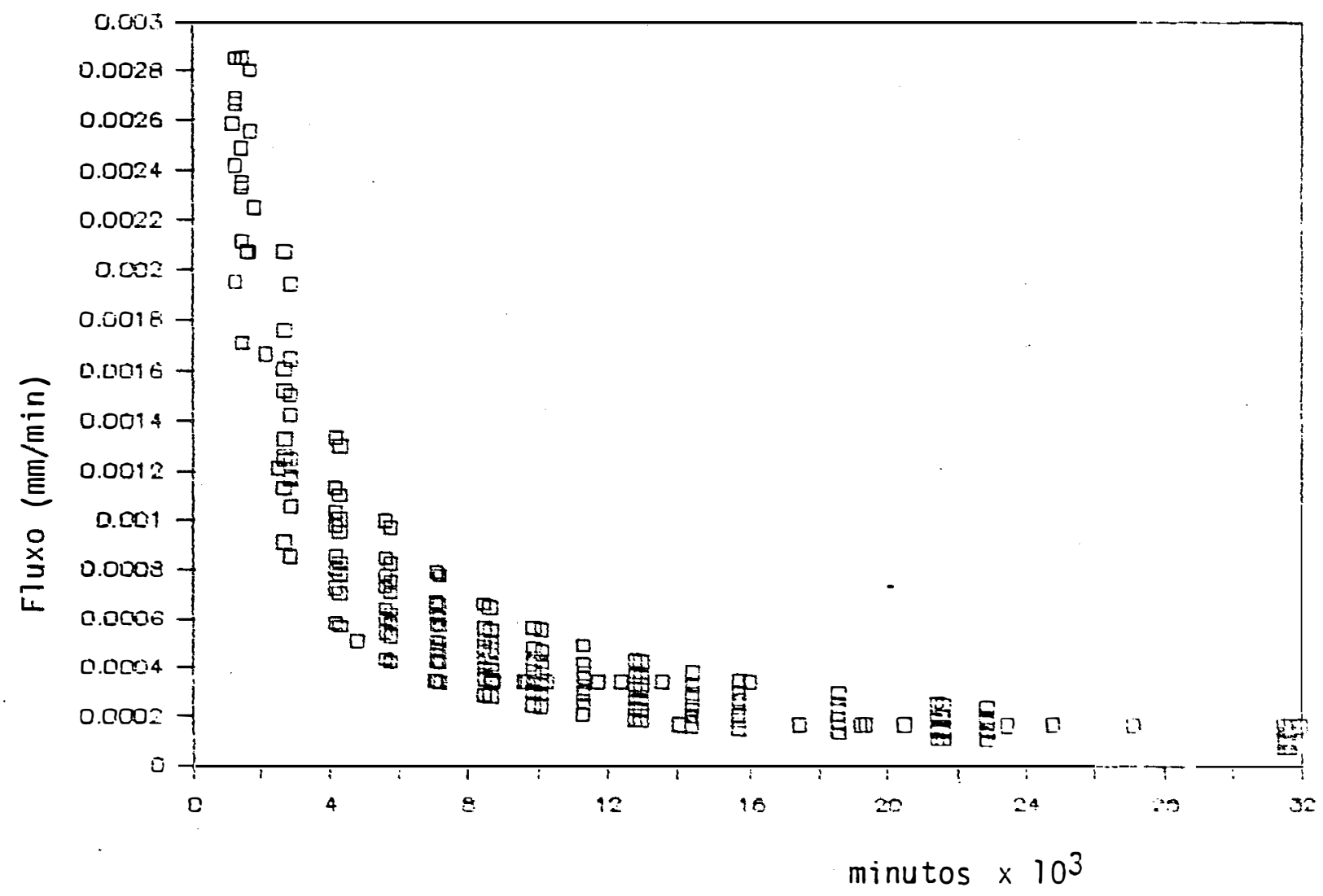

Figura 15a. Distribuição dos fluxos (mm/min) na profundidade de $20 \mathrm{~cm}$ no LVA em função do tempo (minutos $\times 10^{3}$ ). 
93.

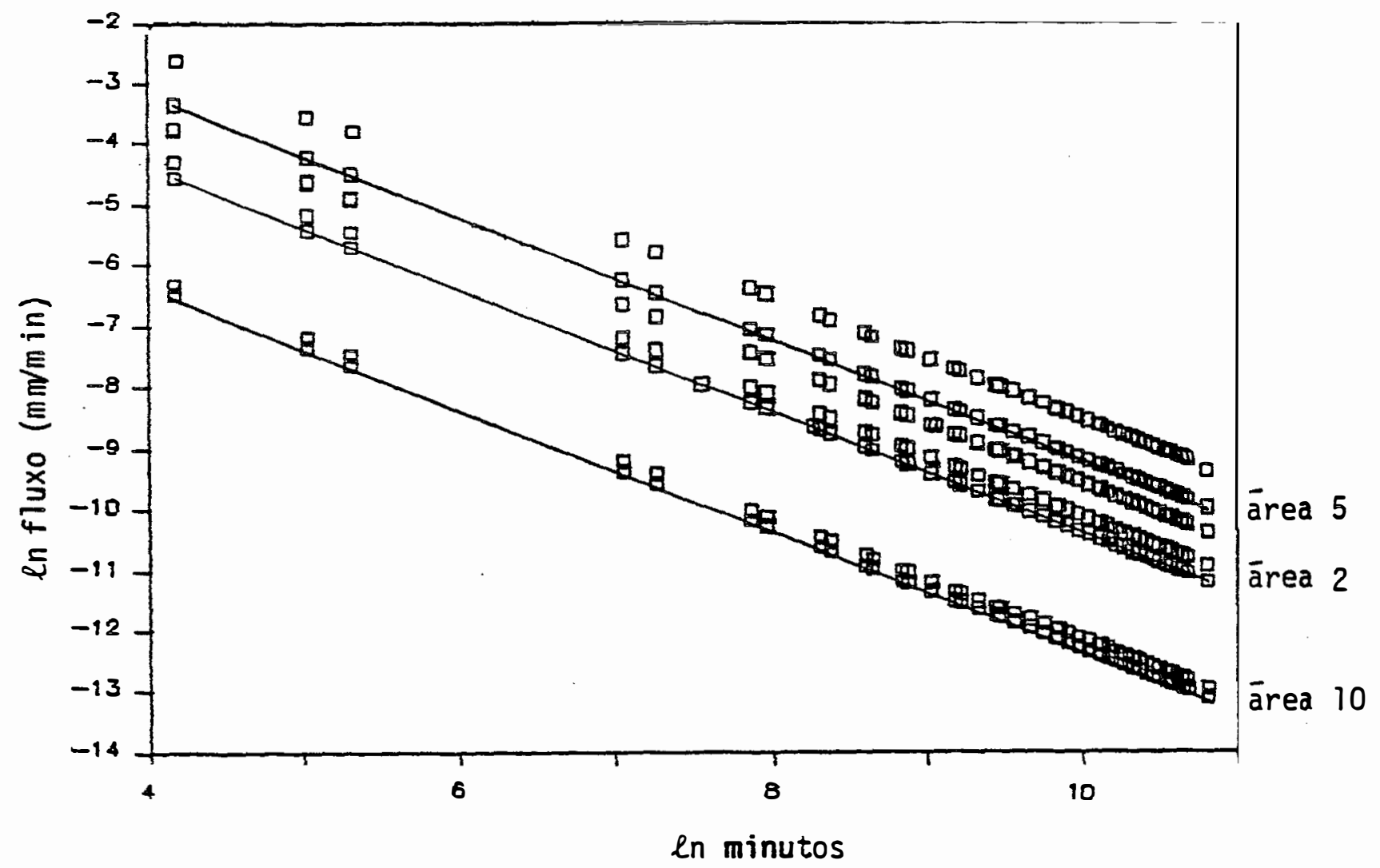

ārea 5: $\ln q=-0,39-1,00 \ln t$

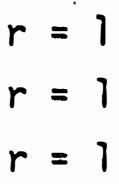

ārea 5: $\ln q=0,81-1,00 \ln t$

ärea 10: $\ln q=-2,16-1,00 \ln t$

$r=1$

Figura 16. Distribuição do fluxo ( $\ell$ n $\mathrm{mm} / \mathrm{min}$ ) na profundidade de $20 \mathrm{~cm}$ na TRE em função do tempo ( $\ell$ m min).

Nota: ārea 1 apresentou fluxo ascendente e foi substituijo pela ārea 2. 


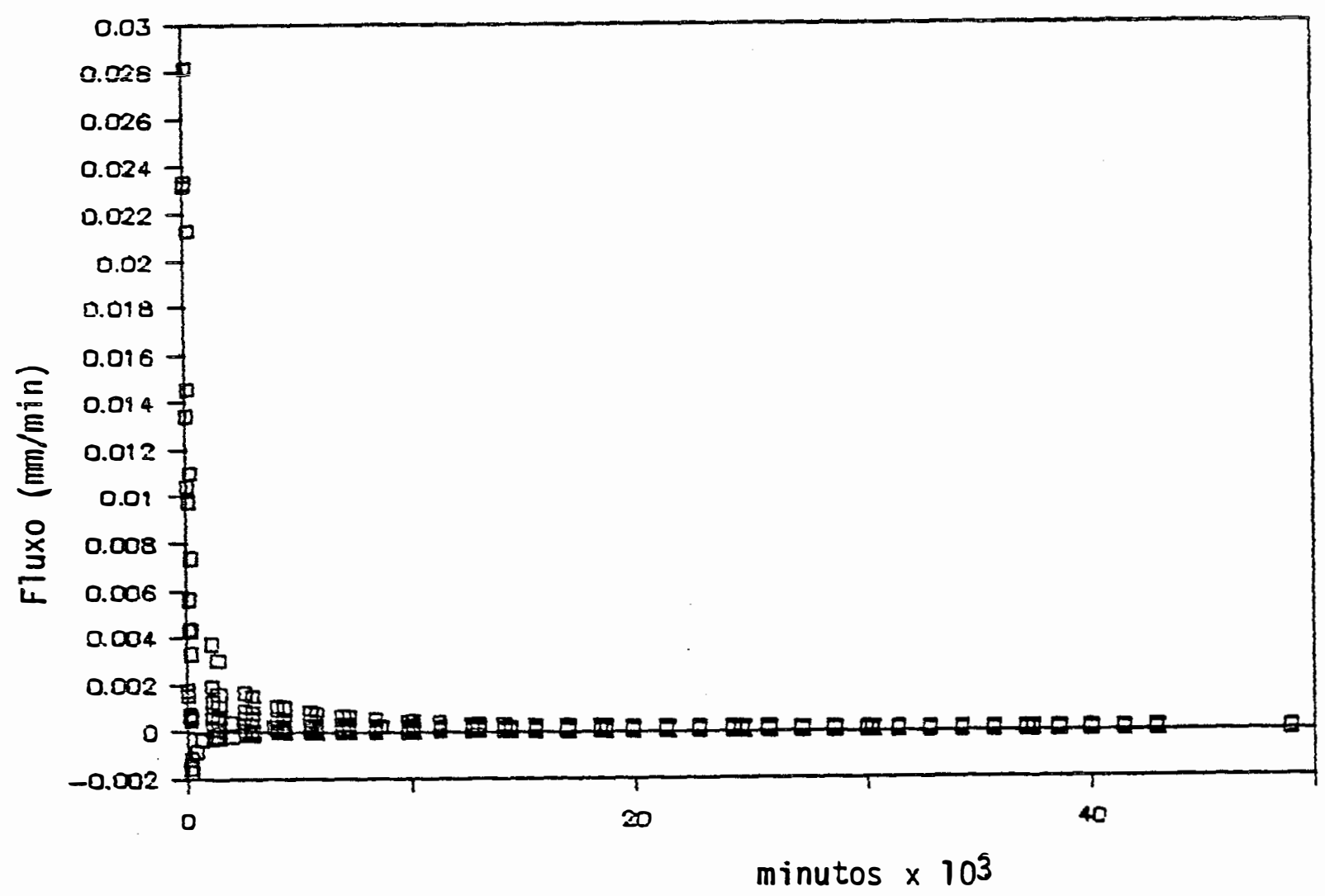

Figura 16a. Distribuição dos fluxos (mm/min) na profundidade de $20 \mathrm{~cm}$ na TRE em função do tempo (minutos $\times 10^{3}$ ). 
95.

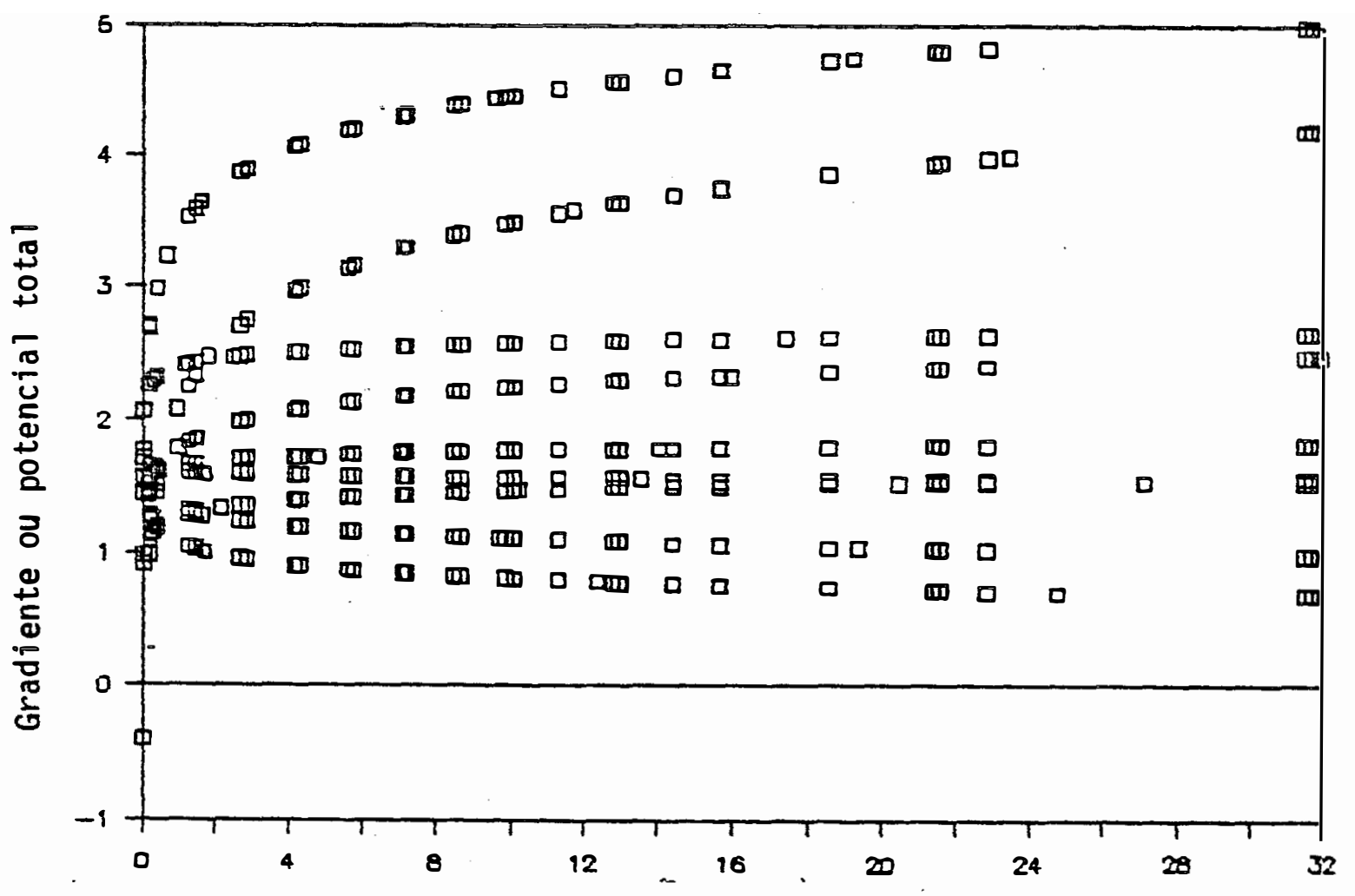

minutos $\times 10^{3}$

Figura 17. Distribuição do gradiente de potencial total na profundidade de $20 \mathrm{~cm}$ no LVA, em função do tempo (minutos $\times 10^{3}$ ). 
96.

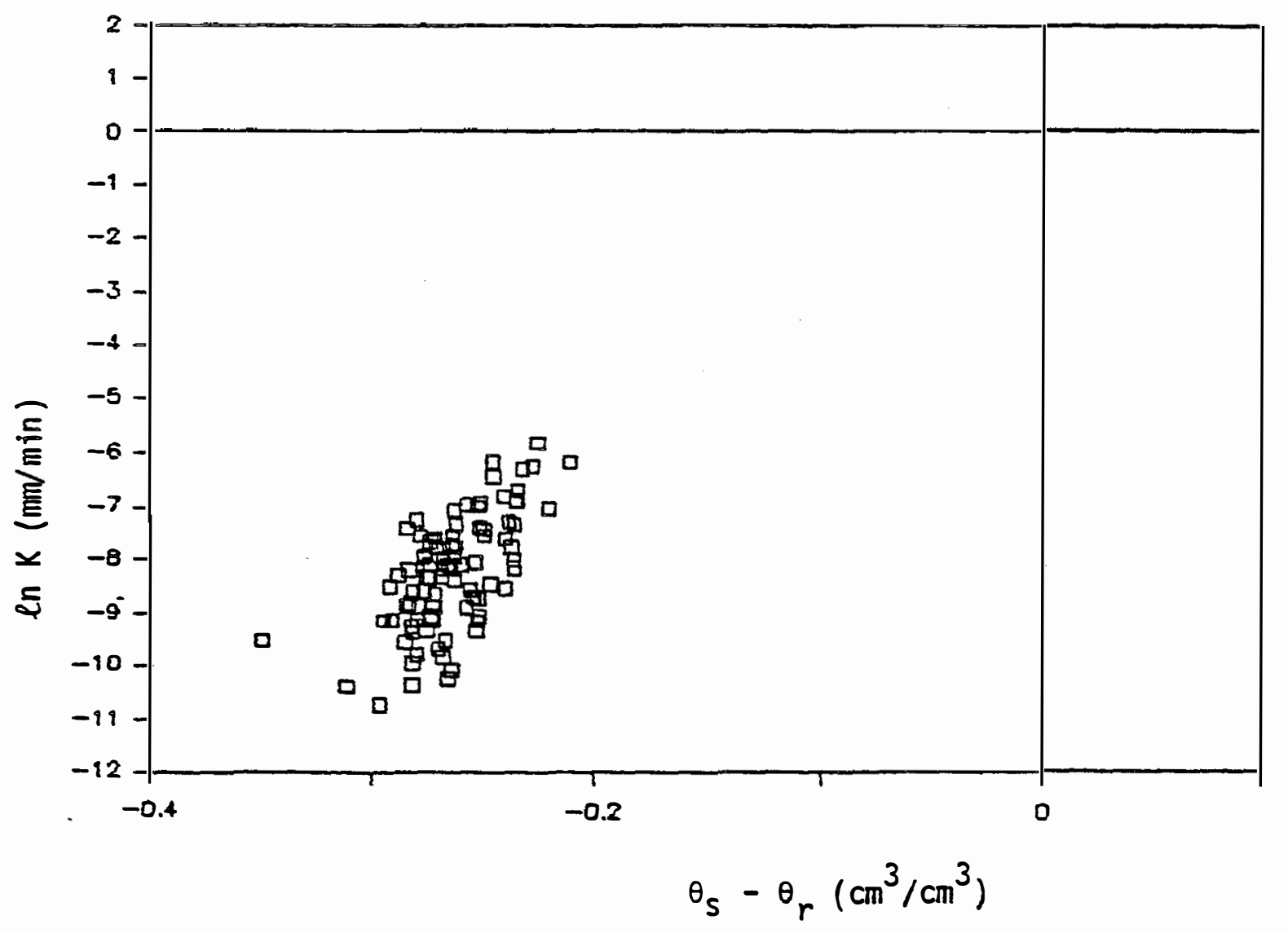

$$
\begin{array}{lll}
\text { ärea 1: } \ln K=6,35+54,34\left(\theta-\theta_{s}\right) & r=0,959 \\
\text { ärea 5: } \ln K=6,60+51,68\left(\theta-\theta_{s}\right) & r=0,954 \\
\text { ärea.9: } \ln K=0,10+29,18\left(\theta-\theta_{s}\right) & r=0,866 \\
\text { ärea 1 a 9: } \ln K=0,42+32,82\left(\theta-\theta_{s}\right) & r=0,648
\end{array}
$$

Figura 18. Distribuiçāo da condutividade hidrāulica (ln mm/ min) na profundidade de $20 \mathrm{~cm}$ no LVA em função da diferença entre a umidade volumētrica saturada $\left(\theta_{s}\right)$ e a umidade volumétrica residual $\left(\theta_{r}\right)$ em $\mathrm{cm}^{3} /$ $\mathrm{cm}^{3}$. 
97.

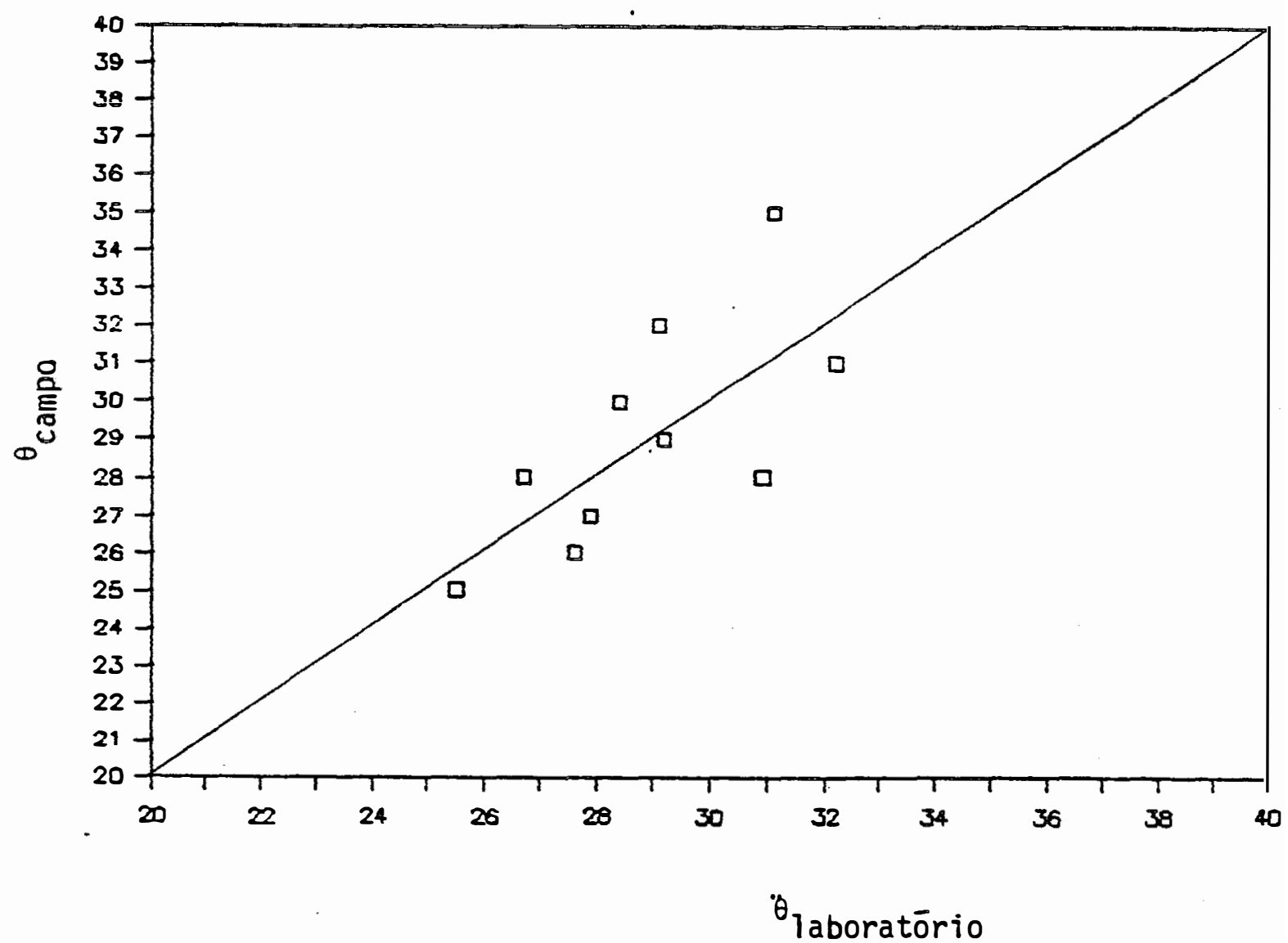

$$
\theta_{\text {campo }}=-0,096+1,01 \quad \theta_{1 a b} \quad r=0,704
$$

Figura 19a. Relação entre a umidade volumētrica $\left(\mathrm{cm}^{3} / \mathrm{cm}^{3}\right)$ determinada em campo $\left(\theta_{C}\right)$ e em laboratōrio $\left(\theta_{L^{\prime}}\right)$ na profundidade de $15 \mathrm{~cm}$ no LVA, na tenção de $-60 \mathrm{~cm}$ de àgua. 
98.

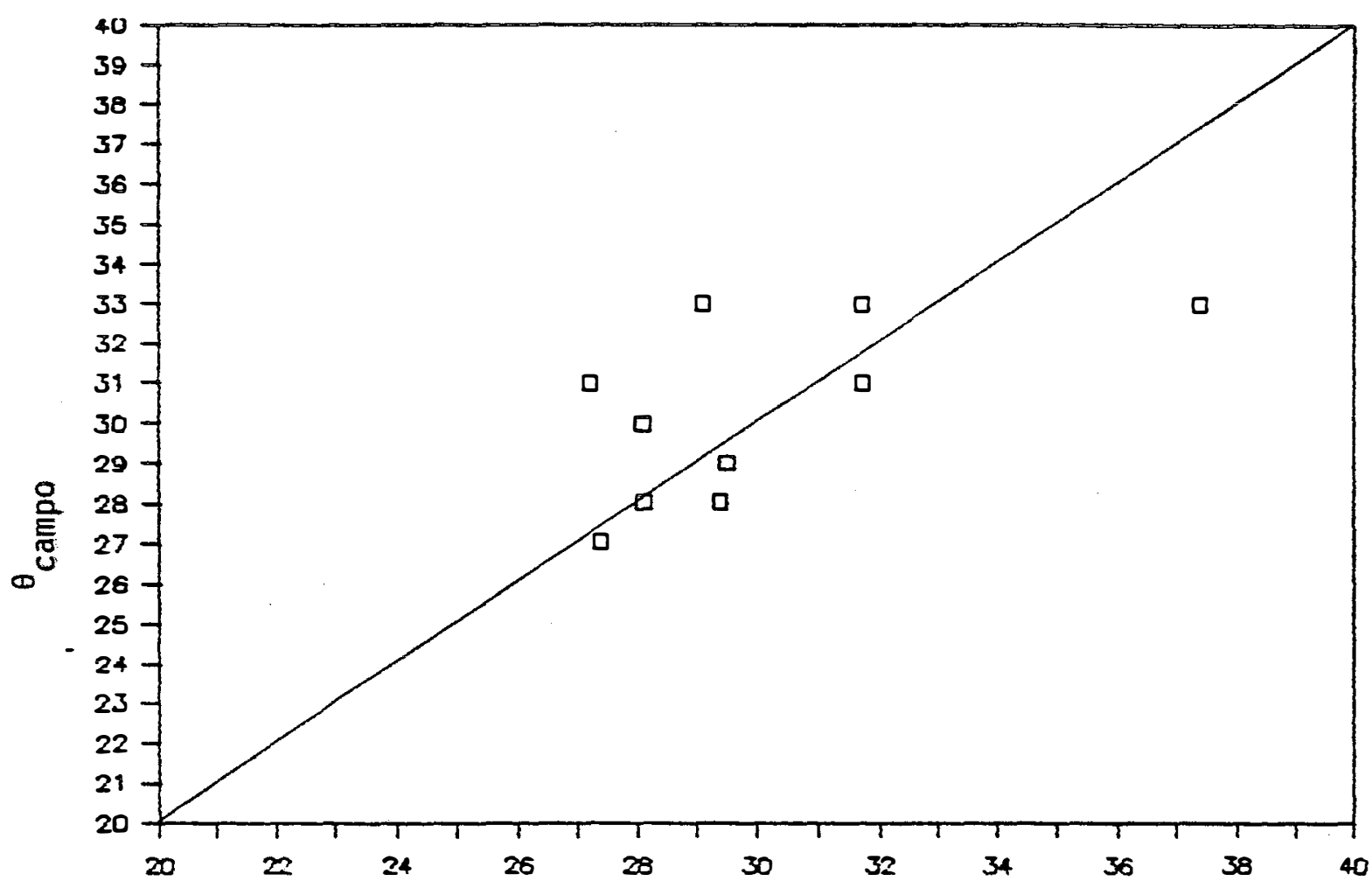

${ }^{\theta}$ laboratōrio

$\theta_{\text {campo }}=5,69+0,8 \theta_{\text {lab }} \quad r=0,594$

Figura 19b. Relação entre a umidade volumētrica $\left(\mathrm{cm}^{3} / \mathrm{cm}^{3}\right)$ determinada em campo $\left(\theta_{C}\right)$ e em laboratōrio $\left(\theta_{L}\right)$ na profundidade de $25 \mathrm{~cm}$ no LVA, na tensão de $-60 \mathrm{~cm}$ de àgua. 
99.

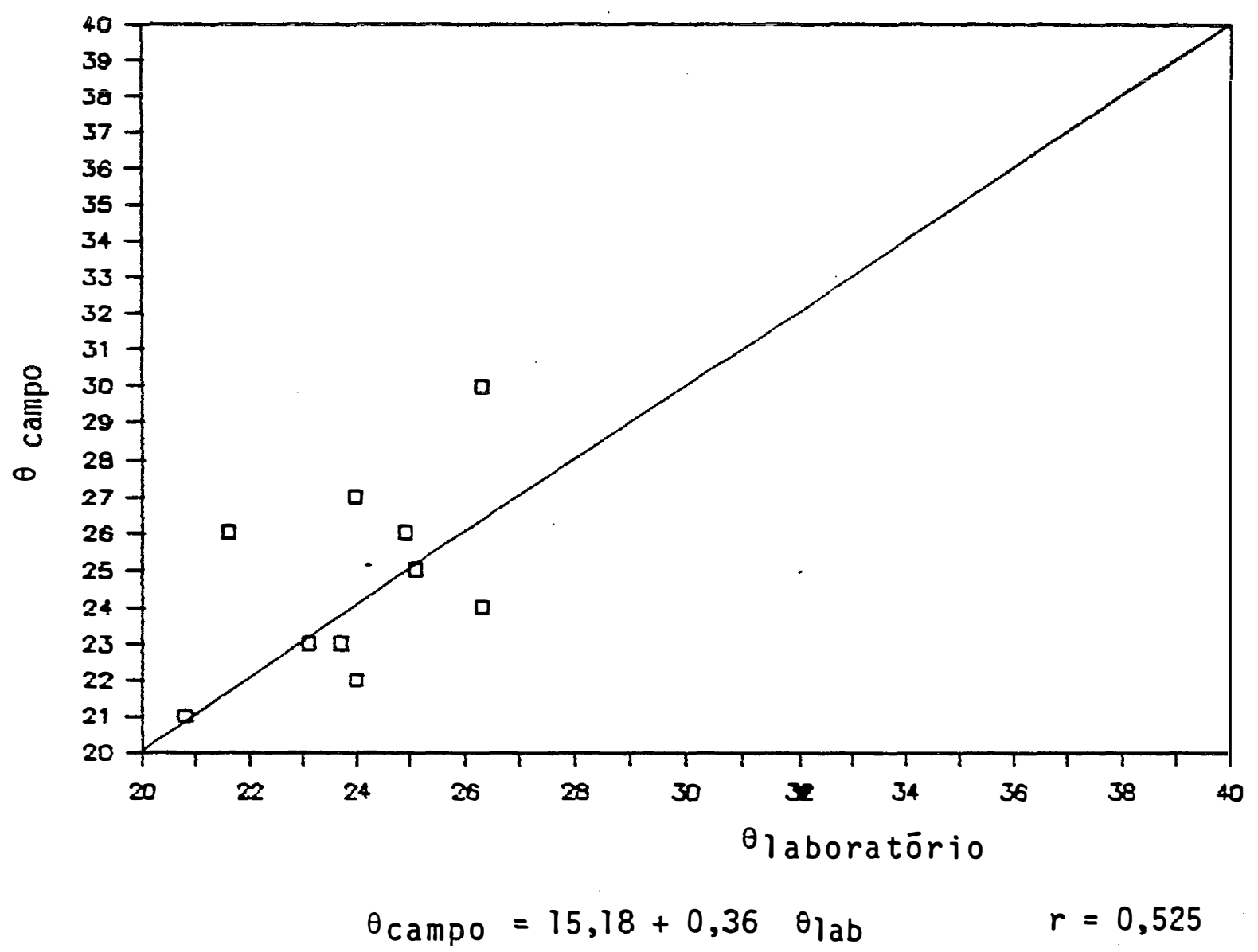

Figura 19c. Relação entre a umidade volumétrica $\left(\mathrm{cm}^{3} / \mathrm{cm}^{3}\right)$ determinada em campo $\left(\theta_{C}\right)$ e em laboratório $\left(\theta_{L}\right)$ na profundidade de $15 \mathrm{~cm}$ no LVA, na tensão de $-100 \mathrm{~cm}$ de àgua. 
100.

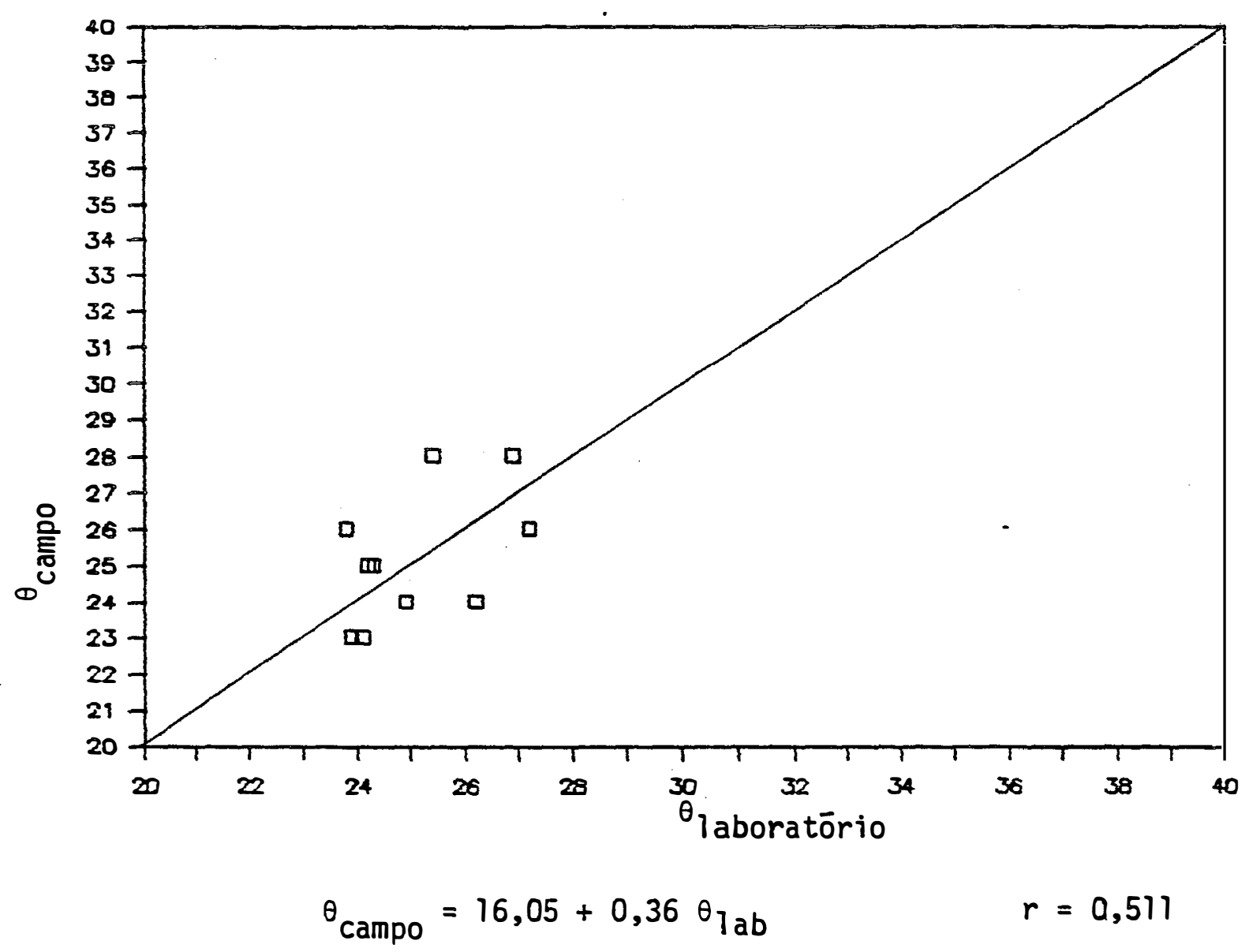

Figura 19d. Relação entre a umidade volumētrica $\left(\mathrm{cm}^{3} / \mathrm{cm}^{3}\right)$ determinada em campo $\left(\theta_{C}\right)$ e em laboratōrio $\left(\theta_{L}\right)$ na profundidade de $25 \mathrm{~cm}$ no LVA, na tensão de $-100 \mathrm{~cm}$ de àgua. 
101.

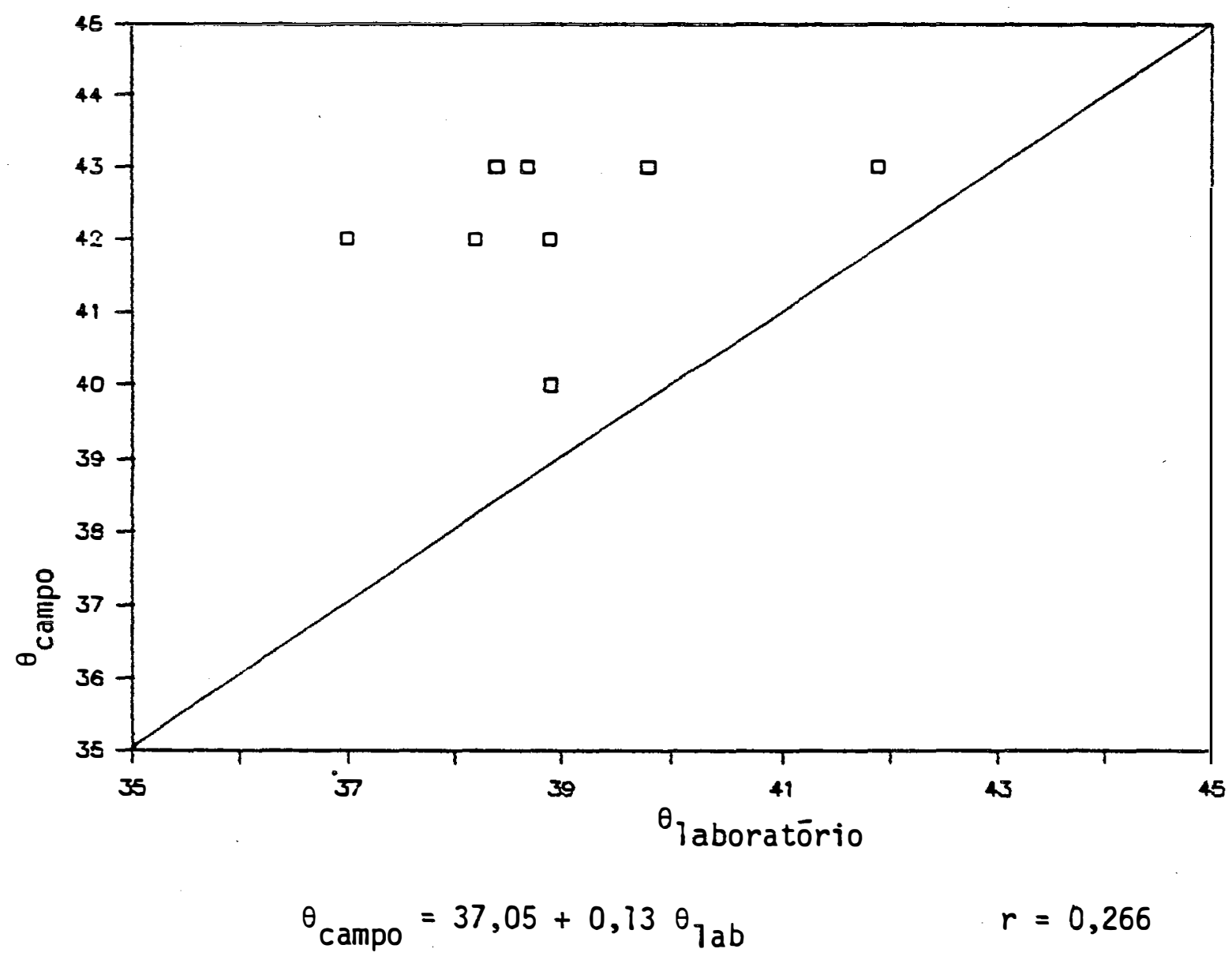

Figura 20a. Relação entre a umidade volumétrica $\left(\mathrm{cm}^{3} / \mathrm{cm}^{3}\right)$ determinada em campo $\left(\theta_{c}\right)$ e em laboratōrio $\left(\theta_{L}\right)$ na profundidade de $15 \mathrm{~cm}$ na TRE, na tensão de $-60 \mathrm{~cm}$ de àgua. 


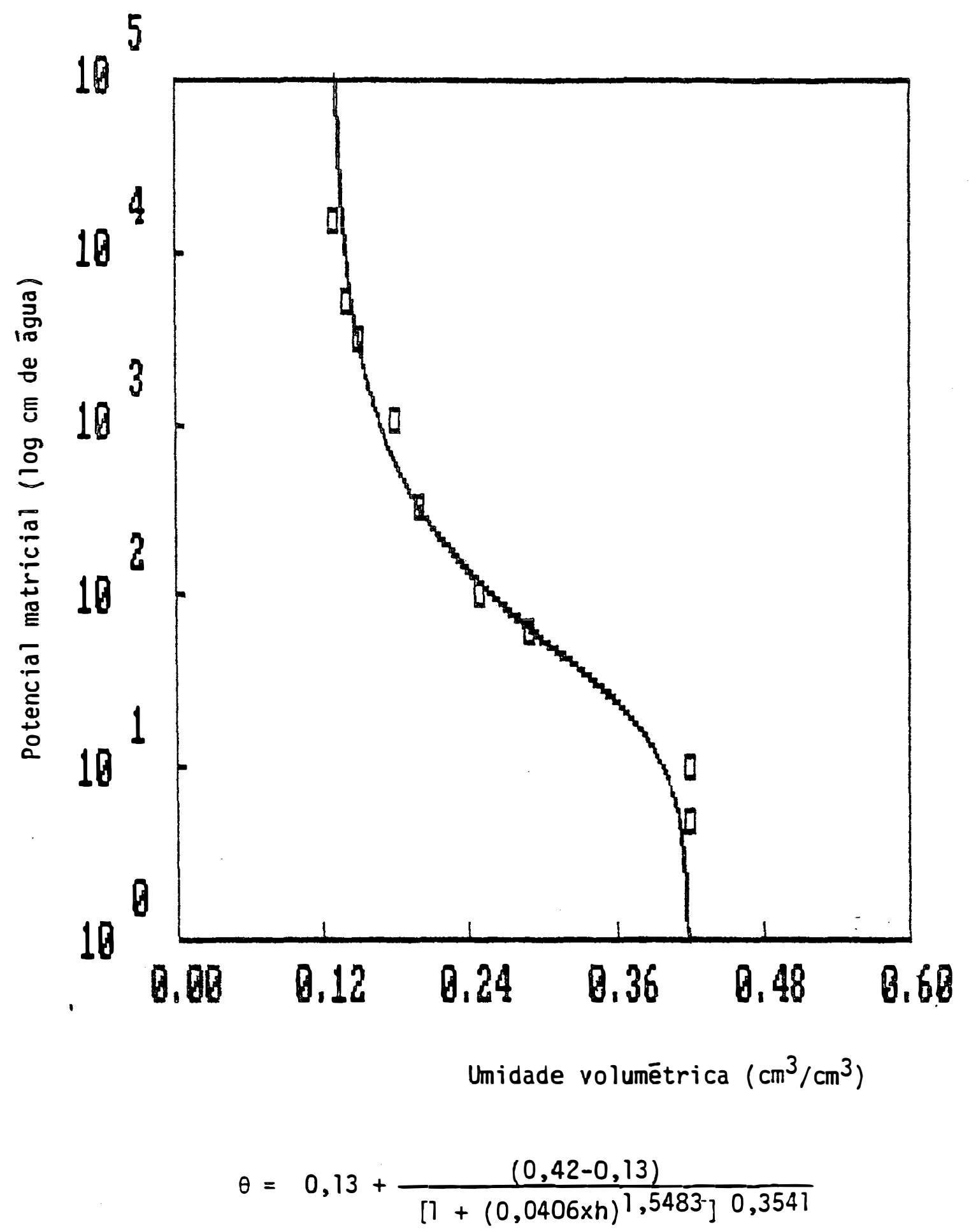

Figura 21. Relação entre a média do potencial mātrico (log $\mathrm{cm}$ de āgua) e a média da umidade volumētrica $\left(\mathrm{cm}^{3} /\right.$ $\mathrm{cm}^{3}$ ) na profundidade de 12 a $15 \mathrm{~cm}$ no LVA. 


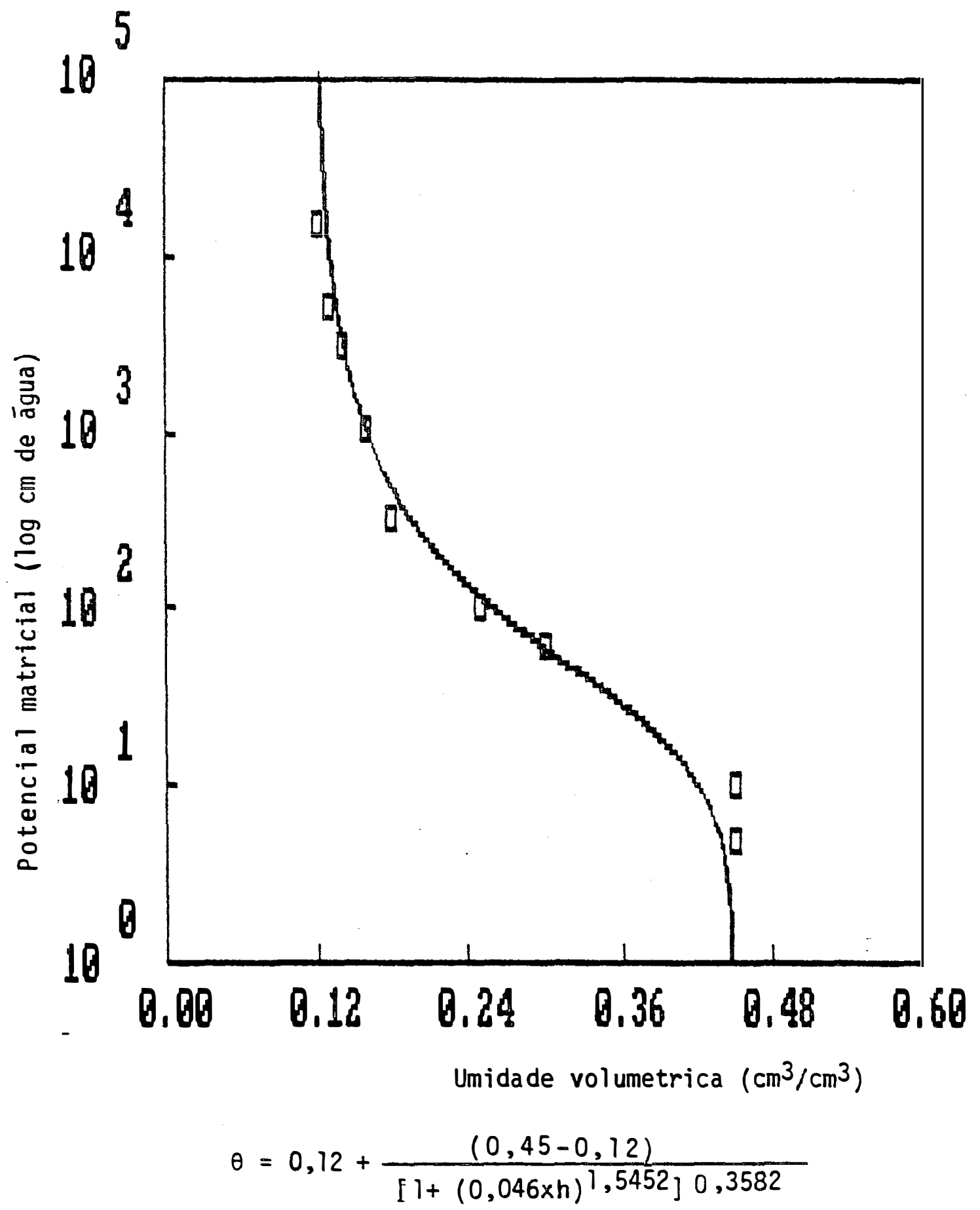

Figura 22. Relaçāo entre a mēdia do potencial mátrico (log $\mathrm{cm}$ de āgua) e a média da umidade volumétrica $\left(\mathrm{cm}^{3} /\right.$ $\mathrm{cm}^{3}$ ) na profundidade de 22 a $25 \mathrm{~cm}$ no LVA. 
104.

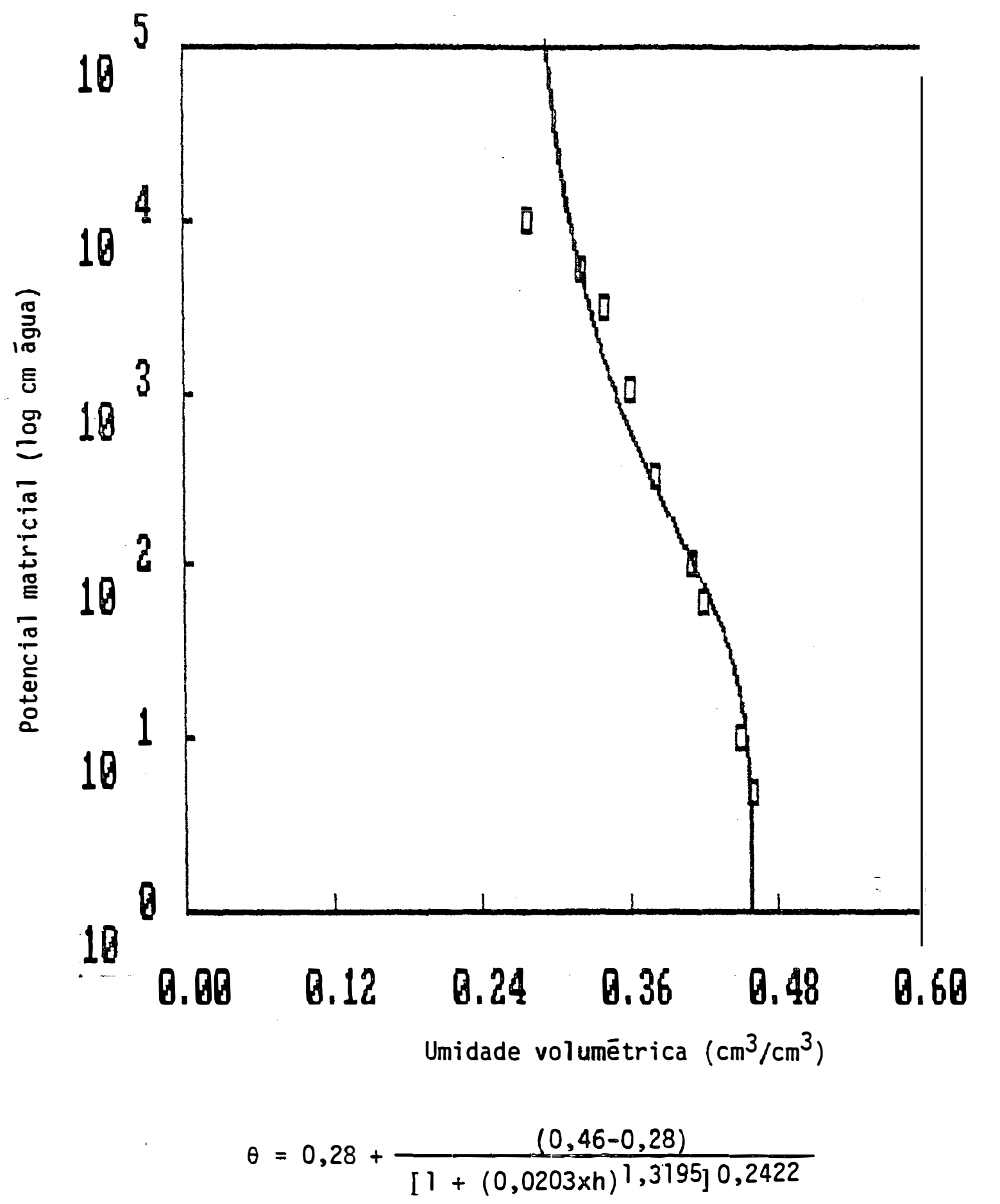

Figura 23. Relação entre a média do potencial mátrico (log $\mathrm{cm}$ de āgua) e a média da umidade volumētrica $\left(\mathrm{cm}^{3} /\right.$ $\mathrm{cm}^{3}$ ) na profundidade de 12 a $15 \mathrm{~cm}$ na TRE. 


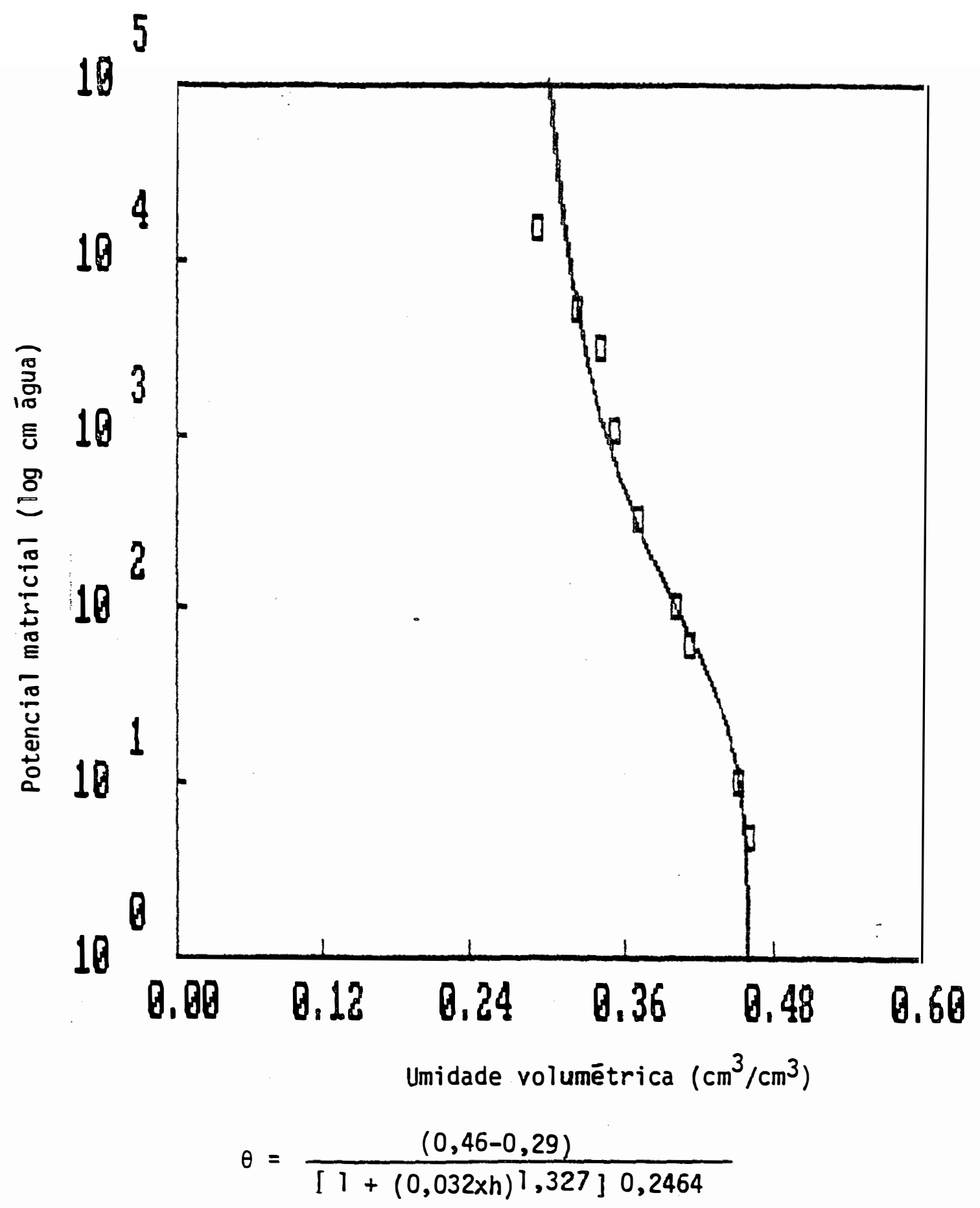

Figura 24. Relação entre a média do potencial mátrico (log $\mathrm{cm}$ de àgua) e a média da umidade volumētrica $\left(\mathrm{cm}^{3} /\right.$ $\mathrm{cm}^{3}$ ) na profundidade de 22 a $25 \mathrm{~cm}$ na TRE. 
106.

A P E N D I C E 


\section{SIMBOLOGIA UTILIZADA}

$A z=$ armazenamento $(\mathrm{mm})$ na camada de 0 a $20 \mathrm{~cm}$

Fluxo $=\min / \mathrm{mm}$

psi 15 = potencial total da água no solo ( $\mathrm{cm}$ de água) na profundidade de $15 \mathrm{~cm}$.

psi 25 = potencial total da água no solo ( $\mathrm{cm}$ de āgua) na profundidade de $25 \mathrm{~cm}$.

Gradiente $=$ gradiente do potencial total

$-\quad=\frac{\text { psi } 15-\text { psi } 25}{10}$

$K=$ condutividade hidrāulica do solo em $\mathrm{mm} / \mathrm{min}$

psi-MD = média do potencial total da āgua no solo $(\mathrm{cm}$ de āgua $)=$

$-\quad=\frac{\text { psi } 15+\text { psi } 25}{2}$

teta $10=$ umidade volumētrica $\left(\mathrm{cm}^{3} / \mathrm{cm}^{3}\right)$ na cada de 0 a $10 \mathrm{~cm}$.

teta 20 = umidade volumétrica $\left(\mathrm{an}^{3} / \mathrm{cm}^{3}\right)$ na camada de 10 a $20 \mathrm{~cm}$

teta $30=$ umidade volumétrica $\left(\mathrm{cm}^{3} / \mathrm{cm}^{3}\right)$ na camada de 20 a $30 \mathrm{~cm}$

teta-MD = mēdia di umidade volumētrica $\left(\mathrm{cm}^{3} / \mathrm{cm}^{3}\right)$ na camada de 0 a $20 \mathrm{~cm}$ $=\frac{\text { teta } 10+\operatorname{teta} 20}{2}$ 


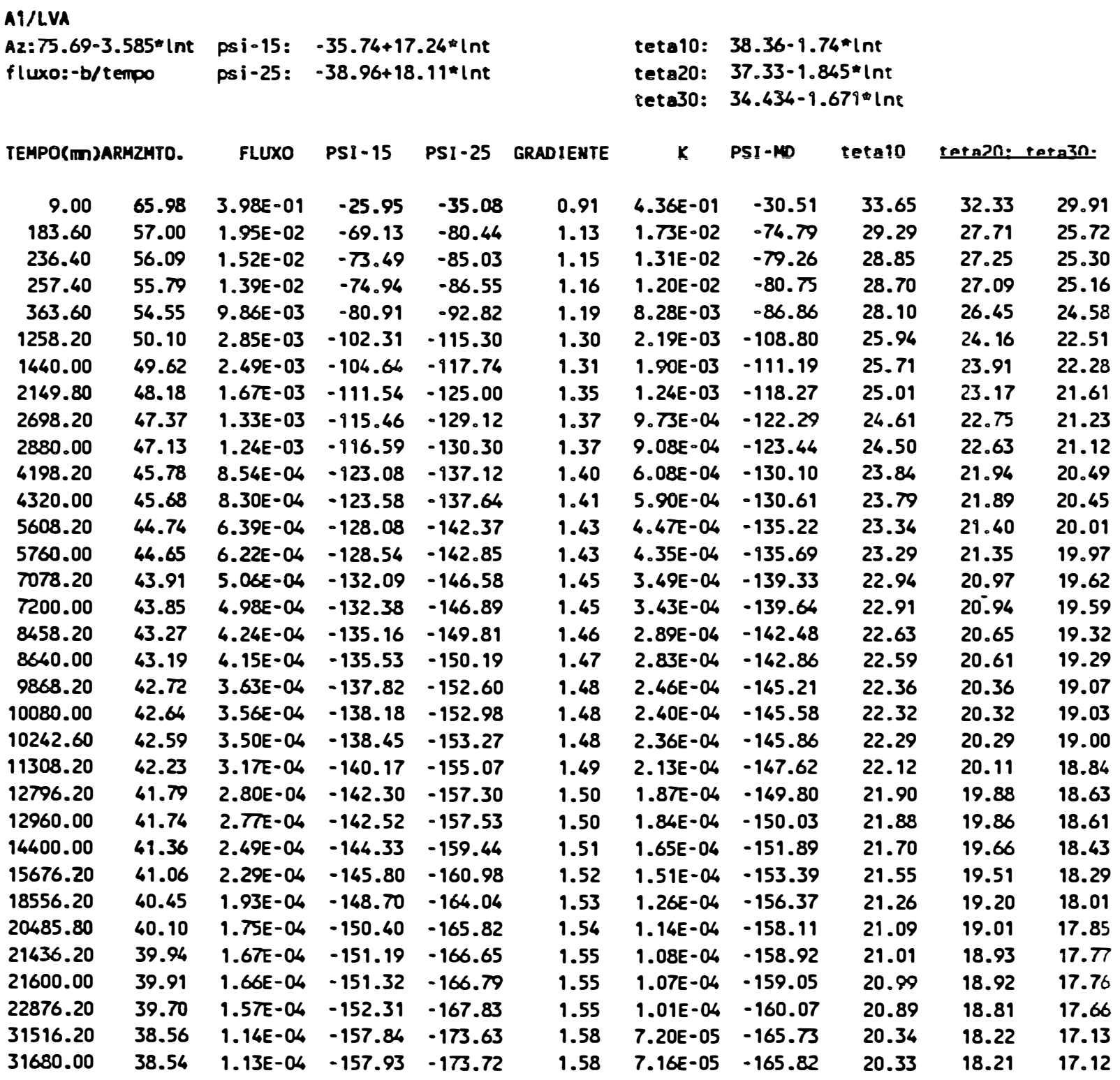


109.

A? ILVA

Az: $72.635-3.358 \star \ln t$

PS1-15: +33.323-14.452*LNT

PS1-25: +39.731-18.908*LNT

TEMPO(m) $)$ ARMZMTO.

FLUXO PSI tet 10: $38.797-1.867=\operatorname{lnt}$ teta20: $33.838-1.491 * \operatorname{lnt}$ tete30: $35.971-1.801 * \operatorname{lnt}$

\begin{tabular}{|c|c|c|c|c|c|c|c|c|c|c|}
\hline 9.00 & 63.54 & $3.73 E-01$ & -20.81 & -36.47 & 1.57 & $2.38 E-01$ & -28.64 & 33.74 & 29.80 & 31.09 \\
\hline 183.60 & 55.13 & $1.83 E-02$ & -57.01 & -83.83 & 2.68 & $6.82 E-03$ & -70.42 & 29.06 & 26.07 & 26.58 \\
\hline 195.00 & 54.94 & $1.72 E-02$ & -57.84 & -84.92 & 2.71 & $6.36 E-03$ & -71.38 & 28.96 & 25.98 & 26.48 \\
\hline 363.60 & 52.84 & $9.23 E-03$ & -66.88 & -96.75 & 2.99 & $3.09 E-03$ & -81.82 & 27.79 & 25.05 & 25.35 \\
\hline 637.20 & 50.85 & $5.2 \pi \cdot 0 \hat{T}$ & $-\pi .00$ & - $10 \overline{7} . \overline{36}$ & 3.26 & $1.63 E-03$ & -99.18 & $26 . \overline{74}$ & 26.21 & 26.34 \\
\hline 1258.20 & 48.67 & $2.6 \pi \mathrm{E}-03$ & -84.82 & -120.23 & 3.54 & $7.54 E-04$ & -102.52 & 25.47 & 23.20 & 23.12 \\
\hline 1440.00 & 48.21 & $2.33 E-03$ & $-86 . \pi$ & -122.78 & 3.60 & $6.48 E-04$ & -104.78 & 25.22 & 22.99 & 22.87 \\
\hline 1619.40 & 47.82 & $2.07 \mathrm{E}-03$ & -88.47 & .125 .00 & 3.65 & $5.68 E-04$ & -106.74 & 25.00 & 22.82 & 22.66 \\
\hline 2698.20 & 46.11 & $1.24 E-03$ & -95.85 & -134.65 & 3.88 & $3.21 E-04$ & -115.25 & 24.05 & 22.06 & 21.74 \\
\hline 2880.00 & 45.89 & $1.17 E-03$ & 96.79. & -135.88 & 3.91 & $2.98 E-04$ & -116.36 & 23.93 & 21.96 & 21.63 \\
\hline 4198.20 & 44.62 & 8.00E-04 & -102.24 & -143.01 & 4.08 & $1.96 E-04$ & -122.62 & 23.22 & 21.40 & 20.95 \\
\hline 4320.00 & 44.53 & $7.77 E-04$ & -102.65 & -143.55 & 4.09 & $1.90 E-04$ & -123.10 & 23.17 & 21.36 & 20.89 \\
\hline 5608.20 & 43.65 & $5.99 E-04$ & -106.42 & -148.49 & 4.21 & $1.42 E=04$ & -127.45 & 22.68 & 20.97 & 20.42 \\
\hline 5760.00 & 43.56 & $5.83 E-04$ & -106.81 & -148.99 & 4.22 & $1.38 E-04$ & -127.90 & 22.63 & 20.93 & 20.38 \\
\hline 7078.20 & 42.87 & $4.74 E-04$ & -109.79 & -152.89 & 4.31 & $1.10 E-04$ & -131.34 & 22.25 & 20.62 & 20.01 \\
\hline 7200.00 & 42.81 & $4.66 E-04$ & -110.03 & -153.21 & 4.32 & $1.08 E-04$ & -131.62 & 22.21 & 20.60 & 19.97 \\
\hline 8458.20 & 42.27 & $3.97 E-04$ & -112.36 & -156.26 & 4.39 & $9.04 E-05$ & -134.31 & 21.91 & 20.36 & 19.68 \\
\hline 8640.00 & 42.20 & $3.89 E-04$ & -112.67 & -156.66 & 4.40 & $8.83 E-05$ & -134.66 & 21.87 & 20.32 & 19.65 \\
\hline 9594.00 & 41.85 & $3.50 E-04$ & -114.18 & -158.64 & 4.45 & $7.87 E-05$ & -136.41 & 21.68 & 20.17 & 19.46 \\
\hline 9868.20 & 49.75 & $3.40 E-04$ & -114.59 & -159.17 & 4.46 & $7.63 E \cdot 05$ & -136.88 & 21.63 & 20.13 & 19.41 \\
\hline 10080.00 & 41.68 & $3.33 E-04$ & -114.90 & -159.57 & 4.47 & $7.46 E-05$ & -137.23 & 21.59 & 20.09 & 19.37 \\
\hline 11308.20 & 41.29 & $2.97 \mathrm{E}-04$ & -116.56 & -161.75 & 4.52 & $6.5 \pi E-05$ & -139.15 & 21.37 & 19.92 & 19.16 \\
\hline 12796.20 & 40.88 & $2.62 E-04$ & -118.34 & -164.08 & 4.57 & $5.74 E-05$ & -141.21 & 21.14 & 19.74 & 18.94 \\
\hline 12960.00 & 40.84 & $2.59 E-04$ & -118.53 & -164.32 & 4.58 & $5.66 E-05$ & -141.43 & 21.12 & 19.72 & 18.92 \\
\hline 14400.00 & 40.48 & $2.33 E-04$ & -120.05 & -166.32 & 4.63 & 5.04E-05 & -143.18 & 20.92 & 19.56 & 18.73 \\
\hline 15676.20 & 40.20 & $2.14 E-04$ & -121.28 & -167.92 & 4.66 & $4.59 E-05$ & -144.60 & 20.76 & 19.46 & 18.57 \\
\hline 18556.20 & 39.63 & $1.81 E-04$ & -123.71 & -171.11 & 4.74 & $3.82 E-05$ & -147.41 & 20.45 & 19.18 & 18.27 \\
\hline 19188.00 & 39.52 & $1.75 E=04$ & -124.20 & -171.74 & 4.75 & $3.68 E-05$ & -147.97 & 20.38 & 19.13 & 18.21 \\
\hline 21436.20 & 39.15 & $1.5 \pi E-04$ & -125.80 & -173.84 & 4.80 & $3.26 E-05$ & -149.82 & 20.18 & 18.97 & 18.01 \\
\hline 21600.00 & 39.12 & $1.55 E-04$ & -125.91 & -173.98 & 4.81 & $3.23 E-05$ & -149.95 & 20.16 & 18.96 & 18.00 \\
\hline 22876.20 & 38.93 & $1.4 \pi E-04$ & -126.74 & -175.07 & 4.83 & $3.045-05$ & -150.90 & 20.06 & 18.87 & 17.89 \\
\hline 31516.20 & 37.85 & $1.07 E-04$ & -131.37 & -181.13 & 4.98 & $2.14 E-05$ & -156.25 & 19.46 & 18.39 & 17.32 \\
\hline 31680.00 & 37.83 & $1.06 E-04$ & -131.44 & -181.23 & 4.98 & $2.13 E-05$ & -156.33 & 19.45 & 18.39 & 17.31 \\
\hline
\end{tabular}


A3/LVA

Az: $73.056-3.387 \ln t$ $q:-b / t$ empo
PSI - 15: $38.5438-18.724 *$ LNT PSI-25: 28.10-17.72*LNT teta10: $40.676-2.043 *$ Ine teta20: $32.379-9.345 \mathrm{lnt}$ tet 30 : 31.588-1.329 int

\begin{tabular}{|c|c|c|c|c|c|c|c|c|c|c|}
\hline 9.00 & 63.88 & $3.76 E-01$ & -27.16 & -44.89 & 1.7 & $2.12 E-01$ & -36.03 & 35.14 & 28.74 & 28.01 \\
\hline 164.00 & 56.22 & $2.35 E-02$ & -69.51 & .85 .00 & 1.55 & $1.52 E-02$ & .77 .26 & 30.52 & 25.69 & 25.02 \\
\hline 183.60 & 55.40 & $1.85 E-02$ & -74.06 & -89.28 & 1.52 & $1.21 E \cdot 02$ & -81.67 & 29.93 & 25.37 & 24.70 \\
\hline 193.20 & 55.26 & $1.73 E-02$ & -73.00 & -90.11 & 1.51 & $1.16 E-02$ & -82.56 & 29.93 & 25.30 & 24.64 \\
\hline 363.60 & 53.09 & $9.32 E-03$ & -86.85 & -101.39 & 1.45 & $6.41 E-03$ & -94.12 & 28.63 & 26.45 & 23.80 \\
\hline 1258.20 & 48.88 & $2.69 E-03$ & -110.10 & -123.39 & 1.33 & $2.03 E-03$ & -196.74 & 26.09 & 22.78 & 22.16 \\
\hline 1440.00 & 48.42 & 2.35E-03 & -112.62 & -125.78 & 1.32 & $1.79 E-03$ & -199.20 & 25.82 & 22.60 & 21.98 \\
\hline 1634.40 & 48.03 & $2.07 E-03$ & -115.00 & -127.86 & 1.29 & 1.61E-03 & -121.43 & 25.58 & 22.44 & 21.83 \\
\hline 2698.20 & 46.30 & $1.26 E-03$ & -124.38 & -136.91 & 1.25 & $1.00 E \cdot 03$ & -130.64 & 24.54 & $21 . \pi$ & 21.15 \\
\hline 2880.00 & 46.08 & $1.18 E-03$ & -925.60 & -938.06 & 1.25 & $9.64 \mathrm{E} \cdot 04$ & -939.83 & 24.40 & 21.67 & 21.07 \\
\hline 4198.20 & 44.80 & 8.07E-04 & -132.66 & -144.74 & 1.21 & $6.68 E \cdot 04$ & - 938.70 & 23.63 & 29.96 & 20.57 \\
\hline 4320.00 & 44.70 & $7.84 E-04$ & -133.19 & .145 .25 & 1.21 & $6.59 E-04$ & -139.22 & 23.57 & 29.12 & 20.53 \\
\hline 5608.20 & 43.82 & $6.04 \mathrm{E}-04$ & -138.08 & -149.87 & 1.18 & $5.12 E-04$ & -143.97 & 23.04 & 20.7 & 20.19 \\
\hline 5760.00 & 43.73 & $5.88 \mathrm{E}-04$ & -138.58 & -150.34 & 1.18 & $5.00 E-04$ & -164.46 & 22.99 & 20.73 & 20.15 \\
\hline 7078.20 & 43.03 & $4.79 E-04$ & -142.46 & .154 .00 & 1.16 & $4.14 E-0.4$ & -148.22 & 22.57 & 20.46 & 19.88 \\
\hline 7200.00 & 42.97 & $4.70 E-04$ & -142.76 & .154 .30 & 1.15 & $4.08 E-04$ & -148.53 & 22.53 & 20.43 & 19.86 \\
\hline 8458.20 & 42.43 & $4.00 E-04$ & -145.7 & -157.15 & 1.14 & $3.52 E-04$ & -151.46 & 22.20 & 20.22 & 19.64 \\
\hline 8640.00 & 42.36 & $3.92 E-04$ & -146.17 & -157.53 & 1.14 & $3.45 E-04$ & -151.85 & 22.16 & 20.19 & 19.61 \\
\hline 9676.80 & 42.00 & $3.50 E-04$ & -148.15 & -159.41 & 1.13 & $3.11 E-0.4$ & -153.78 & 21.94 & 20.05 & 19.47 \\
\hline 9868.20 & 41.91 & $3.43 E-04$ & -148.66 & -159.89 & 1.12 & $3.06 E-04$ & -154.27 & 21.89 & 20.01 & 19.46 \\
\hline 10080.00 & 41.83 & $3.36 E-04$ & -149.06 & -160.26 & 1.12 & $3.00 E-04$ & -154.66 & 21.86 & 19.98 & 19.41 \\
\hline 11308.20 & 41.44 & $3.00 E-04$ & -151.21 & -162.30 & 1.11 & $2.70 E-04$ & $-156 . \pi 3$ & 21.61 & 19.83 & 19.26 \\
\hline 12796.20 & 41.03 & $2.65 E-04$ & -153.52 & -164.49 & 1.10 & $2.41 E-04$ & -159.01 & 21.36 & 19.66 & 19.10 \\
\hline 12960.00 & 40.98 & $2.61 E-04$ & -153.76 & -164.72 & 1.10 & $2.39 E-04$ & -159.24 & 21.33 & 19.66 & 19.08 \\
\hline 14400.00 & 40.63 & $2.35 E-04$ & -155.74 & -166.58 & 1.08 & $2.1 T E-04$ & -161.16 & 21.11 & 19.50 & 18.94 \\
\hline 15676.20 & 40.36 & $2.16 E-0.4$ & -157.33 & -168.09 & 1.08 & $2.01 E-04$ & -162.71 & 20.94 & 19.39 & 18.83 \\
\hline 18556.20 & 39.77 & $1.83 E-04$ & -160.48 & -171.08 & 1.06 & $1.72 E-04$ & -165.78 & 20.60 & 19.16 & 18.60 \\
\hline 19354.20 & 39.63 & $1.73 E-04$ & -161.26 & -171.81 & 1.06 & $1.66 E-04$ & -166.53 & 20.51 & 19.10 & 18.55 \\
\hline 21436.20 & 39.28 & $1.58 E-04$ & -163.18 & -173.63 & 1.04 & $1.51 E-04$ & -168.41 & 20.30 & 18.97 & 18.49 \\
\hline 21600.00 & 39.25 & $1.57 E-04$ & -163.33 & -173.77 & 1.04 & $1.50 E-04$ & -168.55 & 20.29 & 18.96 & 18.40 \\
\hline 22876.20 & 39.06 & $1.48 E-04$ & -164.40 & -174.78 & 1.04 & $1.43 E-04$ & -169.59 & 20.17 & 18.88 & 18.33 \\
\hline 39516.20 & 37.97 & $1.0 \pi \mathrm{E}-04$ & -170.40 & -180.46 & 1.01 & $1.0 \pi E-04$ & .175 .43 & 19.51 & 18.45 & 17.90 \\
\hline 31680.00 & 37.96 & $1.07 E-04$ & -170.50 & -180.55 & 1.01 & $1.06 E-04$ & -175.53 & 19.50 & 18.46 & 17.90 \\
\hline
\end{tabular}


A4/LVA

A2: $68.381-2.461 * \ln t$ $q:-b / t$ empo
PSI-15: 24.623-13.823"LNT

PSI-25: 21.513-14.333"LNT teto10: 35.639-1.226*Int teta20: 32.742-1.235" Int tete30: 27.161-0.697 Int

\begin{tabular}{|c|c|c|c|c|c|c|c|c|c|c|}
\hline \multicolumn{2}{|c|}{ TEMPO(m) ARMZMTO. } & FLUXO & PSI-15 & PSI -25 & GRADIENTE & $\boldsymbol{k}$ & PSI - MD & TETA10 & TETAZO & ETA30 \\
\hline 9.00 & 61.72 & $2.73 E-01$ & -27.81 & -42.30 & 1.45 & $1.89 E-01$ & -35.06 & 32.32 & 29.40 & Cooct \\
\hline 183.60 & 55.55 & $1.34 E-02$ & -62.43 & -78.20 & 1.58 & $8.50 E-03$ & -70.32 & 29.25 & 26.30 & 23.53 \\
\hline 295.20 & 54.40 & $8.34 E-03$ & -68.89 & -85.00 & 1.61 & 5.17E-03 & -76.95 & 28.68 & 25.73 & 23.20 \\
\hline 363.60 & 53.87 & $6.77 E-03$ & -71.88 & -88.00 & 1.61 & $4.20 E-03$ & -79.94 & 28.41 & 5.46 & 3.05 \\
\hline 455.40 & 53.32 & $5.40 E-03$ & $-\pi 5.00$ & -91.20 & 1.62 & $3.33 E-03$ & -83.10 & 28.14 & 25.18 & 22.90 \\
\hline 1258.20 & 50.82 & $1.96 E-03$ & -89.04 & -105.79 & 1.68 & $1.17 E-03$ & -97.41 & 26.89 & 23.93 & 22.19 \\
\hline 1440.00 & 50.48 & $1.71 E-03$ & -90.90 & -107.72 & 1.68 & $1.02 E-03$ & -99.31 & 26.72 & 23.76 & 22.09 \\
\hline 2698.20 & 48.94 & $9.12 E-04$ & -99.58 & -116.72 & 1.71 & $5.32 E-04$ & -108.15 & 25.95 & 22.99 & 21.65 \\
\hline 2880.00 & 48.78 & $8.54 E-04$ & -100.48 & -117.66 & $1 . \pi$ & $4.98 E-04$ & -109.07 & 25.87 & 22.90 & 21.61 \\
\hline 4198.20 & 47.85 & $5.86 E-04$ & -105.69 & -123.06 & 1.74 & $3.38 E-04$ & -114.38 & 25.41 & 22.44 & 21.35 \\
\hline 4320.00 & 47.78 & $5.70 E-04$ & -106.09 & -123.47 & 1.74 & $3.28 E-04$ & -114.78 & .25 .38 & 22.40 & 21.33 \\
\hline 4811.40 & 47.51 & $5.11 E-04$ & -107.60 & -125.00 & 1.74 & $2.94 E-04$ & -116.30 & 25.24 & 22.27 & 21.2 \\
\hline 5608.20 & & $4.39 E-04$ & -109.70 & -127.21 & $1 . \pi 5$ & $2.51 E-04$ & -118.45 & 25.06 & 22.08 & 21.14 \\
\hline 5760.00 & 47.07 & $4.2 \pi E-04$ & -110.07 & -127.59 & $1 . \pi 5$ & $2.44 E-04$ & -118.83 & 25.02 & 22.05 & 21.13 \\
\hline 7031.40 & 46.58 & $3.50 E-04$ & -112.85 & -130.45 & 1.76 & $1.99 E-04$ & -121.65 & 24.78 & 21.80 & 20.9 \\
\hline 7078.20 & 46.56 & $3.48 E-04$ & -112.91 & -130.55 & 1.76 & $1.97 E-04$ & -121.73 & 24.77 & 21.79 & 20.98 \\
\hline 7200.00 & 46.52 & $3.42 E-0.4$ & -113.15 & -130.79 & 1.76 & $1.94 E-04$ & -121.97 & 24.75 & 21.77 & 20.9 \\
\hline 8458.20 & 46.13 & $=04$ & -115.38 & -133.10 & & $1.64 E-04$ & -124.24 & 24.55 & 21.57 & 20.86 \\
\hline 8640.00 & 46.07 & $2.85 E-04$ & -115.67 & -133.40 & 1.77 & $1.61 E-04$ & -124.54 & 24.53 & 21.55 & 20.84 \\
\hline 9868.20 & & $2.49 E-04$ & -117.51 & -135.31 & 1.78 & $1.40 E-04$ & -126.41 & 24.36 & 21.38 & 20.75 \\
\hline 10080.00 & 45.69 & $2.44 E-06$ & -117.80 & -135.61 & 1.78 & $1.37 \mathrm{~T}-04$ & -126.71 & 24.34 & 21.36 & 20.74 \\
\hline 11308.20 & 45.41 & $2.18 E-04$ & - 119.39 & -137.26 & 1.79 & $1.22 E-04$ & -128.33 & 24.20 & 21.22 & 20.66 \\
\hline 12796.20 & 45.11 & $1.92 E-04$ & -121.10 & -139.03 & 1.79 & $1.07 \mathrm{E}-04$ & -130.07 & 24.04 & 21.06 & 20.5 \\
\hline 12960.00 & 45.08 & $1.90 E-04$ & -121.27 & -139.22 & 1.79 & $1.06 E-04$ & -130.25 & 24.03 & 21.05 & 20.5 \\
\hline 14062.80 & 44.88 & $1.75 E-04$ & -122.39 & -140.37 & 1.80 & $9.73 E-05$ & -131.38 & 23.93 & 20.95 & 20.5 \\
\hline 14400.00 & 46.83 & $1.71 E-04$ & -122.66 & -140.65 & 1.80 & $9.50 E-05$ & -131.66 & 23.91 & 20.92 & 20.4 \\
\hline 15676.20 & 44.61 & $1.57 E-04$ & -123.91 & -141.94 & 1.80 & 8.70E-05 & -132.92 & 23.80 & 20.81 & 20.4 \\
\hline 18556.20 & 44.19 & $1.33 E-06$ & -126.24 & -144.36 & 1.81 & $7.32 E-05$ & -135.30 & 23.59 & 20.60 & 20.3 \\
\hline 21436.20 & 43.84 & $1.15 E-06$ & -128.23 & -146.43 & 1.82 & $6.31 E-05$ & -137.33 & 23.41 & 20.43 & 20.2 \\
\hline 21600.00 & 43.82 & $1.14 E-04$ & -128.34 & -146.54 & 9.82 & $6.26 E-05$ & -137.44 & 23.40 & 20.42 & 20.2 \\
\hline 22876.20 & 43.68 & $1.08 E-04$ & -129.13 & -147.36 & 1.82 & $5.90 E-05$ & -138.24 & 23.33 & 20.35 & 20.1 \\
\hline 31516.20 & 42.89 & $7.81 E-05$ & -133.56 & -151.95 & 1.86 & $4.24 E-05$ & -142.76 & 22.94 & 19.95 & 19.9 \\
\hline 31080.00 & 42.88 & $7.77 E-05$ & -133.63 & -152.03 & 1.84 & $4.22 E-05$ & -142.83 & 22.93 & 19.94 & 19.9 \\
\hline
\end{tabular}


112.

A5/LVA

$A z: 74.001-3.0470 \ln t$ $a:-b /$ tempo

TEMPO(m) ARMZMTO.
PS1-15: 45.898-18.631*LNT PSI -25: $37.646-19.637$ LNT tet 10: $37.562 \cdot 1.418 *$ Int

teta20: $36.462-1.629 *$ int

tet $30: 31.440-1.165 *$ int

\begin{tabular}{|c|c|c|c|c|c|c|c|c|c|c|}
\hline 9.00 & $65 . \pi 5$ & $3.39 E-01$ & -19.56 & -40.19 & 2.06 & $1.64 E-01$ & -29.87 & 33.70 & 32.05 & 28.29 \\
\hline 150.60 & 58.74 & $2.02 E-02$ & -62.46 & -85.00 & 2.26 & $8.97 E-03$ & $-\pi . \pi$ & 30.46 & 28.30 & 25.60 \\
\hline 183.60 & 58.12 & $1.66 E-02$ & -66.22 & -88.87 & 2.27 & $7.33 E \cdot 03$ & -77.55 & 30.15 & 27.97 & 25.37 \\
\hline 294.00 & 56.69 & $1.06 E-02$ & $-\pi 5.00$ & -97.96 & 2.30 & $4.51 E-03$ & -86.48 & 29.49 & 27.21 & 26.82 \\
\hline 363.60 & 56.04 & $8.38 E-03$ & -78.95 & -102.16 & 2.32 & $3.61 E-03$ & -90.55 & 29.18 & 26.86 & 26.57 \\
\hline 1177.80 & 52.46 & $2.59 E-03$ & -100.82 & -125.00 & 2.62 & $1.07 E-03$ & -112.91 & 27.52 & 24.94 & .2 \\
\hline 1258.20 & 52.25 & $2.42 E-03$ & -102.08 & -126.28 & 2.42 & $1.00 E-03$ & -114.18 & 27.42 & 24.86 & רים \\
\hline 1660.00 & 51.84 & $2.12 E-03$ & -104.59 & -128.91 & 2.63 & $8.70 E-06$ & .116 .75 & 27.23 & 24.62 & 22.9 \\
\hline 2515.20 & 50.14 & $1.21 E-03$ & .115 .00 & $-139 . \pi 5$ & 2.67 & $4.90 E-06$ & -127.37 & 26.46 & 23.71 & 22.3 \\
\hline 2698.20 & 49.93 & $1.13 E-03$ & -116.29 & -141.11 & 2.48 & $4.55 E-06$ & -128.70 & 26.34 & 23.59 & 22.2 \\
\hline 2880.00 & 49.73 & $1.06 E-03$ & -117.51 & -162.38 & 2.69 & $4.25 E-06$ & -129.96 & 26.25 & 23.69 & 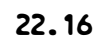 \\
\hline 4198.20 & 48.58 & $7.26 E-04$ & -126.53 & -169.71 & 2.52 & $2.88 E-04$ & -137.12 & 25.71 & 22.87 & 2 \\
\hline 4320.00 & 48.49 & $7.05 E-06$ & -125.06 & -150.26 & 2.52 & $2.80 E-04$ & -137.66 & 25.67 & 22.83 & 21.6 \\
\hline 5608.20 & 47.70 & $5.43 E-06$ & -129.92 & -155.33 & 2.56 & $2.14 E-06$ & -142.63 & 25.30 & 22.40 & 21.3 \\
\hline 5760.00 & 47.62 & $5.29 E-04$ & -130.42 & -155.85 & 2.56 & $2.08 E-04$ & -163.16 & 25.26 & 22.36 & 21.3 \\
\hline 7078.20 & 46.99 & $4.30 E-06$ & -136.26 & -159.86 & 2.56 & $1.688-06$ & -147.06 & 26.97 & 22.02 & 21.11 \\
\hline 7200.00 & 46.94 & $4.23 E-06$ & -134.58 & -160.19 & 2.56 & $1.65 E-0.4$ & -167.38 & 26.95 & 21.99 & 21.0 \\
\hline 8458.20 & 46.45 & $3.60 E-06$ & -137.58 & -163.32 & 2.57 & $1.40 E-06$ & -150.45 & 26.72 & 21.73 & 20.9 \\
\hline 8640.00 & 46.38 & $3.53 E-06$ & -137.98 & -163.73 & 2.58 & $1.3 \pi=-04$ & -150.86 & 26.69 & 21.70 & 20.88 \\
\hline 8705.60 & 46.36 & $3.50 E-06$ & -138.09 & -163.85 & 2.58 & $1.36 E-04$ & -150.97 & 26.68 & 21.69 & 20.8 \\
\hline 9868.20 & 45.98 & $3.09 E-06$ & -160.45 & -166.32 & 2.59 & $1.19 E-06$ & -153.39 & 26.50 & 21.48 & 20. \\
\hline 10080.00 & 45.91 & $3.02 E-06$ & -140.85 & -166.73 & 2.59 & $1.17 E-06$ & -153.79 & 26.47 & 21.45 & 20.7 \\
\hline 11308.20 & 45.56 & $2.69 E-04$ & -162.99 & -168.97 & 2.60 & $1.04 E-06$ & -155.98 & 26.31 & 21.26 & 20.5 \\
\hline 12796.20 & 45.19 & $2.38 E-06$ & -145.29 & -171.37 & 2.61 & $9.13 E-05$ & -158.33 & 24.13 & 21.06 & 20.4 \\
\hline 12960.00 & 45.15 & $2.35 E-06$ & -145.53 & -171.62 & 2.61 & $9.01 E-05$ & -158.57 & 26.11 & 21.06 & 20. \\
\hline 14600.00 & 44.84 & $2.12 E-0.6$ & -167.40 & -173.57 & 2.62 & $8.09 E-05$ & -160.48 & 23.97 & 20.87 & 20.2 \\
\hline 15676.20 & 46.57 & $1.96 E-06$ & -169.08 & -175.31 & 2.62 & $7.61 E-05$ & -162.19 & 23.84 & 20.73 & 20. \\
\hline 17611.60 & 46.26 & $1.73 E-064$ & -150.96 & -177.26 & 2.63 & $6.65 E-05$ & -164.10 & 23.70 & 20.56 & 20.1 \\
\hline 18556.20 & 46.05 & $1.64 \mathrm{E}-0.04$ & -152.22 & -178.59 & 2.64 & $6.23 E-05$ & -165.60 & 23.61 & 20.45 & 19. \\
\hline 21636.20 & 43.61 & $1.62 E-06$ & -154.91 & -181.40 & 2.65 & $5.3 \pi-05$ & -168.15 & 23.40 & 20.22 & 19.8 \\
\hline 21600.00 & 43.59 & $1.61 E-064$ & -155.05 & -181.54 & 2.65 & $5.32 E-05$ & -168.30 & 23.39 & 20.20 & 19.8 \\
\hline 22876.20 & 63.42 & $1.33 E-04$ & -156.12 & -182.66 & 2.65 & $5.02 E-05$ & -169.39 & 23.31 & 20.11 & 19.7 \\
\hline 31516.20 & 42.46 & $9.6 \pi E-05$ & -162.09 & & 2.68 & $3.61 E-05$ & -173.69 & 22.85 & 19.59 & \\
\hline 31680.00 & 42.42 & $9.62 E-05$ & -162.18 & -188.99 & 2.68 & $3.59 E-05$ & -173.59 & 22.85 & 19.58 & 19.3 \\
\hline
\end{tabular}


A6/LVA

$A z: 87.767-4.746 * \ln t$

a: $-b /$ tempo

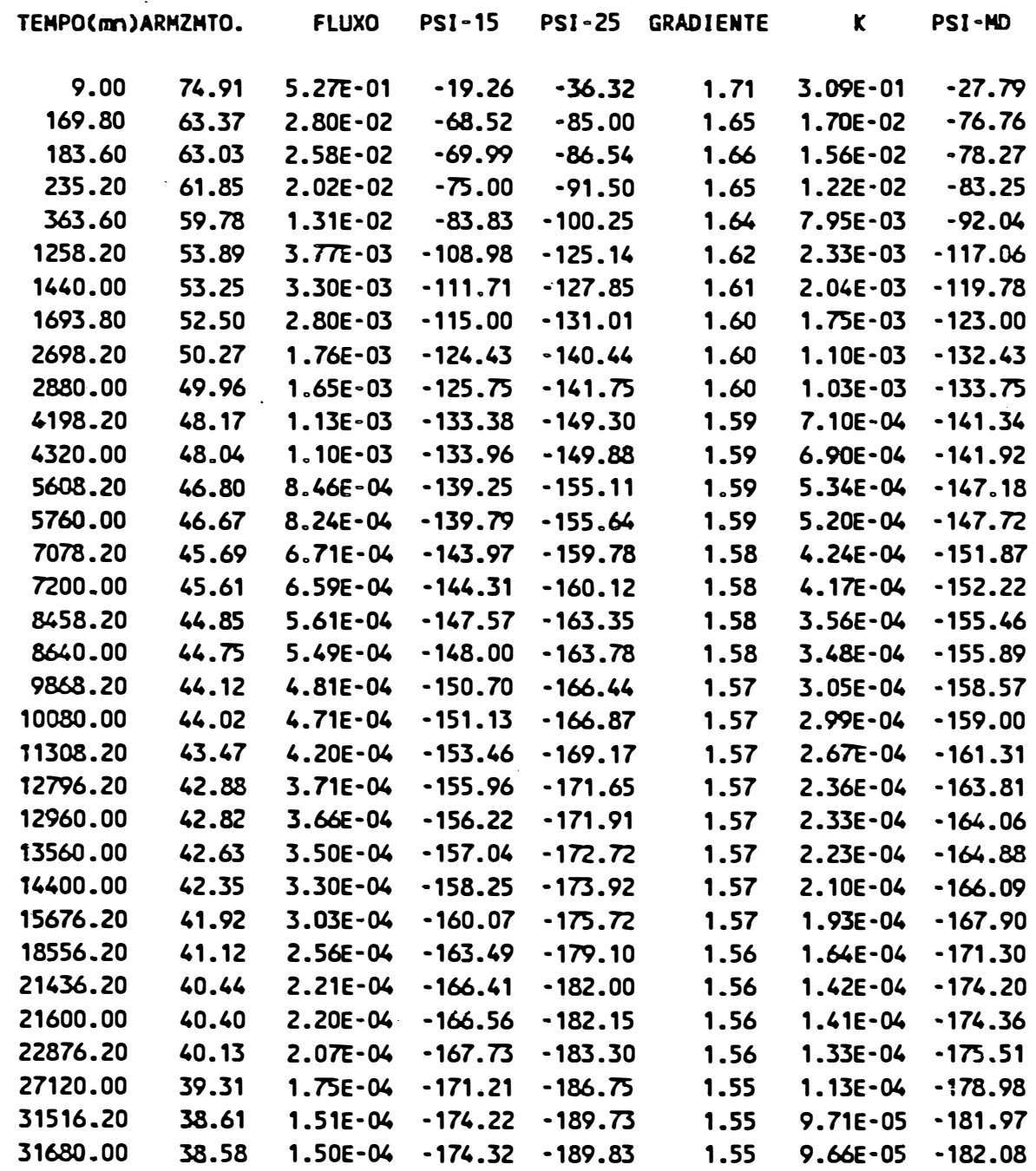

PSI-15: 50.599-20.256"LNT

PSI-25: 42.988-20.053*LNT

\begin{tabular}{|c|c|c|c|c|c|c|c|}
\hline \multicolumn{2}{|c|}{ TEMPO(m) ARMZMTO. } & FLUXO & PSI-15 & PSI -25 & GRADIENTE & $\mathbf{k}$ & PSI - MD \\
\hline 9.00 & 74.91 & 5.2TE-01 & -19.26 & -36.32 & 1.71 & $3.09 E-01$ & -27.79 \\
\hline 169.80 & 63.37 & $2.80 E-02$ & -68.52 & .85 .00 & 1.65 & $1.70 E-02$ & -76.76 \\
\hline 183.60 & 63.03 & $.58 E-02$ & -69.99 & -86.54 & 1.66 & $1.56 E-02$ & .78 .27 \\
\hline 235.20 & 61.85 & $.02 E-02$ & -75.00 & -91.50 & 1.65 & $1.22 E \cdot 02$ & -83.25 \\
\hline 363.60 & 9.78 & $.31 E-02$ & -83.83 & -100.25 & 1.64 & $7.95 E-03$ & -92.04 \\
\hline 1258.20 & 3.89 & $. T R E-03$ & -108.98 & -125.14 & 1.62 & $2.33 E-03$ & -117.06 \\
\hline 1440.00 & 53.25 & $.30 E-03$ & -111.71 & -127.85 & 1.61 & 2.04E-03 & -119.78 \\
\hline 1693.80 & 52.50 & $2.80 E-03$ & -115.00 & -131.01 & 1.60 & $1.75 E-03$ & -123.00 \\
\hline 2698.20 & 50.27 & $.76 E-03$ & -124.43 & -140.46 & 1.60 & $1.10 E-03$ & -132.43 \\
\hline 2880.00 & 49.96 & $1.65 E-03$ & -125.75 & .141 .75 & 1.60 & $1.03 E-03$ & -133.75 \\
\hline 4198.20 & 48.17 & $.13 E-03$ & -133.38 & -149.30 & 1.59 & -06 & -141.34 \\
\hline 4320.00 & 48.04 & $1.10 E-03$ & -133.96 & -149.88 & 1.59 & $6.90 E-04$ & -141.92 \\
\hline 5608.20 & $\infty$ & -06 & -139.25 & & & 06 & -147.18 \\
\hline 5760.00 & 46.67 & $8.24 E-06$ & -139.79 & -155.64 & 1.59 & $5.20 E-06$ & -147.72 \\
\hline 7078.20 & 45.69 & $6.71 E-06$ & -143.97 & -159.78 & 1.58 & $4.24 E-06$ & -151.87 \\
\hline 7200.00 & 45.61 & $6.59 E-06$ & -144.31 & -160.12 & 1.58 & $4.17 E-06$ & -152.22 \\
\hline 8458.20 & 44.85 & $5.61 E-04$ & -147.57 & -163.35 & 1.58 & -06 & -155.46 \\
\hline 8640.00 & 44.75 & $.49 E-04$ & -148.00 & -163.78 & 1.58 & $3.48 E-04$ & -155.89 \\
\hline 9868.20 & 44.12 & $4.81 E-04$ & -150.70 & -166.44 & 1.57 & -04 & -158.57 \\
\hline 10080.00 & 44.02 & 4.7 & .13 & .87 & 7 & -04 & -159.00 \\
\hline 11308.20 & 43.47 & $4.20 E-06$ & -153.46 & -169.17 & 1.57 & $2.67 \mathrm{E}-04$ & -161.31 \\
\hline 12796.20 & 42.88 & $3.71 E-064$ & -155.96 & -171.65 & 1.57 & $2.36 E-04$ & -163.81 \\
\hline 12960.00 & 42.82 & $3.66 E-04$ & -156.22 & - 171.91 & 1.57 & $2.33 E-04$ & -164.06 \\
\hline 13560.00 & 42.63 & $3.50 E-04$ & -157.04 & -172.72 & 1.57 & $2.23 E-04$ & -164.88 \\
\hline 14400.00 & 42.35 & $3.30 E-06$ & -158.25 & -173.92 & 1.57 & $2.10 E-04$ & -166.09 \\
\hline 15676.20 & 41.92 & $3.03 E-06$ & -160.07 & -175.72 & 1.57 & $1.93 E-04$ & -167.90 \\
\hline 18556.20 & 41.12 & $2.56 E-06$ & -163.49 & -179.10 & 1.56 & $1.64 E-04$ & -171.30 \\
\hline 21436.20 & 40.46 & $2.21 E-04$ & -166.41 & -182.00 & 1.56 & $1.42 E-04$ & -174.20 \\
\hline 21600.00 & 40.40 & $2.20 E-04$ & -166.56 & -182.15 & 1.56 & $1.41 E-04$ & -174.36 \\
\hline 22876.20 & 40.13 & $2.07 E-06$ & -167.73 & -183.30 & 1.56 & $1.33 E-04$ & .175 .51 \\
\hline 27120.00 & 39.31 & $1.75 E-06$ & -171.21 & -186.75 & 1.55 & $1.13 E-04$ & $-\$ 78.98$ \\
\hline 31516.20 & 38.61 & $1.51 E-064$ & -174.22 & -189.73 & 1.55 & 9.71E-05 & -181.97 \\
\hline 31680.00 & 38.58 & $1.50 E-04$ & -174.32 & -189.83 & 1.55 & $9.66 \mathrm{E}-05$ & -182.08 \\
\hline
\end{tabular}

teta10: 45.349-2.440* int teta20: 42.418-2.306*Int reta30: 31.495-1.174:Int
TETA10

$\begin{array}{lll}38.74 & 36.17 & 28.32 \\ 32.81 & 30.57 & 25.46 \\ 32.63 & 30.40 & 25.38 \\ 32.03 & 29.83 & 25.08 \\ 30.96 & 28.82 & 24.57 \\ 27.93 & 25.96 & 23.12 \\ 27.60 & 25.65 & 22.96 \\ 27.22 & 25.28 & 22.77 \\ 26.07 & 24.20 & 22.22 \\ 25.91 & 24.05 & 22.14 \\ 24.99 & 23.18 & 21.70 \\ 24.92 & 23.11 & 21.67 \\ 24.29 & 22.51 & 21.36 \\ 24.22 & 22.45 & 21.33 \\ 23.72 & 21.98 & 21.09 \\ 23.68 & 21.94 & 21.07 \\ 23.28 & 21.57 & 20.88 \\ 23.23 & 21.52 & 20.85 \\ 22.91 & 21.21 & 20.70 \\ 22.86 & 21.16 & 20.67 \\ 22.58 & 20.90 & 20.56 \\ 22.27 & 20.61 & 20.39 \\ 22.26 & 20.58 & 20.38 \\ 22.14 & 20.49 & 20.33 \\ 22.00 & 20.35 & 20.26 \\ 21.78 & 20.14 & 20.15 \\ 21.37 & 19.75 & 19.96 \\ 21.02 & 19.42 & 19.79 \\ 21.00 & 19.40 & 19.78 \\ 20.86 & 19.27 & 19.71 \\ 20.44 & 18.87 & 19.51 \\ 20.07 & 18.53 & 19.33 \\ 20.06 & 18.52 & 19.33\end{array}$


AT/LVA

Az: $82.083-4.337 *$ Int $q:-b /$ tempo

TEMPO(m)ARMZMTO. FLUXO PSI-15 PSI-25 GRADIENTE
PS1-15: $50.66-20.26 *$ LNT PSI-25: $41.77-19.1 *$ LNT teta 10: $48.941-2.937 * \operatorname{lnt}$ teta20: $33.142-1.399 * \operatorname{lnt}$ tet830: $33.549-1.390$ Ine

\begin{tabular}{|c|c|c|c|c|c|c|c|c|c|c|}
\hline 9.00 & 70.34 & $4.82 E-01$ & -19.21 & -34.95 & 1.57 & 3.06E-01 & -27.08 & 40.99 & 29.35 & 29.78 \\
\hline 183.60 & 59.48 & $2.36 E-02$ & -69.95 & .82 .79 & 1.28 & $1.84 E-02$ & -76.37 & 33.63 & 25.85 & 26.30 \\
\hline 205.80 & 58.97 & $2.11 E-02$ & -72.33 & -85.00 & 1.27 & $1.66 E-02$ & -78.66 & 33.29 & 25.69 & 26.14 \\
\hline 235.80 & 58.40 & $1.84 E-02$ & -73.00 & -87.52 & 1.25 & $1.4 \pi E-02$ & -81.26 & 32.90 & 25.50 & 25.96 \\
\hline 363.60 & 56.51 & $1.19 E-02$ & -83.79 & -95.84 & 1.21 & $9.90 E-03$ & -89.82 & 31.62 & 24.89 & 25.35 \\
\hline 1258.20 & 51.13 & $3.45 E-03$ & -108.94 & -119.56 & 1.06 & $3.25 E-03$ & -114.25 & 27.98 & 23.16 & 23.63 \\
\hline 1440.00 & 50.54 & $3.01 E-03$ & -111.68 & -122.13 & 1.05 & $2.83 E-03$ & -116.91 & 27.58 & 22.97 & 23.44 \\
\hline 1696.80 & 49.86 & $2.56 E-03$ & -115.00 & -125.14 & 1.01 & $2.52 E-03$ & -120.07 & 27.12 & 22.75 & 23.22 \\
\hline 2698.20 & 47.82 & $1.61 E-03$ & -124.40 & -134.13 & 0.97 & $1.65 E-03$ & -129.26 & 25.74 & 22.09 & 22.57 \\
\hline 2880.00 & 47.54 & $1.51 E-03$ & -125.72 & -135.37 & 0.96 & $1.56 E-03$ & -130.55 & 25.55 & 22.00 & 22.48 \\
\hline 4198.20 & 45.90 & $1.03 E-03$ & -133.36 & -142.57 & 0.92 & $1.12 E-03$ & -137.96 & 26.44 & 21.47 & 21.95 \\
\hline 4320.00 & 45.78 & $1.00 E-03$ & -133.94 & -143.12 & 0.92 & $1.09 E-03$ & -138.53 & 24.36 & 21.43 & 21.91 \\
\hline 5608.20 & 46.65 & $7.73 E-04$ & -139.22 & -148.10 & 0.89 & $8.71 E-04$ & -143.66 & 23.59 & 21.07 & 21.55 \\
\hline 5760.00 & 44.53 & $7.53 E-04$ & -139.77 & -148.61 & 0.88 & $8.51 E-04$ & -144.19 & 23.51 & 21.03 & 21.51 \\
\hline 7078.20 & 43.64 & $6.13 E-04$ & -143.94 & -152.55 & 0.86 & $7.12 E-04$ & -148.24 & 22.91 & 20.74 & 21.23 \\
\hline 7200.00 & 43.56 & $6.02 E-04$ & -144.29 & -152.87 & 0.86 & $7.01 E-04$ & -148.58 & 22.86 & 20.72 & 21.20 \\
\hline 8458.20 & 42.86 & $5.13 E-04$ & -147.55 & & 0.86 & $6.10 E-04$ & -151.75 & 22.38 & 20.49 & 20.98 \\
\hline 8640.00 & 42.77 & 5.02E-04 & -147.98 & -156.36 & 0.84 & $5.99 E-04$ & -152.17 & 22.32 & 20.46 & 20.95 \\
\hline 9868.20 & 42.20 & $4.39 E-04$ & -150.67 & - 158.89 & 0.82 & 5.35E-04 & -154.78 & 21.93 & 20.28 & 20.77 \\
\hline 10080.00 & 42.10 & $4.30 E-04$ & -151.10 & -159.30 & 0.82 & $5.25 E-04$ & -155.20 & 21.87 & 20.25 & 20.74 \\
\hline 11308.20 & 41.60 & $3.84 E-04$ & -153.43 & -161.50 & 0.81 & $4.76 E-04$ & -157.46 & 21.53 & 20.08 & 20.58 \\
\hline 12391.20 & 41.23 & $3.50 E-04$ & -155.19 & -163.15 & 0.80 & $4.40 E-04$ & -159.17 & 21.27 & 19.96 & 20.46 \\
\hline 12796.20 & 41.07 & $3.39 E-04$ & -155.94 & -163.86 & 0.79 & $4.28 E-04$ & -159.90 & 21.17 & 19.91 & 20.40 \\
\hline 12960.00 & 41.01 & $3.35 E-04$ & -156.19 & -164.10 & 0.79 & $4.23 E-04$ & -160.15 & 21.13 & 19.89 & 20.39 \\
\hline 14400.00 & 40.58 & $3.01 E-04$ & -158.23 & -166.02 & 0.78 & $3.87 z-06$ & -162.12 & 20.83 & 19.75 & 20.25 \\
\hline 15676.20 & 40.19 & $2 . \pi T-04$ & -160.05 & -167.73 & 0.77 & $3.60 E-04$ & -163.89 & 20.57 & 19.63 & 20.12 \\
\hline 18556.20 & 39.46 & $2.34 \mathrm{E}-04$ & -163.47 & -170.96 & $0 . \pi 5$ & $3.12 E-04$ & -167.21 & 20.07 & 19.39 & 19.89 \\
\hline 21436.20 & 38.83 & $2.02 E-04$ & -166.39 & -173.71 & 0.73 & $2.76 E-04$ & -170.05 & 19.65 & 19.19 & 19.69 \\
\hline 21600.00 & 38.80 & $2.01 E-04$ & -166.54 & -173.86 & 0.73 & 2. $75 E-04$ & -170.20 & 19.63 & 19.18 & 19.68 \\
\hline 22876.20 & 38.55 & $1.90 E-04$ & -167.71 & -174.95 & $0 . \pi$ & $2.62 E-04$ & -171.33 & 19.46 & 19.10 & 19.60 \\
\hline 24783.00 & 38.19 & $1.75 E-04$ & -169.37 & -176.52 & $0 . \pi$ & $2.45 E-04$ & -172.95 & 19.22 & 18.98 & 19.48 \\
\hline 31516.20 & 37.16 & $1.38 E-04$ & -174.20 & -181.07 & 0.69 & $2.00 E-04$ & -177.64 & 18.52 & 18.65 & 19.15 \\
\hline 31680.00 & 37.14 & $1.37 E-04$ & -174.30 & -181.17 & 0.69 & $1.99 E-04$ & -177.74 & 18.50 & 18.64 & 19.14 \\
\hline
\end{tabular}


A8/LVA

$A z: 78.917-4.107^{*} \ln t$ $q:-b / t$ enpo
PS1-15: 22.62-16.33"LNT PSI-25: 52.87-22.33 LNT teta10: $44.837-2.637 * \operatorname{lnt}$ reta20: $34.079-1.471 *$ int teta30: 29.538-0.902"int

\begin{tabular}{|c|c|c|c|c|c|c|c|c|c|c|}
\hline \multicolumn{2}{|c|}{ TEMPO(畐)ARMZMTO. } & \multirow{2}{*}{$\begin{array}{l}\text { FLUXXO } \\
4.56 E-01\end{array}$} & \multirow{2}{*}{$\begin{array}{l}\text { PSĩ - } 15 \\
-36.60\end{array}$} & \multirow{2}{*}{$\begin{array}{l}\text { PSI-25 } \\
.32 .60\end{array}$} & \multirow{2}{*}{$\begin{array}{r}\text { GRADIENTE } \\
-0.40\end{array}$} & \multirow{2}{*}{ K } & \multirow{2}{*}{$\begin{array}{l}\text { PSI - MD } \\
-34.60\end{array}$} & \multirow{2}{*}{$\begin{array}{l}\text { teta10 } \\
37.70\end{array}$} & \multirow{2}{*}{$\begin{array}{r}\operatorname{teta20} \\
30.10\end{array}$} & \multirow{2}{*}{$\begin{array}{l}\text { teta30 } \\
27.10\end{array}$} \\
\hline 9.00 & 67.80 & & & & & & & & & \\
\hline 157.20 & 58.18 & $2.61 E-02$ & $-\sqrt{5} .00$ & -84.90 & 0.99 & $2.64 E-02$ & -79.95 & 31.52 & 26.65 & 24.98 \\
\hline 183.60 & 57.51 & $2.24 E-02$ & -7.50 & -88.53 & 1.10 & $2.03 E-02$ & -83.02 & 31.09 & 26.49 & 24.84 \\
\hline 363.60 & 54.70 & $1.13 E-02$ & -88.66 & -103.79 & 1.51 & $7.47 E-03$ & -96.23 & 29.29 & 25.41 & 24.22 \\
\hline 940.20 & 50.83 & $4.37 E-03$ & -104.08 & -125.00 & 2.09 & $2.09 E-03$ & -114.54 & 26.80 & 24.02 & 23.37 \\
\hline 1258.20 & 49.60 & $3.26 E-03$ & -108.93 & -131.51 & 2.26 & $1.45 E-03$ & -120.22 & 6.02 & 3.58 & 3.90 \\
\hline 1460.00 & 49.05 & $2.85 E-03$ & -111.14 & -134.52 & 2.34 & $1.22 E-03$ & -122.83 & 25.66 & 3.38 & 2.98 \\
\hline 1824.00 & 48.07 & $2.25 E-03$ & -115.00 & -139.83 & 2.48 & $9.07 E-04$ & -127.41 & 25.03 & 3.03 & 22.76 \\
\hline 2698.20 & 46.47 & $1.52 E-03$ & -121.39 & -148.54 & 2.72 & $5.61 E-04$ & .136 .97 & 24.00 & 2.46 & 22.49 \\
\hline 2880.00 & 46.20 & $1.43 E-03$ & -122.46 & -150.00 & 2.75 & $5.18 E-04$ & -136.23 & 23.83 & 2.36 & 22.35 \\
\hline 4198.20 & 44.65 & $9.78 E-04$ & -128.61 & -158.42 & 2.98 & $3.28 E-04$ & -143.51 & 22.84 & & 22.01 \\
\hline 4320.00 & 64.54 & $9.51 E-04$ & -129.08 & -159.05 & 3.00 & $3.17 E-04$ & -144.07 & 22.76 & $1 . \pi$ & 21.99 \\
\hline 5608.20 & & $7.32 E-04$ & & & & & & .07 & & $1 . \pi 5$ \\
\hline 5760.00 & 43.36 & $7.13 E-04$ & -133.78 & -165.48 & 3.17 & $2.25 E-0.4$ & -149.63 & 22.00 & 21.34 & 21.73 \\
\hline 7078.20 & 42.51 & $5.80 E-04$ & -137.14 & $=170.08$ & 3.29 & $1.76 E-04$ & -153.61 & 21.46 & 21.04 & 21.54 \\
\hline 7200.00 & 42.46 & $5.70 E-04$ & -137.42 & -170.46 & 3.30 & $1.73 E-04$ & -153.94 & 21.42 & 21.01 & 21.53 \\
\hline 8458.20 & 49.78 & $4.86 E-04$ & -140.05 & -174.06 & 3.40 & $1.43 E-04$ & -157.05 & 20.99 & 0.78 & 21.38 \\
\hline 8640.00 & 41.69 & 4.75E-04 & -140.40 & -174.53 & 3.49 & $1.39 E-04$ & -157.47 & 20.93 & 20.75 & 21.36 \\
\hline 9868.20 & 49.14 & $4.16 E-04$ & -142.57 & -177.50 & 3.49 & & -160.03 & 20.58 & & 21.24 \\
\hline 1008 & & TE-04 & & & & & & & & 21.22 \\
\hline 11308.20 & 40.59 & $3.63 E-04$ & -144.79 & -180.54 & 3.57 & $1.02 E-04$ & -162.67 & 20.23 & .35 & 21.12 \\
\hline 11736.20 & 40.43 & $3.50 E-04$ & -145.39 & -181.36 & & 9.73E-05 & -163.38 & 20.13 & 0.30 & 21.09 \\
\hline 12796.20 & 40.08 & $3.21 E-04$ & -146.81 & -183.30 & 3.65 & $8.80 E-05$ & -165.06 & 19.90 & 20.17 & 21.01 \\
\hline 12960.00 & 40.03 & $3.17 E-04$ & -147.02 & -183.59 & 3.66 & 8.6TE-05 & -165.30 & 19.87 & 0.15 & 21.00 \\
\hline 14400.00 & 39.61 & $2.85 E-04$ & -148.66 & -185.83 & 3.72 & $7.6 \pi-05$ & -167.24 & 19.60 & 20.00 & 20.91 \\
\hline 15676.20 & 39.24 & $2.62 E-04$ & -150.13 & -187.84 & $3 . \pi$ & $6.95 E-05$ & -168.98 & 19.36 & 19.87 & 20.82 \\
\hline 18556.20 & 38.55 & $2.21 E-06$ & -152.88 & -191.60 & 3.87 & 5.72E-05 & -172.24 & 18.92 & 19.62 & 20.67 \\
\hline 21436.20 & 37.96 & $1.92 E-04$ & -155.24 & -194.82 & 3.96 & $4.84 E-05$ & .175 .03 & 18.54 & 19.41 & 20.54 \\
\hline $216: 30.00$ & 37.93 & $1.90 \mathrm{E}-04$ & -155.36 & -194.99 & 3.96 & $4.80 E-05$ & .175 .18 & 18.52 & 19.40 & 20.54 \\
\hline 22876.20 & 37.69 & $1.80 E-04$ & -156.30 & -196.28 & 4.00 & $4.49 E-05$ & -176.29 & 18.37 & 19.31 & 20.48 \\
\hline 23468.40 & 37.60 & 1. TSE-04 & -156.66 & $-196 . \pi$ & 4.01 & $4.36 E-05$ & -176.71 & 18.31 & 19.28 & 20.46 \\
\hline 31516.20 & 36.38 & $1.30 E-04$ & -161.53 & -203.43 & 4.19 & 3.11E-05 & -182.48 & 17.52 & 18.84 & 20.19 \\
\hline 31680.00 & 36.35 & $1.30 \mathrm{E}-04$ & -161.61 & -203.55 & 4.19 & $3.09 E-05$ & -182.58 & 17.51 & 18.83 & 20.19 \\
\hline
\end{tabular}


116.

A9/LVA

Az: $91.128-5.596 *$ Int

$q:-b / t$ enpo
PS1-15: $59.600-23.200 *$ LNT

PSI-25: $65.100-25.160$ LNT teta10: $46.265-2.887 *$ LNT

teta20: $44.863-2.709 *$ Int

tets30: $39.230-2.002$ int

\begin{tabular}{|c|c|c|c|c|c|c|c|c|c|c|}
\hline \multicolumn{2}{|c|}{ TEMPO(mn)ARMZMTO. } & \multirow{2}{*}{$\begin{array}{c}\text { FLUXO } \\
6.22 E-01\end{array}$} & \multirow{2}{*}{$\begin{array}{l}\text { PSI - } 15 \\
-18.23\end{array}$} & \multirow{2}{*}{$\begin{array}{l}\text { PSI }-25 \\
-28.03\end{array}$} & \multirow{2}{*}{$\begin{array}{c}\text { GRADIENTE } \\
0.9808\end{array}$} & \multirow{2}{*}{$\begin{array}{c}K \\
6.34 E-01\end{array}$} & \multirow{2}{*}{$\begin{array}{l}\text { PSI - MD } \\
-23.13\end{array}$} & \multirow{2}{*}{$\begin{array}{r}\text { TETA10 } \\
38.45\end{array}$} & \multirow{2}{*}{$\begin{array}{r}\text { TETAZO } \\
37.53\end{array}$} & \multirow{2}{*}{$\begin{array}{r}\text { TETA30 } \\
33.81\end{array}$} \\
\hline 9.00 & $\pi$ & & & & & & & & & \\
\hline 144.60 & 63.32 & $3.8 \pi E-02$ & -70.70 & -85.00 & 1.4296 & $2.71 E-02$ & -77.85 & 31.92 & 31.40 & 29.28 \\
\hline 173.40 & 62.28 & $.23 E-02$ & $-\pi 5.00$ & -89.60 & 1.4600 & $2.21 E-02$ & -82.30 & 31.38 & 30.90 & 28.91 \\
\hline 183.60 & 61.96 & $.05 E-02$ & -76.34 & -91.05 & 1.4717 & $2.07 \mathrm{E}-02$ & -83.69 & 31.22 & 30.74 & 28.79 \\
\hline 363.60 & 58.13 & $.54 E-02$ & -92.19 & -108.24 & 1.6056 & $9.59 E-03$ & -100.22 & 29.24 & 28.89 & 27.43 \\
\hline 971.40 & 52.63 & $5.76 E-03$ & -115.00 & -133.00 & 01 & $3.20 E-03$ & -124.00 & 26.40 & 26.23 & 25.46 \\
\hline 1258.20 & 51.19 & $4.45 E-03$ & -120.99 & -139.48 & 1.8489 & $2.41 E-03$ & -130.23 & 25.66 & 25.53 & 24.94 \\
\hline 1440.00 & 50.43 & $.89 E-03$ & -124.12 & -142.87 & & $2.07 \mathrm{E}-03$ & -133.50 & 25.27 & 25.16 & 24.67 \\
\hline 2698.20 & 46.92 & 2.07E-03 & -138.69 & -158.67 & 85 & $1.046-03$ & -148.68 & 23.46 & 23.60 & 23.41 \\
\hline 2880.00 & 46.55 & $.94 E-03$ & .140 .20 & -160.31 & 2.0112 & $9.66 E-04$ & -150.26 & 23.27 & .28 & 23.28 \\
\hline 4198.20 & 44.44 & $.33 E-03$ & -148.94 & -169.80 & 2.0851 & $6.39 E-04$ & -159.37 & .18 & 22.26 & 22.53 \\
\hline 4320.00 & 44.28 & $O E \cdot 03$ & -149.61 & -170.51 & 2.0907 & $6.20 E-04$ & -160.06 & 22.10 & 22.19 & 22.47 \\
\hline 560 & & $3 E-06$ & & & & -04 & & & & 1.95 \\
\hline 576 & 42.67 & $2 E-06$ & -156.28 & -177.75 & 71 & $4.52 E-04$ & -167.02 & 27 & .41 & 21.90 \\
\hline 707 & & $.91 E-04$ & .06 & & & $3.61 E-04$ & & .6 & 20.85 & 21.48 \\
\hline 7200.00 & 49.43 & $T E-04$ & -161.46 & -183.37 & 08 & $3.55 E-04$ & -172.41 & 62 & 20.80 & 21.45 \\
\hline 8458.20 & 40.52 & $.62 E-04$ & -165.20 & -187.42 & 2.2224 & $2.98 E-04$ & -176.31 & 16 & 37 & 21.13 \\
\hline 8640.00 & 40.40 & $.48 E-04$ & -165.69 & -187.95 & 2.2266 & $2.91 E-04$ & -176.82 & 20.10 & 20.31 & 1.08 \\
\hline 9868.20 & 39.66 & $.67 E-04$ & -168.77 & -191.30 & & $2.52 E-04$ & -180.04 & .71 & 25 & 20.82 \\
\hline 10080.00 & 39.54 & $.55 E-04$ & -169.26 & -191.83 & & & & & & .77 \\
\hline 11308.20 & 38.90 & $4.95 E-04$ & -171.93 & -194.73 & 2.2793 & $2.17 E-04$ & -183.33 & 19.32 & 19.58 & 20.54 \\
\hline 12796.20 & & $4.37 E-04$ & & & & $1.90 E-04$ & & & & 20.30 \\
\hline 12960.00 & 38.16 & $4.32 E-04$ & -173.10 & -198.16 & 2.3060 & $1.87 E-04$ & $-186: 63$ & 18.93 & 19.21 & 20.27 \\
\hline 14600.00 & 37.55 & $3.89 E-0.4$ & -177.54 & -200.81 & 2.3267 & $1.67 E-04$ & -189.17 & 18.62 & 18.92 & 20.06 \\
\hline 15676.20 & 37.07 & $3.57 E-06$ & -179.51 & -202.94 & 2.3433 & $1.52 E-04$ & -191.23 & 18.38 & 18.69 & 19.89 \\
\hline 15988.80 & 36.96 & $3.50 E-04$ & -179.98 & -203.45 & 2.3473 & $1.49 E-04$ & -191.71 & 18.32 & 18.64 & 19.85 \\
\hline 18556.20 & 36.13 & $3.02 E-04$ & -183.42 & -207.19 & 2.3764 & $1.2 \pi E-04$ & -195.30 & 17.89 & 18.24 & 19.55 \\
\hline 21436.20 & 35.32 & $2.61 E-04$ & $-186 . \pi$ & -210.82 & 2.4047 & $1.09 E-04$ & -198.79 & 17.47 & 17.85 & 19.26 \\
\hline 21600.00 & 35.28 & $2.59 E-04$ & -186.95 & -211.01 & & $1.08 E-04$ & -198.98 & 17.45 & 17.83 & 19.25 \\
\hline 22876.20 & 34.96 & $2.45 E-06$ & -188.28 & -212.45 & 2.4174 & $1.01 E-04$ & -200.37 & 17.29 & 17.67 & 19.13 \\
\hline 31516.20 & 33.16 & $1.78 E-04$ & -195.71 & -220.51 & & $7.16 E-05$ & -208.11 & 16.36 & 16.80 & 18.49 \\
\hline 31680.00 & 33.13 & $1.7 \pi E-04$ & -195.83 & .220 .64 & 2.4812 & $7.12 E-05$ & -208.24 & 16.35 & 16.79 & 18.48 \\
\hline 31977.00 & 33.10 & $1.73 E-04$ & -195.98 & -220.81 & 2.4825 & $7.05 E-05$ & -208.40 & 16.33 & 16.77 & 18.47 \\
\hline
\end{tabular}


A1/TRE $A z: 73.375+0.236 * \ln t$
$q:-b / t e m p 0$

psi-15: 5.591-3.51*lnt psi-25: $8.567-3.469 *$ int

tonno(ma)armzmto. fluxo psi-15 psi-25 gradiente tota 10: $38.9422-0.0 * 1 \mathrm{nt}$ terezo: $35.924+0.000047 * \ln$ tet 830 : $38.144+0.000015 * \ln$

\begin{tabular}{|c|c|c|c|c|}
\hline 65 & 36 & -0.21785 & -24.06 & -30.9 \\
\hline 155 & 76.57 & -0.09135 & -27.11 & -33.93 \\
\hline 205 & 74.63 & -0.06907 & -28.09 & -34.90 \\
\hline 674.4 & 74.91 & -0.02100 & -32.27 & -39.03 \\
\hline 1165 & $\pi .04$ & -0.01215 & -34.19 & -40.93 \\
\hline 348.8 & $\pi 5.08$ & -0.01050 & -36.71 & -41.4 \\
\hline 1460 & $\pi .09$ & -0.00983 & -34.94 & -41.6 \\
\hline 2605 & $\pi .23$ & -0.00546 & -37.02 & -43.7 \\
\hline 2880 & 75.25 & -0.00492 & -37.37 & -46.0 \\
\hline 4045 & 75.34 & -0.00350 & -38.56 & -45.2 \\
\hline 4320 & $\pi .35$ & -0.00328 & -38.79 & -45.4 \\
\hline 5485 & $\pi .49$ & -0.00258 & -39.63 & -46.3 \\
\hline 5760 & $\pi .42$ & -0.00246 & -39.80 & -46.4 \\
\hline 6925 & 75.46 & -0.00206 & -40.45 & -47.1 \\
\hline 200 & $\pi 5.47$ & -0.00197 & -40.58 & -47.2 \\
\hline 8365 & $\pi .51$ & -0.00169 & -41.11 & -47.7 \\
\hline 9805 & $\pi 5.54$ & -0.00146 & -41.67 & -48.3 \\
\hline 90080 & 75.55 & -0.00140 & -61.77 & -48.4 \\
\hline 11245 & $\pi .58$ & -0.00126 & -42.15 & -48.7 \\
\hline 12685 & $\pi .60$ & -0.00112 & -42.57 & \\
\hline 12960 & 75.61 & -0.00109 & -42.65 & -69.2 \\
\hline 14125 & $\pi .63$ & -0.00100 & -42.95 & -49.5 \\
\hline 14400 & $\pi .63$ & -0.00098 & -43.02 & -49.6 \\
\hline 95565 & $\pi .65$ & -0.00091 & -43.29 & -49.9 \\
\hline 17005 & $\pi 5.67$ & -0.00083 & -43.60 & -50.2 \\
\hline 18465 & 73.69 & -0.00077 & -43.89 & -50.5 \\
\hline 18720 & $\pi .70$ & -0.00076 & -43.94 & -50.5 \\
\hline 19885 & 75.71 & -0.00071 & -44.15 & -50.7 \\
\hline 21325 & $\pi . \pi 3$ & -0.00068 & -46.40 & -51.0 \\
\hline 22765 & 75.74 & -0.00062 & -44.62 & -51.2 \\
\hline 24205 & $\pi .76$ & -0.00059 & -44.84 & -51.4 \\
\hline 24480 & 75.76 & -0.00058 & -44.88 & -51.4 \\
\hline 25645 & $\pi . \pi$ & -0.00055 & -45.04 & -51.6 \\
\hline 27085 & $\pi .78$ & -0.00052 & -45.23 & -51.8 \\
\hline 28525 & 75.80 & -0.00050 & -45.42 & -52.0 \\
\hline 29965 & 75.81 & -0.00047 & -45.59 & -52.1 \\
\hline 30240 & 75.81 & -0.00047 & -45.62 & -52.2 \\
\hline 31405 & $\pi .82$ & -0.00045 & -45.75 & -52.3 \\
\hline 32865 & $\pi .83$ & -0.00043 & -45.91 & -52.5 \\
\hline 34285 & 75.84 & -0.00041 & -46.06 & -52.6 \\
\hline 35725 & $\pi .85$ & -0.00060 & -46.21 & -52.8 \\
\hline 37165 & $\pi .86$ & -0.00038 & -46.35 & -52.9 \\
\hline 37440 & $\pi .86$ & -0.00038 & -46.37 & -52.8 \\
\hline 38605 & $\pi .87$ & -0.00037 & -46.48 & -53.0 \\
\hline 60045 & $\pi 5.88$ & -0.00035 & -46.61 & -53.2 \\
\hline 69685 & $\pi .88$ & -0.00034 & -46.73 & -53.3 \\
\hline 62925 & $\pi .89$ & -0.00033 & -46.85 & -53.4 \\
\hline 68960 & $\pi 5.92$ & -0.00029 & -67.31 & -53.8 \\
\hline
\end{tabular}

0.69

0.68

0.68

0.68

0.67

0.67

0.67

0.67

0.67

0.67

0.67

0.67

0.67

0.67

0.67

0.67

0.66

0.66

0.66

0.66

0.66

0.66

0.66

0.66

0.66

0.66

0.66

0.66

0.66

0.66

0.66

0.66

0.66

0.66

0.66

0.66

0.66

0.66

0.66

0.66

0.66

0.66

0.66

0.66

0.66

0.66

0.66

0.66
$-0.31789131$ $-0.13400600$ $-0.10149227$ $-0.03107922$ $-0.01804806$ $-0.01560523$ $-0.01462024$ $-0.00891193$ $-0.00736114$ $-0.00523771$ $-0.00490627$ $-0.00386986$ $-0.00368621$ $-0.00306955$ $-0.00295302$ $-0.00254410$ $-0.00217259$ $-0.00211367$ $-0.00189597$ $-0.00168199$ $-0.00164652$ $-0.00151152$ $-0.00147781$ $-0.00137251$ $-0.00125697$ $-0.00115942$ $-0.00114249$ $-0.00107596$ $-0.00100374$ $-0.00094063$ $-0.00088500$ $-0.00087512$ $-0.00083561$ $-0.00079145$ $-0.00075174$ $-0.00071583$ $-0.00070936$ $-0.00068321$ $-0.00065366$ $-0.00062616$ $-0.00060107$ $-0.00057793$ $-0.00057371$ $-0.00055650$ $-0.00053661$ $-0.00051810$ $-0.00050082$ $-0.00043945$
$-27.4938 .942235 .9241938 .14406$

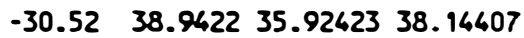
$\begin{array}{lll}-31.50 & 38.942235 .9242538 .14407\end{array}$ .35 .6538 .942235 .9243038 .14409 $-37.5638 .942235 .9243338 .14410$

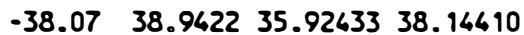

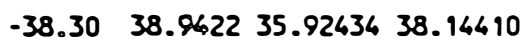
$-40.3738 .942235 .9243638 .14611$ $-40.72 \quad 38.942235 .9243738 .14411$ $-41.9038 .942235 .9243938 .14412$ $-42.93 \quad 38.942235 .9243938 .14412$ $-42.9638 .942235 .9244038 .14412$ $-43.1438 .942235 .9244038 .14412$ $-43.78 \quad 38.942235 .9244138 .14413$ $-43.9138 .942235 .9244938 .14413$ $-44.4438 .942235 .9244238 .14413$ $-44.9938 .942235 .9244338 .14413$ $\begin{array}{lll}-45.09 & 38.942235 .9246338 .14613\end{array}$ $-45.4738 .942235 .9246338 .14613$ $-45.8938 .942235 .9244438 .94614$ $-45.9738 .942235 .9246438 .14614$ $-46.2738 .942235 .9246438 .14414$ $-46.3338 .942235 .9244538 .14614$ $-46.6038 .942235 .9244538 .14414$ $-46.9138 .942235 .9244538 .14414$ $-47.2038 .942235 .9264638 .14414$ $-47.2538 .942235 .9244638 .14414$ $-47.4638 .942235 .9244638 .14416$ $-47.7038 .942235 .9244638 .14614$ $-47.93 \quad 38.942235 .9244738 .14415$ $\begin{array}{lll}-48.15 & 38.942235 .9244738 .14615\end{array}$ $-48.18 \quad 38.942235 .9244738 .14415$

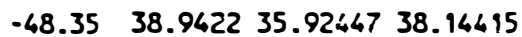

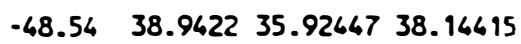

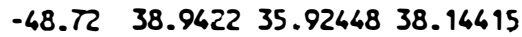
$-48.8938 .942235 .9244838 .14415$ $-48.9238 .942235 .9244838 .16415$ $-49.0538 .942235 .9244838 .14615$ $\begin{array}{llll}-49.21 \quad 38.9422 & 35.92448 & 38.14615\end{array}$ $-49.3638 .942235 .9244938 .14415$ $-49.5038 .942235 .9244938 .146915$ $-49.6438 .942235 .9244938 .14415$ $-49.6738 .942235 .9244938 .16695$ $-49.77 \quad 38.942235 .9264938 .14615$ $\begin{array}{lll}-49.90 \quad 38.9422 & 35.9244938 .14415\end{array}$

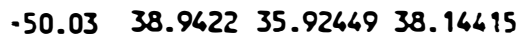
$-50.16 \quad 38.942235 .9245038 .14416$ $-50.6038 .962235 .9265038 .16616$ 
A2JTRE

$A z=83.16-0.6 \pi \cdot \ln t$ $q:-b /$ tempo
PS1-15: 7.516-4.523 $\operatorname{lnt}$ PS1-25: $10.631-3.719 *$ Int teta10: $60.665-0.00001 * \operatorname{lnt}$ tet $820: 37.163-0.00003 * \ln t$ teta30: $38.10+0.000003 * \operatorname{lnt}$

psi-md teta10 teta20 teta30

\begin{tabular}{|c|c|c|c|c|c|}
\hline 65 & $80.316 .25 E-01$ & -26.36 & -29.89 & 0.35 & 1.770926040 \\
\hline 155 & $79.73 \quad 2.62 E-01$ & -30.30 & -33.13 & 0.28 & 0.925994818 \\
\hline 205 & $79.561 .98 E-01$ & -31.56 & -36.17 & 0.26 & 0.760550966 \\
\hline 1165 & $78.363 .49 E-02$ & -39.62 & -60.63 & 0.12 & 0.288563664 \\
\hline 1440 & $78.22 \quad 2.82 E-02$ & -40.38 & -61.62 & 0.10 & 0.271758758 \\
\hline 193:4.4: & $78.022 .10 E-02$ & -61.71 & -42.51 & 0.08 & 0.262129087 \\
\hline 2605 & $\pi .82$ 1.56E-02 & -43.06 & -43.62 & 0.06 & 0.277759156 \\
\hline 2880 & $77.75 \quad 1.61 E-02$ & -63.51 & -43.99 & 0.05 & 0.293608087 \\
\hline 3868.8 & 7.55 1.05E-02 & -44.85 & -45.09 & 0.02 & 0.431821546 \\
\hline 6045: & $\pi .52$ 1.00E-02 & -65.05 & -45.26 & 0.02 & 0.483746259 \\
\hline 4320 & $\pi .479 .40 E-03$ & -45.35 & -45.50 & 0.02 & 0.607778104 \\
\hline 5485 & $7.317 .61 E-03$ & -46.43 & -46.39 & 0.00 & $-1.98 \pi \pi 156$ \\
\hline 5760 & $\pi .287 .05 E-03$ & -46.65 & -46.57 & -0.01 & -0.92077004 \\
\hline 6925 & $\pi .15$ 5.8TE-03 & -47.48 & -47.26 & -0.02 & -0.26106200 \\
\hline 2.200 & $\pi .135 .64 E-03$ & -47.66 & -47.40 & -0.03 & -0.22038071 \\
\hline 8365 & $\pi .03 \quad 4.86 E-03$ & -48.33 & -47.96 & -0.04 & -0.12896981 \\
\hline 9805 & $76.92 \quad 4.16 E-03$ & -69.05 & -48.55 & -0.05 & -0.08215233 \\
\hline 10080 & $76.90<.03 E-03$ & -49.18 & -48.65 & -0.05 & $-0.076535 \pi$ \\
\hline 11245 & $76.83 \quad 3.61 E-03$ & -49.67 & -49.06 & -0.06 & -0.05878836 \\
\hline 12685 & $76.76 \quad 3.20 E-03$ & -50.22 & -49.51 & -0.07 & -0.06501698 \\
\hline 12960 & $76.73 \quad 3.13 E-03$ & -50.32 & -49.59 & -0.07 & -0.04301892 \\
\hline 14125 & $76.672 .88 E-03$ & -50.70 & -49.91 & -0.08 & -0.03604676 \\
\hline 16400 & $76.66 \quad 2.82 E-03$ & -50.79 & -49.98 & -0.08 & -0.03467355 \\
\hline 15565 & $76.612 .61 E-03$ & -51.16 & -50.27 & -0.09 & -0.02979671 \\
\hline 17005 & $76.55 \quad 2.39 E-03$ & -51.56 & -50.60 & -0.09 & -0.02522462 \\
\hline 18445 & $76.492 .20 E-03$ & -51.91 & -50.90 & -0.10 & -0.02175602 \\
\hline 98720 & $76.482 .17 E-03$ & -51.98 & -50.95 & -0.10 & -0.02118544 \\
\hline 19885 & $76.44 \quad 2.04 E-03$ & -52.25 & -51.18 & -0.11 & -0.01904182 \\
\hline 21325 & $76.391 .90 E-03$ & -52.57 & -51.64 & -0.11 & -0.01687196 \\
\hline 22765 & $76.351 .78 E-03$ & -52.86 & -51.68 & -0.12 & -0.01510196 \\
\hline 24205 & $76.311 .68 E-03$ & -53.16 & -51.91 & -0.12 & -0.01363443 \\
\hline 26480 & $76.301 .66 E-03$ & -53.19 & -51.95 & -0.12 & -0.01338251 \\
\hline 25645 & $76.271 .58 E-03$ & -53.40 & -52.12 & -0.13 & -0.01260072 \\
\hline 27085 & $76.23 \quad 1.50 E-03$ & -53.65 & -52.33 & -0.13 & -0.01135108 \\
\hline 28525 & $76.191 .62 E-03$ & -53.88 & -52.52 & -0.16 & $-0.0104<869$ \\
\hline 29965 & $76.161 .36 E-03$ & -56.11 & -52.70 & -0.16 & -0.00966576 \\
\hline 30260 & $76.16 \quad 1.36 E-03$ & -54.15 & -52.76 & -0.16 & -0.00952796 \\
\hline 31405 & $76.13 \quad 1.29 E-03$ & -56.32 & -52.88 & -0.16 & -0.00898088 \\
\hline $328: 5$ & $76.10 \quad 1.26 E-03$ & -56.52 & -53.04 & -0.15 & -0.00837747 \\
\hline 34285 & $76.071 .18 E-03$ & -54.72 & -53.20 & -0.15 & -0.00784236 \\
\hline 35725 & $76.04 \quad 1.14 E-03$ & -54.90 & -53.36 & -0.15 & -0.00736497 \\
\hline 37165 & $76.021 .098-03$ & -55.08 & -53.50 & -0.16 & -0.00693635 \\
\hline 37660 & $76.011 .085-03$ & -55.11 & -53.53 & -0.16 & -0.00686009 \\
\hline 38605 & $\pi .991 .05 E-03$ & -55.25 & -53.65 & -0.16 & -0.00655102 \\
\hline $600 \leq 5$ & T5.97 1.01E-03 & -55.42 & -53.78 & -0.16 & -0.00620176 \\
\hline 6.1485 & TS.96 9.79E-04 & -55.58 & -53.91 & -0.17 & -0.00588430 \\
\hline 62925 & $\pi 5.929 .66 E-04$ & -55.73 & -56.04 & -0.17 & -0.00559466 \\
\hline 48960 & $\pi 5.838 .30 E-04$ & -56.33 & -56.53 & -0.18 & -0.00461638 \\
\hline
\end{tabular}

$-28.1340 .6649537 .1628738 .10001$ $-31.7140 .6469637 .1628438 .10001$ $-32.8640 .6649637 .1628638 .10001$ $-40.0260 .6649237 .1627838 .10002$ $-40.9040 .6469237 .1627838 .10002$ $-42.1140 .6449237 .1627738 .10002$ $-43.3640 .6649237 .1627638 .10002$ $-43.7540 .6469237 .1627638 .10002$ $-66.9740 .6649937 .1627538 .10002$ $-45.1540 .6649137 .1627538 .10002$ $-45.4240 .6449137 .1627438 .10002$ $-46.4140 .6469137 .1627438 .10002$ $-46.6140 .6469137 .1627438 .10002$ $-47.3740 .6649137 .1627338 .10002$ $-47.5340 .6649137 .1627338 .10002$ $-48.1540 .6469037 .1627238 .10002$ $-48.8040 .6649037 .1627238 .10002$ $-48.9240 .6649037 .1627238 .10002$ $-49.3740 .6469037 .1627238 .10002$ $-49.8640 .6469037 .1627138 .10002$ $-49.9540 .6449037 .1627138 .10002$ $-50.3140 .6449037 .1627138 .10002$ $-50.3940 .6449037 .1627138 .10002$ $-50.7140 .6449037 .1627138 .10002$ $-51.0740 .6449037 .1627038 .10002$ $-51.4140 .6649037 .1627038 .10002$ $-51.4740 .6649037 .1627038 .10002$ $-51.7240 .6649037 .1627038 .10002$ $-52.0040 .6449037 .1627038 .10002$ $-52.2740 .6648937 .1626938 .10003$ $-52.5340 .6648937 .1626938 .10003$ $-52.5740 .6648937 .1626938 .10003$ $-52.7640 .6648937 .1626938 .10003$ $-52.9940 .6468937 .1626938 .10003$ $-53.2040 .6648937 .1626938 .10003$ $-53.4040 .6468937 .1626938 .10003$ $-53.4640 .6648937 .1626938 .10003$ $-53.6040 .6468937 .1626838 .10003$ $-53.7840 .6648937 .1626838 .10003$ $-53.9640 .6648937 .1626838 .10003$ $\begin{array}{llll}-54.1340 .66489 & 37.1626838 .10003\end{array}$ $-54.2940 .6648937 .1626838 .10003$ $-54.3240 .6468937 .1626838 .10003$ $-54.4540 .6648937 .1626838 .10003$ .54 .6040 .6468937 .1626838 .10003 $-54.7540 .6648937 .1626838 .10003$ $-54.8940 .6468937 .1626738 .10003$ $-55.4340 .6648937 .1626738 .10003$ 
A3/TRE

Az:74.287+0.351*lnt $q:-b / t$ enpo
PSI-15: 5.89-5.16*LNT

PSi-25: $9.67-3.63$ LNT
TETA10: $49.776-0.00003 *$ LNT

TETA20: $36.16+0.000016$ "LNT

TETA30: $39.205 \$ 0.000008 *$ LNT tempo(m) armemto. fluxo psi-15 psi-25 gradiente k psi-md tetalo teta20 teta30

\begin{tabular}{|c|c|c|c|c|c|c|c|c|c|}
\hline 65 & $\pi . \pi$ & -0.32400 & -30.57 & -29.65 & -0.09 & $3.53 E+00$ & -30.1141 .77587 & 36.16005 & 39.20503 \\
\hline 155 & 76.06 & -0.13587 & -35.03 & -32.63 & -0.26 & $5.65 E-01$ & -33.8341 .77584 & 36.16007 & 39.20504 \\
\hline 205 & 76.16 & -0.10273 & -36.47 & -33.59 & -0.29 & $3.56 E-01$ & -35.0341 .77584 & 36.16007 & 39.20506 \\
\hline 414.6 & 76.71 & -0.02100 & -46.63 & -39.03 & -0.56 & 3.TSE-02 & -41.8341 .77579 & 36.16009 & 39.20505 \\
\hline 1165 & 76.7 & -0.01808 & -45.40 & -39.55 & -0.59 & $3.09 E-02$ & -42.4741 .77578 & 36.16009 & 39.20505 \\
\hline 1440 & 76.86 & -0.01463 & -46.49 & -40.27 & -0.62 & $2.35 E-02$ & -43.3841 .77578 & 36.16010 & 39.20505 \\
\hline 2005.8 & 76.95 & -0.01050 & -48.17 & -41.40 & -0.68 & $1.55 E-02$ & -44.7941 .77577 & 36.16010 & 39.20506 \\
\hline 2605 & 7.05 & -0.00808 & -49.54 & .42 .31 & $-0 . \pi$ & $1.12 E-02$ & -45.9241 .77576 & 36.16011 & 39.20506 \\
\hline 2880 & 7.08 & -0.00731 & -50.05 & -42.65 & -0.74 & $9.88 E-03$ & -46.3541 .77576 & 36.16011 & 39.20506 \\
\hline 6045 & $\pi .20$ & -0.00521 & .51 .80 & -43.82 & -0.80 & $6.52 E-03$ & -47.8141 .77575 & 36.16011 & 39.20506 \\
\hline 4320 & $\pi .23$ & -0.00688 & -52.16 & -46.06 & -0.81 & $6.02 E-03$ & -48.0941 .77574 & 36.16011 & 39.20506 \\
\hline 5485 & 7.31 & -0.00386 & -53.36 & -46.86 & -0.85 & $4.52 E-03$ & -49.1141 .77574 & 36.16012 & 39.20506 \\
\hline 5760 & $\pi .33$ & -0.00366 & -53.62 & -45.03 & -0.86 & $4.26 E-03$ & -49.3241 .77574 & 36.16012 & 39.20506 \\
\hline 6925 & $\pi .39$ & -0.00304 & -54.56 & -45.66 & -0.89 & $3.42 E-03$ & -50.1141 .77573 & 36.16012 & 39.20507 \\
\hline$\pi 200$ & 7.40 & -0.00293 & -54.76 & -45.79 & -0.90 & $3.26 E=03$ & -50.2841 .77573 & 36.16012 & 39.20507 \\
\hline 8365 & 7.46 & -0.00252 & -55.53 & -46.31 & -0.92 & $2.73 E-03$ & -50.9241 .77572 & 36.16012 & 39.20507 \\
\hline 9805 & 7.51 & -0.00215 & -56.35 & -46.85 & -0.95 & $2.26 E-03$ & -51.6041 .77572 & 36. & 39.20507 \\
\hline 10080 & 7.52 & -0.00209 & -56.49 & -46.95 & -0.95 & $2.19 E-03$ & -51.7241 .77572 & 36.16012 & 39.20507 \\
\hline 11245 & $\pi .56$ & -0.00187 & -57.05 & -47.32 & -0.97 & $1.92 E-03$ & -52.1941 .77572 & 36.16013 & 39.20507 \\
\hline 12685 & 7.60 & -0.00166 & -57.67 & -47.76 & -0.99 & $1.67 \mathrm{~T}-03$ & -52.7141 .77571 & 36.16013 & 39.20507 \\
\hline 12960 & 7.61 & -0.00163 & -57.78 & -47.81 & -1.00 & $1.63 E-03$ & -52.8041 .77571 & 36. & 39.20507 \\
\hline 16125 & 7.64 & -0.00169 & -58.23 & -48.11 & -1.01 & $1.4 \pi E-03$ & -53.1741 .77571 & 36.16013 & 39.20507 \\
\hline 16400 & 7.65 & 0.00150 & -58.35 & -48.19 & -1.02 & $-1.48 E-03$ & .2741 .77571 & 36 & 20507 \\
\hline 15565 & 7.68 & -0.00135 & -58.73 & -48.64 & -1.03 & $1.32 E-03$ & -53.5841 .77571 & 36.16013 & 39.20507 \\
\hline 17005 & 7.71 & -0.00126 & -59.18 & -48.74 & -1.04 & $1.19 E-03$ & -53.9641 .77570 & 36.16013 & 39.20507 \\
\hline 184645 & $\pi .73$ & -0.00114 & -59.60 & -49.02 & -1.06 & $1.08 E-03$ & -54.3141 .77570 & 36.16013 & 39.20507 \\
\hline 18720 & 7.74 & -0.00113 & -59.67 & -49.07 & -1.06 & $1.06 E-03$ & -54.3741 .77570 & 36.16013 & 39.20507 \\
\hline 19885 & 7.76 & -0.00106 & -59.98 & -49.28 & -1.07 & $9.89 E-04$ & -54.6341 .77570 & 36.1 & 39.20507 \\
\hline 21325 & 77.79 & -0.00099 & -60.34 & -49.52 & -1.08 & $9.12 E-04$ & .54 .9341 .77570 & 36.16013 & 39.20507 \\
\hline 22765 & 7.81 & -0.00093 & -60.68 & -49.74 & -1.09 & $8.46 E-0.4$ & .77569 & 36. & 0508 \\
\hline 24205 & 77.83 & -0.00087 & -60.99 & -49.95 & -1.10 & $7.88 E-04$ & -55.4741 .77569 & 36.16014 & 39.20508 \\
\hline 26480 & 77.83 & -0.00086 & -61.05 & -49.99 & -1.11 & $7.78 E-046$ & .77569 & 014 & 39.20508 \\
\hline 25645 & 77.85 & -0.00082 & -61.29 & -50.15 & -1.11 & 7.3TE-0.6 & -55.7241 .77569 & 36.16014 & 39.20508 \\
\hline 27085 & 77.87 & -0.00078 & -61.57 & -50.36 & -1.12 & $6.92 E-04$ & -55.9641 .77569 & 36.16014 & 39.20508 \\
\hline 28525 & 77.89 & -0.00074 & -61.86 & -50.52 & -1.13 & $6.52 E-046$ & $-56.18 \quad 41.77569$ & 36.16014 & 39.20508 \\
\hline 29965 & 77.91 & -0.00070 & -62.09 & -50.69 & -1.16 & $6.16 E-04$ & -56.3941 .77569 & 36.16014 & 39.20508 \\
\hline 30260 & 7.91 & -0.00070 & -62.14 & -50.72 & -1.16 & $6.10 E-04$ & -56.4341 .77569 & 36.16014 & 39.20508 \\
\hline 31405 & 77.92 & -0.00067 & -62.33 & -50.85 & -1.15 & $5.84 E-04$ & -56.5941 .77568 & 36.16014 & 39.20508 \\
\hline 32845 & 7.94 & -0.00066 & -62.56 & -51.00 & -1.16 & $5.55 E-0.6$ & -56.78 & 36.16014 & 39.20508 \\
\hline 34285 & 7.95 & -0.00061 & -62.78 & -51.15 & -1.16 & $5.28 E-0.6$ & -56.9741 .77568 & 36.16014 & 39.20508 \\
\hline 35725 & 77.97 & -0.00059 & -63.00 & -51.29 & -1.17 & $5.0<E-04$ & -57.1441 .77568 & 36.16014 & 39.20508 \\
\hline 37165 & $\pi .98$ & -0.00057 & -63.20 & -51.42 & -1.18 & $4.81 E-04$ & -57.3141 .77568 & 36.16014 & 39.20508 \\
\hline 37460 & 77.98 & -0.00056 & -63.26 & -51.45 & -1.18 & $4.7 \pi E-04$ & -57.3441 .77568 & 36.16014 & 39.20508 \\
\hline 35605 & $\pi .9$ & -0.00055 & -63.39 & -51.55 & -1.18 & $4.61 E-04$ & -57.4741 .77568 & 36.16014 & 39.20508 \\
\hline 40045 & 78.01 & -0.00053 & -63.58 & .51 .68 & -1.19 & $4.42 E-0.6$ & -57.6341 .77568 & 36.16014 & 39.20508 \\
\hline 41485 & 78.02 & -0.00051 & -63.76 & -51.80 & -1.20 & $4.24 E-04$ & -57.7841 .77568 & 36.16014 & 39.20508 \\
\hline 42925 & 78.03 & -0.00049 & -63.94 & -51.92 & -1.20 & $4.08 E-04$ & -57.9341 .77567 & 36.16014 & 39.20508 \\
\hline \multirow[t]{2}{*}{68960} & 78.08 & -0.00043 & -64.62 & -52.37 & -1.22 & $3.51 E-04$ & -58.6941 .77567 & 36.16015 & 39.20508 \\
\hline & 78.79 & -0.00006 & -75 & -59.30 & -1.57 & $3.63 E-05$ & -67.1541 .77561 & 36.16017 & 39.20510 \\
\hline
\end{tabular}


AL/TRE

Az: $95.326-1.515 * \ln t$

q: - b/ tempo
PSI-15: 25.548-6.93*LNT

PS1-25: $13.498-4.567$ LNT
TETA10: $\quad 45.097-0.00012 *$ LNT

TETA20: 38.879-0.00003"LNT

TETA30: 39.016-0.000003 tempo(m) armemto. fluxo
PSI-15 PSI-25 gradiente

psi-nd tetalo teta20 teta30

65
155
205
1165
1460
2605
2880
4045
4320
5485
5760
6925
7200
8365
8657.6
9805
10080
11245
12685
12960
14125
14600
15565
17005
18465
18720
19885
21325
22765
26205
24480
25645
27085
28525
29965
30240
31405
32845
34285
35725
37185
37640
38655

1.22

1.01

0.95

0.56

0.49

0.35

0.32

0.26

0.23

0.17

0.16

0.12

0.11

0.07

0.06

0.03

0.03

0.00

$-0.03$

$-0.03$

$-0.05$

$-0.06$

$-0.08$

$-0.10$

$-0.12$

$-0.12$

$-0.13$

$-0.15$

$-0.17$

$-0.18$

$-0.18$

$-0.19$

$-0.21$

$-0.22$

$-0.23$

$-0.23$

$-0.26$

$-0.25$

$-0.26$

$-0.27$

$-0.28$

$-0.28$

$-0.29$

$-0.30$

$-0.31$

$-0.32$

$-0.35$
1.14760613 0.57878923

0.46814548

0.14560510

0.12974674

0.10071820

0.09779696

0.09267931

0.09272309

0.09719309

0.09928380

0.11372261

0.11885676

0.15352160

0.16745290

0.27882097

0.33757435

0.29699628

$-0.25959931$

$-0.21467644$

$-0.12139449$

$-0.10942726$

$-0.07689107$

$-0.05518755$

$-0.04265920$

$-0.06061187$

$-0.03615703$

$-0.02835078$

$-0.02408407$

$-0.02083030$

$-0.02029578$

$-0.01827633$

$-0.01622468$

$-0.01456493$

$-0.01316739$

$-0.01290727$

$-0.01196937$

$-0.01096427$

$-0.01009813$

$-0.00934506$

$-0.00868512$

$-0.00856832$

$-0.00810270$

$-0.00758544$

$-0.00712342$

$-0.00670860$

$-0.00535439$
$-24.4745 .0964938 .8788739 .01598$ $-29.4745 .0963938 .8788639 .01598$ $-31.0845 .0963638 .8788439 .01598$ $-41.0645 .0961538 .8787839 .01597$ $-42.2845 .0961238 .8787839 .01597$ $-45.6945 .0960538 .8787639 .01597$ $-46.2745 .0960438 .8787639 .01597$ $.48 .2245 .0960038 .878 \pi 339.01597$ $-48.6045 .0959938 .8787439 .01597$ $-49.9745 .0959638 .8787439 .01597$ \begin{tabular}{l}
-50.2545 .0959638 .8787439 .01597 \\
\hline
\end{tabular} $-51.3145 .0959338 .8787339 .01597$ $-51.5345 .0959338 .8787339 .01597$

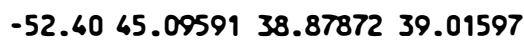
-52.5945 .0959138 .8787239 .01597
-53.3145 .0958938 .8787239 .01597 -53.3145 .0958938 .8787239 .01597 $-53.4745 .0958938 .8787239 .01597$ $-54.1045 .0958838 .87872 \quad 39.01597$ $-54.7945 .0958638 .8787139 .01597$

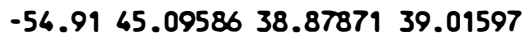
$-55.6145 .0958538 .8787139 .01597$ $\begin{array}{llll}-55.5245 .0958538 .87871 & 39.01597\end{array}$ $-55.9745 .09584 \quad 38.8787139 .01597$
-56.4745 .0958538 .8787039 .01597 $-56.4745 .0958338 .8787039 .01597$ $-56.9645 .0958238 .8787039 .01597$ $\begin{array}{lll}-57.0345 .0958138 .87870 & 39.01597\end{array}$ -57.3745 .0958138 .8787039 .01597
-57.7845 .0958038 .8787039 .01597 -57.7845 .0958038 .8787039 .01597
-58.1545 .0957938 .8786939 .01596 $-58.1545 .0957938 .8786939 .01596$

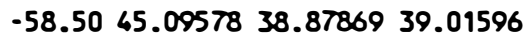
-58.5745 .0957838 .8786939 .01596
-58.8445 .0957838 .8786939 .01596 $-58.8445 .0957838 .8786939 .01596$ $-59.1545 .0957738 .8786939 .01596$ $-59.4545 .0957638 .8786939 .01596$ .59 .7345 .0957638 .8786939 .01596 $-59.7845 .0957638 .8786939 .01596$ $-60.0045 .0957538 .8786839 .01596$ $-60.2645 .0957538 .8786839 .01596$ $-60.5145 .0957438 .8786839 .01596$ $-60.7445 .0957438 .8786839 .01596$ $-60.9745 .0957338 .8786839 .01596$ $-61.0145 .0957338 .8786839 .01596$ $-61.1945 .0957338 .8786839 .01596$ $-61.4045 .0957238 .8786839 .01596$ $-61.6045 .0957238 .8786839 .01596$ $-61.8045 .0957138 .8786739 .01596$ $-62.5545 .0957038 .8786739 .01590$ 
A5/TRE

Az: $76.972-0.099 \cdot \ln t$ $q:-b / t e m p o$ psi-15: 10.8-6.089*lnt

psi-25: $14.24-3.84 *$ Int teta10: $41.14-0.00004 * \ln t$ teta20: $35.7 \cdot 0.000002$ lnt tet 30 : $38.376 \cdot 0.000002 * \ln$ tempo(m) k

psiomd teraio tetazo tera3o

\begin{tabular}{|c|c|c|c|c|c|}
\hline 65 & $6.569 .14 E-02$ & -29.62 & -26.7 & -0.28 & -0.32122321 \\
\hline 155 & $76.473 .83 E-02$ & -34.91 & -30.11 & -0.48 & -0.07979155 \\
\hline 205 & $76.452 .90 E-02$ & -36.61 & -31.18 & -0.54 & -0.05333515 \\
\hline 282.6 & $76.412 .10 E-02$ & -38.57 & -32.41 & -0.62 & -0.03411343 \\
\hline 565.2 & $76.34 \quad 1.05 E-02$ & -42.79 & -35.07 & -0.77 & -0.01360586 \\
\hline 1165 & $76.275 .10 E-03$ & -47.19 & -37.84 & -0.93 & -0.00545477 \\
\hline 1440 & 76.25 4.13E-03 & -48.48 & -38.66 & -0.98 & -0.00419859 \\
\hline 2605 & $76.192 .28 E-03$ & -52.09 & -40.93 & -1.12 & -0.00206316 \\
\hline 2880 & $76.18 \quad 2.06 E-03$ & -52.70 & -41.32 & -1.14 & -0.00181137 \\
\hline 4045 & 76.15 1.47E-03 & -54.77 & -42.62 & -1.22 & -0.00120845 \\
\hline 4320 & $76.14 \quad 1.38 E-03$ & -55.17 & -42.87 & -1.23 & 11789 \\
\hline 5485 & 76.12 1.08E-03 & -56.62 & -43.79 & -1.28 & 084356 \\
\hline 5760 & $76.11 \quad 1.03 E-03$ & -56.92 & -43.97 & -1.29 & 665 \\
\hline 6925 & $76.108 .58 E-06$ & -58.04 & -44.68 & -1.36 & 64189 \\
\hline$\pi 200$ & $76.098 .25 E-06$ & -58.28 & -44.83 & -1.35 & -0.00061334 \\
\hline 8365 & $76.08 \quad 7.10 E-06$ & -59.19 & -45.49 & -1.38 & -0.00 \\
\hline 9805 & $76.06 \quad 6.06 E-04$ & -60.16 & -46.02 & -1.41 & -0.00042824 \\
\hline 10080 & $76.065 .89 E-04$ & -60.33 & -46.12 & -1.42 & 1473 \\
\hline 11245 & $76.055 .28 E-04$ & -61.00 & -46.54 & -1.45 & -0.0 \\
\hline 12685 & $76.06 \quad 4.68 \mathrm{E}-06$ & -61.73 & -47 & & \\
\hline 12960 & $76.034 .58 E-06$ & -61.86 & -47.09 & -1.48 & -0.0 \\
\hline 14125 & $76.03 \quad 4.21 E-06$ & -62.38 & -47.42 & -1.50 & 28093 \\
\hline 14400 & $76.024 .13 E-04$ & -62.50 & -47.49 & -1.50 & -0.0 \\
\hline 15565 & $76.023 .82 E-06$ & -62.98 & -47.79 & -1.52 & -0.0 \\
\hline 17005 & $76.013 .49 E-04$ & -63.51 & -48.13 & -1.54 & -0.00022701 \\
\hline 18445 & $76.003 .22 E-06$ & -64.01 & -48.44 & -1.56 & 0683 \\
\hline 18720 & $76.003 .17 \mathrm{E}-06$ & & -48.50 & & \\
\hline 19885 & $\pi 5.992 .99 E-06$ & -64.47 & -48.73 & -1.57 & 8978 \\
\hline 21325 & $\pi 5.992 .79 E-06$ & .64 .89 & -49.00 & -1.59 & $\pi 521$ \\
\hline 22765 & $75.98 \quad 2.61 E-04$ & -65.29 & -49.25 & -1.60 & 16262 \\
\hline 24205 & $\pi 5.972 .45 E-04$ & -65.66 & -49.48 & -1.62 & 5164 \\
\hline $2 \div 480$ & $\pi 5.972 .43 E-04$ & -65.73 & -49.53 & -1.62 & -0.00014970 \\
\hline 25645 & $\pi 5.972 .32 \mathrm{E}-04$ & -66.02 & -49.70 & -1.63 & 199 \\
\hline 27085 & $75.962 .19 E-04$ & -66.35 & -49.91 & -1.64 & 3363 \\
\hline 28525 & $75.962 .088-04$ & -66.66 & -50.11 & -1.66 & 2580 \\
\hline 29965 & $75.951 .98 E-06$ & -66.98 & -50.30 & -1.67 & 1896 \\
\hline 30240 & $75.951 .96 \mathrm{E}-04$ & -67.02 & .50 .34 & -1.67 & -0.00019773 \\
\hline 31405 & $\pi 5.951 .89 E-06$ & -67.25 & -50.48 & -1.68 & 1279 \\
\hline 32845 & $75.96 \quad 1.81 E-06$ & -67.52 & -50.65 & -1.69 & -0.00010720 \\
\hline $3 \div 285$ & $75.961 .73 E-06$ & -67.78 & -50.82 & -1.70 & -0.00010219 \\
\hline 35725 & $\pi 5.931 .66 E-04$ & -68.03 & -50.98 & -1.71 & -0.00009746 \\
\hline 37165 & $\pi 5.931 .60 \mathrm{E}-04$ & -68.28 & -51.13 & -1.71 & -0.00009320 \\
\hline 37440 & $75.931 .59 E-04$ & -68.32 & .51 .15 & -1.72 & -0.00009242 \\
\hline 38605 & $75.93 \quad 1.54 E-06$ & -68.51 & -51.27 & -1.72 & -0.00008927 \\
\hline 40045 & $\pi 5.921 .48 E-04$ & -68.73 & .51 .41 & -1.73 & -0.00008565 \\
\hline 41485 & $75.921 .43 E-04$ & -68.96 & -51.55 & -1.74 & -0.00008230 \\
\hline 42925 & $75.921 .38 E-04$ & -69.15 & .51 .68 & -1.75 & -0.00007919 \\
\hline 48960 & $\pi 5.901 .21 E-04$ & .69 .95 & -52.18 & -1.78 & -0.00006827 \\
\hline
\end{tabular}

.28 .2041 .1378335 .6999138 .37599 $-32.5141 .1377935 .6998938 .37598$ $-33.9041 .1377835 .6998938 .37598$ $-35.4941 .137775 .6998838 .37598$ $-38.9341 .1377435 .6998738 .37598$ $-42.5241 .1377135 .6998538 .37598$ $-43.5741 .1377035 .6998538 .37598$

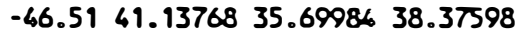
$-47.0141 .1376835 .6998438 .37598$ $-48.6941 .1376635 .6998338 .37598$ $-49.0241 .1376635 .6998338 .37398$

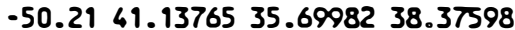
.50 .4541 .1376535 .6998238 .37598 $-51.3641 .1376435 .6998238 .37398$ $-51.5641 .1376635 .6998238 .37598$ $-52.3041 .1376335 .6998138 .37598$ $-53.0941 .1376335 .6998138 .37598$ $-53.2341 .1376335 .6998138 .37598$ $-53.7741 .1376235 .6998138 .37598$ $-54.3741 .1376235 .6998138 .37598$ $-54.4741 .1376235 .6998138 .37598$

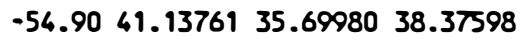
.55 .0041 .1376135 .6998038 .37598 $-55.3841 .1376135 .6998038 .37598$

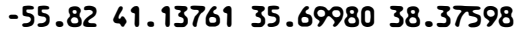
$-56.2241 .1376035 .6998038 .37598$ $-56.3041 .1376035 .6998038 .37598$ $-56.6041 .1376035 .6998038 .37598$ -56.9441 .1376035 .6998038 .37598
-57.2741 .1375935 .6997938 .37597 $-57.2741 .1375935 .6997938 .37597$

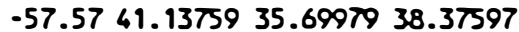
$-57.6341 .1375935 .6997938 .37397$ $-57.8641 .1375935 .6997938 .37597$ -58.1341 .1375935 .6997938 .37597 \begin{tabular}{l}
-58.3941 .1375835 .6997938 .37597 \\
\hline
\end{tabular} -58.6341 .1375835 .6997938 .37597
-58.6841 .1375835 .6997938 .37597 -58.6841 .1375835 .6997938 .37597
-58.8741 .1375835 .6997938 .37597

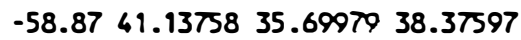

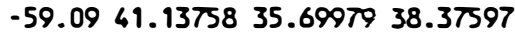
\begin{tabular}{l}
-59.3041 .1375835 .6997938 .37597 \\
\hline
\end{tabular} $\begin{array}{llll}-59.5041 .13758 \quad 35.69979 & 38.37597\end{array}$ $-59.7041 .1375735 .6997838 .37597$ $-59.7441 .1375735 .6997838 .37597$ \begin{tabular}{l}
-59.8941 .1375735 .6997838 .37597 \\
\hline
\end{tabular} $-60.0741 .1375735 .6997838 .37597$ $-60.2541 .1375735 .6997838 .37597$ $-60.4241 .1375735 .6997838 .37597$ -61.0741 .1375635 .6997838 .37597 
A6/TRE

Az: $94.54-2.26 \ln t$

fluxo: $-b / t$ empo psi15:6.452-5.77lnt

psi25:12.75-3.703int teto10:40.41-0.00013int

tets20:36.06-0.00006 int

tet $030: 38.8-0.00 \operatorname{lnt}$

TEMPO(Mn)ARMAZMTO. FLUXO PSI-15 PSI-25 GRADIENTE K PSI-MD TETA-10 TETA-20 TETA-30

\begin{tabular}{|c|c|c|c|c|c|c|c|c|c|c|}
\hline 65 & 85.19 & $3.48 E-02$ & -32.64 & -27.70 & -0.49 & -0.07036907 & -30.1657 & 40.40945 & 36.05983 & 38.8 \\
\hline 155 & 83.16 & $1.46 E-02$ & -37.65 & -30.91 & -0.67 & -0.02163335 & -34.2806 & 40.40934 & 36.05979 & 38.8 \\
\hline 205 & 82.51 & 1. 10E-02 & -39.26 & -39.95 & -0.73 & -0.01506366 & -35.6044 & 40.40930 & 36.05978 & 38.8 \\
\hline 282.6 & 78.58 & $8.00 E-03$ & -49.29 & -38.37 & -9.09 & -0.00732666 & -43.8313 & 40.40908 & 36.05971 & 38.8 \\
\hline 565.2 & 78.10 & $4.00 E-03$ & -50.51 & -39.16 & -9.16 & -0.00352178 & -44.8348 & 40.40905 & 36.05970 & 38.8 \\
\hline 1165 & 76.76 & $1.94 E-03$ & -53.93 & -41.35 & -9.26 & -0.00154194 & -47.6416 & 40.40897 & 36.05968 & 38.8 \\
\hline 1640 & 76.54 & $1.57 E-03$ & -56.51 & -41.72 & -1.28 & -0.00122721 & -48.1168 & 40.40896 & 36.05968 & 38.8 \\
\hline 2605 & $\pi .7$ & $8.68 E-06$ & -56.47 & -42.98 & -1.35 & -0.00066302 & -49.7252 & 40.40892 & 36.05966 & 38.8 \\
\hline 2880 & $\pi .62$ & $7.85 E-04$ & -56.85 & -43.22 & -1.36 & -0.00057581 & -50.0367 & 40.40891 & 36.05966 & 38.8 \\
\hline 4065 & $\pi .08$ & $5.59 E-06$ & -58.23 & -46.11 & -1.41 & -0.00039562 & -51.1672 & 40.40888 & 36.05965 & 38.8 \\
\hline 4320 & 74.97 & $5.23 E-06$ & -58.51 & -44.29 & -1.42 & -0.00036780 & -51.3989 & 40.40887 & 36.05965 & 38.8 \\
\hline 5485 & 74.56 & $4.12 E-04$ & -59.57 & -46.97 & -1.46 & -0.00028212 & -52.2710 & 40.40885 & 36.05964 & 38.8 \\
\hline 5760 & 76.47 & $3.92 E-06$ & -59.80 & -45.11 & -9.47 & -0.00026717 & -52.4556 & 40.40886 & 36.05964 & 38.8 \\
\hline 6925 & 74.13 & $3.26 E-04$ & -60.66 & -45.67 & -1.50 & -0.00021762 & -53.1656 & 40.40882 & 36.05963 & 38.8 \\
\hline 7200 & $\pi 3 . \pi$ & $3.14 E-06$ & -69.58 & -46.26 & -1.53 & -0.00020482 & -53.9177 & 40.40880 & 36.05963 & 38.8 \\
\hline 8365 & 73.71 & $2.70 E-06$ & -61.74 & -46.36 & -1.54 & -0.00017564 & -54.0486 & 40.40880 & 36.05963 & 38.8 \\
\hline 9805 & 73.46 & $2.30 E-06$ & -62.37 & -46.76 & -1.56 & -0.00014767 & -54.5665 & 40.40878 & 36.05962 & 38.8 \\
\hline 10080 & 73.19 & $2.26 E-06$ & -63.07 & -47.21 & -1.59 & -0.00016138 & -55.1371 & 40.40877 & 36.05962 & 38.8 \\
\hline 11245 & 73.14 & $2.01 E-06$ & -63.19 & -47.29 & -1.59 & -0.00012638 & -55.2386 & 40.40876 & 36.05962 & 38.8 \\
\hline 12685 & 72.94 & $1.78 E-06$ & -63.69 & -47.61 & -1.61 & -0.00011079 & -55.6462 & 40. & 61 & 38.8 \\
\hline 12960 & $\pi . \pi$ & $1.74 E-06$ & -64.25 & -47.97 & -1.63 & -0.00010710 & -56.1059 & 40.40874 & 36.05961 & 38.8 \\
\hline 16125 & 72.52 & $1.60 E-0.6$ & -64.76 & -48.29 & -1.65 & -0.00009717 & -56.5268 & 40.40873 & 36.05961 & 38.8 \\
\hline 14600 & 72.34 & $1.57 E-06$ & -65.23 & -48.59 & -1.66 & -0.00009435 & -56.9097 & 40.40872 & 36.05960 & 38.8 \\
\hline 15565 & $\pi .31$ & $1.45 E-04$ & -65.31 & -48.65 & -1.67 & -0.00008713 & -56.9798 & $40.408 \pi 2$ & 36.05960 & 38.8 \\
\hline 17005 & 72.17 & $1.33 E-06$ & -65.66 & -48.87 & -1.68 & -0.00007916 & -57.2657 & 40.40871 & 36.05960 & 38.8 \\
\hline 18445 & 72.01 & $1.23 E-06$ & -66.06 & -49.13 & -1.69 & -0.00007235 & -57.5967 & 40.40870 & 36.05960 & 38.8 \\
\hline 18720 & 71.87 & $1.21 E-06$ & -66.64 & -49.37 & -1.71 & -0.00007073 & -57.9061 & 40.40869 & 36.05959 & 38.8 \\
\hline 19885 & 71.73 & $1.14 E-04$ & -66.79 & -49.60 & $-9 . \pi$ & -0.00006609 & -58.1965 & 40.40868 & 36.05959 & 38.8 \\
\hline 21325 & 71.70 & $1.06 E-06$ & -66.86 & -49.64 & -1.72 & -0.00006154 & -58.2500 & 40.40868 & 36.0 & 38.8 \\
\hline 22765 & 71.60 & $9.93 E-05$ & -67.13 & -49.81 & -1.73 & -0.00005733 & -58.4702 & 40.40868 & 36.05959 & 38.8 \\
\hline 24205 & 71.47 & $9.34 E-05$ & -67.46 & -50.01 & -1.74 & -0.00005357 & -53.7288 & 40.40867 & 36.05959 & 38.8 \\
\hline 24480 & 79.36 & $9.23 E-05$ & -67.74 & -50.21 & -1.75 & -0.00005264 & -58.9741 & 40.40866 & 36.05958 & 38.8 \\
\hline 25645 & 79.26 & $8.81 E-05$ & -68.03 & -50.39 & -1.76 & -0.00004996 & -59.2073 & 40.40865 & 36.05958 & 38.8 \\
\hline 27085 & 71.22 & $8.34 E-05$ & -68.08 & -50.42 & -9.77 & -0.00006725 & -59.2506 & 40.40865 & 36.05958 & 38.8 \\
\hline 28525 & 71.16 & $7.92 E-05$ & -68.30 & -50.56 & -9.7 & -0.00004667 & -59.4296 & 40.40865 & 36.05958 & 38.8 \\
\hline 29965 & 71.06 & $7.56 E-05$ & -68.56 & -50.73 & -1.78 & -0.00004230 & -59.6418 & 40.40866 & 36.05958 & 38.8 \\
\hline 30240 & 70.94 & $7.4 \pi E-05$ & -68.80 & -50.89 & -1.79 & -0.00004171 & -59.8650 & 40.40866 & 36.05958 & 38.8 \\
\hline 31405 & 70.85 & $7.20 E-05$ & -69.04 & -51.04 & -1.80 & -0.00003997 & -60.0398 & 40.40863 & 36.05958 & 38.8 \\
\hline 32845 & 70.76 & $6.88 E-05$ & -69.27 & -51.19 & -1.81 & -0.00003805 & -60.2269 & 40.40863 & 36.05957 & 38.8 \\
\hline 34285 & 70.74 & $6.59 E-05$ & -69.31 & -51.21 & -1.81 & -0.00003642 & -60.2618 & 40.40863 & 36.05957 & 38.8 \\
\hline 35725 & 70.67 & $6.33 E-05$ & -69.49 & -51.33 & -1.82 & -0.00003483 & -60.4069 & 40.40862 & 36.05957 & 38.8 \\
\hline 37165 & 70.59 & $6.08 E-05$ & -69.70 & -51.46 & -1.82 & -0.00003336 & -60.5803 & 40.40862 & 36.05957 & 38.8 \\
\hline 37460 & 70.51 & $6.06 E-05$ & -69.90 & -51.59 & -1.83 & -0.00003296 & -60.7476 & 40.40861 & 36.05957 & 38.8 \\
\hline 38605 & 70.43 & $5.85 E-05$ & -70.10 & -51.72 & -9.84 & -0.0000318: & -60.9092 & 40.40561 & 36.05957 & 38.8 \\
\hline 40045 & 70.13 & $5.64 E-05$ & -70.86 & -52.21 & -1.87 & -0.00003025 & -61.5321 & 40.40859 & 36.05956 & 38.8 \\
\hline
\end{tabular}


123.

AT/TRE

Az: $114.77-4.36 \operatorname{lnt}$

fluxo:-b/tempo

TEMPO(m) psi $15: 11.45-6.531$ lnt psi25:13.88-3.57lnt teta10:40.81-0.00017int

teta20:38.73-0.00013ine teta30:38.12-0.00005ine

\begin{tabular}{|c|c|c|c|c|c|}
\hline 65 & 3549 & $6.71 E-02$ & -30.81 & -26.02 & -0.48 \\
\hline 155 & 92.77562 & $2.81 E-02$ & -36.49 & -29.13 & -0.76 \\
\hline 205 & 91.55635 & $2.13 E-02$ & -38.31 & -30.12 & -0.82 \\
\hline 82.6 & 83.97926 & $.54 E-02$ & -49.66 & 36.33 & -1.33 \\
\hline 65.2 & 83.05507 & $7.71 E-03$ & -51.05 & -37.08 & -1.40 \\
\hline 1165 & 80.46991 & $3.74 E-03$ & -54.92 & -39.20 & -9.57 \\
\hline 1440 & 80.03225 & $3.03 E-03$ & -55.57 & -39.56 & -1.60 \\
\hline 2605 & 78.55086 & $.6 \pi-03$ & -57 & -40.77 & -9.70 \\
\hline 2880 & 78.26402 & $1.51 E-03$ & -58.22 & -41.00 & -1.72 \\
\hline 4045 & 7.22278 & $1.08 E-03$ & -59.78 & -41.86 & -1.79 \\
\hline 4320 & 77.00944 & $.01 E-03$ & -60.10 & -42.03 & -1.81 \\
\hline 5485 & 76.20614 & $7.95 E-04$ & -61.30 & -42.69 & -1.86 \\
\hline 5760 & 76.03631 & $7.57 E-04$ & -61.56 & -42.83 & -1.87 \\
\hline 6925 & $\pi 5.38226$ & $6.30 E-04$ & -62.54 & -43.36 & -1.92 \\
\hline 7200 & 74.68958 & -04 & & -43.93 & -1.96 \\
\hline 8365 & 74.56895 & IE-OL & $-63 . \pi 5$ & -44.03 & -9.97 \\
\hline 9805 & 74.09199 & $E-04$ & -64.47 & -44.42 & -2.00 \\
\hline 10080 & 73.56650 & $E-04$ & -65.26 & -44.85 & -2.04 \\
\hline 11245 & 73.47297 & $3.88 E-04$ & -65.40 & -44.93 & -2.05 \\
\hline 12685 & 73.09758 & $3.44 E-04$ & -65.96 & -45.23 & -2.07 \\
\hline 12960 & 72.67422 & $E-06$ & -66.59 & -45.58 & -2.10 \\
\hline 14125 & $\pi .2$ & & & -45.90 & -2.13 \\
\hline 14400 & 71.93386 & $E-06$ & -67.70 & -46.19 & -2.15 \\
\hline & & & & & -2.16 \\
\hline 17005 & 71.60603 & $2.56 E-04$ & -68.19 & -46.45 & -2.17 \\
\hline 18445 & 71.30114 & $2.36 E-04$ & -68.65 & -46.70 & -2.19 \\
\hline 18720 & 71.01617 & $2.33 E-04$ & -69.08 & -46.94 & -2.21 \\
\hline 19885 & 70.74869 & $E-04$ & -69.48 & -47.16 & -2.23 \\
\hline 21325 & & & -69 & -47 & -2.24 \\
\hline 22765 & 70.49667 & $1.92 E-04$ & -69.85 & -47.36 & -2.25 \\
\hline 24205 & 70.25842 & $1.80 E-04$ & -70.21 & -47 & -2.27 \\
\hline 24480 & 70.03252 & $1.78 E-04$ & -70.55 & -47.74 & -2.28 \\
\hline 25645 & 69.81774 & $1.70 E-04$ & -70.87 & -47.92 & -2.30 \\
\hline 27085 & 69.77990 & $1.61 E-04$ & -70.93 & -47.95 & -2.30 \\
\hline 28525 & 69.61305 & $1.53 E-04$ & -71.18 & -48.09 & -2.31 \\
\hline 29965 & 69.41754 & $1.46 E-04$ & -71.47 & -48.25 & -2.32 \\
\hline 30240 & 69.23061 & $1.44 E-04$ & $-71 . \pi 5$ & -48.40 & -2.34 \\
\hline 31405 & 69.05099 & $1.39 E-04$ & -72.02 & -48.55 & -2.35 \\
\hline 32845 & 68.87866 & $1.33 E-04$ & -72.28 & -48.69 & -2.36 \\
\hline 34285 & 68.84651 & $1.2 \pi E-04$ & -72.32 & -48.71 & -2.36 \\
\hline 35725 & 68.71288 & $1.22 E-04$ & -72.52 & -48.82 & -2.37 \\
\hline 37165 & 68.55317 & $1.1 T E-04$ & -72.76 & -48.95 & -2.38 \\
\hline 37440 & 68.39910 & $1.16 E-04$ & -72.99 & -49.08 & -2.39 \\
\hline 38605 & .25029 & $1.13 E-04$ & -73.22 & -49.20 & -2.40 \\
\hline (OPOE & .67661 & $1.09 E-04$ & -74.08 & -49.67 & -2.64 \\
\hline
\end{tabular}

$-0.14002478-28.41740 .8092938 .7294538 .11979$ $-0.03820020-32.806840 .8091438 .7293438 .11974$ $-0.02596406-34.218840 .8090938 .7293038 .11973$ $\begin{array}{lllll}-0.01156875 & -42.993940 .8087938 .7290838 .11964\end{array}$ $-0.00552443-44.066240 .8087638 .7290538 .11963$ $\begin{array}{lll}-0.00238089 & -47.058140 .8026638 .7289738 .11960\end{array}$ $\begin{array}{lllll}-0.00189047 & -47.5649 & 40.80344 & 38.72896 & 38.11960\end{array}$ $\begin{array}{llllll}-0.00098327 & -49.2805 & 40.80858 \quad 38.72892 \quad 38.11958\end{array}$ $\begin{array}{lllll}-0.00087932 & -49.612740 .8085738 .7289138 .11958\end{array}$ $\begin{array}{lllll}-0.00060137-50.8186 & 40.80853 \quad 38.72888 & 38.11956\end{array}$

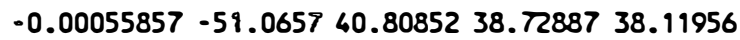
$\begin{array}{llll}-0.00042704 & -51.996040 .8084938 .7288538 .11955\end{array}$ $-0.00040415-52.192740 .8084938 .7288438 .11955$ $\begin{array}{lllll}-0.00032837 & -52.950140 .8084638 .72882 & 38.11954\end{array}$ $-0.00030827-53.752340 .8084338 .7288038 .11954$ $-0.00026423-53.892040 .8084338 .7288038 .11953$ $-0.00022178-54.444440 .8084138 .7287838 .11953$ $-0.00021196-55.053040 .8083938 .728738 .11952$ $\begin{array}{lllll}-0.00018941 & -55.161340 .8083938 .72876 & 38.11952\end{array}$ $-0.00016584-55.596040 .8083738 .7287538 .11952$

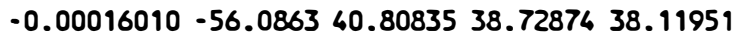

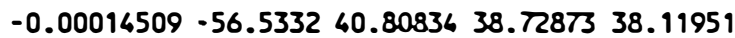
$-0.00014073-56.943740 .8083338 .7287238 .11950$ $\begin{array}{llll}-0.00012993 & -57.018540 .8083238 .72872 & 38.11950\end{array}$ $\begin{array}{llllll}-0.00011795 & -57.323640 .8083138 .7287138 .11950\end{array}$

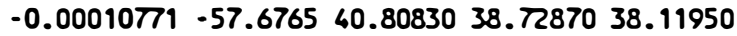
$\begin{array}{lllll}-0.00010520 & -58.006540 .80829 & 38.72869 & 38.11949\end{array}$ $\begin{array}{lll}-0.00009823 & -58.316340 .8082838 .7286838 .11949\end{array}$ $\begin{array}{lllll}-0.00009146 & -58.373340 .80828 & 38.72868 & 38.11949\end{array}$ $\begin{array}{llll}-0.00008515 & -58.608240 .8082738 .7286838 .11949\end{array}$ $-0.00007951-58.884140 .8082638 .7286738 .11948$ $\begin{array}{llll}-0.00007809 & -59.145740 .8082538 .7286638 .11948\end{array}$ $-0.00007407-59.3944 \quad 40.8082438 .7286538 .11948$ $-0.00007005-59.440640 .8082438 .7286538 .11948$ $\begin{array}{lll}-0.00006619 & -59.631540 .8082338 .7286538 .11948\end{array}$ $\begin{array}{lllll}-0.00006265 & -59.857940 .8082338 .72864 & 38.11948\end{array}$ $\begin{array}{lllll}-0.00006174 & -60.0746 \quad 40.8082238 .72864 & 38.11947\end{array}$ $\begin{array}{llllll}-0.00005914 & -60.2824 & 40.80821 & 38.72863 & 38.11947\end{array}$ $\begin{array}{llllll}-0.00005627 & -60.4820 & 40.8082138 .72863 & 38.11947\end{array}$ $\begin{array}{llllll}-0.00005386 & -60.519240 .8082038 .72863 & 38.11947\end{array}$ $\begin{array}{lllll}-0.00005149 & -60.674040 .8052038 .7286238 .11947\end{array}$ $\begin{array}{lllll}-0.00004927 & -60.858940 .8081938 .72862 & 38.11947\end{array}$ $\begin{array}{lllll}-0.00004869 & -61.037440 .8081938 .7286138 .11946\end{array}$

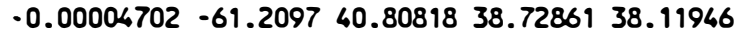
$\begin{array}{lllll}-0.00004461 & -61.874140 .8081638 .7285938 .11946\end{array}$ 
A8/TRE

Az:90.11-1.5061nt fluxo: $-b /$ tempo

\begin{tabular}{|c|c|c|c|c|c|c|}
\hline & & FLUXO & PSI - 15 & PSI -25 & GRADIENTE & $x$ \\
\hline 65 & 83.82 & $2.32 E-02$ & -29.17 & -25.96 & -0.32296 & -0.07173921 \\
\hline 955 & 82.59 & $9.72 E-03$ & -34.29 & -29.31 & -0.49720 & -0.01954142 \\
\hline 205 & 82.09 & $7.35 E-03$ & -35.93 & -30.40 & -0.55326 & -0.01327819 \\
\hline 282.6 & 79.48 & $5.33 E-03$ & -46.17 & -37.15 & -0.90162 & -0.00591053 \\
\hline 565.2 & 79.16 & $2.66 E-03$ & -47.41 & -37.97 & -0.94411 & -0.00282226 \\
\hline 1165 & 78.27 & $1.29 E-03$ & -50.99 & -40.28 & -1.06297 & -0.00121612 \\
\hline 1440 & 78.19 & $1.05 E-03$ & -51.50 & -40.67 & -1.08309 & -0.00096559 \\
\hline 2605 & 7.60 & $5.78 E-04$ & -53.50 & -41.99 & -9.15119 & -0.00050218 \\
\hline 2880 & $\pi .50$ & $5.23 E-04$ & -53.89 & -42.24 & -1.16438 & -0.00046909 \\
\hline 4045 & 7.14 & $3.72 E-04$ & -55.29 & -43.17 & -1.21225 & -0.00030712 \\
\hline 4320 & $\pi .07$ & $3.49 E-04$ & -55.58 & -43.36 & -1.22206 & -0.00028526 \\
\hline 5485 & 76.79 & $2.75 E-06$ & .56 .66 & -44.07 & -1.25900 & -0.00029808 \\
\hline 5760 & 76.73 & $2.61 E-06$ & -56.89 & -44.23 & -1.26680 & -0.00020639 \\
\hline 6925 & 76.51 & $2.17 E-04$ & -57.78 & -44.81 & -1.29687 & -0.00016768 \\
\hline 7200 & 76.27 & $2.09 E-06$ & -58.71 & -45.43 & -1.32872 & -0.00015741 \\
\hline 8365 & 76.23 & $9.80 E-04$ & -58.88 & -45.53 & -1.33427 & -0.00013493 \\
\hline 9805 & 76.06 & $1.54 E-04$ & -59.52 & -45.96 & -1.35619 & -0.00011325 \\
\hline 10080 & $\pi .88$ & $1.49 E-04$ & -60.23 & -46.43 & -1.38035 & 10823 \\
\hline 11245 & $\pi 5.85$ & $1.34 E-04$ & -60.36 & -46.59 & -1.38465 & -0.00009672 \\
\hline 12685 & $\pi . \pi$ & $1.19 E-06$ & -60.86 & -46.84 & -1.40191 & -0.00008468 \\
\hline 12960 & $\pi .57$ & $1.16 E-04$ & -61.43 & -47.22 & -9.42138 & -0.00008175 \\
\hline 16925 & $\pi .44$ & $1.07 \mathrm{TE}-04$ & -61.96 & -47.56 & -1.43912 & -0.00007408 \\
\hline 14400 & $\pi .32$ & $1.05 E-04$ & -62.43 & -47.88 & -1.45542 & -0.00007185 \\
\hline 15565 & 75.29 & $9.68 E-05$ & -62.52 & -47.96 & -1.45838 & -0.00006636 \\
\hline 17005 & $\pi 5.20$ & $8.86 E-05$ & -62.88 & -48.17 & -1.47049 & -0.00006022 \\
\hline 18445 & $\pi .10$ & 8. $16 E-05$ & -63.29 & -48.46 & -1.48451 & -0.000055 \\
\hline 18720 & $\pi 5.00$ & 8.06E-05 & -63.67 & -48.70 & -1.49761 & -0.00005371 \\
\hline 19885 & 74.91 & 7.5TE-05 & -64.04 & -48.94 & -1.50991 & -0.00005015 \\
\hline 21325 & 74.89 & $7.06 E-05$ & -64.10 & -48.98 & -1.51217 & -0.00004670 \\
\hline 22765 & 74.82 & $6.62 E-05$ & -64.38 & -49.16 & -1.52149 & -0.00004347 \\
\hline 24205 & 74.74 & $6.22 E-05$ & -64.70 & -49.37 & -1.53245 & -0.00004060 \\
\hline 24480 & 74.66 & $6.15 E-05$ & -65.00 & -49.57 & -1.54283 & -0.00003987 \\
\hline 25645 & 74.59 & $5.8 T E-05$ & -65.29 & -49.7 & -9.55271 & -0.00003782 \\
\hline 27085 & 74.57 & $5.56 E-05$ & -65.35 & -49.80 & -1.55456 & -0.00003576 \\
\hline 28525 & 76.52 & $5.28 E-05$ & -65.57 & -69.95 & -1.56212 & -0.00003379 \\
\hline 29965 & 74.45 & $5.03 E-05$ & -65.83 & -50.12 & -1.57111 & -0.00003198 \\
\hline 30260 & 74.38 & $4.98 E-05$ & -66.09 & -50.29 & -1.57971 & -0.00003152 \\
\hline 31405 & 76.32 & $6.80 E-05$ & -66.33 & -50.45 & -1.58796 & -0.00003019 \\
\hline 32845 & 74.26 & $4.59 E-05$ & -66.56 & -50.60 & -1.59588 & -0.00002873 \\
\hline 34285 & 74.25 & $4.39 E-05$ & -66.60 & -50.63 & -1.59736 & -0.00002749 \\
\hline 35725 & 74.20 & $6.22 E-05$ & -66.79 & -50.75 & -1.60350 & -0.00002628 \\
\hline 37165 & 74.15 & $4.05 E-05$ & -67.00 & -50.89 & -1.61085 & -0.00002515 \\
\hline 37640 & 74.10 & $4.02 E-05$ & -67.21 & -59.03 & -1.61793 & -0.00002486 \\
\hline 38605 & 74.05 & $3.90 E-05$ & -67.41 & -51.16 & $-1.626 \pi$ & -0.00002400 \\
\hline $400 \leq 5$ & 73.85 & $3.76 E-05$ & -68.18 & -59.67 & -1.65115 & $-0.000022 \pi$ \\
\hline
\end{tabular}

psi 15: $10.43 \cdot 5.891$ nt psi25: $15.28-3.885 \ln t$ tet $10: 39.99-0.00001 \ln t$

teta20:37.48-0.00006/nt teto30:38.69-0.00001int
PSI-HD TETA-10 TETA-20 TETA-30

$-27.5539 .9899537 .4797438 .68995$ $-39.8039 .9899437 .4796938 .68994$ .33 .1739 .9899437 .4796838 .68994 $-41.6639 .9899237 .4795738 .68992$ $-42.6939 .9899237 .4795638 .68992$ $-45.5939 .9899237 .4795238 .68992$ $-46.0839 .9899237 .4795238 .68992$ $-47.7439 .9899137 .4795038 .68991$ $-48.0639 .9899137 .4794938 .68991$ $-49.2339 .9899137 .4794838 .68991$ $-49.4739 .9899137 .4794838 .68991$ $-50.3739 .9899137 .4794638 .68991$ $-50.5639 .9899137 .4794638 .68991$ $-51.2939 .9899037 .4794538 .68990$ $-52.0739 .9899037 .4794438 .68990$ $-52.2039 .9899037 .4794438 .68990$ $-52.7439 .9899037 .4794438 .68990$ $-53.3339 .9899037 .4794338 .68990$ $-53.4339 .9899037 .4796338 .68990$ $-53.8539 .9899037 .4794238 .68990$ $-54.3339 .9899037 .4794238 .68990$ $-54.7639 .9899037 .6794138 .68990$ $-55.1639 .9899037 .4794138 .68990$ $-55.2339 .9899037 .4794038 .68990$ $-55.5339 .9899037 .4794038 .68990$ $-55.8739 .9899037 .4794038 .68990$ $-56.1939 .9898937 .4793938 .68989$ $-56.4939 .9898937 .4793938 .68989$ .56 .5439 .9898937 .4793938 .68989 $-56.7739 .9898937 .4793938 .68989$ -57.0439 .9898937 .4793838 .68989
-57.2939 .9898937 .4793838 .68989 $-57.2939 .9898937 .4793838 .68989$ .57 .5339 .9898937 .4793838 .68989 $-57.5739 .9898937 .4793838 .68989$ $-57.7639 .9898937 .6793738 .68989$ $-57.9839 .9898937 .4793738 .68989$ $-58.1939 .9898937 .4793738 .68989$ $-58.3939 .9898937 .4793738 .68989$ $-58.5839 .9898937 .6793638 .68989$ $-58.6239 .9898937 .4793638 .68989$ $-58.7739 .9898937 .4793638 .68989$ $-58.9539 .9898937 .4793638 .68989$ $-59.1239 .9898937 .4793638 .68989$ $-59.2939 .9898937 .6793538 .68989$ $-59.9339 .9898937 .4793538 .68989$ 
125.

A9/TRE

Az: $81.93-0.873$ int fluxo:-b/tempo

TEMPO(m) $)$ ARMAZMTO. psi 15: 10.29-5.04lnt psi $25: 14.33-3.829 \ln t$ tet $a 10: 42.55-0.508 \ln t$

teta20:39.38-0.367Int

tet $a 30: 41.23-0.377$ int

\begin{tabular}{|c|c|c|c|c|c|c|c|c|c|c|}
\hline 65 & .28 & $.35 E-02$ & -25.75 & -26.65 & 0.090481 & 0.148776362 & -26.2013 & 40.42961 & 37.8478 & 39.656 \\
\hline 155 & 77.52 & $.65 E-03$ & -30.13 & 29.98 & $-0.014 \pi 5$ & -0.38249507 & -30.0550 & 39.98794 & 37.52906 & 39.32862 \\
\hline 205 & 7.27 & $E-03$ & -31.54 & 31.05 & -0.04861 & 0.08779513 & -39.2948 & 39.84591 & 37.426645 & 39.22322 \\
\hline 282.6 & 5.75 & $10 E=03$ & -40.29 & -37.70 & -0.25902 & -0.01195353 & -38.9996 & 96327 & 8880 & 56820 \\
\hline 365.2 & 5.57 & 55E-03 & -41.36 & & -0.28468 & .00543797 & -39.9394 & 38.85562 & & 38.48830 \\
\hline 1165 & 5.05 & $11 E-06$ & -44.35 & & -0.35667 & 0.00210694 & -42.5681 & 38.55448 & & \\
\hline 1440 & 6.96 & $.08 E-04$ & -44.86 & .17 & -0.36862 & 0.00164838 & -43.0132 & & & 38.22698 \\
\hline 2605 & 74.66 & $.36 E-04$ & -46.57 & 42.47 & -0.40976 & 0.00081972 & -44.5195 & 3093 & 33197 & 09892 \\
\hline 2880 & 74.61 & $E-04$ & -46.90 & -42.72 & & 0.00072731 & & & 30783 & \\
\hline 4045 & & & & & & & & & & \\
\hline 4320 & 6.35 & $E-04$ & & & -0.45256 & 754 & & & & \\
\hline 5485 & 4.19 & $D E-0.4$ & -49.28 & 44.53 & & 033593 & & & & 9622 \\
\hline 5760 & .16 & & & & & & & & & 8154 \\
\hline 6925 & .0s & E-06 & 23 & & & & & 883 & & \\
\hline & & $-0,0$ & & & & & & & & \\
\hline 8365 & 3.86 & $E-04$ & & .97 & & D102 & & & & \\
\hline 9805 & $\pi$ & & & & & & & & & \\
\hline 10080 & 3.66 & 05 & 3 & & & & 879 & 132 & & 803 \\
\hline 11245 & 3.64 & $E-05$ & 44 & 93 & 77 & 27 & 830 & 943 & 406 & 995 \\
\hline 12685 & & 05 & & & & & & & & \\
\hline 12960 & 3.48 & 05 & & & & & & & & \\
\hline 141 & 3. & 05 & & & & & & & & \\
\hline 14600 & 3.36 & $=-05$ & & 28 & 51 & 238 & 480 & 014 & 512 & 689 \\
\hline 155 & , & & & & & & & 262 & & \\
\hline 17005 & 7 & 05 & & & & & & & & \\
\hline 184 & 3 & & & & & & & & & \\
\hline $187 \mathrm{c}$ & 3.15 & 05 & 8 & 99 & & & & & & \\
\hline 1988 & 5.10 & 05 & & & & & & & 338 & 644 \\
\hline 21325 & 09 & 05 & & & & & & & & 018 \\
\hline & & & & & & & & & & \\
\hline 24 & 3.00 & -05 & & & & & & & & \\
\hline 24680 & 2.95 & 05 & 61 & .95 & 30 & & 814 & 866 & 511 & $\$ 253$ \\
\hline 25665 & 2.91 & 05 & & 14 & & 230 & & & 704 & 396 \\
\hline 27085 & 72.90 & & & & & 944 & 403 & 900 & & .052 \\
\hline & & & & & & & & & & \\
\hline 298 & & & & & & & & & & \\
\hline 30240 & 9 & $=-05$ & & 65 & 58 & 327 & 971 & 522 & 761 & 319 \\
\hline 31405 & 2.76 & -05 & & & & & & & & \\
\hline 32845 & 2.72 & -05 & & & & & 547 & & & 278 \\
\hline 342 & & & & & & & & & & \\
\hline $35 \pi$ & & & & & & & & & & \\
\hline 37165 & 72.66 & $=-05$ & & & -0 & 25 & 857 & 633 & 062 & 3466 \\
\hline 37460 & 72.63 & $2.34 E-05$ & & & -0.69166 & & 8424 & & & 2132 \\
\hline 38505 & 72.60 & & & & & & & & & \\
\hline & & & & & & & 5770 & & & \\
\hline 41485 & & & & & & & & & & \\
\hline 42925 & 81.93 & $E-05$ & & & & -0.000 & & 37.13105 & 35.46513 & 37.20846 \\
\hline 40900 & 81.93 & $1.79 E-05$ & .59 .14 & -52.02 & $-0.711 \pi$ & -0.00002511 & -55.5770 & 37.06623 & 35.41685 & 37.15886 \\
\hline
\end{tabular}


126.

A10/TRE

$A 2: \pi 5.93-0.115 * \ln t$ fluxo: $-b / t$ empo
PS1-15: $-4.389-3.864 * \ln t$

PSI-25: $8.399-3.447 * \ln t$ teta10: $34.97+0.366 * \operatorname{lnt}$

teta20: $40.957-0.481 * \operatorname{lnt}$

teta30: 39.028-0.111*int

TEMPO(m))ARMAZHTO. FLUXO PSI-95 PSI-25 GRADIENTE $K$ PSI-MD TETA-10 TETA-20 TETA-30

\begin{tabular}{|c|c|c|c|c|c|c|c|c|c|c|}
\hline 65 & $\pi .45$ & $1 . T$ TE-03 & -35.52 & -30.89 & -0.45 & $-0.00390 \pi T$ & -33.26 & 36.50 & 38.95 & 38.56 \\
\hline 155 & $\pi .35$ & $7.42 E-04$ & -38.88 & .33 .99 & -0.49 & -0.00151738 & -36.43 & 36.82 & 38.53 & 38.47 \\
\hline 205 & $\pi .32$ & $5.61 E-04$ & -39.96 & -34.95 & -0.50 & $\cdot 0.00112058$ & -37.45 & 36.92 & 38.40 & 38.44 \\
\hline 282.6 & $\pi .12$ & $4.07 E-06$ & -46.67 & -40.94 & -0.57 & -0.00071017 & -43.81 & 37.55 & 37.56 & 38.26 \\
\hline 565.2 & 75.09 & $2.03 E-04$ & -47.49 & -41.67 & -0.58 & -0.00034970 & -44.58 & 37.63 & 37.66 & 38.22 \\
\hline 1165 & $\pi .03$ & $9.87 E-05$ & -49.78 & -43.71 & -0.61 & -0.00016275 & -46.75 & 37.85 & 37.18 & 38.15 \\
\hline 1460 & 75.01 & $7.99 E-05$ & -50.17 & -46.06 & -0.61 & -0.00013076 & -47.11 & 37.89 & 37.13 & 38.14 \\
\hline 2605 & 74.97 & $6.61 E-05$ & -51.48 & -45.23 & -0.62 & -0.00007065 & -48.36 & 38.01 & 36.96 & 38.11 \\
\hline 2880 & 76.97 & $3.99 E-05$ & -51.73 & -45.46 & -0.63 & -0.00006362 & -48.60 & 38.03 & 36.93 & 38.10 \\
\hline 4045 & 74.94 & 2.84E-05 & -52.66 & -46.28 & -0.64 & -0.00004459 & -49.47 & 38.12 & 36.82 & 38.07 \\
\hline 4320 & 74.93 & $2.66 \mathrm{E}-05$ & -52.85 & -46.45 & -0.64 & -0.00004162 & -49.65 & 38.14 & 36.79 & 38.07 \\
\hline 5485 & 74.91 & 2. 10E-05 & -53.56 & -47.09 & -0.65 & -0.00003239 & -50.32 & 38.21 & 36.70 & 38.05 \\
\hline 5760 & 74.91 & $2.00 E-05$ & -53.71 & -47.22 & -0.65 & -0.00003077 & -50.46 & 38.22 & 36.69 & 38.04 \\
\hline 6925 & 74.89 & $1.66 \mathrm{E}-05$ & -54.29 & -47.74 & -0.66 & -0.00002535 & -51.01 & 38.28 & 36.61 & 38.03 \\
\hline 7200 & 74.87 & $1.60 E-05$ & -54.90 & -48.28 & -0.66 & -0.00002616 & -51.59 & 38.33 & 36.54 & 38.01 \\
\hline 8365 & 74.87 & $1.3 \pi-05$ & -55.01 & -48.38 & -0.66 & -0.00002074 & -51.69 & 38.34 & 36.52 & 38.00 \\
\hline 9805 & 74.86 & $1.17 E-05$ & -55.63 & -48.76 & -0.67 & $-0.00001 \pi 57$ & -52.09 & 38.38 & 36.47 & 37.99 \\
\hline 10030 & 74.84 & $1.14 E-05$ & -55.90 & -49.17 & -0.67 & -0.00001696 & -52.53 & 38.43 & 36.61 & 37.98 \\
\hline 11245 & 74.84 & $1.02 E-05$ & -55.98 & -49.25 & -0.67 & -0.00001519 & -52.61 & 38.44 & 36.40 & 37.98 \\
\hline 12685 & 74.83 & $9.07 E-06$ & -56.31 & -49.54 & -0.68 & -0.00001339 & -52.93 & 38.47 & 36.36 & 37.97 \\
\hline 12960 & 74.82 & $8.87 E-06$ & -56.69 & -49.88 & -0.68 & -0.00001303 & -53.28 & 38.50 & 36.32 & 37.96 \\
\hline 16125 & 74.81 & $8.14 E-06$ & -57.03 & -50.18 & -0.68 & -0.00001189 & -53.61 & 38.54 & 36.27 & 37.95 \\
\hline 14600 & 74.80 & $7.99 E-06$ & -57.36 & -50.46 & -0.69 & -0.00001161 & -53.90 & 38.57 & 36.23 & 37.94 \\
\hline 15565 & 74.80 & $7.39 E-06$ & -57.40 & -50.51 & -0.69 & -0.00001073 & -53.96 & 38.57 & 36.23 & 37.94 \\
\hline 17005 & 74.79 & $6.76 E-06$ & -57.63 & -50.72 & -0.69 & -0.00000978 & -54.18 & 38.59 & 36.20 & 37.93 \\
\hline 18665 & 74.78 & $6.23 E-06$ & -57.90 & -50.96 & -0.69 & -0.00000898 & -54.63 & 38.62 & 36.16 & 37.92 \\
\hline 18720 & 74.78 & $6.14 E-06$ & -58.16 & -51.19 & -0.70 & -0.00000882 & -54.67 & 38.64 & 36.13 & 37.91 \\
\hline 19885 & 74.77 & $5.78 E-06$ & -58.39 & -51.40 & -0.70 & -0.00000827 & -54.90 & 38.66 & 36.10 & 37.91 \\
\hline 21325 & 74.77 & $5.39 E-06$ & -58.64 & -51.64 & -0.70 & 0770 & -54.94 & 38.67 & 36.10 & 37.91 \\
\hline 22765 & 74.76 & $5.05 E-06$ & -58.62 & -51.60 & -0.70 & -0.00000720 & .55 .11 & 38.69 & 36.07 & 37.90 \\
\hline 24205 & 74.76 & 4.75E-06 & -58.83 & -51.79 & -0.70 & -0.00000675 & -55.31 & 38.71 & 36.05 & 37.90 \\
\hline 26480 & $74 . \pi 5$ & 4.7DE-06 & -59.03 & -51.97 & -0.71 & -0.00000665 & -55.50 & 38.72 & 36.02 & 37.89 \\
\hline 25645 & 74.74 & $4.68 E-06$ & -59.22 & -52.14 & -0.71 & -0.00000633 & -55.68 & 38.74 & 36.00 & 37.88 \\
\hline 27085 & 74.74 & $4.25 E-06$ & -59.25 & -52.17 & -0.71 & -0.00000599 & -55.71 & $38 . \pi 5$ & 36.00 & 37.88 \\
\hline 28525 & 74.74 & $4.03 E-06$ & -59.40 & -52.30 & -0.71 & -0.00000568 & -55.85 & 38.76 & 35.98 & 37.88 \\
\hline 29985 & 74.73 & $3.84 E-06$ & -59.57 & -52.45 & -0.71 & -0.00000539 & -56.01 & 38.78 & 35.96 & 37.87 \\
\hline 30260 & 74.73 & $3.80 E-06$ & .59 .76 & -52.60 & -0.71 & -0.00000533 & -56.17 & 38.79 & 35.94 & 37.87 \\
\hline 31405 & 76.72 & $3.66 E-06$ & -59.90 & -52.74 & -0.72 & -0.00000512 & -56.32 & 38.81 & 35.92 & 37.86 \\
\hline $328 \div 5$ & 74.72 & $3.50 E-06$ & -60.05 & -52.88 & $-0 . \pi$ & -0.00000488 & -56.46 & 38.82 & 35.90 & 37.86 \\
\hline 34285 & 74.72 & $3.35 E-06$ & -60.03 & -52.90 & -0.72 & -0.00000467 & -56.49 & 38.82 & 35.89 & 37.86 \\
\hline 35725 & 74.72 & $3.22 E-06$ & .00 .20 & .53 .01 & -0.72 & -0.00000468 & -56.60 & 38.84 & 35.89 & 37.86 \\
\hline 37165 & 74.71 & $3.09 E-06$ & $-60.3 i$ & -53.13 & $-0 . \pi$ & -0.00000430 & -56.74 & 38.85 & 35.86 & 37.85 \\
\hline $374 \div 0$ & 74.71 & $3.07 E-06$ & .60 .48 & -53.26 & -0.72 & -0.00000425 & -56.87 & 38.86 & 35.84 & 37.85 \\
\hline 38605 & $7 \dot{4} .70$ & $2.98 E-06$ & .60 .61 & -53.37 & -0.72 & -0.00000612 & -56.99 & 38.87 & 35.83 & 37.84 \\
\hline $400 \div 5$ & 74.69 & $2.87 E-06$ & .61 .12 & -53.83 & -0.73 & -0.00000394 & -57.47 & 38.92 & 35.76 & 37.83 \\
\hline 41685 & $\pi .93$ & 2. $\pi R E-06$ & -19.39 & -16.60 & $\cdot 0.28$ & -0.00000996 & -18.00 & 36.97 & 40.96 & 39.03 \\
\hline 42925 & 75.93 & $2.68 E-06$ & -19.39 & -16.60 & -0.28 & -0.00000961 & -18.00 & 36.97 & 40.96 & 39.03 \\
\hline 48960 & 75.93 & $2.35 E-06$ & -19.39 & -16.60 & -0.28 & -0.00000842 & -18.00 & 36.97 & 40.96 & 39.03 \\
\hline
\end{tabular}

